University of Massachusetts Amherst

ScholarWorks@UMass Amherst

Doctoral Dissertations 1896 - February 2014

$1-1-2003$

\title{
The availability of salient and conceptually central properties of concepts in different contexts.
}

\author{
Ferne Joi Friedman-Berg \\ University of Massachusetts Amherst
}

Follow this and additional works at: https://scholarworks.umass.edu/dissertations_1

\section{Recommended Citation}

Friedman-Berg, Ferne Joi, "The availability of salient and conceptually central properties of concepts in different contexts." (2003). Doctoral Dissertations 1896 - February 2014. 3298.

https://scholarworks.umass.edu/dissertations_1/3298

This Open Access Dissertation is brought to you for free and open access by ScholarWorks@UMass Amherst. It has been accepted for inclusion in Doctoral Dissertations 1896 - February 2014 by an authorized administrator of ScholarWorks@UMass Amherst. For more information, please contact scholarworks@library.umass.edu. 
FIVE COLLEGE DEPOSITORY 


\title{
THE AVAILABILITY OF SALIENT AND CONCEPTUALLY CENTRAL PROPERTIES OF CONCEPTS IN DIFFERENT CONYEXTS
}

\author{
A Dissertation Presented \\ by \\ FERNE JOI FRIEDMAN-BERG
}

Submitted to the Graduate School of the

University of Massachusetts Amherst in partial fulfillment

of the requirements for the degree of

DOCTOR OF PHILOSOPHY

February 2003

Cognitive Psychology 
(c) Copyright by Ferne Joi Friedman-Berg 2003

All Rights Reserved 


\section{A Dissertation Presented}

by

FERNE JOI FRIEDMAN-BERG

Approyed as to style and content by:

\section{dracol recorel}

Arnold D. Well, Chair
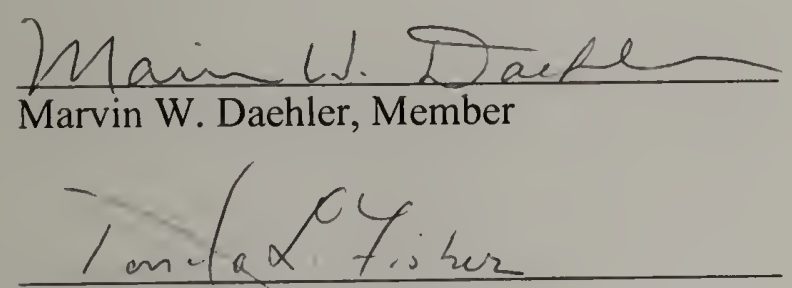

Denald L. Fisher, Member

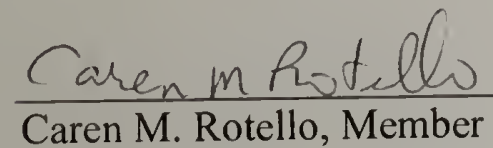

Thuenda A. howh

Melinda A. Novak, Department Head

Department of Psychology 


\section{DEDICATION}

To Ed and Grant-thank you for always being there. 


\section{ACKNOWLEDGMENTS}

I would like to thank my advisor, Arnold Well, for his many years of guidance and patience. You deserve a special "thank you" for never giving up on me and always having the patience to read just one more draft. Thank you to my committee members for providing guidance for my dissertation, and for the long-distance coordination of my defense and thanks to my undergraduate RA's for helping to run these studies.

A special thanks goes to my friends and colleagues at the Federal Aviation Administration's William J. Hughes Technical Center in the Research and Development Human Factors Lab and at Titan Systems Corporation. Your support and your willingness to listen to all the twists and turns involved in completing my dissertation were truly appreciated.

To my friends from Philadelphia who cheered me on throughout graduate school, I will always appreciate your love and friendship. To my friends at Tobin Hallthank you for your commiseration. To Eva and Trina, thank you for listening to my statistical dilemmas just one more time.

Last, but certainly not least, I cannot forget to thank the most important people in my life-my family. Mom and Dad- thank you for listening, thank you for supporting me in more ways than I can ever repay, and thank you for believing in me. Jennifer and Andrea-thank you for being sisters who I could always call when a new crisis arose. To my grandmother and grandfather who never failed to brag about me to your friends- I love you always. Finally, thanks to my loving husband Ed, my own personal cheerleading squad, and my wonderful son Grant who brought warmth, laughter, and love into my life. Without you both, none of this would have been possible. 


\title{
THE AVAILABILITY OF SALIENT AND CONCEPTUALLY CENTRAL PROPERTIES OF CONCEPTS IN DIFFERENT CONTEXTS
}

\section{FEBRUARY 2003}

\section{FERNE JOI FRIEDMAN-BERG, B.A., TEMPLE UNIVERSITY \\ M.S., UNIVERSITY OF MASSACHUSETTS AMHERST \\ Ph.D., UNIVERSITY OF MASSACHUSETTS AMHERST}

\author{
Directed by: Professor Arnold D. Well
}

This work investigated the ways in which the properties of a concept are activated when that concept is accessed. There has been considerable debate about how closely property information is tied to concepts and under what conditions it is available (e.g., Margolis and Lawrence, 1999). If property information is automatically activated, it should be detectable in both frequency estimation and speeded response tasks. According to Barsalou and Ross' automaticity hypothesis (1986, p.117), “...people become sensitive to the frequency of non-presented information through automatic processing of presented items by well-established memory structures." On this account, if a list of concepts is presented, participants may be sensitive to the frequency of their properties. Therefore, after studying a list of items, participants should be able to estimate the number of items that were "red" or "sweet" without recalling individual items. Naturally, some properties are more important to a concept than others and are more likely to be activated. Sloman, Love, and Ahn (1998) developed a taxonomy of conceptual properties. Using ratings obtained in a variety of tasks, they performed a 
factor analysis that revealed three factors: centrality, salience, and diagnosticity. In these studies, I manipulated centrality and salience to appraise their relative importance for the activation of properties. Barsalou's (1982) work on context-independent and context-dependent properties asserts that the activation of properties may be automatic or strategic, depending on the property type. In both a frequency estimation task and a sentence-word priming task, I manipulated context to evaluate whether central or salient properties are context-dependent. In the sentence-word priming task, I was also able to assess degrees of context dependency. I found that: 1) people demonstrated frequency sensitivity to both central and salient properties but were more sensitive to central properties 2) central properties appear to be activated faster than salient properties as indicated by the slopes in the frequency estimation task and reaction times in the sentence-word priming task 3 ) the activation of both central and salient properties appear to be context-dependent or situated (Barsalou, 2000), with the activation of central properties being moderately context-dependent and that of salient properties, highly context-dependent. 
ACKNOWLEDGMENTS

ABSTRACT

LIST OF TABLES

LIST OF FIGURES

\section{CHAPTER}

1. INTRODUCTION

Conceptual Centrality, Salience and Diagnosticity: Defining Kinds of Properties. 2

Frequency Tasks as a Measure of Property Activation

Some Problems with Earlier Research.......................................................... 12

Frequency Sensitivity as a Measure of Property Activation................................. 14

Property Verification as a Measure of Property Activation..................................15

Defining Context in Frequency Estimation and Property Verification Tasks .... 15

Experimental Design Summary ...................................................................... 16

2. ITEM GENERATION AND SALIENCE \& CENTRALITY RATINGS FOR PROPERTIES

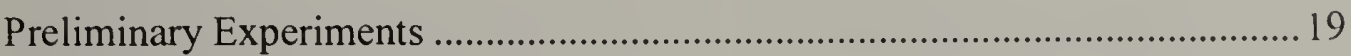

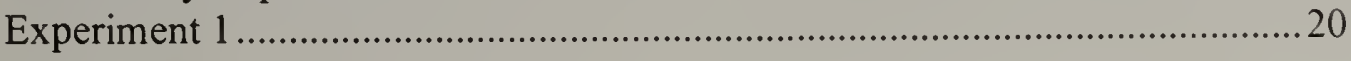

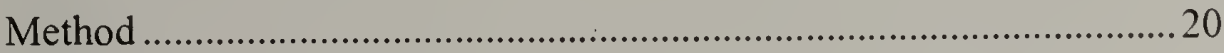

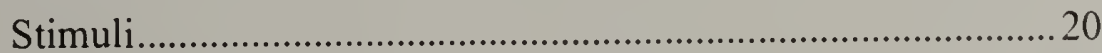

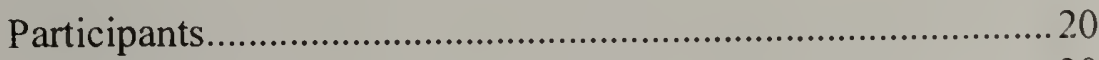

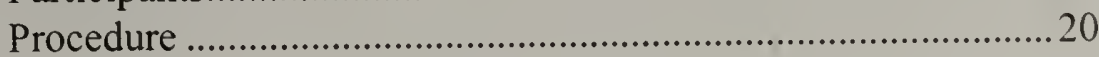

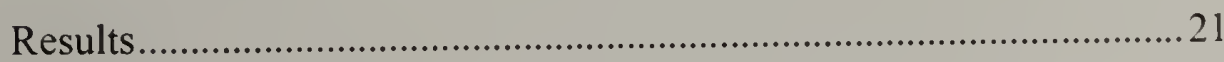

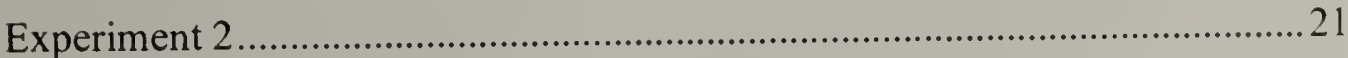

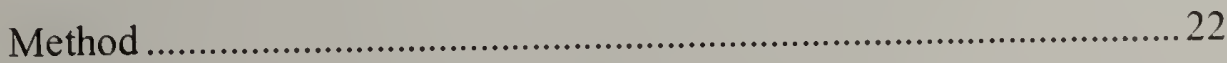

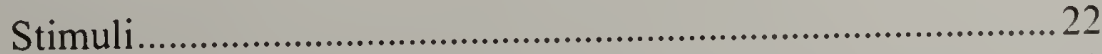

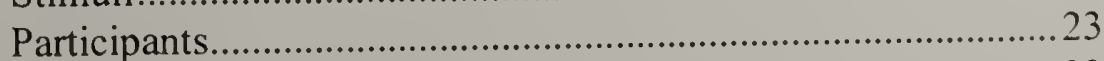

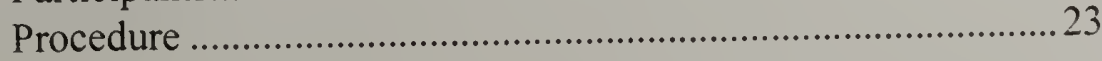

Results 
Experiment 3 .

Method

Stimuli 32

Participants

Learning Phase

Frequency Estimation Phase

Hypotheses

Recall Test

Results.

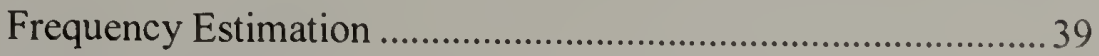

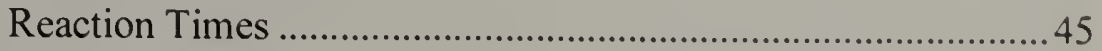

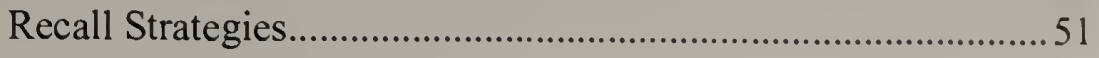

Discussion

4. PROPERTY VERIFICATION AS A MEASURE OF CONTEXT-

DEPENDENCY FOR SALIENT AND CONCEPTUALLY CENTRAL

PROPERTIES

Experiment 4 55

Method

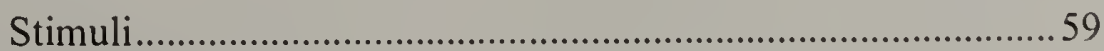

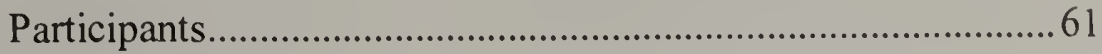

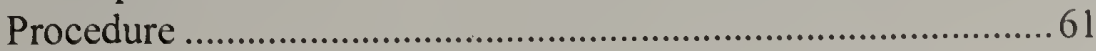

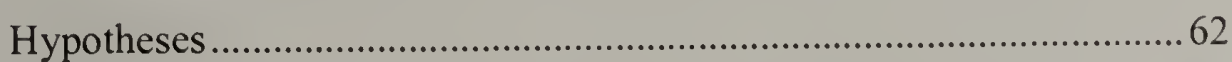

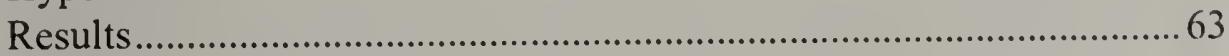

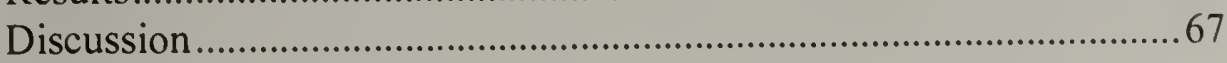

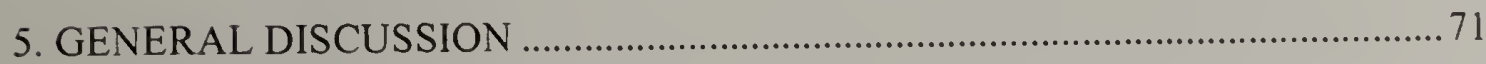

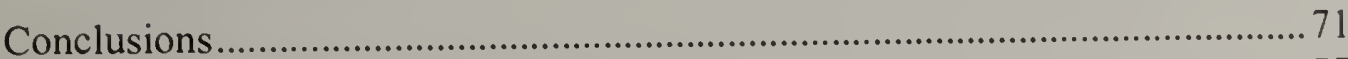

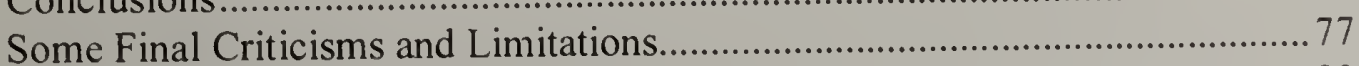

Future Directions ................................................................................ 80

\section{APPENDICES}

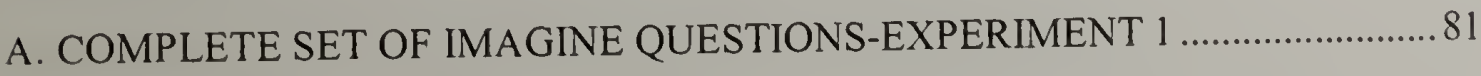

B. COMPLETE SET OF SURPRISE QUESTIONS-EXPERIMENT 1 ...................... 103 


\section{LIST OF TABLES}

Table

1. Measures for Different Conceptual Property Distinctions 6

2. Questions to Measure Centrality, Salience, and Diagnosticity. 22

3. Means Ratings for Experiment 3 Items 26

4. Stimuli for High Salience/Low Centrality 33

5. Stimuli for High Centrality/Low Salience 34

6. Estimated Frequency by Actual Frequency for High Salience/Low Centrality Items: Random Order.

7. Estimated Frequency by Actual Frequency for High Centrality/Low Salience Items: Random Order.

8. Estimated Frequency by Actual Frequency: Non-Random Order. 40

9. Mean Slopes of Regressing Estimated Frequency on Actual Frequency by Conditions....

10. Mean Slopes of Regressing Estimated Frequency by Actual Frequency for List

Types (Random Presentation Order)

11. Mean Slopes of Regressing Estimated Frequency by Actual Frequency for Instruction Types (Random Presentation Order).

12. Reaction Time (msec) by Frequency for High Salience/Low Centrality Items:

Random Order.

13. Reaction Time (msec) by Frequency for High Centrality/Low Salience Items:

Random Order.

14. Reaction Time (msec) by Frequency for Non-Random Order ...

15. Mean Slope of Regressing Reaction Time on Frequency.

16. Mean Slope of Regressing Reaction Time on Frequency List Types (Random Order)

17. Mean Slope of Regressing Reaction Time on Frequency for Instruction Types (Random Order) 
18. Design of Experiment 4

19. Predictions for Degrees of Context Dependence 58

20. Sample Property Verification Sentences in Different Contexts 60

21. Mean Response Speeds $\left(\mathrm{sec}^{-1}\right)$ as a Function of Probe and Sentence Type 65

22. Mean Reaction Times (msec) as a Function of Probe and Sentence Type .66 


\section{LIST OF FIGURES}

Figure

1. Estimated Frequency by Actual Frequency for Each Instruction Type--Random Order.

2. Estimated Frequency by Actual Frequency for Each Order Type--Neutral Instructions Only

3. Estimated Frequency by Actual Frequency for Each List Type--Random Order ....42

4. Estimated Frequency by Actual Frequency for Each List Type--Non-Random Order.

5. Estimated Frequency by Actual Frequency for Each Condition--Random Order .... 43

6. Reaction Time for Each Frequency by Instruction Type--Random Order 48

7. Reaction Time for Each Frequency by List Order--Neutral Instructions Only ........ 48

8. Reaction Time for Each Frequency by List Type--Random Order .49

9. Reaction Time for Each Frequency by List Type--Non-Random Order

10. Reaction Time for Each Frequency by Condition--Random Order .50

11. Response Speeds $\left(\mathrm{sec}^{-1}\right)$ for Sentence Type by Probe Type 


\section{CHAPTER 1 \\ INTRODUCTION}

"A great deal of research on the psychology of concepts has been directed at their
componential structure, especially as it relates to categorization. Virtually everyone
believes that concepts should be analyzed in terms of constituent attributes or features.
For example, the concept of stallion may be understood in terms of features such as
animate, four-legged, male, adult, and so on. Thus, the criteria for kinds of concepts
based on structural differences would be based primarily on differences in the kinds of
features in a concept and the relations among these features." --Medin, Lynch, and
Solomon (2000), p. 123 .

What kind of information is available when we access a concept? The debate over how we store, learn, and think about concepts has continued from the 1950's

(Bruner, Goodnow, \& Austin, 1956), through the work of Eleanor Rosch (1978), and continues up to the present (Medin, Lynch, \& Solomon, 2000). The main purpose of this dissertation is to explore what kind of property ${ }^{\prime}$ information is activated with a concept and whether the kind of property information that is activated differs depending on the context or task.

This work set out to examine whether certain kinds of properties are automatically activated when a concept is processed regardless of context, or whether what is activated is crucially dependent on context. In Barsalou's (1982) work on context-independent and context-dependent properties, he argued that "contextindependent properties form the core meanings of words" (p. 82) and are activated regardless of context. Only context-dependent properties appeared to be affected by what Barsalou called contextual relevance. However, recently Sloman and Ahn (1999) argued that both tasks and context could affect a property's centrality. They stated that,

\footnotetext{
${ }^{1}$ Hereafter, properties and features will be used interchangeably.
} 
"the centrality of a category's feature is relative to the function being served by the category. The importance of a feature depends not only on the identity of the feature and its relation to other conceptual features, but also on the goal of the agent using the concept"(pp. 534-535). Therefore, it seems that Sloman and Ahn might predict that conceptual cores are not rigid but can change, given the task, agent, or the context, implying that all properties are context-dependent.

\section{Conceptual Centrality, Salience and Diagnosticity: Defining Kinds of Properties}

Recent work on features and properties (e.g. Ahn, 1998; Corter \& Gluck 1992; Estes \& Glucksberg, 2000; Malt, Ross, \& Murphy, 1995; Markman \& Wisniewski, 1997; Sloman, Love, \& Ahn, 1998; Wisniewski \& Love, 1998) has demonstrated convincingly that there are different kinds of properties. Sloman et al. found that salience, diagnosticity, and centrality were important for predicting behavior in a wide variety of cognitive tasks, including prediction, induction, inference, categorization, and conceptual combination. It seems reasonable, therefore, that salient, central, or diagnostic properties may differ in their availability when concepts are accessed in a natural setting. Sloman et al. defined all of these factors and these are the definitions used in these studies.

What are centrality, diagnosticity, and salience? First, Sloman et al. (1998) talked about two types of centrality. Conceptual centrality ${ }^{2}$ was defined as how central a property was in a network of the concept's properties. The more properties in memory that are tied to (dependent upon) a specific feature, the more conceptually

${ }^{2}$ Sloman, Love, and Ahn (1998) use the terms conceptual centrality and immutability somewhat interchangeably, but for the sake of consistency, 1 primarily use the term conceptual centrality. 
central that property is. Sloman et al. argued that highly mutable features were not related to a concept's coherence but morc immutable, conceptually central features were. For example, "lays eggs" would be a more conccptually central property of hen engine than "is brown". Conceptual centrality "represents the degrec to which the feature is integral to the mental representation of an object." (Sloman et al., p.190).

Conceptual centrality may be measured by surprisc, using questions such as how surprised would you be to find an item of concept $x$ that did not have feature $y$ (Sloman et al., 1998)? It can also be measured with "ease-of-imagining", "goodness-ofexample", and "similarity-to-an-ideal" questions. "Ease-of-imagining" can be measured using questions of the type how easily can you imagine a real $x$ that does not have property $y$ ? "Goodness-of-example" questions ask how good an example of an $x$ would you consider an $x$ that did not ever have property $y$ ? Lastly, "similarity-to-anideal" may be measured with the question how similar is an $x$ that doesn't have property $y$ to an ideal $x$ ?

The other type of centrality, category centrality relates to the "boundaries of a category's feature space." (Sloman et al., 1998, p. 192) and is defined as the variability of properties of concepts in the world (as opposed to in memory). It often is indistinguishable from conceptual centrality but is measured differently than conceptual centrality. Whereas conceptual centrality deals with the intension of the category, category centrality deals with the extension of a category. Sloman et al. used two question types to measure category centrality: counterfactual naming and variability. Counterfactual naming questions ask would something be called an $x$ even if it did not ever have property $y$ ? Variability asks for something akin to category validity (i.e., 
$\operatorname{Pr}($ feature|category)) by asking questions of the type what percentage of $x$ 's have property $y$ ? However, because a factor analysis by Sloman et al. demonstrated that eonceptual and category centrality were virtually indistinguishable, these two factors were collapsed into one for the purpose of these experiments.

Diagnosticity, another property type assessed by Sloman et al. (1998), refers to how informative a property is for a category in relation to its informativeness for other categories in the set of categories that have that property (i.e., $\operatorname{Pr}$ (Categoryl|Feature)/ $\operatorname{Pr}($ Set of categories with property $x \mid F$ eature $))$. It also refers to what they call the inferential potency of a property, or how many features a given property allows us to infer. As an illustration of how centrality differs from diagnosticity, round may be conceptually central (immutable) for basketball, but it has little informativeness because many other things are round, and therefore is not highly diagnostic. However, round is somewhat inferentially potent beeause it allows us to infer that something can roll.

Diagnosticity can be measured using cue validity questions of the sort of all the things that have property $y$, how many of them are x's? It can also be measured via inferential potency questions of the type what proportion of an $x$ 's features would you predict would be present if all you knew about the object was that it had property? It should be noted that diagnosticity seems to be most relevant when a context is defined. For example, "are blue" is primarily diagnostic for blueberries in the context of fruits, but is not diagnostic when the context of "other fruits" is not defined. Because of this limitation, diagnosticity was not systematically manipulated. However, to ensure against possible eonfounding of diagnosticity with centrality and salience, diagnosticity was roughly equated in all lists of items. 
Lastly, salience refers to the "intensity" of a feature, regardless of context. For example, the red color of a fire engine may be salient, but it certainly isn't a diagnostic or conceptually central property of fire engines. It is measured both by prominence and by availability questions. Prominence questions ask how prominent in your conception of an $x$ is it that it has property $y$ ? This is similar to what Barsalou (1982) used to measure context-independent properties. Availability is usually measured through speeded responses using yes/no questions such as an $x$ has property $y$.

Sloman et al. (1998) asked participants to rate attributes on questions designed to measure conceptual centrality, category centrality, diagnosticity, and salience (see Table 1). They found that there were three factors measured by these questions, and these three factors corresponded to centrality, diagnosticity, and salience. However, although Sloman et al. were able to demonstrate that people could differentiate centrality, salience, and diagnosticity, they did not explore the specific role these factors play in our memory for concepts.

So, how might these different factors influence the availability of properties when concepts are activated? Sloman et al. (1998) ștated, "mutability judgments are derived from thinking about the internal structure of concepts." Because of how important conceptually central (immutable) properties are, and how intertwined they are with other properties of a concept, conceptually central properties may be activated when a concept is processed.

Some work has shown that in the interpretation of metaphor and in conceptual combination, we generally do not map onto conceptually central properties (Love, 1996). For example, when interpreting frog car people generally do not map "hops" 
onto "car" because the motion of a car is conceptually central and so relatively immutable, but they may map "green" onto "car" because color is a much less conceptually central property of cars. When making inductive inferences, we are also

Table 1. Measures for Different Conceptual Property Distinctions

1. Conceptual centrality/mutability

a) How surprised would you be to find an item of conccpt $x$ that did not have feature $y$ ?

b) How easily can you imagine a real $x$ that does not havc property $y$ ?

c) How good an example of an $x$ would you consider an $x$ that did not ever have property $y$ ?

d) How similar is an $x$ that doesn't have property $y$ to an ideal $x$ ?

\section{Category centrality}

a) Would something be called an $x$ even if it did not ever have property $y$ ?

b) What percentage of $x$ 's have property $y$ ?

\section{Diagnosticity}

a) Of all the things that have property $y$, how many of them are $x$ 's?

b) What proportion of an x's features would you predict would be present if all you knew about the object was that it had property y?

\section{Salience}

a) How prominent in your conception of an $x$ is it that it has property $y$ ?

b) An $x$ has property $y$ ? (speeded)

more likely to project conceptually central features than less central ones (Sloman et al., 1998). Therefore, it seems as though people are able to selectively access the centrality of properties in order to perform these tasks.

However, it is also possible that salience increases the likelihood that a property would be accessed when a concept is activated. There are a number of experimental results that demonstrate the importance of salience. Tversky and Hemenway (1984) pointed out that when participants were asked to generate parts of objects, they tended 
to generate properties that were perceptually salient in addition to properties that were functionally significant. ${ }^{3}$ Johnson and Mervis (1998) found that novices rely heavily on perceptually salient features, and it is these features that tend to most influence novices' similarity decisions. In Billman and Heit's focused sampling model (1988) the probability of choosing a property is dependent on its salience. Kersten and Billman (1997) examined the effect of correlational structure on event category learning, and they found that although participants had an easier time learning a rule embedded in a rich correlational structure, rules that dealt with salient attributes were easier to learn than those which dealt with less salient attributes. Kersten, Goldstone, and Schaffert (1998) found that what they call an attentional persistence mechanism increases attention to those properties that are known to be salient.

Lastly, Lamberts' (1995) work on the Extended Generalized Context Model (EGCM) has examined when and how salient and central properties are accessed when concepts are activated. The EGCM is a process model of categorization of the time course of categorization that makes specific predictions about how different kinds of properties (stimulus dimensions) affect categorization. In the EGCM, categorization is contingent upon similarity, and similarity is computed as a function of time based on two critical aspects of stimuli: perceptual salience and utility/informativeness. Higher perceptual salience results in earlier featural inclusion and utility, which is similar to centrality, affects similarity but is not linked to processing time. Therefore, the EGCM predicts that salience influences categorization decisions early in processing, but

\footnotetext{
${ }^{3}$ It is interesting to note that children pay attention to salient properties prior to when they attend to functional significance. The implications for property availability in children is an interesting question (but see also Mervis \& Greco, 1984).
} 
centrality primarily impacts categorization decisions later in proeessing. Lamberts has demonstrated, in accord with the predietions of the EGCM, that for eoneepts learned in a laboratory setting, rapidly-made eategory decisions are based on the perceptually salient features of the item, but later responses are based more on the utility value of a dimension.

However, it is important to note that Lamberts' work dealt primarily with responses made under time pressure. Because people in morc naturalistic settings typically have time to aceess a concept as they go about their daily lives, it is important to study the kind of information that is available when a coneept is fully aecessed in natural settings. In addition, Lamberts' used only artificial categories with a limited number of dimensions that were learned in a laboratory setting. Although these types of category learning tasks offer experimenters a great amount of experimental control, there are also a number of eritieisms that ean be levied against these types of experiments. First, participants in the laboratory may rely on strategies to encode studied exemplars that would not be used when learning about eoneepts in a natural setting. Participants are also given feedback during eategory learning tasks that is typically not given in natural settings. These stratcgies and feedback may lead participants to encode features and use these features differently than they would for conccpts that are more naturalistic. Thus, the kinds of property information that are available for concepts storcd in long term memory may well be different than the kinds of property information shown to be available for catcgories lcarned in a laboratory setting. Thesc studies will look at how different property types are activated for more natural concepts. Lastly, although the work of Lamberts examincs which kinds of 
properties may be available when a concept is activated, it does not cxamine how different property types are affected by differcnt contexts.

It seems reasonable to think that different contexts may systcmatically alter the kind of properties that become active for a concept. In this work, I hope to provide a more principled demonstration as to how different kinds of properties arc activated in different contexts. For example, round is a "stable" or what Sloman et al. (1998) might call a conceptually central property of basketball. Barsalou (1982) would also say that round is a context-independent property of basketball. However, Medin et al. (2000) and Barsalou (1983) also point out that less central properties such as floats may be accessed for basketball in the context of an ad hoc category for which buoyancy is important. Barsalou (1982) would call this a context-dependent property of basketball. For example, the goal-derived category "things to take from a boat when it is sinking" may highlight or activate the property floats in service of the goal of saving oneself from drowning, which in turn may activate or resonate with the property floats for concepts such as basketball. This seems to demonstrate that different contexts could potentially alter the availability of property information.

\section{Frequency Tasks as a Measure of Property Activation}

What kind of task might be useful to explore the kinds of properties that are available when a concept is activated in memory? It has been shown that people are able to accurately estimate the frequency of non-presented information implicitly expressed in presented items. Barsalou and Ross (1986) showed this to be the case for superordinate categories. Therefore, participants may be able to estimate the frequency of items that have a specific property without having to consciously retrieve the item. If 
so, this would seem to suggest that propcrty information bccomes available from concepts when that concept is activated, whether people dircetly cncode frequency information (Hasher \& Zacks, 1979; Jonides \& Jones, 1992) or acccss frequency information in a more indirect manner (Williams \& Durso, 1986; Jonides \& NavchBenjamin, 1987; Hintzman, 1988; Brown, 1995; Brown, 1997).

There has been no evidence that people are sensitive to property frequency. As noted above, some studies have demonstrated sensitivity to the frequency of superordinate categories (Alba, Chromiak, Hasher, \& Attig, 1980; Barsalou \& Ross, 1986; Williams \& Durso, 1986) in a list of learned items, even though participants were never shown the superordinates during the list presentation. However, Barsalou and Ross and others (Sanders, Gonzalez, Murphy, Liddle \& Vitina, 1987; Spalding \& Murphy, 1999; Wattenmaker, 1993) have found no evidence that properties of concepts were automatically activated when an item was encountered. Spalding and Murphy, and Wattenmaker found that when participants learned artificial exemplars presented as feature lists to participants during a learning phase, these participants could accurately estimate the frequency with which a property appeared in these items. However, these experiments presented the properties explicitly, and so are not demonstrations of sensitivity to implicitly presented information.

Barsalou and Ross (1986) argued that this failure and that of others to demonstrate sensitivity to property frequency occurred, not because properties were not activated when a concept was processed, but rather that sensitivity to property frequency requires completion of both stages of a two-stage process. In the first stage, properties need to be automatically activated as an item is encountered. In the second 
stage, this activated property information must also interact with a pre-existing memory structure to have people demonstrate sensitivity to frequency information. Barsalou and Ross argued that because we don't often deal with properties in their own right, we do not have very well developed memory structures for properties, and therefore do not complete the second stage of processing.

Barsalou and Ross (1986) explained their success in demonstrating sensitivity to superordinate frequency by arguing that, unlike property information, superordinate information is represented in memory in these pre-existing structures along with the item information. They stated that, "items belonging to the same superordinate are processed together sufficiently often that strong relations develop between items and later enable sensitivity to superordinate frequency. In contrast, items sharing the same property may not be processed together, the result being the interitem relations necessary for frequency sensitivity never develop" (Barsalou and Ross, p.129). Their argument was that we don't often think about the kinds of things that belong to the property sweet but we often use the superordinate furniture. This is why, they reason, subjects are able to complete both stages of processing necessary to demonstrate sensitivity to superordinate frequency but not property frequency. Barsalou and Ross concluded, “...although both superordinates and properties are automatically activated, only superordinates possess the kind of representation whose activation results in frequency sensitivity." (Barsalou and Ross, p.127).

Looking at how to design a frequency estimation task to measure automatic sensitivity to property frequency, it is important to be aware that people use two types of estimation strategies when judging frequency: enumeration and non-enumeration 
(Williams \& Durso, 1986; Brown, 1995). Enumeration occurs when pcople can consciously retrieve specific items for each category, whercas non-cnumeration occurs when there is no conscious retrieval. In previous research, decreasing the responsc time during a frequency estimation task did not decrease the accuracy of frequency estimates (Williams \& Durso, 1986), but did increase the likelihood that participants used more automatic, non-enumeration processes. Therefore, when analyzing results from frequency estimation studies, they must be analyzed in two ways. First, they should be analyzed without regard to reaction times to see if there is any sensitivity to property frequency regardless of estimation strategy. In addition, because the goal of these studies was to look at the kind of properties that are automatically activated in "neutral" and biasing contexts, results should be analyzed with respect to reaction times to ensure that they do not increase with increasing frequency. ${ }^{4}$

\section{$\underline{\text { Some Problems with Earlier Research }}$}

Barsalou and Ross (1986) tried and failed to demonstrate sensitivity to property frequency. However, there were a number of problems with their study. First, some of the items chosen by Barsalou and Ross were not very good examples of their categories. For example, for the property "pointed" they used the items "sword", "nail", "porcupine", and "pineapple". The first two items seem to be good examples of things with the property "pointed", but the last two are not very good examples. In fact, if I had to pick a property to describe both pineapples and porcupines, I would probably use the word "prickly", not "pointed". If Barsalou and Ross were trying to be exact, they

\footnotetext{
${ }^{4}$ These non-enumeration processes have been divided into those that deal with direct retrieval of frequency information and those that deal with memory assessment (Brown, 1995), but this distinction will not be dealt with in these studies.
} 
should have noted that only the quills of the porcupine and the scales of a pineapple have points.

A second criticism is that many items used on their lists belonged to not just one property category. Indeed, often items belonged to both a superordinate and a property category. Therefore, what was intended by Barsalou and Ross (1986) to be the frequency of a specific category may not have been the actual frequency of that category when all of the items that should have been on that list are counted. For example "poisonous" was one of the property categories they used. It included one item: carbon monoxide. However, ammonia, which can also be poisonous, appeared on the list under the category "smells". "Attacks" was supposed to be an empty property category, but the item "owls", which is an example of an animal that attacks, was on the list under the superordinate "birds". On a different list, "liquids" was designated as an empty category. However, on the same list, under various categories, were the items cider, cola, stream, and vinegar which all could be considered to have the property "liquid".

In addition, Barsalou and Ross (1986) alluded to the fact that they may not have found an effect for properties because of their choice of items and properties. They noted that the properties they chose might have had different senses. For example, they pointed out that their items for the property "smells", which included garlic, perfume, coffee, and skunk, might have all instantiated different senses of the property "smell". Garlic is smelly but not putrid, perfume can be sweet- or spicy-smelling, coffee has a strong odor, and skunks just plain stink. It might be the case that if items were chosen that instantiated the same sense of the property (for example four items that "have a bad 
smell"), these might be more likely to be represented in well-established mcmory structures. Then, participants might be more likely to show sensitivity to these properties.

\section{Frequency Sensitivity as a Measure of Property Activation}

However, what if sense is not the factor that influences what is stored along with concepts in well-represented memory structures? What other kind of distinctions might be relevant and important to consider when thinking about the kind of propertics that would be activated in memory along with concepts? As pointed out above, some properties are more important for an item than others are, and the centrality and/or salience of the property may determine whether or not it is activated. If central or salient properties were automatically activated, this would be in accord with Barsalou and Ross' automaticity hypothesis (1986), which stated that people should be automatically sensitive to context-independent properties (Barsalou, 1982).

In this dissertation, I examined conceptually central and salient properties and their availability for concepts in different contexts. I used a frequency sensitivity task to examine property activation. Two alternative hypotheses were used to guide this research. First, because some work indicates that conceptually central features seem to be important for concepts (Sloman et al., 1998), participants given lists of items that have the same conceptually central property may be able to directly estimate the frequency of items with that property. Alternatively, because other research indicates that salient features are more prominent than less salient features, when concepts are activated participants may demonstrate a greater sensitivity to the frequency of items with the same salient property. Therefore, I used two types of items, one type rated 
high on centrality and low on salience and another type rated high on salience and low on centrality, the purpose of which was to increase the likelihood of finding sensitivity to property frequeney.

\section{Property Verification as a Measure of Property Activation}

It is important to note that although the frequeney estimation task might demonstrate that people are sensitive to implicitly presented properties, because the number of frequencics that ean be presented is limited, the task may not be sufficiently sensitive to reveal small differences in activation between salient and conceptually central properties. Because a property verification task uses reaction time data, it should be more capable of detecting smaller differences in degrees of context dependence.

\section{Defining Context in Frequency Estimation and Property Verification Tasks}

To examine property sensitivity in diffcrent contexts, the type of orienting task used defined the context. I used "ncutral", salienec-biasing, and centrality-biasing contexts. It should bc noted that in Experiment 3, "context" referred to the instructions participants received to induce them process the items in different ways, whereas in Experiment 4 context was used to refer to sentence context. It is theoretically unclear whether people will be sensitive to the frequency of salient and central properties in a "neutral" context. Although Barsalou (1982) argued that there are context-independent properties that become active in any context, it is possible that participants might only show sensitivity for different kinds of properties of items when they process them in particular ways. In addition, if a similar pattern of results is found for both the frequency estimation task and the property verification task, this will provide 
converging evidence about which types of properties are activated and under what conditions.

\section{Experimental Design Summary}

This research consisted of three components:

(1) First, appropriate stimulus material were generated. In two preliminary studies, participants generated lists of concept-property pairs, and then a second group of participants rated the properties for centrality, salience, and diagnosticity with respect to the concepts, using the procedures of Sloman et al. (1998). The goal of these preliminary studies was to obtain concepts with properties that varied in centrality and salience while equating the degree of diagnosticity. From this, I was able to develop lists of high centrality/low salience properties and low centrality/high salience properties.

(2) Next, the availability of property information was investigated using a frequency-estimation task. According to the automaticity hypothesis of Barsalou and Ross (1986), participants may be directly sensitive to the frequency of their properties. If so, after presentation of a list of items, participants should be able to estimate the number of presented items having certain properties without recalling the individual items.

Of course, as pointed out above, some properties are more important to a concept than others, and are therefore more likely to be activated. In addition, simply presenting a list of concepts may not be adequate to activate their property information. It might be necessary, in order to make contact with the memory structures that underlie sensitivity to frequency information, for items be processed in a context that facilitates 
activation of property information. Therefore, the frequency estimation experiment was conducted with two between-subject factors: property type (two levels) and orienting task (three levels). The property type manipulation varied the centrality and salience of the properties to the categories, using the high salience and high centrality lists developed earlier. There were also three orienting tasks. Participants were presented with a list of items and were told to either (1) learn them for free recall; (2) develop an image of each item; or (3) consider the purpose and function of each item.

It was hypothesized that if property activation is context-independent, participants should show sensitivity to property frequency in a "neutral" context. However, if participants do not demonstrate sensitivity to frequency for either property type in the "neutral" context, then the orienting tasks in which participants form an image or consider the internal structure of an item should bias participants to be sensitive to salient and conceptually central properties, respectively.

(3) The final experiment consisted of a speeded property verification task. Because frequency estimation tasks can be relatively insensitive, small differences in property activation for the two different types of properties may not be detectable. It was hoped that a task in which a speeded response was made to indicate whether an item has a certain property would be able to detect these small effects.

In this study, there were two within-subject factors (type of sentence frame and property type). Participants were given sentence frames (4 levels) with a subject noun underlined and were asked to verify whether a property ( 2 levels) appearing on the computer screen after the sentence presentation belongs to the subject noun. Each subject noun was paired with each level of property: a high salience property and a high 
centrality property. In addition, to measure the effect of different contexts, three different biasing sentence contexts were constructed for each subject noun: a saliencebiased sentence context, a "neutral" sentence context, and a centrality-biased sentence context. In addition, in a matched set of "true" control sentences, each property was paired with a less highly related subject noun, for a total of 4 levels of "true" sentence frames. An equal number of non-matched, "false" property verification sentences were also tested.

It was hypothesized that if salient or conceptually central properties are contextindependent, as defined by Barsalou (1982), reaction times should be the same regardless of sentence context (for "true" sentences). If either salient or conceptually central properties are context-dependent, it was further hypothesized that there may be varying degrees of context-dependence. If so, different patterns of response times should be associated with the degree of context-dependence. For high contextdependence, reaction times should be shortest in the appropriate biasing context and longer in all other contexts, but for moderate context-dependence reaction, times could be equally short in both an appropriate biasing context and a "neutral" context and longer only in a different biasing context.

To conclude, the main questions asked in this dissertation include the following: (1) Are conceptually central or salient properties more likely to be context-dependent? (2) What factors influence the availability of properties? Can different types of processing make different kinds of properties more accessible? (3) Lastly, are there degrees of context-dependency? 


\section{CHAPTER 2 \\ ITEM GENERATION AND SALIENCE \& CENTRALITY RATINGS FOR PROPERTIES}

\section{Preliminary Experiments}

One purpose of this research was to investigate whether people are able to estimate frequency for "non-presented" information -- specifically for property information that may be activated when category names are processed. If people are able to estimate the frequency with which properties are activated in a list of category names, is this sensitivity dependent upon whether the property is conceptually central or conceptually salient?

In order to conduct the frequency estimation experiment, it was first necessary to generate an adequate number of property-item pairs that varied both in conceptual centrality and in salience. The purpose of the first two preliminary experiments was to generate the necessary stimulus material. The purpose of the first experiment was simply to generate property-item pairs by giving participants a property and then asking them to generate items that have this property. The purpose of the second experiment was to obtain centrality, diagnosticity, and salience ratings for these property-item pairs. The goal was to obtain two sets of property-item pairs: high centrality and low centrality. For each property, it was necessary to find as many as five items for which a property was rated, say, high on salience and low on centrality. These ratings were then used to create lists of property-item pairs for use in Experiment 3 that differed on measures of the centrality and salience of properties while being equated for diagnosticity. 


\section{Experiment 1}

Method

\section{$\underline{\text { Stimuli }}$}

Properties were chosen so partieipants were able to generate items that ineluded both natural kinds and artifacts. Because frequency estimation was the task used in Experiment 3 , there needed to be property eategories that eontained varying numbers of items. Specifically, to use property eategories with frequencies 0,1 , and 5 , there was a need for property eategories with up to five items for which the property had high salience, and propcrty categories with up to five items for which the property had high centrality (see Experiment 2). Properties presented to participants included the following:

Smclly, Liquid, Hot, Sweet, Sharp, Slimy, Wooden, Yellow, Noisy, Sour, Soft, Noisy, Cold, Has Seeds, Grows On Trees, Has Skin, Has Fur, Walks, Hops, Flies, Has Wheels, Grainy, Scary, Clear, Reflective, Salty, Ferocious, Has Leaves, Sticky, Fast, Transparent, Round, Triangular, Poisonous, Dangerous, Rolls, Rubber, Plastic, Glass, Stores Things, Juiey, Is Large, Red, Swims, Has A Tail, Alive, Edible, Leather, Has A Handle, Is Spicy, Loud, Extravagant, Spotted, Freezing, Furry, Tall, Green, Blue, Orange, Crunchy, Has a Shell

\section{$\underline{\text { Participants }}$}

In Experiment 1 there were 5 participants. Participants were all graduate students at the University of Massachusetts.

\section{Procedure}

Participants were given the booklets containing the 61 property categories to completc on their own. The participants' task was to generate for each property as many related items as possible in two minutes. Participants were asked to generate any 
related items that came to mind. At the beginning of the booklet, participants were given the following instructions:

All things have properties that are related to them. For example, flamingoes are pink. In this experiment, you will be given a property like pink, and your task will be to think of things that have this property. So, for pink, in addition to flamingo you might write down bubble gum, pigs, etc. We want you to write down as many different pink things as you can. You can take up to two minutes to generate things for the property pink before you should turn the page and go on to the next property. If you finish generating examples before two minutes are up, you may go on to the next item. Thank you for your participation.

\section{Results}

Participants were able to generate a sufficient number of items for each property category. For example, for the property poisonous participants generated the following items: cyanide, lead, chemicals, venom, strychnine, ammonia, bleach, roach killer, weed killer, spiders, gas, household cleaners, berries, and hemlock. These generated items were then used to create the questions for Experiment 2. These questions were then used to obtain ratings of salience, centrality, and diagnosticity. Some items that only marginally fit the relevant property category were culled from the final list used to create the questions For a complete list of the property/item pairs that were generated by participants and that were chosen by the experimenter see the Experiment 2 question lists in Appendices A-D.

\section{Experiment 2}

The purpose of Experiment 2 was to obtain ratings of salience, conceptual centrality, and diagnosticity for property-item pairs that were used in Experiment 3. Some of the questions used by Sloman et al. (1998) were used to obtain ratings of centrality, salience, and diagnosticity (see Tables $1 \& 2$ ). 


\section{Method}

\section{$\underline{\text { Stimuli }}$}

Participants were presented with items generated in Experiment 1 and were asked how the corresponding properties related to the item with respect to centrality, salience, or diagnosticity. The relevant item-property pair was rated on centrality, diagnosticity, and salience (see Table 2), but any individual participant only answered one question type to avoid any possible influence of responses on one question type to another (Sloman, et al, 1998).

Table 2. Questions to Measure Centrality, Salience, and Diagnosticity

1. Conceptual centrality/mutability

How surprised would you be to find an ice cube that is not cold?

How easily can you imagine a real ice cube that is not cold?

2. Salience

How prominent in your conception of an ice cube is it that it is cold?

3. Diagnosticity

Of all the things that are cold. how many of them are ice cubes?

One question for salience and diagnosticity and two questions for centrality were chosen from the list of possible questions used by Sloman et al. (1998, see Table 2). They were chosen by selecting those questions for each factor that had the smallest correlations with the other two factors. Ratings for centrality and salience were made on a scale of 1 to 10 , where 1 indicated low centrality or low salience and 10 indicated high centrality or high salience. The "surprise" question and the "ease-of-imagining" question, which both loaded high for centrality in Sloman et al., were used as measures 
of centrality. One measure of salience (availability) could only be assessed with a reaction time task. Thus, the "prominence" question, which could be rated on a 1-10 scale, was used as the measure of salience. Lastly, diagnosticity was quantified using the "cue validity" question. Because of the probabilistic nature of the diagnosticity question, participants were asked to respond on a scale of 0-100.

\section{$\underline{\text { Participants }}$}

In Experiment 2 there were a total of 184 participants. The participants were all University of Massachusetts undergraduates. They received course credit for their participation.

\section{Procedure}

Participants were asked to rate a portion of the item and property pairs for a single question type. That is, each participant saw only centrality questions, salience questions or diagnosticity questions and then, within each type, saw only a subset of the total number of questions. For the ease of imagining, surprise, and prominence questions, each participant made 395 ratings (see Table 2 for sample questions). For these categories, the questions were divided into two subsets-Set A and Set B. The conditional probability questions were divided into three subsets of 263, 263, and 264 questions because these questions were expected to take longer to answer (Set A, Set B, and Set C). Each participant rated only one of these subsets (see Appendices A-D for a complete list of questions). On average, participants were able to complete the rating task in less than 30 minutes.

Participants were given the following instructions before beginning the rating task. The rating scale was present as participants made each rating. 
Surprise instructions: You are going to see a series of questions where you will be asked how surprised you would be to find an item that did not have a specific property. For example--how surprised would you be to find an ice cube that is not cold? You should make your ratings on a scale from 1 to 10 , where 10 means you would be extremely surprised to find an ice cube that wasn't cold and 1 means you wouldn't be very surprised to find an ice cube that wasn't cold. After making your response for each item/property pair, a new item will come up until you have finished all of the ratings.

\section{Rating scale:}

$\begin{array}{llllllllll}1 & 2 & 3 & 4 & 5 & 6 & 7 & 8 & 9 & 10\end{array}$

not at

all surprised

extremely surprised

Ease-of-imagining instructions: You are going to see a series of questions where you will be asked how easy it would be to imagine an item that did not have a specific property. For example--how easy is it to imagine an ice cube that is not cold? You should make your ratings on a scale from 1 to 10 , where 10 means its very hard to imagine an ice cube that isn't cold and 1 means it's very easy to imagine an ice cube that isn't cold.

\section{Rating scale:}

$\begin{array}{lrrrrrrrrrr}1 & 2 & 3 & 4 & 5 & 6 & 7 & 8 & 9 & 10 \\ \text { easy to } & & & & & & & & \\ \text { imagine } & & & & & & & & & \\ \text { hard to } & \text { imagine }\end{array}$

Prominence instructions: You are going to see a series of questions where you will be asked how much does a property stand out for a specific item. For example--how much does the property cold stand out in your thoughts about ice cubes? You should make your ratings on a scale from 1 to 10 , where 10 means cold really stands out and 1 means cold doesn't stand out very much at all.

\section{Rating scale:}

$\begin{array}{lrrrrrrrrrr}1 & 2 & 3 & 4 & 5 & 6 & 7 & 8 & 9 & 10 \\ \begin{array}{l}\text { does not } \\ \text { stand out }\end{array} & & & & & & & & & & \\ \text { really } \\ \text { stands out }\end{array}$


Diagnosticity instructions: You are going to sec a series of questions where you will be asked Of all the things that have a specific property, how many of them are in a specific category. For example--of all the things that arc cold how many of them are ice cubes? You should make your ratings on a scale from 0 to 100 , where 100 means all of the things that are cold are ice cubes and 0 means none of the things that are cold are ice cubes.

\title{
Rating scale:
}

$\begin{array}{lllllllllll}0 & 10 & 20 & 30 & 40 & 50 & 60 & 70 & 80 & 90 & 100\end{array}$

nothing with

property $\mathrm{x}$

is a $y$

\author{
all things \\ with property $x$ \\ are y's
}

Set A and Set B of the ease-of-imagining questions were rated by 19 and 20 participants, respectively. Set A and Set B of the surprise questions were both rated by 21 participants. Set A of the prominence questions was rated by 20 participants and Sct B was rated by 21 participants. Lastly, Set A of the conditional probability questions was rated by 20 participants and Sets $B$ and $C$ were both rated by 21 participants.

\section{Results}

The ratings were collected and an average was computed for each item by each question type. Appendix E contains a complete set of means for all of the items by each question type. These ratings were then used to construct lists of high centrality items and high salience items. The high centrality items and high salience items were selected in the following manner. First, a planned comparison was conducted on the two centrality items compared to the salience items [ ( (Centrality1 + Centrality2 $) / 2)-$ Salience ]. Those items that were rated by participants as significantly different at the .05 level on centrality and salience were extracted from the list. These items were then 
used to construct the final lists used in Experiment 3. For Experiment 3, items needed to meet the following criteria:

- There needed to be seven property categories with 0 items, seven property categories with 1 item, and seven property categories with 5 items.

- The items that were chosen needed to be rated significantly higher on centrality than on salience or significantly higher on salience than on centrality.

- Within a given list (high salience or high centrality), the items that were chosen needed to belong (with a few exceptions), to only one property category.

To comply with the specified criteria, a small number of items on the final lists were not significant at the .05 level, but the mean ratings were in the appropriate direction (see Table 3).

All items and their ratings on centrality, salience, and diagnosticity can be found in Appendix E, with significant differences on centrality and salience indicated by bullets. Also, Appendix F and Appendix G contain the two lists of significant items that were extracted from the list in Appendix E. List 1 contains all of the itens that were rated high on salience and low on centrality and List 2 contains all of the items that were rated high on centrality and low on salience.

Table 3. Means Ratings for Experiment 3 Items

\begin{tabular}{|c|c|c|c|c|c|c|}
\hline & & $\begin{array}{c}\text { Centrality } \\
1 \text { (C1) } \\
\end{array}$ & $\begin{array}{c}\text { Centrality } \\
2 \text { (C2) }\end{array}$ & $\begin{array}{c}\text { Salience } \\
\mathrm{S} \\
\end{array}$ & $\begin{array}{c}\text { Contrast } \\
\text { Significance } \\
\end{array}$ & $\begin{array}{l}95 \% \text { Confidence } \\
\text { Interval-Contrast }\end{array}$ \\
\hline & & & & & \multicolumn{2}{|c|}{ Null Hypothesis: $(\mathrm{C} 1+\mathrm{C} 2) / 2-\mathrm{S}=0$} \\
\hline \multicolumn{7}{|c|}{ POISONOUS } \\
\hline$\because$ & VENOM & 8.1 & 7.3 & 9.3 & .029 & -1.9 to -.11 \\
\hline$\ddot{\circ}$ & $\begin{array}{l}\text { Indicates } \\
\text { Indicates }\end{array}$ & $\begin{array}{l}\text { ality } \\
\text { cee }\end{array}$ & & & & \\
\hline
\end{tabular}




\section{CLEAR}

GLASS

$\%$ PLASTIC

$\%$ CELLOPHANE

WINDOW

SARAN WRAP

\begin{tabular}{ll}
\hline 4.2 & 3.4 \\
\hline 3.7 & 3.1 \\
\hline 6.4 & 5. \\
\hline 6.4 & 5.5 \\
\hline 6.7 & 5. \\
\hline
\end{tabular}

3.4

8.6

$<.001$

$6.2<.001$

.013

$\begin{array}{ll}7.9 & .013 \\ 8.5 & .004\end{array}$

.014

$-4.110-2.1$

-2.9 to -.88

$-2.410-.31$

$\begin{array}{llll}5.5 & 8.5 & .004 & -2.710-.54\end{array}$

\section{HAS WHEELS}

- VAN

- TRAIN

- roller coAster

- GO-CART

- BUS

\section{RUBBER}

- GARDENHOSE

ORANGE

\& PUMPKIN

GLASS

- LIGHT BULB

8.9

8.4

8.7

8.3

8.6

8.8

8.9

8.6

7.3

7.1

7.0

6.8

.19

-2.6 to -.30

.269 to 1.91

.666 to 2.68

.792 to 2.74

.13 to 2.04

.027

$-4.8 \mathrm{E}-02$ to 1.65

.064

.

-.36 to 1.78

-2.38 to -.25

.274 to 1.77

.008

\section{GROWS ON TREES}

- BANANA

- PEARS

- LEMONS

- LIMES

- PEACHES

\section{STORES THINGS}

- BANK

IS RED

* FIRE ENGINE

HAS A TAIL

- WHALE

- ELEPHANT

- COW

- KANGAROO

- BIRD

\section{IS LEATHER}

* POCKETBOOK

$\because$ BOOT

* BELT

* COUCH

$\because$ WALLET

\begin{tabular}{ll}
\hline 8.3 & 8.5 \\
\hline 8.5 & 8.4 \\
\hline 8.4 & 8. \\
\hline 8.4 & 7.9 \\
\hline 8.8 & 8. \\
\hline
\end{tabular}

\begin{tabular}{l}
8.5 \\
8.4 \\
\hline 7.0 \\
\hline 8.9 \\
\hline
\end{tabular}

6.8

6.9

6.0

5.7

7.1

8.1

5.8

.001

.74 to 2.71

.22 to 1.98

.37 to 1.98

.53 to 2.41

.618 to 2.58

.25 to 1.86

.01

.74 to 2.71

-2.90 to -.89

$\begin{array}{lllll}7.2 & 5.8 & 9.6 & <.001 & -2.90 \text { to }-.89\end{array}$

\begin{tabular}{llllc}
7.9 & 8.4 & 5.9 & .02 & .265 to 2.90 \\
\hline 7.8 & 8.3 & 5.8 & .008 & .41 to 2.63 \\
\hline 7.5 & 7.6 & 6.2 & .035 & $7.089 \mathrm{E}-02$ to 1.92 \\
\hline 7.0 & 8.1 & 5.5 & .008 & .411 to 2.56 \\
\hline 6.7 & 6.3 & 4.9 & .059 & -4.46 E- 02 to 2.40 \\
\hline
\end{tabular}

\begin{tabular}{ll}
3.3 & 1.8 \\
\hline 4.2 & 3.5 \\
\hline 4.7 & 3.2 \\
\hline 2.0 & 1.8 \\
\hline 3.1 & 2.2 \\
\hline
\end{tabular}

\begin{tabular}{ll}
6.6 & $<.001$ \\
7.1 & $<.001$ \\
8.2 & $<.001$ \\
\hline 6.3 & $<.001$ \\
8.2 & $<.001$
\end{tabular}

-3.56 to -1.94

-3.05 to -.99

-3.91 to -1.93

-3.57 to -1.76

-4.42 to -2.68 
HAS A HANDLE

- UMBRELLA

5.2

$<.001$

1.26103 .01

IS STICKY

- TAR

- HONEY

\section{7}

9.3

- SYRUP

- MOLASSES

- JELLY

\section{IS SMELLY}

$\because$ GARBAGE

$\because$ MANURE

SKUNKS

$\because$ FOOT

- GYM SOCK

- BLEACH

- GARLIC

- HALITOSIS

- SULFUR

- ONION

\section{(IS) LIQUID}

\begin{tabular}{|c|c|c|c|c|c|}
\hline - SODA & 8.8 & 8.4 & 7.0 & .043 & $3.128 \mathrm{E}-02$ to 1.87 \\
\hline - BEER & 9.3 & 8.7 & 7.2 & .011 & .23 to 1.69 \\
\hline WINE & 9.3 & 8.9 & 7.1 & .004 & .38 to 1.88 \\
\hline ALCOHOL & 9.1 & 8.6 & 7.2 & .05 & $6.157 \mathrm{E}-04$ to 1.68 \\
\hline SOUP & 7.7 & 7.9 & 5.7 & .009 & .33 to 2.22 \\
\hline \multicolumn{6}{|l|}{ (IS) HOT } \\
\hline OVEN & 3.5 & 6.1 & 7.9 & $<.001$ & -3.30 to -1.02 \\
\hline STOVE & 2.9 & 5.6 & 7.5 & $<.001$ & -3.39 to -1.26 \\
\hline FIREPLACE & 3.9 & 6.1 & 7.2 & .023 & -2.62 to -.21 \\
\hline HEATER & 4.6 & 5.3 & 7.6 & .002 & -2.90 to -.69 \\
\hline SUMMER & 4.1 & 4.4 & 7.8 & $<.001$ & -3.32 to -1.17 \\
\hline \multicolumn{6}{|l|}{ (IS) SWEET } \\
\hline CANDY & 6.3 & 4.1 & 8.8 & $<.001$ & -3.36 to -1.34 \\
\hline \multicolumn{6}{|l|}{ (IS) SHARP } \\
\hline$\because \quad$ KNIFE & 5.9 & 5.0 & 9.5 & $<.001$ & -3.64 to -1.83 \\
\hline$\because \quad$ SWORD & 6.4 & 5.7 & 9.4 & $<.001$ & -3.07 to -1.36 \\
\hline RAZOR & 7.1 & 5.3 & 9.2 & $<.001$ & -2.86 to -1.14 \\
\hline SCISSORS & 5.8 & 5.0 & 7.3 & .016 & -2.29 to -.25 \\
\hline$\because \quad$ BLADES & 6.6 & 6.0 & 9.0 & $<.001$ & -2.65 to -.92 \\
\hline \multicolumn{6}{|l|}{ HOPS } \\
\hline KANGAROO & 7.5 & 8.0 & 9.3 & .006 & -1.79 to- .31 \\
\hline
\end{tabular}


(IS) SLIMY

- MUCUS

- LEECH

- JELLYFISH

- LOTION

- OIL

\begin{tabular}{ll}
\hline 8.9 & 8. \\
\hline 7.9 & 7.7 \\
\hline 8.1 & 8.1 \\
\hline 7.4 & 6.3 \\
\hline 7.8 & 7.8 \\
\hline
\end{tabular}

\begin{tabular}{ll}
\hline 8.1 & 7.5 \\
\hline 7.7 & 6.3 \\
\hline 8.1 & 6.5 \\
\hline 6.3 & 4.5 \\
\hline 7.8 & 5.2 \\
\hline
\end{tabular}

$\begin{array}{ll}7.5 & .072 \\ 6.3 & .028\end{array}$

.028

$-6.84 \mathrm{E}-02$ to 1.54

$\begin{array}{ll}6.3 & .028 \\ 6.5 & .036\end{array}$

.12 to 2.01

$4.5 \quad .003$

$7.52 \mathrm{E}-02$ to 2.16

$.003 \quad .58$ to 2.62

$5.2 \quad .00$

.75 to 2.74

HAS LEAVES

- LETTUCE

9.2

8.0

6.4

.008

.375 to 2.32

(IS) YELLOW

\begin{tabular}{lll}
$*$ SUN & 6.4 \\
$\vdots$ LEMON & 7.3 \\
CORN & 4.8 \\
$\vdots$ SCHOOL BUS & 6.3 \\
\hline & TAXI & 5.0
\end{tabular}

$6.4 \quad 5.3$

7.3

4.8

6.3

5.0

\begin{tabular}{ll}
\hline 5.3 & 8.2 \\
\hline 6.3 & 9.4 \\
\hline 4.9 & 7.0 \\
\hline 5.1 & 8.6 \\
\hline 4.0 & 7.7 \\
\hline
\end{tabular}

.007
.001
.012
.001
.001

-2.63 to -.44

-2.56 to -.74

-2.60 to -.34

-2.93 to -.80

$\begin{array}{ll}8.6 & .001 \\ 7.7 & .00\end{array}$

-3.24 to -.96

\section{(IS) GREEN}

* GRASS

4.2

3.9

$9.1<.001$

-4.40 to 2.53

\section{(IS) LOUD}

- AVALANCHE

6.5

7.8

5.1

.011

.332 to 2.45

IS GRAINY

- SANDPAPER

9.2

8.7

8.1

.137

-.19 to 1.3

\section{FLIES}

* BIRD

6.

5.6

9.6

$<.001$

-3.27 to -1.31

\section{IS COLD}

\begin{tabular}{clccccc}
\hline & SNOW & 8.2 & 8.2 & 9.1 & .107 & -1.26 to .127 \\
\hline FREEZER & 7.5 & 7.7 & 9.0 & .02 & -1.74 to -.16 \\
\hline \multirow{*}{*}{ ANTARCTIC } & 8.5 & 8.7 & 9.2 & .215 & -1.04 to .239 \\
\hline WINTER & 4.6 & 5.4 & 9.2 & $<.001$ & -3.77 to -1.87 \\
\hline REFRIGERATOR & 5.4 & 5.8 & 7.3 & .027 & -2.17 to -.135 \\
\hline
\end{tabular}




\section{CHAPTER 3 \\ USING FREQUENCY JUDGMENTS TO TEST SENSITIVITY TO SALIENT AND \\ CONCEPTUALLY CENTRAL PROPERTIES}

\section{Experiment 3}

The purpose of Experiment 3 was to explore (1) whether conceptually central or salient properties are activated sufficiently when activating a concept for participants to demonstrate sensitivity to property frequency, and (2) whether sensitivity to frequency depends on the manner in which the presented items are processed. Barsalou's theory of context-independent properties (1982) states that some properties are activated in any context. According to his theory, it should be possible to get people to demonstrate sensitivity to the frequency of a context-independent property in a list of learned items in any context. Therefore, participants given lists of items that a) are highly related to salient or central properties b) instantiate the same sense of a property, and c) are related to only one of the properties being probed in the test phase, should show sensitivity to property frequency regardless of context. As pointed out previously, there currently exists no evidence as to whether or not participants can be made to demonstrate sensitivity to property frequency (Barsalou \& Ross, 1986; Saunders et al., 1987). If sensitivity to the frequency of properties were found only in biasing contexts, this would provide evidence against a strong version of Barsalou's theory. In addition, if sensitivity were found for either salient or conceptually central properties in the "neutral" context, this would help to further define the nature of properties that are referred to as context-independent properties. 
To ensure that this experiment cxamined automatic activation of properties in different contexts rather than strategic activation, incidental orienting tasks were used so that participants would not intentionally process property frequency (Grcene, 1984; Naveh-Benjamin \& Jonides, 1986; Williams \& Durso, 1986). For cxamplc, in condition 1, a neutral, non-biasing context, participants were asked to lcarn a list of items for free recall. They were not told about the frequency estimation task.

Participants in conditions 2 and 3 were also told that they would receive a free recall test, but, in addition, were asked to study the items in specific ways. The purpose of these instructions was to test whether or not it was necessary to orient participants towards specific aspects of the items to enable them to access pre-existing memory structures for properties and whether different types of orienting tasks activate different types of properties.

Many levels-of-processing and imagery studies have shown that certain kinds of tasks may orient participants towards salient properties of items, and thus lead to better recollection (e.g. Anderson \& Reder, 1979; Belleza, 1996; Bower \& Winzenz, 1970; Craik \& Lockhart, 1972; Craik \& Tulving, 1975; McDaniel \& Pressley, 1987; Pavio, 1995). It was hypothesized that if property activation is sensitive to context (Barsalou, 1982) then participants in the high salience condition who were given a visual imagery task in condition 2 which orients them towards perceptual properties would be more likely to demonstrate sensitivity to salient properties. Participants in the high centrality group should not be similarly affected by this orienting task.

Because conceptually central properties are highly related to the internal structure of a concept, to orient participants towards conceptually central properties, 
participants were asked to think about the internal structure of each item in condition 3. It was hypothesized that these participants would be more likely to demonstrate a greater sensitivity to conceptually central properties than participants in the low centrality group would.

Lastly, if participants are sensitive to either salient or conceptually central properties regardless of context, there should be no difference in sensitivity between conditions.

\section{Method}

\section{$\underline{\text { Stimuli }}$}

Two lists of items were constructed using 21 property categories each for high centrality and high salience. Property categories and item lists were chosen using the results of Experiments 1 and 2 (See Table 3 and Appendices A-G). The same stimuli were used for each biasing condition. Lists of items were constructed, such that for each property for a level of a given factor there were 0,1 , or 5 items. Seven property categories contained 0 items, seven contained 1 item, and seven contained 5 items for a total of 42 items (See Table 4 and Table 5). The items in the high centrality list had an average rating of $8.15(S D=.60)$ for centrality and $6.29(S D=.92)$ for salience, and these ratings differed significantly, $t(42)=19.563, p<.001$. The average diagnosticity rating for these items was $43.60(S D=8.83)$. The items chosen for the final high salience list had an average rating of $8.32(S D=1.01)$ for salience and $5.53(S D=1.64)$ for centrality, which also differed significantly, $t(42)=15.06, p<.001$. The average diagnosticity rating for these items was $47.87(S D=8.24)$. 
Table 4. Stimuli for High Salience/Low Centrality

\begin{tabular}{|c|c|c|}
\hline 0 Item Categories & 1 Item Categories & 5 Item Categories \\
\hline Is Salty & $\begin{array}{l}\text { Is Poisonous } \\
\text { Venom }\end{array}$ & $\begin{array}{l}\text { Is Hot } \\
\text { Oven } \\
\text { Stove } \\
\text { Heater } \\
\text { Fireplace } \\
\text { Summer }\end{array}$ \\
\hline Is Purple & $\begin{array}{l}\text { Is Orange } \\
\text { Pumpkin }\end{array}$ & $\begin{array}{l}\text { Is Sharp } \\
\text { Knife } \\
\text { Sword } \\
\text { Razor } \\
\text { Scissors } \\
\text { Blades }\end{array}$ \\
\hline Is Spotted & $\begin{array}{l}\text { Is Red } \\
\text { Fire engine }\end{array}$ & $\begin{array}{l}\text { Is Yellow } \\
\text { Sun } \\
\text { Lemon } \\
\text { Corn } \\
\text { Taxi } \\
\text { School bus }\end{array}$ \\
\hline Swims & $\begin{array}{l}\text { Is Sweet } \\
\text { Candy }\end{array}$ & $\begin{array}{l}\text { Is Leather } \\
\text { Belt } \\
\text { Boot } \\
\text { Pocketbook } \\
\text { Couch } \\
\text { Wallet }\end{array}$ \\
\hline Is Spicy & $\begin{array}{l}\text { Is Green } \\
\text { Grass }\end{array}$ & $\begin{array}{l}\text { Is Clear } \\
\text { Glass } \\
\text { Plastic } \\
\text { Cellophane } \\
\text { Window } \\
\text { Saran wrap }\end{array}$ \\
\hline Is Funny & $\begin{array}{l}\text { Flies } \\
\text { Bird }\end{array}$ & $\begin{array}{l}\text { Is Cold } \\
\text { Snow } \\
\text { Freezer } \\
\text { Winter } \\
\text { Refrigerator } \\
\text { Antarctica } \\
\end{array}$ \\
\hline Is Liquid & $\begin{array}{l}\text { Hops } \\
\text { Kangaroo }\end{array}$ & $\begin{array}{l}\text { Smells bad } \\
\text { Garbage } \\
\text { Manure } \\
\text { Skunks } \\
\text { Feet } \\
\text { Gym Socks }\end{array}$ \\
\hline
\end{tabular}


Table 5. Stimuli for High Centrality/Low Salience

\begin{tabular}{|c|c|c|}
\hline 0 Item Categories & $1 \mathrm{Itcm}$ Catcgories & 5 Item Categories \\
\hline Is Leather & $\begin{array}{l}\text { Is Grainy } \\
\text { Sandpaper }\end{array}$ & $\begin{array}{l}\text { Has Wheels } \\
\text { Bus } \\
\text { Van } \\
\text { Roller Coaster } \\
\text { Go Cart } \\
\text { Train }\end{array}$ \\
\hline Is Sharp & $\begin{array}{l}\text { Is Glass } \\
\text { Light bulb }\end{array}$ & $\begin{array}{l}\text { Has a Tail } \\
\text { Whale } \\
\text { Elephant } \\
\text { Cow } \\
\text { Kangaroo } \\
\text { Bird }\end{array}$ \\
\hline Is Orange & $\begin{array}{l}\text { Has Leaves } \\
\text { Lettuce }\end{array}$ & $\begin{array}{l}\text { Grows on Trces } \\
\text { Bananas } \\
\text { Pears } \\
\text { Peaches } \\
\text { Limes } \\
\text { Lemons }\end{array}$ \\
\hline Is Purple & $\begin{array}{l}\text { Has a Handle } \\
\text { Umbrella }\end{array}$ & $\begin{array}{l}\text { Is Slimy } \\
\text { Leeches } \\
\text { Oil } \\
\text { Mucus } \\
\text { Lotion } \\
\text { Jellyfish }\end{array}$ \\
\hline Is Salty & $\begin{array}{l}\text { Stores Things } \\
\text { Bank }\end{array}$ & $\begin{array}{l}\text { Is a Liquid } \\
\text { Soda } \\
\text { Beer } \\
\text { Wine } \\
\text { Soup } \\
\text { Alcohol }\end{array}$ \\
\hline Is Funny & $\begin{array}{l}\text { Is Loud } \\
\text { Avalanche }\end{array}$ & $\begin{array}{l}\text { Is Sticky } \\
\text { Tar } \\
\text { Honey } \\
\text { Syrup } \\
\text { Molasses } \\
\text { Jelly }\end{array}$ \\
\hline Is Reflective & $\begin{array}{l}\text { Is Rubber } \\
\text { Garden hose }\end{array}$ & $\begin{array}{l}\text { Smells Bad } \\
\text { Bleach } \\
\text { Garlic } \\
\text { Halitosis } \\
\text { Sulfur } \\
\text { Onion }\end{array}$ \\
\hline
\end{tabular}




\section{$\underline{\text { Participants }}$}

In Experiment 3, the participants were 142 University of Massachusetts

undergraduates. All participants were able to complete the experiment in less than 30 minutes and they received course credit for their participation.

\section{Learning Phase}

The design of the experiment was a 2 (list types) $\times 3$ (instruction conditions) design. Each subject participated in only one of the six conditions and participants were randomly assigned to either the high centrality or the high salience lists for instruction condition 1 (Neutral), 2 ( Imagery), or 3 (Structure). In condition 1, participants were told that their task was to learn a list of 42 items for a free recall task. They were not told how the items related to the property categories (Brown, 1997). Each item was presented on the computer at a 4-second presentation rate. The following instructions were given:

In condition 1, participants were given the following neutral instructions:

You are going be presented with a list of items. Each item will appear individually on your computer screen and you will have 4 seconds to study the item. Your job is to study each item, so that you can recall it later. You will be tested on your memory for the list after you are done studying the items.

In condition 2, participants were given the following imagery instructions:

You are going be presented with a list of items. Each item will appear individually on your computer screen and you will have 4 seconds to study the item. Your job is to study each item, so that you can recall it later. You will be tested on your memory for the list after you are done studying the items. To help you recall these items, for each item on this list you should try to create an image. Remember that images can not only be visual, but they can also include other senses. For example, imagine walking along a beach. You can, in your image, have a picture of the beach, the feel of the sand between your toes, the smell of the ocean and the sound of the ocean. 
In condition 3, participants were given the following instructions:

You are going be presented with a list of items. Each item will appcar individually on your computer screen and you will have 4 seconds to study the item. Your job is to study each item, so that you can recall it later. You will be tested on your memory for the list after you are done studying the items. To help you recall these itcms, for each item on this list you should try to think about the internal structure of each item For example you might think about what is it about the internal structure of a refrigerator that makes it a refrigerator. Remember that the internal structure of an itcm can bc mechanical, biological, or related to an item's physical structurc. For example, a chair is a chair because of its physical form that allows sitting, a car is a car becausc of its engine, wheels, etc. which allows driving, and a bird is a bird becausc of its biology that gives it wings etc.

Because additional time was available to run participants, two non-randomized conditions were added to the experiment. These conditions were addcd to increase the chances of finding significant frequency effects. In the non-random conditions, participants were presented with the same lists of high centrality and high salience items used in conditions 1-6, but presentation order was not randomized. Instead, participants were first presented with all of the frequency 5 items and then all of the frequency 1 items. Participants were given no indication as to where the category groups started or ended, and were not told in advance that items in the list belonged to any type of property category. They were given the identical instructions that were given to participants in the neutral instruction condition (instruction condition 1).

\section{Frequency Estimation Phase}

After the learning trials, all participants were told that they were going to be given a frequency test. Participants were told that the words on the studied list belonged to different property categories and they were given an example of how an item may belong to a property category. They were told to imagine that different kind of pink items were on the list (i.e. flamingoes, bubble gum, and pigs). Participants 
were advised that different numbers of itcms had becn presented for cach property category and their job was to judge how many items were in each group. They were also informed that there may have been many pink things or therc may have been no pink things at all (Brown, 1995; Brown, 1997). Finally, they were given instructions to make their estimate as quickly and as accurately as possible (Barsalou \& Ross, 1986).

For the frequency estimation phase, a keyboard press initiated a trial. A property category then appeared at the center of the computer screen, and participants were asked to type in an exact frequency estimate on the computer as fast and as accurately as possible and then press the enter key after they were finished typing their estimate. After typing in an estimate and pressing the enter key, participants then pressed the spacebar when they were ready to begin the next trial. The frequency estimation phase was the same for all six conditions.

\section{Hypotheses}

It was hypothesized that if the stimuli were examples of context-independent properties, then these properties should lead to accurate estimates of frequency in the frequency test phase for all conditions, even in condition 1, because contextindependent properties should be activated even in this "neutral" context (Barsalou, 1982). It was unclear, a priori, if evidence for sensitivity to context-independent properties was obtained in this "neutral" condition, whether estimates would be more accurate for high centrality or high salience items.

A second hypothesis was that if property activation is highly context-dependent, there may be insufficient activation in condition 1 to detect sensitivity to property frequency, but if property activation is moderately context-dependent there may simply 
be less sensitivity to frequency in condition 1 than in condition 2. A third hypothesis was that if property activation is context-dependent, then for condition 2 the imagery participants in the high salience group might show a greater sensitivity to frequency than participants in the high centrality group. Likewise, for condition 3, participants in the high centrality group might demonstrate a greater sensitivity to frequency than participants in the high salience group.

As a post hoc test of the strategy used by participants to estimate frequencics, the reaction times for different frequencies were compared within each condition for each list type. Brown $(1995,1997)$ stated that if participants use non-enumeration strategies, estimates of frequency should rise with actual frequency, but there should not be a corresponding increase in response times for higher frequencies.

\section{Recall Test}

Following the frequency test, participants in all conditions were given a structured recall test. The purpose of this task was to ensure that subjects did study the list of items and could demonstrate that they had some explicit memory for those items, regardless of their performance on the frequency estimation task. This should divert any criticism that a failure to demonstrate sensitivity to property frequency is simply the result of participants having not learning the list of items during the study phase.

Participants were given a booklet with the property category headings and were asked to recall as many items as they could for each property category. On the last page of the booklet, all participants were asked about any strategies that they might have used during the learning phase independent of any instructions. This was to examine whether participants used imagery or structural cues to aid them in recall. 


\section{Results}

\section{Frequency Estimation}

First, frequency estimates were related to actual frequency (see Tables 6-8 and Figures 1-5). In descriptive terms, looking at the graphs of estimated frequency plotted against actual frequency, it is clear that frequency estimates rose with actual frequency regardless of instructions or list type (see Figures 1-5). It is also clear that in most cases subjects overestimated the low frequency items (frequency 0 and 1) and underestimated the high frequency items (frequency 5). In a repeated measures ANOVA on the randomized condition, there was a significant linear trend for frequency $(F(1,111)=$ $172.70, p<.001)$. There was also a significant linear interaction of frequency by list type $(F(1,11)=7.43, p=.007)$.

Table 6. Estimated Frequency by Actual Frequency for High Salience/Low Centrality Items: Random Order

\begin{tabular}{cccccc}
\hline $\begin{array}{c}\text { Actual } \\
\text { Frequency }\end{array}$ & Statistic & $\begin{array}{c}\text { Neutral } \\
\text { Instructions } \\
n=19\end{array}$ & $\begin{array}{c}\text { Imagery } \\
\text { Instructions } \\
n=20\end{array}$ & $\begin{array}{c}\text { Structural } \\
\text { Instructions } \\
n=18\end{array}$ & $\begin{array}{c}\text { Total } \\
N=57\end{array}$ \\
\hline \multirow{3}{*}{0} & Mean & .74 & 1.19 & 2.01 & 1.30 \\
\cline { 2 - 6 } & $S E$ & .44 & .43 & .45 & .25 \\
\cline { 2 - 6 } & $\boldsymbol{C I}$ & $-.14-1.62$ & $.33-2.04$ & $1.10-2.91$ & $.80-1.82$ \\
\hline \multirow{3}{*}{1} & Mean & 1.62 & 2.10 & 2.62 & 2.10 \\
\cline { 2 - 6 } & $\boldsymbol{S E}$ & .55 & .53 & .56 & .32 \\
\cline { 2 - 6 } & $\boldsymbol{C I}$ & $.52-2.71$ & $1.04-3.17$ & $1.50-3.74$ & $1.48-2.74$ \\
\hline \multirow{2}{*}{5} & Mean & 2.46 & 2.77 & 3.00 & 2.74 \\
\cline { 2 - 6 } & $\boldsymbol{S E}$ & .32 & .31 & .33 & .18 \\
\cline { 2 - 6 } & $\boldsymbol{C I}$ & $1.82-3.10$ & $2.15-3.39$ & $2.34-3.66$ & $2.37-3.11$ \\
\hline
\end{tabular}


Table 7. Estimated Frequency by Actual Frequency for High Centrality/Low Salience Items: Random Order

\begin{tabular}{cccccc}
\hline $\begin{array}{c}\text { Actual } \\
\text { Frequency }\end{array}$ & Statistic & $\begin{array}{c}\text { Neutral } \\
\text { Instructions } \\
n=20\end{array}$ & $\begin{array}{c}\text { Imagery } \\
\text { Instructions } \\
n=21\end{array}$ & $\begin{array}{c}\text { Structural } \\
\text { Instructions } \\
n=19\end{array}$ & $\begin{array}{c}\text { Total } \\
N=60\end{array}$ \\
\hline \multirow{2}{*}{0} & Mean & 1.33 & 1.07 & 1.48 & 1.29 \\
\cline { 2 - 6 } & $\boldsymbol{S E}$ & .36 & .35 & .37 & .21 \\
\cline { 2 - 6 } & $\boldsymbol{C I}$ & $.62-2.04$ & $.38-1.76$ & $.75-2.21$ & $.88-1.70$ \\
\hline \multirow{3}{*}{1} & Mean & 2.18 & 1.76 & 2.43 & 2.11 \\
\cline { 2 - 6 } & $\boldsymbol{S E}$ & .45 & .44 & .46 & .26 \\
\cline { 2 - 6 } & $\boldsymbol{C I}$ & $1.29-3.07$ & $.89-2.62$ & $1.52-3.34$ & $1.61-2.64$ \\
\hline \multirow{2}{*}{5} & Mean & 3.76 & 3.14 & 3.53 & 3.47 \\
\cline { 2 - 6 } & $\boldsymbol{S E}$ & .33 & .32 & .34 & .19 \\
\cline { 2 - 6 } & $\boldsymbol{C I}$ & $3.11-4.41$ & $2.50-3.77$ & $2.87-4.20$ & $3.10-3.85$ \\
\hline
\end{tabular}

Table 8. Estimated Frequency by Actual Frequency: Non-Random Order

\begin{tabular}{cccc} 
& & $\begin{array}{c}\text { High Centrality /Low } \\
\text { Salience }\end{array}$ & High Salience /Low Centrality \\
\hline \multirow{2}{*}{$\begin{array}{c}\text { Actual } \\
\text { Frequency }\end{array}$} & Statistic & $\begin{array}{c}\text { Neutral Instructions } \\
n=13\end{array}$ & $\begin{array}{c}\text { Neutral Instructions } \\
n=12\end{array}$ \\
\hline \multirow{3}{*}{0} & Mean & 1.43 & .60 \\
\cline { 2 - 4 } & $\boldsymbol{S E}$ & .28 & .30 \\
\cline { 2 - 4 } & $\boldsymbol{C I}$ & $.84-2.02$ & $-.017-1.21$ \\
\hline \multirow{3}{*}{$\mathbf{1}$} & Mean & 2.89 & 1.43 \\
\cline { 2 - 4 } & $\boldsymbol{S E}$ & .54 & .56 \\
\hline \multirow{3}{*}{5} & $\boldsymbol{C I}$ & $1.78-4.00$ & $.27-2.59$ \\
\cline { 2 - 4 } & Mean & 4.23 & 3.73 \\
\cline { 2 - 4 } & $\boldsymbol{S E}$ & .33 & .34 \\
\cline { 2 - 4 } & $\boldsymbol{C I}$ & $3.55-4.91$ & $3.02-4.44$ \\
\hline
\end{tabular}




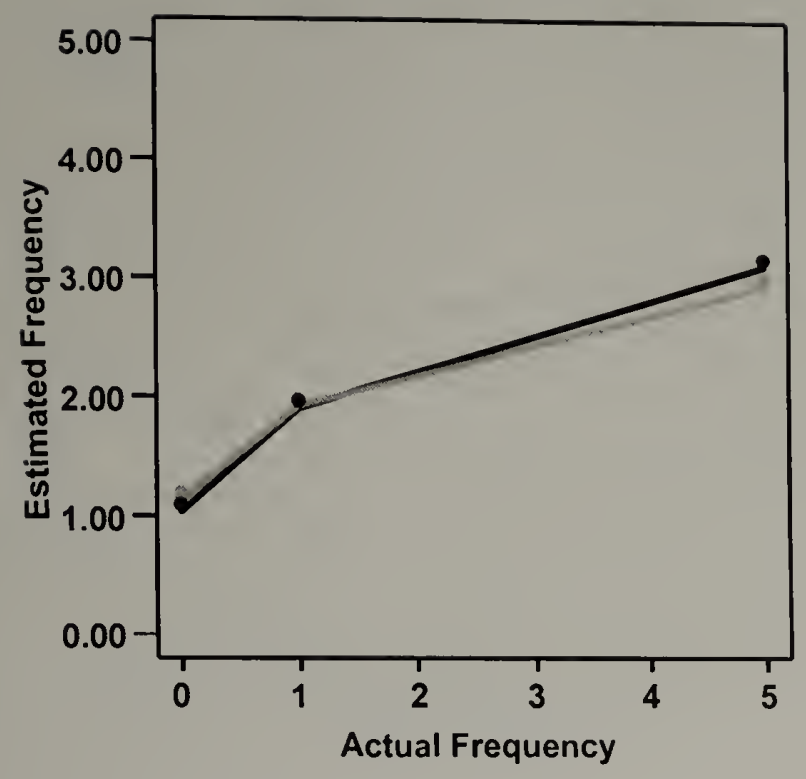

\section{Instruction Type}

- Neutral

Imagery

Structure/Function

Figure 1. Estimated Frequency by Actual Frequency for Each Instruction Type-Random Order

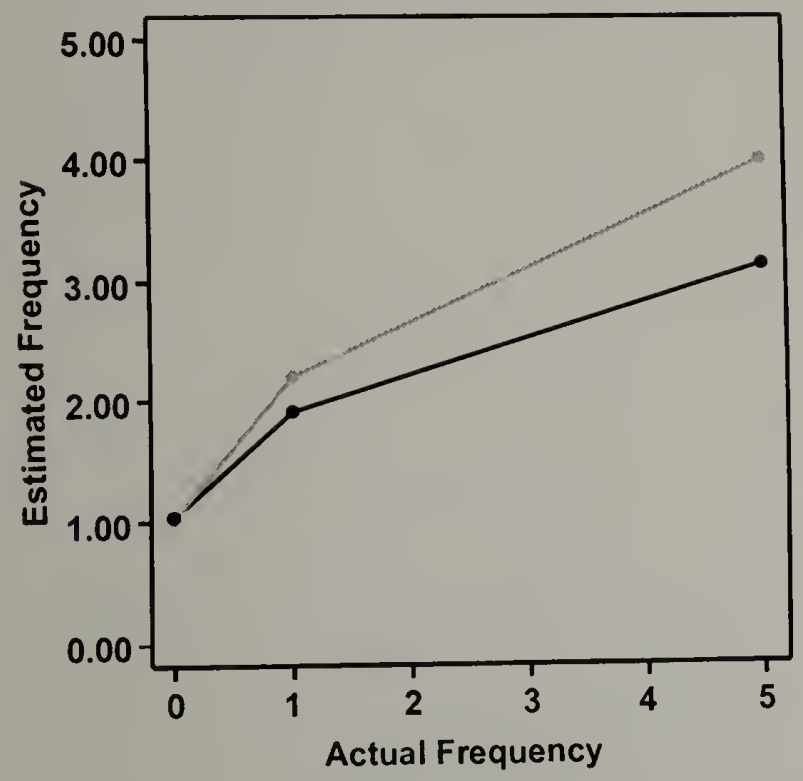

\section{List Order \\ Random \\ Non-Random}

Figure 2. Estimated Frequency by Actual Frequency for Each Order Type--Neutral Instructions Only 


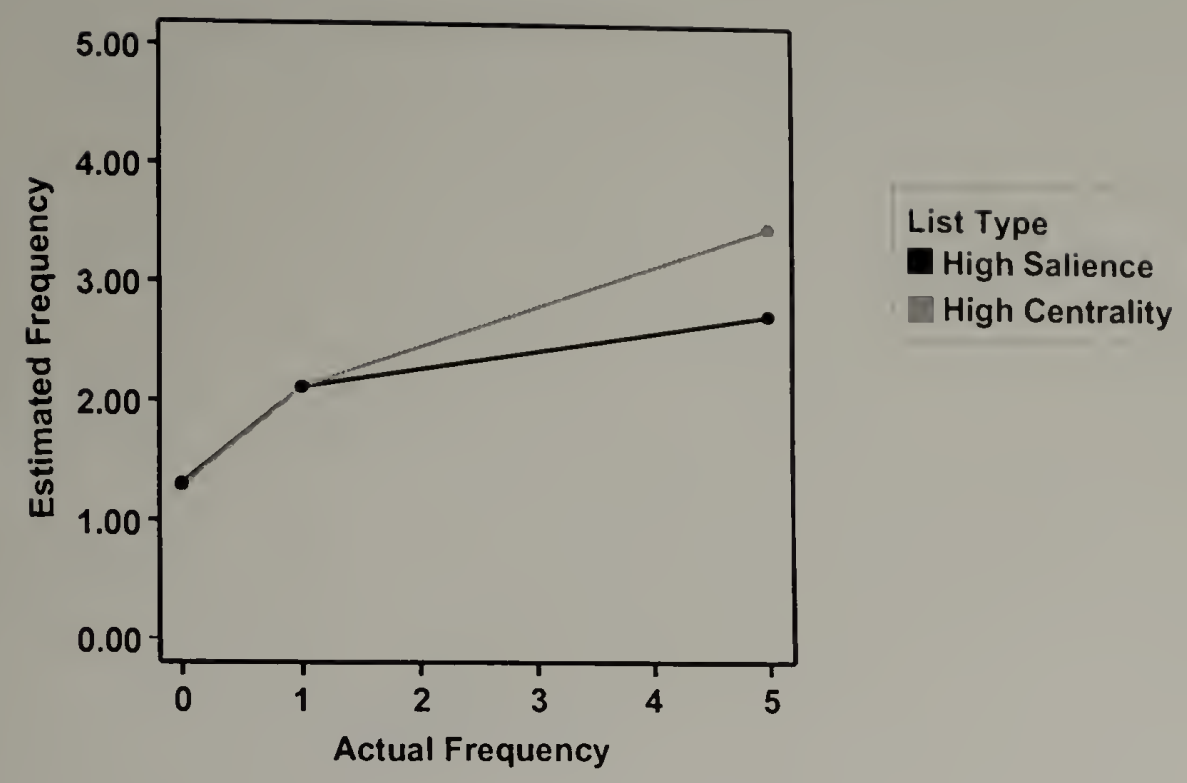

Figure 3. Estimated Frequency by Actual Frequency for Each List Type--Random Order

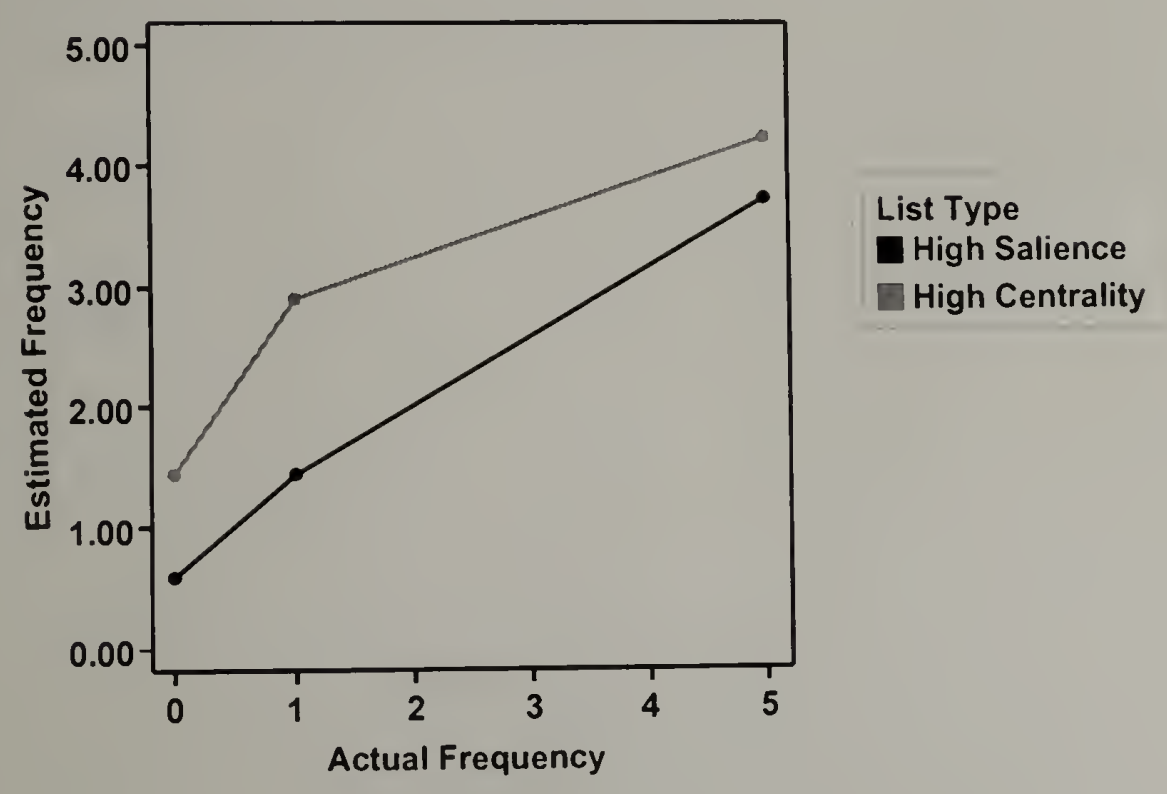

Figure 4. Estimated Frequency by Actual Frequency for Each List Type--Non-Random Order 

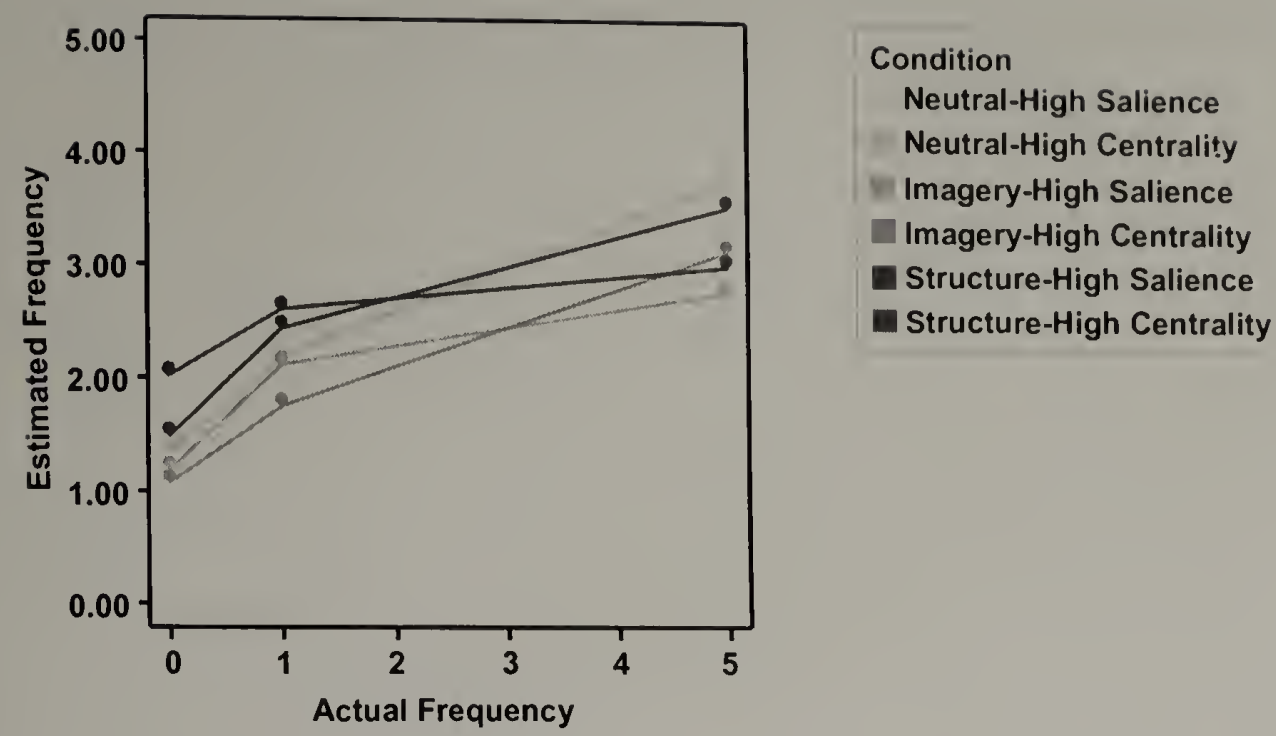

Figure 5. Estimated Frequency by Actual Frequency for Each Condition--Random Order

Next, for each participant, estimated frequency was regressed on actual frequency. From this regression, a slope was obtained for each participant. After computing the slope for each participant, the average slopes in each condition were computed and then were compared to zero to determine whether participants demonstrated any sensitivity to property frequency. Participants in five of the six conditions showed sensitivity to property frequency (see Table 9), with slopes being significantly different from 0 (all $p$ 's $<.001$ ). In the randomized condition, significant slopes ranged from a low of .27 in the imagery instruction/high centrality list $(t(20)=6.08, p<.001)$ to a high of .46 in the neutral instruction/high centrality list $(t(19)=6.59, p<.001)$. The high salience list paired with the function instructions was the only condition in which the slope was not significant $(t(17)=1.48, p=.151$, see Table 9$)$. 
Collapsing over instruction conditions, both list types (high salience \& high centrality) had slopes significantly different than 0 with the high salicnce list having a slope of $.25(t(56)=6.02, p<.001)$ and the high centrality list having a slope of .41 $(t(59)=12.72, p<.001$, see Table 10$)$.

Lastly, collapsing over list types, all three instruction conditions (neutral, imagery, \& function) had slopes significantly different from 0 (see Table 11). The neutral instruction condition had a slope of $.38(t(38)=9.03, p<.001)$, the imagery instruction condition had a slope of $.34(t(40)=10.83, p<.001)$, and the function instruction condition had a slope of $.27(t(36)=4.27, p<.001)$.

An ANOVA for slope by list type and instruction type found a main effect of list type, indicating that the average slopes of the high salience and high centrality groups (random order only) were significantly different $(.25$ vs. $.41, F(1,111)=9.09, p=.003)$. This indicated that the two list types differed in their slopes, with the slope of the high centrality group being greater than the slope of the high salience group. For the different instruction conditions, there was no evidence that their slopes differed significantly from one another $(F(2,111)=1.49, p=.23)$. There was also no instruction by list type interaction $F(2,111)=.21, \mathrm{p}=.81)$.

Table 9. Mean Slopes of Regressing Estimated Frequency on Actual Frequency by Conditions

\begin{tabular}{ccccccccc}
\hline $\begin{array}{c}\text { Instruction } \\
\text { Condition }\end{array}$ & $\begin{array}{c}\text { List } \\
\text { Type }\end{array}$ & $\begin{array}{c}\text { Presentation } \\
\text { Order }\end{array}$ & $\begin{array}{c}\text { Mean } \\
\text { Slope }\end{array}$ & $\begin{array}{c}\text { Confidence } \\
\text { Interval }\end{array}$ & $\boldsymbol{t}$ & df & $\boldsymbol{S E}$ & $\begin{array}{c}\text { Sig. } \\
\text { (2-tailed) }\end{array}$ \\
\hline Neutral & HS/LC & Random & .31 & $.22-.39$ & 7.24 & 18 & .04 & $<.001$ \\
\hline Neutral & HC/LS & Random & .46 & $.31-.61$ & 6.59 & 19 & .06 & $<.001$ \\
\hline Imagery & HS/LC & Random & .27 & $.18-.37$ & 6.08 & 19 & .04 & $<.001$ \\
\hline Imagery & HC/LS & Random & .39 & $.31-.48$ & 9.98 & 20 & .04 & $<.001$ \\
\hline Function & HS/LC & Random & .17 & $-.07-.41$ & 1.48 & 17 & .11 & .158 \\
\hline Function & HC/LS & Random & .37 & $.25-.49$ & 6.64 & 18 & .06 & $<.001$ \\
\hline Neutral & HS/LC & Non-Random & .61 & $.46-.76$ & 9.19 & 11 & .07 & $<.001$ \\
\hline Neutral & HC/LS & Non-Random & .50 & $.35-.64$ & 7.38 & 12 & .07 & $<.001$ \\
\hline
\end{tabular}


Table 10. Mean Slopes of Regressing Estimated Frequency by Actual Frequency for List Types (Random Presentation Order)

\begin{tabular}{ccccccc}
\hline $\begin{array}{c}\text { List } \\
\text { Type }\end{array}$ & $\begin{array}{c}\text { Mean } \\
\text { Slope }\end{array}$ & $\begin{array}{c}\text { Confidence } \\
\text { Interval }\end{array}$ & $t$ & $d f$ & $S E$ & $\begin{array}{c}\text { Sig. } \\
\text { (2-tailed) }\end{array}$ \\
\hline HS/LC & .25 & $.17-.33$ & 6.02 & 56 & .04 & $<.001$ \\
\hline HC/LS & .41 & $.34-.47$ & 12.72 & 59 & .04 & $<.001$ \\
\hline
\end{tabular}

Table 11. Mean Slopes of Regressing Estimated Frequency by Actual Frequency for Instruction Types (Random Presentation Order)

\begin{tabular}{ccccccc}
\hline $\begin{array}{c}\text { Instruction } \\
\text { Condition }\end{array}$ & $\begin{array}{c}\text { Mean } \\
\text { Slope }\end{array}$ & $\begin{array}{c}\text { Confidence } \\
\text { Interval }\end{array}$ & $\boldsymbol{t}$ & $\boldsymbol{d f}$ & $\boldsymbol{S E}$ & $\begin{array}{c}\text { Sig. } \\
\text { (2-tailed) }\end{array}$ \\
\hline Neutral & .38 & $.29-.47$ & 9.03 & 38 & .04 & $<.001$ \\
\hline Imagery & .34 & $.27-.39$ & 10.83 & 40 & .03 & $<.001$ \\
\hline Function & .27 & $.14-.40$ & 4.27 & 36 & .06 & $<.001$ \\
\hline
\end{tabular}

\section{$\underline{\text { Reaction Times }}$}

Reaction times were also examined (Brown, 1995,1997) to test whether participants used more automatic, non-enumeration strategies or less automatic, enumeration strategies when making their frequency estimates. As stated previously, if participants were using more automatic, non-enumeration strategies there should be an increase in frequency estimates corresponding to an increase in actual frequency, but there should be no such increase in reaction times (Brown, 1995,1997). Although it was clear that participants' frequency estimates did increase with actual frequency, there was no corresponding increase in response times (see Tables 12-14 and Figures 6- 
10). An average reaction time slope was computed for each subject and then an average slope was computed for each condition. These averaged slopes were then compared to zero. All but three were not significantly different from zero. In the randomized condition, the non-significant slopes ranged from a low of $-10.09 \mathrm{msec} / \mathrm{item}$ in the function instruction/high centrality condition $(t(18)=-.08, p=.94)$ to a high of -86.65 $\mathrm{msec} /$ item in the neutral instruction/high salience condition $(t(18)=-1.31, p=.21)$.

For the three slopes that were significantly different from zero (neutral instructions/high salience, function instructions/high salience, and neutral instructions collapsed over list type), the slopes were negative $(-165.37 \mathrm{msec} / \mathrm{item}, t(19)=-2.45, p=$ $.02 ;-105 \mathrm{msec} /$ item, $\mathrm{t}(17)=-2.21, \mathrm{p}=.04 ;$ and $-127.03 \mathrm{msec} / \mathrm{item}, \mathrm{t}(38)=-2.69, \mathrm{p}=.01$ ), indicating that reaction times were actually decreasing with increased frequency. These results appear to indicate that subjects were using a more automatic, non-enumeration strategy when estimating frequency.

Table 12. Reaction Time (msec) by Frequency for High Salience/Low Centrality Items: Random Order

\begin{tabular}{|c|c|c|c|c|c|}
\hline $\begin{array}{c}\text { Actual } \\
\text { Frequency }\end{array}$ & Statistic & $\begin{array}{c}\text { Neutral } \\
\text { Instructions } \\
n=19\end{array}$ & $\begin{array}{c}\text { Imagery } \\
\text { Instructions } \\
n=20\end{array}$ & $\begin{array}{c}\text { Structural } \\
\text { Instructions } \\
n=18\end{array}$ & $\begin{array}{l}\text { Total } \\
N=57\end{array}$ \\
\hline \multirow{3}{*}{0} & Mean & 5094.72 & 4993.68 & 4313.74 & 4812.64 \\
\hline & $S E$ & 416.62 & 746.92 & 434.15 & 324.29 \\
\hline & $C I$ & $\begin{array}{c}4219.44- \\
5970.01 \\
\end{array}$ & $\begin{array}{c}3430.36- \\
6556.99\end{array}$ & $\begin{array}{c}3397.77- \\
5229.71\end{array}$ & $\begin{array}{c}4163.01- \\
5462.27\end{array}$ \\
\hline \multirow{3}{*}{1} & Mean & 4795.66 & 4479.31 & 3265.06 & 4201.31 \\
\hline & $S E$ & 426.57 & 560.29 & 307.62 & 271.05 \\
\hline & $C I$ & $\begin{array}{c}3899.46- \\
5691.86 \\
\end{array}$ & $\begin{array}{c}3306.61- \\
5652.01 \\
\end{array}$ & $\begin{array}{c}2616.04- \\
3914.08 \\
\end{array}$ & $\begin{array}{r}3658.33- \\
4744.30 \\
\end{array}$ \\
\hline \multirow{3}{*}{5} & Mean & 4590.65 & 4994.29 & 3471.36 & 4378.81 \\
\hline & $S E$ & 421.30 & 554.08 & 316.35 & 269.15 \\
\hline & $C I$ & $\begin{array}{c}3705.52- \\
5475.77\end{array}$ & $\begin{array}{c}3834.57- \\
6153.00\end{array}$ & $\begin{array}{c}2803.92- \\
4138.79\end{array}$ & $\begin{array}{r}3839.63- \\
4917.00 \\
\end{array}$ \\
\hline
\end{tabular}


Table 13. Reaction Time (msec) by Frequency for High Centrality/Low Salience Items: Random Order

\begin{tabular}{|c|c|c|c|c|c|}
\hline $\begin{array}{c}\text { Actual } \\
\text { Frequency }\end{array}$ & Statistic & $\begin{array}{c}\text { Neutral } \\
\text { Instructions } \\
n=20 \\
\end{array}$ & $\begin{array}{c}\text { Imagery } \\
\text { Instructions } \\
n=21 \\
\end{array}$ & $\begin{array}{c}\text { Structural } \\
\text { Instructions } \\
n=19 \\
\end{array}$ & $\begin{array}{l}\text { Total } \\
N=60 \\
\end{array}$ \\
\hline \multirow{3}{*}{0} & Mean & 5708.07 & 6068.43 & 6437.44 & 6065.16 \\
\hline & $S E$ & 551.60 & 684.50 & 852.24 & 399.86 \\
\hline & $C I$ & $\begin{array}{c}4553.56- \\
6862.59 \\
\end{array}$ & $\begin{array}{l}4640.58- \\
7496.27 \\
\end{array}$ & $\begin{array}{c}4646.95- \\
8227.92\end{array}$ & $\begin{array}{c}5265.05- \\
6865.27 \\
\end{array}$ \\
\hline \multirow{3}{*}{1} & Mean & 6076.84 & 5620.48 & 6584.59 & 6077.90 \\
\hline & $S E$ & 766.55 & 573.91 & 894.38 & 426.68 \\
\hline & $C I$ & $\begin{array}{c}4472.43- \\
7681.25 \\
\end{array}$ & $\begin{array}{l}4423.33- \\
6817.64 \\
\end{array}$ & $\begin{array}{l}4705.57- \\
8463.60 \\
\end{array}$ & $\begin{array}{r}5224.13- \\
6931.68 \\
\end{array}$ \\
\hline \multirow{3}{*}{5} & Mean & 5059.28 & 5559.59 & 6439.39 & 5671.42 \\
\hline & $S E$ & 482.71 & 676.20 & 1101.29 & 449.21 \\
\hline & $C I$ & $\begin{array}{c}4048.95- \\
6069.61\end{array}$ & $\begin{array}{c}4149.06- \\
6970.13 \\
\end{array}$ & $\begin{array}{r}4125.68- \\
8753.11 \\
\end{array}$ & $\begin{array}{c}4772.55- \\
6570.29 \\
\end{array}$ \\
\hline
\end{tabular}

Table 14. Reaction Time (msec) by Frequency for Non-Random Order

\begin{tabular}{|c|c|c|c|}
\hline & & \multirow[b]{2}{*}{$\begin{array}{c}\text { High Centrality /Low } \\
\text { Salience }\end{array}$} & \multirow[b]{2}{*}{$\begin{array}{l}\text { High Salience /Low } \\
\text { Centrality }\end{array}$} \\
\hline & & & \\
\hline $\begin{array}{c}\text { Actual } \\
\text { Frequency }\end{array}$ & Statistic & $\begin{array}{l}\text { Neutral Instructions } \\
n=13\end{array}$ & $\begin{array}{c}\text { Neutral Instructions } \\
n=12\end{array}$ \\
\hline \multirow{3}{*}{$\mathbf{0}$} & Mean & 4870.65 & 6061.40 \\
\hline & $S E$ & 510.48 & 668.29 \\
\hline & $C I$ & $3758.41-5982.88$ & $4590.52-7532.29$ \\
\hline \multirow{3}{*}{1} & Mean & 5333.11 & 6212.51 \\
\hline & $S E$ & 779.91 & 731.88 \\
\hline & $C I$ & $3633.83-7032.39$ & $4601.64-7823.39$ \\
\hline \multirow{3}{*}{5} & Mean & 5889.60 & 6138.71 \\
\hline & $S E$ & 964.65 & 1309.66 \\
\hline & $C I$ & $3787.80-7991.41$ & $3256.16-9021.26$ \\
\hline
\end{tabular}




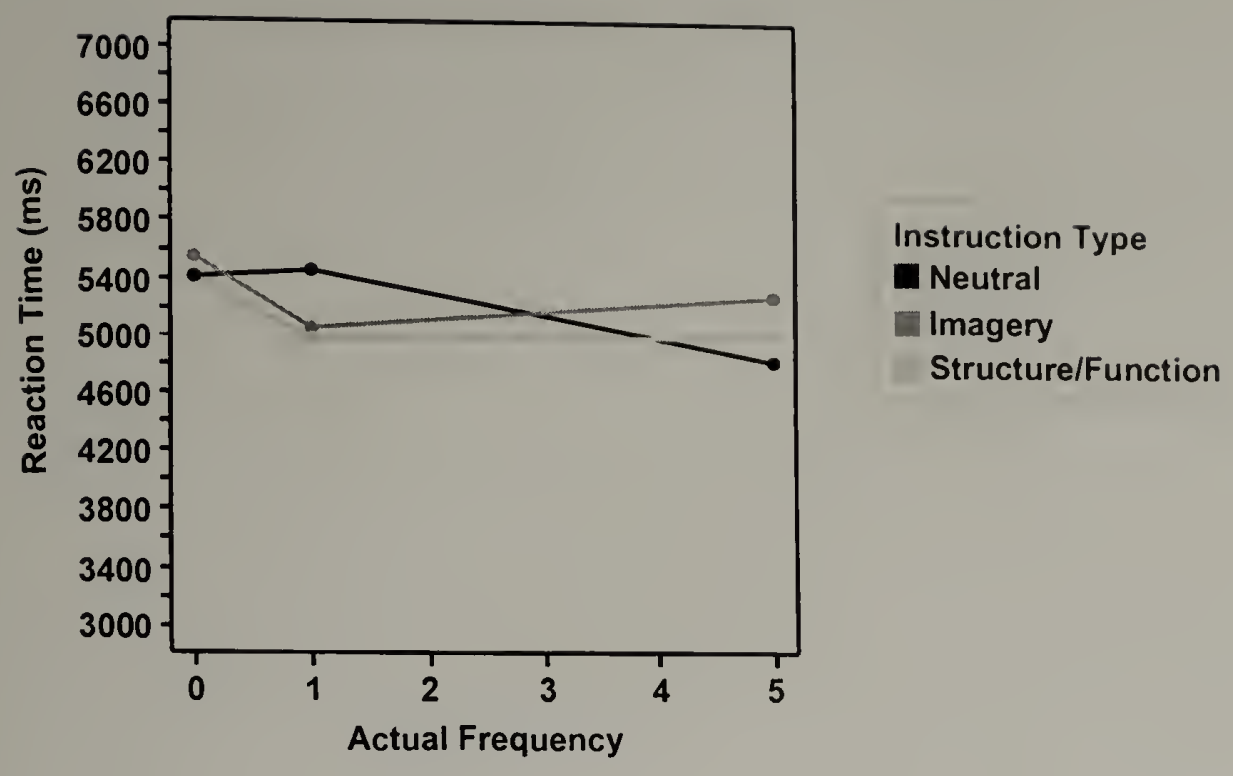

Figure 6. Reaction Time for Each Frequency by Instruction Type--Random Order

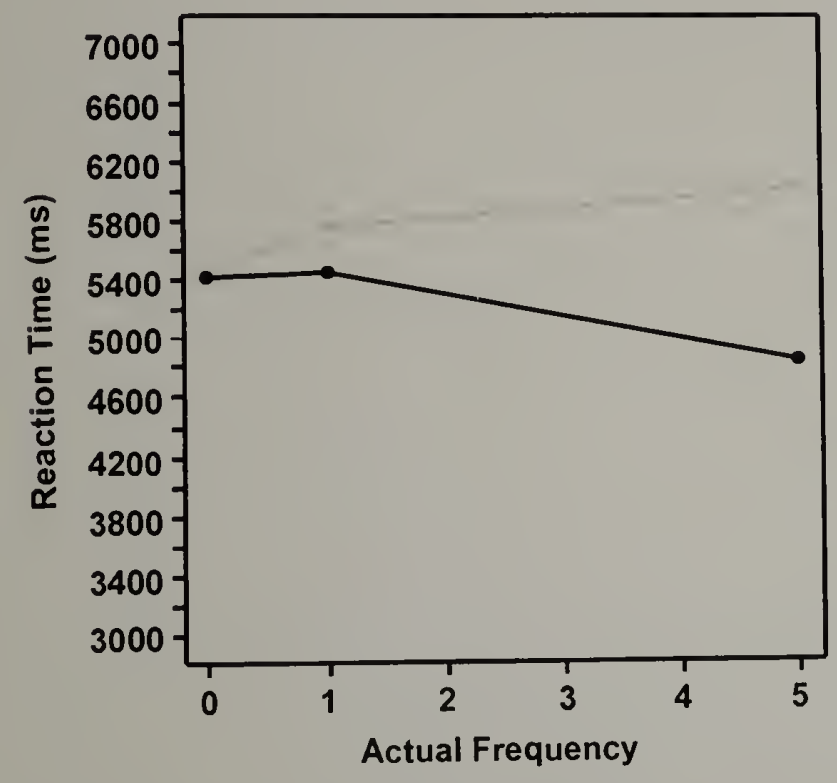

List Order

Random

Non-Random

Figure 7. Reaction Time for Each Frequency by List Order--Neutral Instructions Only 


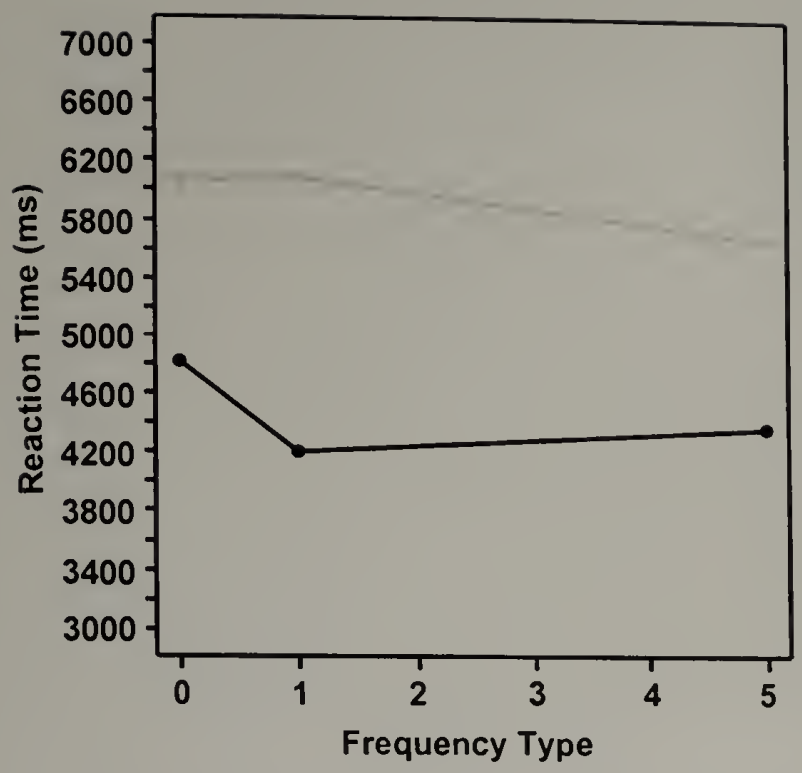

List Type

High Salience

High Centrality

Figure 8. Reaction Time for Each Frequency by List Type--Random Order

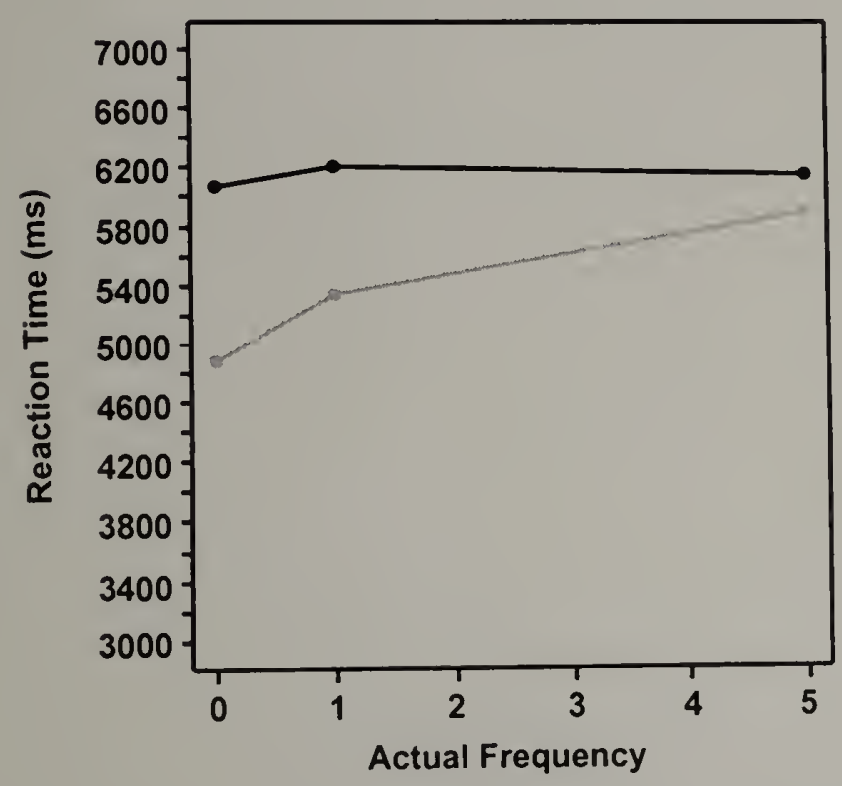

List Type

High Salience

High Centrality

Figure 9. Reaction Time for Each Frequency by List Type--Non-Random Order 


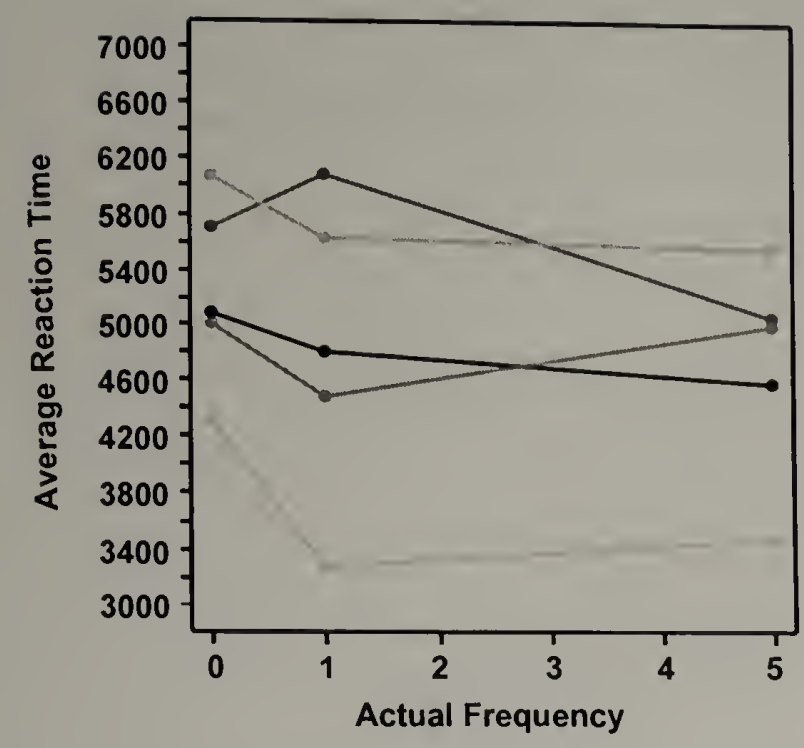

Condition

Neutral-High Salience

Neutral-High Centrality

Imagery-High Salience

Imagery-High Centrality

Structure-High Salience

Structure-High Centrality

Figure 10. Reaction Time for Each Frequency by Condition--Random Order

Table 15. Mean Slope of Regressing Reaction Time on Frequency

\begin{tabular}{ccccccccc}
\hline $\begin{array}{c}\text { Instruction } \\
\text { Condition }\end{array}$ & $\begin{array}{c}\text { List } \\
\text { Type }\end{array}$ & Randomization & $\begin{array}{c}\text { Mean } \\
\text { Slope }\end{array}$ & CI & $t$ & $d f$ & $S E$ & Sig. \\
\hline Neutral & HS/LC & Random & -86.65 & $\begin{array}{c}-226.00- \\
52.69\end{array}$ & -1.31 & 18 & 66.32 & .21 \\
\hline Neutral & HC/LS & Random & -165.37 & $\begin{array}{c}-306.54- \\
-24.20\end{array}$ & -2.45 & 19 & 67.45 & .02 \\
\hline Imagery & HS/LC & Random & 36.87 & $\begin{array}{c}-145.91- \\
219.65\end{array}$ & .42 & 19 & 87.33 & .68 \\
\hline Imagery & HC/LS & Random & -77.04 & $-236.87-$ & -1.01 & 20 & 76.62 & .33 \\
& & & & 82.78 & & & & \\
\hline Function & HS/LC & Random & -105.60 & $-206.32-$ & -2.21 & 17 & 47.74 & .04 \\
& & & & -4.89 & & & & \\
\hline Function & HC/LS & Random & -10.09 & $-270.10-$ & -.08 & 18 & 123.76 & .94 \\
& & & & 249.92 & & & & \\
\hline Neutral & HS/LC & Non-Random & 5.77 & $-350.94-$ & .04 & 11 & 162.07 & .97 \\
& & & & 362.49 & & & & \\
\hline Neutral & HC/LS & Non-Random & 185.31 & $-161.51-$ & 1.16 & 12 & 159.18 & .27 \\
& & & & 532.14 & & & & \\
\hline
\end{tabular}


Table 16. Mean Slope of Regressing Reaction Time on Frequency List Types (Random Order)

\begin{tabular}{ccccccc}
\hline $\begin{array}{c}\text { List } \\
\text { Type }\end{array}$ & $\begin{array}{c}\text { Mean } \\
\text { Slope }\end{array}$ & $\begin{array}{c}\text { Confidence } \\
\text { Interval }\end{array}$ & $\boldsymbol{t}$ & $d f$ & $S E$ & Sig. \\
\hline HS/LC & -49.30 & $-131.17-32.57$ & -1.21 & 56 & 40.87 & .23 \\
\hline HC/LS & -85.28 & $-189.86-19.30$ & -1.63 & 59 & 52.26 & .11 \\
\hline
\end{tabular}

Table 17. Mean Slope of Regressing Reaction Time on Frequency for Instruction Types (Random Order)

\begin{tabular}{ccccccc}
\hline $\begin{array}{c}\text { Instruction } \\
\text { Condition }\end{array}$ & $\begin{array}{c}\text { Mean } \\
\text { Slope }\end{array}$ & $\begin{array}{c}\text { Confidence } \\
\text { Interval }\end{array}$ & $t$ & $d f$ & $S E$ & Sig. \\
\hline Neutral & -127.02 & $-222.45--31.59$ & -2.69 & 38 & 47.14 & .01 \\
\hline Imagery & -21.47 & $-138.48-95.53$ & -.37 & 40 & 57.89 & .71 \\
\hline Function & -56.56 & $-192.90-79.78$ & -.84 & 36 & 67.22 & .41 \\
\hline
\end{tabular}

\section{$\underline{\text { Recall Strategies }}$}

The data from the recall test given after the frequency estimation task indicate that participants, when given the relevant property categories, were able to remember specific exemplars presented during the learning phase, both for the high salience items and for the high centrality items. However, it was not clear from the comments made by participants, that all participants were following instructions on how to learn the items.

For instance, one participant who was learning the list with the conceptually central properties using the structure instructions said the following:

(1) For many of the things I imagined what they would do to my body. Ex.-Leech would be painful and take out blood. For lotion, I looked down at my dry hands. I imagined what sandpaper would feel like on my skin. I imagined what the noise of the train was. I used imagery for basically everything that I did remember. 
Other participants made comments such as:

(2) I tried to picture things and connect them like 'elephant' with a 'garlic' 'beer'...It had limitations, so I stopped after maybe $10 \ldots$ but $k$ ept using the visual imagery to help me remember the words.

(3) I just tried to remember images. It seems I remembered things I likcd \& disliked the most or ones I could get a vivid image of.

(4) I tried to put things together in categories. Also tried to remember things that stuck out. I also tried to make up stories and have images of the words be a part of them.

which seems to indicate that a large proportion of participants chose to use imagery, even when instructed to use another method.

\section{Discussion}

The goal of Experiment 3 was to test whether participants would demonstrate sensitivity to implicitly presented information. In previous research, Barsalou and Ross (1986) and a number of other researchers (Sanders et al., 1987; Spalding \& Murphy, 1999; Wattenmaker, 1993) were unable to find evidence for the automatic activation of properties when encountering an item. Barsalou and Ross stated that participants were not sensitive to property frequency, a form of implicitly presented information, because they were not completing both stages of a two-stage process. Although Barsalou and Ross felt that participants were automatically activating properties when encountering concepts (stage 1), they argued that this property information, once activated, needed to interact with a pre-existing memory structure for researchers to detect this sensitivity to frequency information (stage 2). Barsalou and Ross contended that because individuals do not typically encounter properties in isolation, people have not developed memory structures for properties, and so do not complete stage 2 of the two-stage process. 
In my study, I hypothesized that if properties were selccted that instantiated the same sense of the property, and that were ratcd high on conceptual centrality or conceptual salience, property activation might be sufficient to contact pre-existing memory structures. If this activation was sufficient to contact these structures, then people should demonstrate sensitivity to property frequency. In addition, I hypothesized that if property activation is context-independent, then participants should demonstrate sensitivity to property frequency in a "neutral" context, but if property activation is context-dependent, participants may be more likely to demonstrate sensitivity to property frequency only in an appropriate biasing context.

Participants in Experiment 3 did demonstrate sensitivity to property frequency. In fact, sensitivity to property frequency was demonstrated regardless of list type and instruction type. Therefore, there appears to be firm evidence that both salient and conceptually central properties can be activated for concepts regardless of context. In addition, according to the logic of Barsalou and Ross (1986), there must be pre-existing memory structures for both central and salient properties.

These findings are also in accord with other work (Love, 1996; Sloman et al., 1998) that indicates that people are able to selectively access the centrality of properties. Furthermore, the evidence from this experiment suggests that conceptually central properties are activated more strongly than conceptually salient properties. Frequency estimates were more accurate (as indicated by slope) for high centrality properties than they were for high salience properties.

One final question is whether sensitivity to property frequency was due to conscious retrieval strategies used by participants to enumerate the number of items 
they encountered for a given property or to non-conscious processes. If response times did not increase with frequency cstimates, this would indicate that participants were not consciously searching through memory for exemplars which instantiate a specific property, but were instead using non-enumerative strategies (Williams \& Durso, 1986). In examining the reaction time data, there was preliminary evidence that propertics were being automatically activated when participants encountered an itcm having that property. When probed about a specific property, the evidence indicates that participants in Experiment 3 were able to access the number of items which instantiated these properties without consciously retrieving specific exemplars. However, given the extremely long reaction times overall, another study with response deadlines should be done to confirm this finding. Therc was no evidence, however, in Experiment 3, of any context effects. 
CHAPTER 4

\section{PROPERTY VERIFICATION AS A MEASURE OF CONTEXT-DEPENDENCY FOR SALIENT AND CONCEPTUALLY CENTRAL PROPERTIES}

\section{Experiment 4}

To explore subtler differences between the availability of highly salient and highly central properties in unbiased and biased contexts, Experiment 4 used a task similar to a property verification paradigm used by Barsalou (1982) to study contextindependent (CI) and context-dependent (CD) properties. Although in Experiment 3, context was defined by how participants were instructed to learn the list of items, it is possible that participants did not actually use these strategies when learning the items. In fact the evidence from the strategies that were reported by participants indicated that at least some participants tended to use whatever strategy helped them to recall the most items rather than the strategy that they were instructed to use.

Barsalou argued that if a property is context-independent, then time to verify that property for a particular concept should not vary regardless of the sentence frame into which the concept was embedded. Specifically, Barsalou (1982) said, "The primary difference between $\mathrm{CI}$ and $\mathrm{CD}$ information is simply the means by which they are activated: CI information is activated by the word for a concept, whereas CD information is activated by relevant contexts in which the word is encoded." (p.91). For example, if smelly is a context-independent property of skunk, then the time to indicate "true" for this property when preceded by the related sentence "The skunk stunk up the neighborhood" should not be any different than the speed for the unrelated sentence "The skunk was under the large willow". However, if smelly were a context- 
dependent property of skunk then speeds should be greater in the related than in the unrelated condition.

Barsalou (1982) used two conditions: an unbiased, or what he called an "unrelated condition" and a same-biasing condition and what he called a "related condition". In this experiment, both of these conditions were used. In addition, a third condition was created to bias participants towards a different kind of property (differentbiasing). It is possible that if there are degrees of property dependency, then a property, which may be activated equally in both a same-biased and unbiased context, may not be activated as strongly in a condition which biases participants towards a different kind of property. For example, because the sentence "I took a photograph of the skunk" makes you think about how a skunk looks, you may be less likely to think about a skunk's smell. Therefore, it is possible that verification speeds for a property may be the highest in both the unbiased and same-biasing context, and may be lower in the differentbiasing context.

To explore the activation of salient and conceptually central properties for each concept, three sentence frame types (same-biasing, unbiased, different-biasing) were crossed with two property types (high salience and high centrality-see Table 18). In addition to the three experimental sentence frame types, a control sentence frame was constructed such that its subject noun was weakly related to its property (Barsalou, 1982). The purpose of this control sentence was to provide a baseline response speed against which response speed on the three experimental sentences could be measured. Participants should be able to respond faster if properties are highly related to their subject nouns than if they are weakly associated, as in the control sentences. 


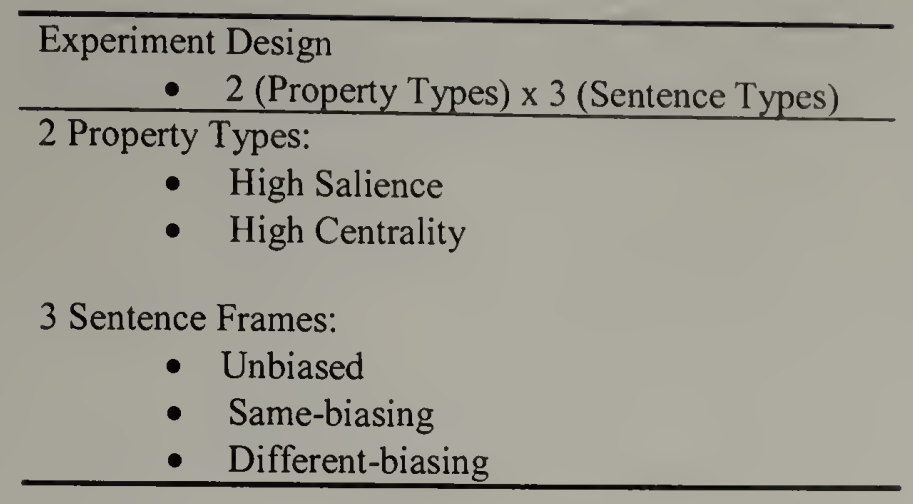

If property activation for context-independent properties is automatic, then in an unbiased context, it should take less time to verify a context-independent property than a context-dependent property. There should also be no systematic difference in response speeds for a context-independent property in the three different types of sentence frames (high context-independence). If a property is context-dependent then response speeds will vary across sentence frames, being the greatest in the same-biased condition. However, depending on the degree of context-dependence, response speeds may either be lower in both the unbiased and different biased conditions (high context dependence), or they may be the same in the both the same-biased and unbiased conditions and lower in only the different-biased conditions (moderate contextdependence--see Table 19).

Specifically, if salient properties are context-independent, then response speeds should be the same in the salience-biased, unbiased, and conceptual centrality-biased context. If salient properties are context-dependent, then response speeds should be the highest in the salience-biased condition. However, in the unbiased condition, response 
speeds may be the same as in the salicnce-biased condition and lower only in the conceptual centrality-biased condition, indicating that the activation of salient properties is only moderately context-dependent, or they may be lower in both the unbiased and in the conceptual centrality-biased conditions, indicating that the activation of salient properties is highly context-dependent.

Table 19. Predictions for Degrees of Context Dependence

\section{High Context Independence:}

- Speed to verify context-independent property in an unbiased contcxt should be higher than for context-dependent properties.

- There should be no systematic differences in response speeds for a context-independent property in the different types of sentence frames.

\section{Moderate Context Dependence:}

- Speed to verify a property will vary across sentence frames, being the highest in the same-biased condition.

- Speed to verify a property will be the same in the both the same-biased and unbiased conditions and be lower in only the different-biased conditions.

\section{High Context Dependence:}

- Speed to verify a property will vary across sentencc frames, being the highest in the same-biased condition.

- Specd to verify a property will be lowest in both the unbiased and different biased conditions and will be highest in the same-biased condition.

Alternatively, if conceptually central propcrties are context-independent, then response speeds should be the same in the salience-biased, unbiascd, and conceptual centrality-biased context. If conceptually central properties are context-dependent, then response speeds should be highest in the centrality-biased condition. However, they 
may be just as high in the unbiased condition and lower only in the salience-biased condition, indicating that the activation of conceptually central properties is only moderately context-dependent, or they may be lower in both the unbiased and in the salience-biased conditions, indicating that the activation of conceptually central properties is highly context-dependent.

\section{Method}

\section{$\underline{\text { Stimuli }}$}

Seventy-two items ( e.g. frogs) were chosen for the true sentences, to creatc sentences for four different frame types (see Table 20). The chosen item always appeared at the end of the sentence and was always in capital letters. Each of the 72 items appeared in three different sentence frames including a salience-biased frame, a centrality-biased frame, and an unbiased frame (see Table 20). Each participant only saw a subset of eighteen sentences each for salience-biased, centrality-biased, and unbiased sentences. Each item was paired with two properties to create 144 itemproperty pairs. The properties were chosen so that one of the properties was a highly salient property (e.g. are green) of the item (e.g. frogs) and one of the properties was a highly central property (e.g. eats flies) of the item (e.g. frogs). Five undergraduate research assistants confirmed that the properties chosen for each item were either salient or central and that all of the sentence frames were biased appropriately.

Control sentences were also created in which the relevant item was only weakly related to the property (see Table 20). These control sentences were not based on the 72 items, but were built around the 144 properties, so that each property was paired once with an item for which the property was only weakly related. Seventy-two false 
sentence-property pairs were also created and this set was secn by all of the participants.

Therefore, in an individual experimental session, participants saw a total of 144 test

sentences, seventy-two of which were true and seventy-two of which were false.

In addition to responding to the property verification sentences, participants

were also asked periodically to respond to comprehension questions (sec Appendix $\mathrm{H}$ ).

Each participant saw seventy-two comprehension questions. For half of the qucstions,

the correct answer was yes, and for the other half the correct answer was no. The

purpose of the comprehension questions was two-fold. First, the questions motivated

participants to pay attention throughout the entire experiment. Second, they provided

additional motivation for participants pay attention to the entire sentence, not just the

capitalized word at the end of the sentence.

Table 20. Sample Property Verification Sentences in Different Contexts

\begin{tabular}{|c|c|c|}
\hline & Properties & Contexts \\
\hline True & $\underset{<}{\text { are green }}$ & $\begin{array}{l}\text { Salience-biased-- The lily pad provided camouflage for the } \\
\text { FROGS. }\end{array}$ \\
\hline True & eats flies & \\
\hline & $\begin{array}{l}\text { are green } \\
?\end{array}$ & $\begin{array}{l}\text { Unbiased-- Little Johnny went to the pond to catch } \\
\text { FROGS. }\end{array}$ \\
\hline True & eats flies & \\
\hline True & $\begin{array}{l}\text { are green } \\
>\end{array}$ & $\begin{array}{l}\text { Centrality-biased--Timmy wanted to get food for the } \\
\text { FROGS. }\end{array}$ \\
\hline True & eats flies & \\
\hline True & are green & Control--Kara picked flowers and cut the STEMS. \\
\hline True & eats flies & Control--Climbing on the tree branch was an IGUANA. \\
\hline False & is square & $\begin{array}{l}\text { False--Karen couldn't believe Jack thought he saw a } \\
\text { WITCH. }\end{array}$ \\
\hline
\end{tabular}

Eight different lists of the seventy-two true sentences were constructed (see

Appendix $\mathrm{H}$ for the eight full lists of true sentences and the list of false sentences). To 
create these eight final lists, the seventy-two true sentences were divided into eight groups of nine sentences each, one for each type of sentence contcxt along with their corresponding property types. A Latin Square design was used to detcrminc which sentence frame for each property appeared in each list. This cnsurcd that cach itcm appeared paired with a true sentence frame only once in each list. Hencc, the seventytwo "true" sentences in each of the four final lists were made up of 18 centrality-biased sentences ( 9 items that were paired with a highly salient property and 9 that werc paired with a highly central property), 18 salience-biased sentences ( 9 salient/9central), 18 unbiased sentences ( 9 salient/9 central), and 18 control sentences ( 9 salient/9 central). The presentation order of all sentences was randomized for each subject.

\section{$\underline{\text { Participants }}$}

In Experiment 4, there were 64 participants. The data from 19 of these were dropped from the analysis because their responses indicated they were not responding appropriately (i.e. they gave all yes or all no responses). This left 45 participants who were included in the analysis. This unusually high proportion of bad participants was most likely due to the fact that a large portion of this data was not collected until end of the spring semester when there tends to be a higher proportion of bad participants. The participants were all University of Massachusetts undergraduates. Each participant was able to complete the experiment in less than 30 minutes and they received course credit for their participation.

\section{Procedure}

Participants were asked to read sentences that contained at least one noun (e.g. FROG). The relevant noun was capitalized and always appeared at the end of the 
sentence. The sentence was presented on the sereen and participants pressed the spacebar to move on to the property probe (c.g. eats flies). When the probe appeared on the screen, participants indicated their response by pressing the J button on the keyboard to indicate that the probe was a property of the capitalized noun or the F button to indicate that it was not. Response speeds were measured from the onset of the probe presentation to the time the response was made. Instructions were given to remind participants to respond to the property probe as quickly and as accurately as possible. Participants were also instructed that they would periodically receive comprehension questions that were based on the sentences they were reading (see Appendix $\mathrm{H}$ for a completc list of comprehension questions). This gave participants incentive to read the entire sentence and not to just focus on the last word. Participants used the same keys ( $J$ and F) to indicate their YES/NO answers to the comprehension questions.

Hypotheses

The first hypothesis was that if property activation for context-independent properties is automatic, then response specds for context-independent propertics should be higher than for context-dependent propertics in an unbiased context and should be cqually high in all sentence frames, but if a property is context-dependent then response speeds will vary across sentence frames. A second hypothesis was that, depending on the degrec of context-dependence, response specds may be lower than the same-biased condition in both the unbiased and different-biased conditions, or they may be the same in the both the same-biased and unbiased conditions and lower in only the differentbiased conditions. A third hypothesis was that if a property is context-independent, then response speeds should be lower in the control condition than in any of the 
contexts, because a control sentence should be designed so that its subject is only weakly related to its corresponding property, whercas in the expcrimental conditions, the subject noun will be chosen to maximize the relatedness between it and its corresponding properties.

To be specific, if salient properties are context-independent, then response speeds should be the same in the salience-biascd, unbiased, and conceptual ccntralitybiased context and response speeds in these contexts should bc higher than the response speed in the control condition. However, if salient properties are context-dependent, response speed will be highest in the salience-biased condition. Thcy also may be just as high in the unbiased condition and lower in the conceptual centrality-biased condition. This would indicate that the activation of salient propertics is only moderately context-dependent. They also may be lower in both the unbiased and in the conceptual centrality-biased conditions. This would indicate that the activation of salient properties is highly context-dependent. The implications are the same for the conceptually central properties.

\section{Results}

Because response latencies are usually positively skewed, response latencies were converted to response speeds by taking their reciprocals (1/RT) in order to reduce the impact of outliers (as recommended by Ratcliff, 1993). In addition, the response to the first sentence presented to each participant was omitted because these tended to be very slow (up to 40 seconds in one instance) and responses under 100 milliseconds were dropped. The mean response speed for thc correct responses was then computed for each participant in each condition. The mean response speeds averaged across 
participants are presented in Table 21 and Figure 11 and the mean reaction times are presented in Table 22.

The results from Experiment 4 are consistent with the findings from Experiment 3 (see Table 21 for response speeds and 22 for reaction times). Response speeds for the conceptually central properties in the same-biasing and unbiased sentence frame were higher $(F(1,44)=7.091, p=.011)$, on average, than speeds for the salient propertics in the same sentence frames. Looking at just the unbiased sentence context, response speeds for the conceptually central probe were higher than response speeds for the conceptually salient probe $(F(1,44)=4.36, p=.04)$. For the centrality-biased sentence context, response speeds were marginally higher for the central probes than for the salient probes $(F(1,44)=2.66, p=.10)$. These results, taken as a whole, appear to indicate that in the unbiased sentence context, conceptually central properties are activated more readily than conceptually salient properties and in the centrality-biased sentence context, conceptually central properties are activated somewhat more readily than conceptually salient properties.

Second, the response speed for the central property in the salient sentence frame was lower than the response speed for the central property in the unbiased and centrality-biased sentence frames $(F(1,44)=6.36, p=.015)$. This result suggests, based on earlier predictions, that the activation of conceptually central properties is moderately context-dependent. Although the response speed for the salient property in the salient-biased sentence appears to be higher than response speeds in the unbiased and centrality-biased context, which would suggest high context dependency for the 
activation of salient properties, the result of this contrast was not significant $(F(1,44)=1.53, p=.22)$.

When examining the pattern of findings for the three types of experiment questions, there was a significant sentence type by probe type interaction $(F(2,88)=3.07$, $p=.05)$. This result indicates that the pattern of response speeds for the central probes is different from the pattern for the salient probes. For the central probes, response

Table 21. Mean Response Speeds $\left(\sec ^{-1}\right)$ as a Function of Probe and Sentence Type

\begin{tabular}{|c|c|c|c|c|c|c|}
\hline & & \multicolumn{4}{|c|}{ Sentence Type } & \multirow[b]{2}{*}{$\begin{array}{c}\text { Marginal } \\
\text { Means }\end{array}$} \\
\hline $\begin{array}{l}\text { Property } \\
\text { Type }\end{array}$ & & Unbiased & $\begin{array}{c}\text { Central } \\
\text { Bias }\end{array}$ & $\begin{array}{c}\text { Salience } \\
\text { Bias }\end{array}$ & Control & \\
\hline \multirow{3}{*}{ Central } & $\bar{X}$ & .867 & .862 & .822 & .803 & .839 \\
\hline & $S E$ & .033 & .032 & .031 & .028 & .029 \\
\hline & $C I$ & $.801-.934$ & $.798-.927$ & $.760-.885$ & $.746-.860$ & $.781-.897$ \\
\hline \multirow{3}{*}{ Salient } & $\bar{X}$ & .820 & .825 & .848 & .807 & .825 \\
\hline & $S E$ & .031 & .035 & .030 & .031 & .028 \\
\hline & $C I$ & $.758-.883$ & $.755-.896$ & $.787 \div .909$ & $.745-869$ & $.769-.882$ \\
\hline \multirow{3}{*}{$\begin{array}{c}\text { Marginal } \\
\text { Means }\end{array}$} & $\bar{X}$ & .844 & .835 & .844 & .805 & .832 \\
\hline & $S E$ & .030 & .028 & .032 & .027 & .028 \\
\hline & $C I$ & $.784-.904$ & $.780-.908$ & $.779-.892$ & $.750-.860$ & $.776-.888$ \\
\hline
\end{tabular}

speeds were highest in the unbiased and centrality-biased condition and lower in the salience-biased condition and for the salient probes, although not significant, response speeds were lower in the unbiased and centrality-biased condition and higher in the 
salience-biased condition. Again, this pattern of responding supports the hypothesis that the activation of conceptually central properties is moderately context-dependent, while the activation of conceptually salient properties may be highly context-dependent.

Table 22. Mean Reaction Times (msec) as a Function of Probe and Sentence Type

\begin{tabular}{cccccc}
\cline { 2 - 4 } $\begin{array}{l}\text { Property } \\
\text { Type }\end{array}$ & Unbiased & $\begin{array}{c}\text { Central } \\
\text { Bias }\end{array}$ & $\begin{array}{c}\text { Salience } \\
\text { Bias }\end{array}$ & Control & $\begin{array}{c}\text { Marginal } \\
\text { Means }\end{array}$ \\
\hline Central & 1153 & 1160 & 1217 & 1245 & 1192 \\
\hline Salient & 1220 & 1212 & 1179 & 1239 & 1212 \\
\hline $\begin{array}{c}\text { Marginal } \\
\text { Means }\end{array}$ & 1185 & 1198 & 1185 & 1242 & 1202 \\
\hline
\end{tabular}

Lastly, the response speed for all three experimental sentences, averaged over probe type, was higher than the response speed for the control sentences $(F(1,44)=8.20$, $p=.006$ ). This, along with the previous results would indicate that the control sentences were correctly designed so that their subject was only weakly related to its property. This result also clearly demonstrates that both salience and centrality are important factors when talking about category properties and when trying to understand how properties are related to a given concept. 


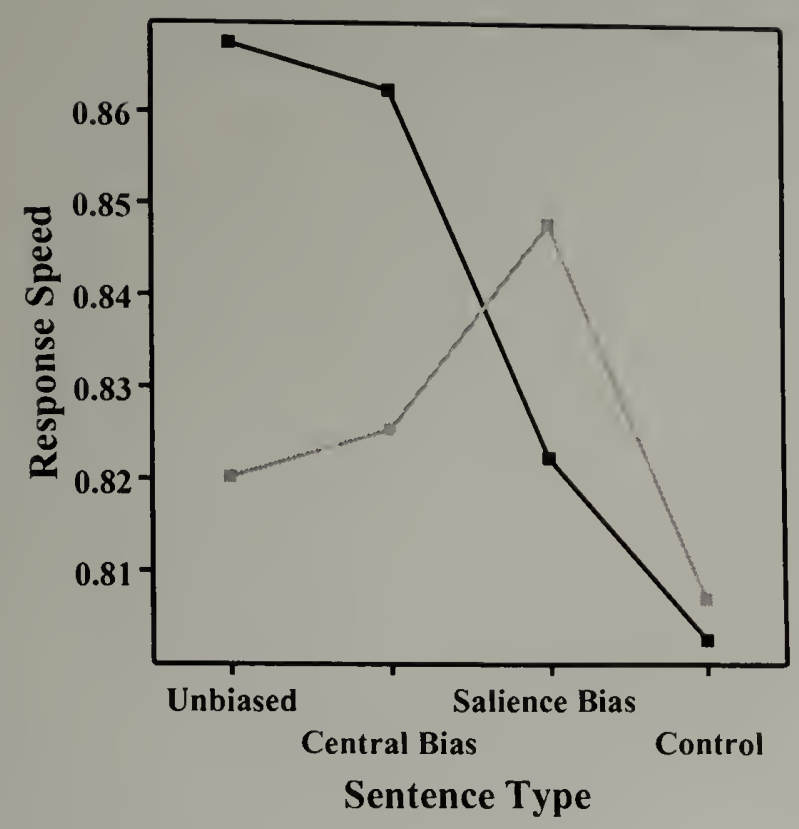

Probe Type

Central

Salient

Figure 11. Response Speeds $\left(\mathrm{sec}^{-1}\right)$ for Sentence Type by Probe Type

Discussion

Barsalou (1982) stated that some kinds of properties might be contextindependent while others may only be activated in relevant contexts. If either salient or conceptually central properties are context-independent, then response speeds should not depend upon sentence context but if they are context-dependent, there may be varying degrees of context-dependence. For highly context-dependent properties, response speeds should be highest in the same-biasing context and lower in the other contexts. For moderately context-dependent properties, response speeds may be equally high in the same-biasing and unbiased contexts and may only be lower in the differentbiasing context. 
The results appear to indicate that there is a difference in the activation patterns for central and salient properties. Highly central properties appear to be more readily available and more quickly activated than highly salient properties. For both the unbiased sentence type and the centrality-biased sentence type, the response speeds for the highly central properties were significantly higher than the response speeds for the highly salient properties. These results are consistent with the findings in Experiment 3, that people are more sensitive to the frequency of central properties than of salient properties.

The results also indicate that property availability for central properties is moderately context-dependent (see Table 21). Response speeds were higher in the same-biasing and unbiased contexts and lower in the different-biasing context. This finding supports the work of Sloman and Ahn (1999), by demonstrating that conceptual cores appear not to be rigid, but do have some degree of flexibility. Although the results were not significant for the salient properties, the pattern of results for the salient properties seems to be consistent with the hypothesis that salient properties are highly context-dependent. This would make sense, given that what is salient for an object is more likely to vary in different contexts (Barsalou, 1993), but what is central for a property is much more stable. However, in support of the work of Sloman and Ahn (1999), the evidence from Experiment 4 demonstrates that conceptual cores appear not to be rigid, but do have some degree of flexibility.

One critique of Experiment 4 was that the sentence contexts may have raised the activation level of some property probes before participants reached the noun prime at the end of the sentence (a pre-noun prime bias). For example, when participants read the 
sentence frame, "The lily pad provided camouflage for the FROGS. " the salient property "green" may have been activated before participants reached the prime "frogs". However, the same sentence frame should not have activated the central property "eats flies". If a sufficient number of sentence frames were construeted in this manner, then this may have created a bias for increased response specds for one type of sentence frame paired with one type of property.

A post-hoc analysis was conducted where I examined all of the sentence framcs paired with all of their property probes for this type of bias. For the centrality-biased sentence frame paired with the central property and the salient-biased frame paired with the salient property, there was no significant difference in the overall proportion of prenoun prime biased sentences (mean proportions respectively are .34 and $.24, \chi^{2}(1$, $144)=2.15, p=.14)$. There was also not a significant difference in the proportion of pre-noun prime biased sentence contexts when comparing the unbiased sentence frames paired with both the central and salient properties (mean proportions respectively are .08 and $\left..07, \chi^{2}(1,144)=.10, p=.75\right)$. This indicates that the finding that conceptually central properties are activated more readily than conceptually salient properties in both unbiased and same-biasing contexts cannot be attributed to the manner in which the sentence frames were constructed.

Lastly, there was no significant difference in the proportion of pre-noun prime biased sentence contexts when comparing the average of the unbiased and centralitybiased sentence frames paired with the central property to the salient-biased sentence frame paired with the central property (mean proportions respectively are .21 and .17 , $\mathrm{t}(213)=-.87, p=.39)$. Therefore, the finding that central properties are activated more 
readily in unbiased and same-biasing contexts than different biasing contexts also cannot be attributed to the manner in which these sentences were conducted. It appears that the evidence for the context-dependency of central properties is valid. 


\section{CHAPTER 5}

\section{GENERAL DISCUSSION}

\section{Conclusions}

Why is it interesting to study and understand what kinds of property information are activated in different contexts? By demonstrating that differcnt propertics arc activated in different contexts, we can gain insight into how concepts arc organized, stored, and accessed in long-term memory. Komatsu (1992) argucd that without a way to constrain which attributes, regardless of context, are relevant for a given concept, exemplar models are faced with the same problem as the classical view of categorization. Just as it is difficult for classical theories to define what counts as a necessary and sufficient feature, there is no principled way for exemplar models or other category learning models to decide a priori which features are relevant for a concept and how the relevance of features could change in different contexts. For example, there are infinitely many properties for a simple concept like frog (e.g. green, eats flies, has skin, lives in a pond, can be eaten, breathes, has a tongue, can hop, etc.). However, in any given context, we only activate or retrieve a subset of these properties. What we activate is strongly affected by context surrounding the encounter with an item, but theories of category learning have yet to specify how context affects which properties are retrieved and whether classes of properties are affected differently in different contexts. The present studies, by exploring how central and salient properties are context-dependent and how different contexts affect property activation, have begun to explore and define these constraints. 
Because past frequency estimation studies established that people could demonstrate sensitivity to implicit information (Barsalou \& Ross, 1986), people should be sensitive to property frequency. In Experiment 3, the first significant finding of these studies was that participants in every context demonstrated frequency sensitivity to both conceptually central and conceptually salient properties. However, when a concept is activated, Sloman et al. (1998) would predict that central properties should resonate more strongly with a concept than salient properties because they should have more connections with that concept. Consequently, participants should be more likely to retrieve that concept or make contact with the concept's representation in memory when presented with a conceptually central property than when presented with a conceptually salient property. This would lead to more accurate frequency estimates for conceptually central properties than for conceptually salient properties. In fact, Experiment 3 demonstrated that participants were more accurate at estimating the frequency of conceptually central properties, a finding in accord with Sloman et al.'s theory that conceptually central properties are those properties that are central in a network of properties related to a given concept.

Although prior researchers have been unable to demonstrate sensitivity to property frequency (Barsalou \& Ross, 1986; Sanders et al., 1987; Spalding \& Murphy, 1999; Wattenmaker, 1993) for any type of property information, Experiment 3 provides clear evidence that people can be sensitive to property frequency for a variety of property types. Not only does property information appear to be activated when a concept is encountered (Barsalou \& Ross' stage 1) but this activated information must be interacting with pre-existing memory structures (Barsalou \& Ross' stage 2) as 
evidenced by sensitivity to property frequency. Based on findings from Experiment 3 , there appears to be convincing evidence that prc-cxisting memory structures exist for both salient and central property types.

If there are pre-existing memory structures for salient and central properties, what are these memory structures like--are thcy inflexible and rigid or are they flexible? Do these pre-existing memory structures, and possibly the flexibility with which they are tied to concepts differ depending on the type of property bcing activated? Recent work by Barsalou and colleagues (Barsalou, 2000; Wu and Barsalou, 2001; Ych \& Barsalou, 2000) has focused on the importance of situated concepts, which are very relevant to any discussion of the context-dependent nature of propertics. However, unlike Barsalou's (1982) theory of context-dependent and context-independent properties, Barsalou, in his more recent work, has argued that all concepts have some components that are situationally specific (Thesis 1--see Yeh \& Barsalou). In the theory of situated concepts, certain types of properties will always have the ability to become more or less relevant for a concept in different situations (Thesis 2). Yeh and Barsalou (p. 39) argue “...people do not store concepts in isolation-they store them with their background situations. Thus when situations become active, they activate their associated concepts...Conversely, when concepts become active, they activate their associated situations... When a concept is processed in a particular situation, properties become active for it that are relevant in the situation." Based on this account, there may not be core properties that become active for a concept in all situations. Sloman and Ahn's (1999) theory that category centrality is relative and that conceptual cores are not rigid appears to be in accord with the theory of situated concepts. So, in 
fact, are the results from Experiment 4, which clearly demonstrate that the activation of central properties is context-dependent.

If, in fact, all concepts are context-dependent (or situated) and conceptual cores are flexible, why would salient properties be more affected by the surrounding context or situation than central properties? Neither theory alone provides a reasoned account as to how situations may differentially activate different kinds of properties and whether or not property flexibility varies for different property types. When taken together, however, I feel that the two theories provide a reasoned account as to why conceptually central properties would be less context-dependent or less situated than conceptually salient properties. According to Sloman et al. (1998), features that are more conceptually central also tend to be those properties that are more immutable than conceptually salient properties. Although very few properties of concepts are completely immutable (e.g. unmarried for bachelor), those properties that are more immutable should be those properties that show a lesser degree of context dependency. This is, in fact, what the results of these studies demonstrated. Conceptually central (more immutable) properties produced a pattern of response speeds that indicated moderate context-dependence. The response speeds for the conceptually salient, more mutable properties indicated that the activation of these properties was highly contextdependent. These results are also consistent with a theory of context-dependent concepts. Because conceptually central properties are more immutable, and therefore more relevant in a variety of contexts, the cognitive system would be best served if these properties are brought to mind more readily and in more contexts than 
conceptually salient propertics, which may be perceptually prominent but may have less inferential potency (Chaigneau \& Barsalou, 2001) bccausc of thcir mutability.

One might ask why context effects were found in Expcriment 4 and not in Experiment 3. Recent work (Solomon \& Barsalou, 2001; Wu \& Barsalou, 2001) has provided a possible explanation for this inconsistency. Solomon and Barsalou and $\mathrm{Wu}$ and Barsalou both demonstrated that people perceptually simulate concepts when asked to perform tasks such as property generation and property verification. Wu and Barsalou (p. 2) argued, "uninstructed neutral subjects should spontancously construct perceptual simulations to represent concepts and thereforc should perform similarly to imagery subjects..." They stated that this occurs because when people encode a specific instance of a concept they store not just the abstracted exemplar, but also the neural states that occurred when perceiving the instance. Then, when retrieving these concepts from memory, people retrieve not an amodal concept, but a perceptually simulated concept. In their experiments (Solomon \& Barsalou, Wu \& Barsalou), the evidence indicated that participants performed perceptual simulations even when performing tasks such as property generation and property verification in neutral contexts. If the participants in Experiment 3 were perceptually simulating the list items in the neutral context and in the function context because of a precxisting bias to perform such simulations, therc would be no evidence of context effects, because participants would be creating an image in all contexts. Because the sentencc-property verification priming task in Experiment 4 looked at reaction time data, it was most likely more sensitive to different contcxt effects. 
In conclusion, what have thesc studies shown us about context dependency? Although the data from Experiment 3 was inconclusive regarding the effect of context on property activation, the data from Experiment 4 demonstrates context dependence for central properties and suggests context dependence for salicnt properties. These findings support the work of both Sloman and Ahn (1999), who stated that conceptual cores can change based on the task and on the context, and the more recent work of Barsalou (2000) and Yeh and Barsalou (2000), who hypothesized that all concepts are situated concepts and are affected by the situational context both at learning and at retrieval. Barsalou (2000, p. 4) stated, "By focusing on situations, the cognitive system simplifies many tasks. Rather than having to search everything in memory across all situations, the cognitive system focuses on the knowledge and skills relevant in the current situation."

Turning to the frequency estimation data, there is convincing evidence to indicate that property activation is automatic (Hasher \& Zacks, 1984). However, as demonstrated in Experiment 4, the properties that are activated may not be the same in every context. This evidence for automatic activation in combination with the evidence as to how different property types show varying degrees of context dependency provides experimental support for Barsalou \& Ross' automaticity hypothesis (1986) that people should show a greater frequency sensitivity to moderately context-dependent properties (central properties) than to highly context-dependent properties (Barsalou, 1982).

In addition to these findings, these studies also demonstrate the importance of conceptually central properties in concept representation (Ahn, 1998; Love, 1996; 
Sloman et al., 1998). People do seem to be able to selectively access the centrality of properties. The evidence from Experiments 3 and 4 demonstrates that conceptually central properties are not only activated when a concept is activated, but are also activated more strongly than conceptually salient properties. This is evidenced both by more accurate frequency estimates (Experiment 3 ) and by consistently shorter property verification reaction times (Experiment 4) for conceptually salient properties.

In summary, these studies support the following conclusions:

1) All concepts are context-dependent and thus the properties brought to mind along with these concepts vary across situations or contexts (Barsalou, 2000; Yeh \& Barsalou, 2000).

2) Conceptually central and more immutable properties appear to be less context-dependent than conceptually salient properties (Ahn, 1998; Barsalou, 2000; Sloman \& Ahn, 1999; Sloman, Love, \& Ahn, 1998; Yeh \& Barsalou, 2000).

3) Conceptually central properties are brought to mind more consistently and more rapidly than conceptually salient properties (Barsalou \& Ross, 1986; Hasher \& Zacks, 1984).

\section{$\underline{\text { Some Final Criticisms and Limitations }}$}

Although these findings are interesting and add to our knowledge of conceptual representation, there are a few potential criticisms that should be addressed. First, I did not examine other classification schemas for types of properties. For example, one existing schema classifies properties as components, regions, or materials. When talking about a pencil, "has an eraser" would be a component, "tip" would be a region, and "lead" would be a material. Work by Winston, Chaffin, \& Herrmann (1987; see also Solomon \& Barsalou, 2001) has demonstrated that people view property goodness as being highest for components, less good for regions, and lowest for 
materials. Consequently, people are ablc to vcrify components more quickly than they can verify regions, and regions more quickly than they can vcrify materials. It is possible that property goodness was confounded with property type. If so, participants may have had faster reaction times to conceptually central properties not bccause they are activated more readily, but because more conceptually central propertics than conceptually salient properties were components. This classification schema for properties, however, is not the only possible classification schema for propertics. In fact, components, regions, and materials would only be relevant property types for concrete objects, not for more abstract concepts. It is important for future work to explore whether other classification schemas are relevant for understanding property activation.

Second, although the reaction time evidence from Experiment 3 appears to indicate that participants used more automatic, non-enumerative strategies when judging frequency, the results do not definitively rule out the possibility that participants did use enumeration. Although reaction times did not increase with increasing frequency, as they should when people use enumerative strategies, the average reaction times in this experiment were on the order of 4 to 6 seconds, which could have been enough time for participants to retrieve and count specific exemplars. In addition, the fact that reaction times did not increase with increasing frequency may have been due to extremely long reaction times for the 0 frequency items. Participants may have continued to search their memory for items which instantiated the 0 frequency property after an initial search returned no items, even though they had been informed in the instructions that there might be properties which occurred with 
frequencies of 0 . If so, thesc longer latencics would mask any evidence of increasing latencies with increasing frequencies. To cxplore this issue further, Experiment 3 should be re-run using response deadlines during the frequency estimation phase.

In Experiment 4, the average response latency was $1100-1300 \mathrm{msec}$. It is important to point out, in fact, that these studics only provide an account of how different property types recruit attention in different contexts, not at diffcrent points in processing. However, if we wish to look at the time course of property activation, as predicted by Lamberts' EGCM $(1995,1998)$, we would need to have rcsponses made at much shorter latencies. In fact, to test the EGCM, both Experiment 3 and Experiment 4 should be rerun using response deadlines to more accurately assess how different types of properties are accessed at different points in processing. For Experiment 3, the EGCM should predict that participants may only be sensitive to the frequency of salient properties, given a short response deadline, wheras they should be sensitive to both salient and central properties given longer response deadlines. For Experiment 4, reaction times could no longer be the dependent measure, given that response deadlines would be used, but accuracy could instead be used to measure any changes in the activation of the different types of properties. The EGCM should predict that responses would be more accurate for salient properties early in processing, but would be equally accurate for salient and central properties given more processing time.

In addition, I would like to address my initial criticisms of Barsalou and Ross' (1986) study. Prior to running Experiment 3, I had commented that the items chosen by Barsalou and Ross were not very good examples of their categories. I also felt that they chose many items which instantiated a number of different properties in the set of probe 
properties. Lastly, I indicated that Barsalou and Ross ehose many items which instantiated different senses of the same property. Looking back on the eare that I took to avoid these problems when choosing properties for Experiment 3, I was unable, given the constraints of the stimuli seleetion process, to eompletely avoid the same problems.

\section{Future Directions}

Future studies that look to explore how different properties are activated in different contexts should be directed at clarifying how, during learning, people decide which features are and are not relevant for a given exemplar. They should try to further define how property relevance changes in different situations. Studying these issues should help us develop a mechanism by which exemplar models or other category learning models can determine which features are relevant for a concept (Lamberts 1995, 1998), which features are not relevant for a eoneept, and, most importantly, how the relevance of features could change in different contexts. In addition, as noted previously, future studies should also be directed towards exploring other classifieation schemas for property types. Despite the fact that salience and centrality both appear to be important for understanding some of the above issues, other schemas may be more meaningful in different situations. Although these studies provide a preliminary examination of some of these issues, much work remains to be done in future studies to clarify how and to what extent context affects property activation for different types of properties. 


\section{APPENDIX A}

\section{COMPLETE SET OF IMAGINE QUESTIONS-EXPERIMENT I}

\section{Set A}

1. How easy is it to imagine a snake that isn't scary?

2. How easy is it to imagine a monster that isn't scary?

3. How easy is it to imagine a vampire that isn't scary?

4. How easy is it to imagine a bat that isn't scary?

5. How easy is it to imagine a spider that isn't scary?

6. How easy is it to imagine a haunted house that isn't scary?

7. How easy is it to imagine a ghost that isn't scary?

8. How easy is it to imagine a witch that isn't scary?

9. How easy is it to imagine a nightmare that isn't scary?

10. How easy is it to imagine a car that isn't fast?

11. How easy is it to imagine a cheetah that isn't fast?

12. How easy is it to imagine a plane that isn't fast?

13. How easy is it to imagine a millisecond that isn't fast?

14. How easy is it to imagine a leopard that isn't fast?

15. How easy is it to imagine a roadrunner that isn't fast?

16. How easy is it to imagine a sports car that isn't fast?

17. How easy is it to imagine a racecar that isn't fast?

18. How easy is it to imagine track athletes that aren't fast?

19. How easy is it to imagine a horse race that isn't fast?

20. How easy is it to imagine a Concorde that isn't fast?

21. How easy is it to imagine a train that isn't fast?

22. How easy is it to imagine a speedboat that isn't fast?

23. How easy is it to imagine light that isn't fast?

24. How easy is it to imagine cyanide that isn't poisonous?

25. How easy is it to imagine lead that isn't poisonous?

26. How easy is it to imagine chemicals that aren't poisonous?

27. How easy is it to imagine venom that isn't poisonous?

28. How easy is it to imagine strychnine that isn't poisonous?

29. How easy is it to imagine ammonia that isn't poisonous?

30. How easy is it to imagine bleach that isn't poisonous?

31. How easy is it to imagine roach killer that isn't poisonous?

32. How easy is it to imagine a weed killer that isn't poisonous?

33. How easy is it to imagine a spider that isn't poisonous? 
34. How easy is it to imagine a gas that isn't poisonous?

35. How easy is it to imagine a household cleaner that isn't poisonous?

36. How easy is it to imagine a berry that isn't poisonous?

37. How easy is it to imagine hemlock that isn't poisonous'?

38. How easy is it to imagine a clock face that isn't round?

39. How easy is it to imagine a traffic circle that isn't round?

40. How easy is it to imagine a ring that isn't round?

41. How easy is it to imagine a wheel that isn't round?

42. How easy is it to imagine glasses that aren't round?

43. How easy is it to imagine a dome that isn't round?

44. How easy is it to imagine a planet that isn't round?

45. How easy is it to imagine a moon that isn't round?

46. How easy is it to imagine a CD that isn't round?

47. How easy is it to imagine a record that isn't round?

48. How easy is it to imagine eyes that aren't round?

49. How easy is it to imagine a ball that isn't round?

50. How easy is it to imagine a lollipop that isn't round?

51. How easy is it to imagine an orange that isn't round?

52. How easy is it to imagine an earth that isn't round?

53. How easy is it to imagine a sun that isn't round?

54. How easy is it to imagine a cookie that isn't round?

55. How easy is it to imagine a glass that isn't clear?

56. How easy is it to imagine water that isn't clear?

57. How easy is it to imagine tears that aren't clear?

58. How easy is it to imagine plastic that isn't clear?

59. How easy is it to imagine air that isn't clear?

60. How easy is it to imagine cellophane that isn't clear?

61. How easy is it to imagine Plexiglas that isn't clear?

62. How easy is it to imagine a window that isn't clear?

63. How easy is it to imagine eyeglasses that aren't clear?

64. How easy is it to imagine saran wrap that isn't clear?

65. How easy is it to imagine broth that isn't clear?

66. How easy is it to imagine contacts that aren't clear?

67. How easy is it to imagine bread that isn't grainy?

68. How easy is it to imagine wood that isn't grainy?

69. How easy is it to imagine cereal that isn't grainy?

70. How easy is it to imagine sand that isn't grainy? 
71. How easy is it to imagine dirt that isn't grainy?

72. How easy is it to imagine grout that isn't grainy?

73. How easy is it to imagine sandpaper that isn't grainy?

74. How easy is it to imagine sugar that isn't grainy?

75. How easy is it to imagine a desk that isn't wooden?

76. How easy is it to imagine a chair that isn't wooden?

77. How easy is it to imagine a bed that isn't wooden?

78. How easy is it to imagine a house that isn't wooden?

79. How easy is it to imagine shutters that aren't wooden?

80. How easy is it to imagine pirate legs that aren't wooden?

81 . How easy is it to imagine a door that isn't wooden?

82. How easy is it to imagine birdhouses that aren't wooden?

83. How easy is it to imagine fence posts that aren't wooden?

84. How easy is it to imagine dressers that aren't wooden?

85. How easy is it to imagine a bench that isn't wooden?

86. How easy is it to imagine a crate that isn't wooden?

87. How easy is it to imagine a tree that isn't wooden?

88. How easy is it to imagine a baseball bat that isn't wooden?

89. How easy is it to imagine a puppet that isn't wooden?

90. How easy is it to imagine blocks that aren't wooden?

91. How easy is it to imagine floors that aren't wooden?

92. How easy is it to imagine cabinets that aren't wooden?

93. How easy is it to imagine an oar that isn't wooden?

94. How easy is it to imagine a log cabin that isn't wooden?

95. How easy is it to imagine pencils that aren't wooden?

96. How easy is it to imagine a raft that isn't wooden?

97. How easy is it to imagine a car that doesn't have wheels?

98. How easy is it to imagine a truck that doesn't have wheels?

99. How easy is it to imagine a bicycle that doesn't have wheels?

100. How easy is it to imagine a tricycle that doesn't have wheels?

101. How easy is it to imagine an airplane that doesn't have wheels?

102.How easy is it to imagine a van that doesn't have wheels?

103. How easy is it to imagine a skateboard that doesn't have wheels?

104.How easy is it to imagine a scooter that doesn't have wheels?

105. How easy is it to imagine a motorcycle that doesn't have wheels?

106. How easy is it to imagine a wheelchair that doesn't have wheels?

107. How easy is it to imagine an office chair that doesn't have wheels? 
108. How easy is it to imagine a wagon that doesn't have wheels?

109. How easy is it to imagine a wheelbarrow that doesn't have wheels?

110. How easy is it to imagine a train that doesn't have wheels?

111. How easy is it to imagine a unicycle that doesn't have wheels?

112. How easy is it to imagine a baby carriage that doesn't have wheels?

113. How easy is it to imagine a roller coaster that doesn't have wheels?

114. How easy is it to imagine a go-cart that doesn't have wheels?

115. How easy is it to imagine a bus that doesn't have wheels?

116. How easy is it to imagine a matchbox car that doesn't have wheels?

117. How easy is it to imagine roller skates that don't have wheels?

118. How easy is it to imagine roller blades that don't have wheels?

119. How easy is it to imagine toys that don't have wheels?

120. How easy is it to imagine a tire that isn't rubber?

121. How easy is it to imagine a ball that isn't rubber?

122. How easy is it to imagine a doll that isn't rubber?

123. How easy is it to imagine a garden hose that isn't rubber?

124. How easy is it to imagine latex gloves that aren't rubber?

125. How easy is it to imagine rain boots that aren't rubber?

126. How easy is it to imagine an eraser that isn't rubber?

127. How easy is it to imagine dish gloves that aren't rubber?

128. How easy is it to imagine Tupperware that isn't plastic?

129. How easy is it to imagine a CD case that isn't plastic?

130. How easy is it to imagine a cup that isn't plastic?

131. How easy is it to imagine straws that aren't plastic?

132. How easy is it to imagine shampoo bottles that aren't plastic?

133. How easy is it to imagine soda bottles that aren't plastic?

134. How easy is it to imagine a pen that isn't plastic?

135.How easy is it to imagine shopping bags that aren't plastic?

136. How easy is it to imagine cassette tapes that aren't plastic?

137. How easy is it to imagine a milk jug that isn't plastic?

138. How easy is it to imagine a bottle that isn't plastic?

139. How easy is it to imagine an apricot that isn't orange?

140. How easy is it to imagine a carrot that isn't orange?

141. How easy is it to imagine a construction sign that isn't orange?

142. How easy is it to imagine an orange that isn't orange?

143. How easy is it to imagine Sunkist soda that isn't orange?

144. How easy is it to imagine a road cone that isn't orange? 
145. How easy is it to imagine a tiger that isn't orange?

146. How easy is it to imagine a sun that isn't orange?

147. How easy is it to imagine a pumpkin that isn't orange?

148. How easy is it to imagine a grape that isn't juicy?

149. How easy is it to imagine citrus fruit that isn't juicy?

150. How easy is it to imagine candy that isn't juicy?

151. How easy is it to imagine a melon that isn't juicy?

152. How easy is it to imagine an orange that isn't juicy?

153. How easy is it to imagine a strawberry that isn't juicy?

154. How easy is it to imagine a plum that isn't juicy?

155. How easy is it to imagine a steak that isn't juicy?

156. How easy is it to imagine a pineapple that isn't juicy?

157. How easy is it to imagine an apple that isn't juicy?

158. How easy is it to imagine a peach that isn't juicy?

159. How easy is it to imagine a grapefruit that isn't juicy?

160. How easy is it to imagine a drinking glass that isn't glass?

161. How easy is it to imagine a TV screen that wasn't glass?

162. How easy is it to imagine a window that isn't glass?

163. How easy is it to imagine a mirror that isn't glass?

164. How easy is it to imagine a vase that isn't glass?

165. How easy is it to imagine a bowl that isn't glass?

166. How easy is it to imagine a wine glass that isn't glass?

167. How easy is it to imagine a green house that isn't glass?

168. How easy is it to imagine a bottle that isn't glass?

169. How easy is it to imagine a cup that isn't glass?

170. How easy is it to imagine a light bulb that isn't glass?

171. How easy is it to imagine a windshield that isn't glass?

172.How easy is it to imagine a Tupperware container that doesn't store things?

173. How easy is it to imagine a box that doesn't store things?

174. How easy is it to imagine a bag that doesn't store things?

175.How easy is it to imagine a closet that doesn't store things?

176. How easy is it to imagine a crate that doesn't store things?

177. How easy is it to imagine a dresser that doesn't store things?

178. How easy is it to imagine a cabinet that doesn't store things?

179. How easy is it to imagine an attic that doesn't store things?

180. How easy is it to imagine a garage that doesn't store things?

181. How easy is it to imagine a trunk that doesn't store things? 
182. How easy is it to imagine drawers that don't store things?

183. How easy is it to imagine a suitcase that doesn't store things?

184. How easy is it to imagine a pantry that doesn't store things?

185. How easy is it to imagine a cellar that doesn't store things?

186. How easy is it to imagine a chest that doesn't store things?

187. How easy is it to imagine a locker that doesn't store things?

188. How easy is it to imagine a folder that doesn't store things?

189. How easy is it to imagine a computer file that doesn't store things?

190.How easy is it to imagine a desk that doesn't store things?

191. How easy is it to imagine a shelf that doesn't store things?

192.How easy is it to imagine a refrigerator that doesn't store things?

193. How easy is it to imagine a time capsule that doesn't store things?

194. How easy is it to imagine a safe that doesn't store things?

195.How easy is it to imagine a shed that doesn't store things?

196. How easy is it to imagine a bank that doesn't store things?

197.How easy is it to imagine a fruit that isn't grown on trees?

198. How easy is it to imagine an apple that isn't grown on trees?

199. How easy is it to imagine an orange that isn't grown on trees?

200. How easy is it to imagine a banana that isn't grown on trees?

201.How easy is it to imagine leaves that aren't grown on trees?

202.How easy is it to imagine bark that isn't grown on trees?

203. How easy is it to imagine flowers that aren't grown on trees?

204.How easy is it to imagine plums that aren't grown on trees?

205. How easy is it to imagine pears that aren't grown on trees?

206. How easy is it to imagine lemons that aren't grown on trees?

207.How easy is it to imagine limes that aren't grown on trees?

208. How easy is it to imagine grapefruits that aren't grown on trees?

209. How easy is it to imagine a fungus that isn't grown on trees?

210 . How easy is it to imagine peaches that aren't grown on trees?

211 . How easy is it to imagine branches that aren't grown on trees?

212. How easy is it to imagine cherries that aren't grown on trees?

213. How easy is it to imagine pinecones that aren't grown on trees?

214. How easy is it to imagine nuts that aren't grown on trees?

215. How easy is it to imagine an animal that doesn't have fur?

216. How easy is it to imagine a dog that doesn't have fur?

217. How easy is it to imagine a cat that doesn't have fur?

218 . How easy is it to imagine a bear that doesn't have fur? 
219. How easy is it to imagine a tiger that doesn't have fur?

220. How easy is it to imagine a lion that doesn't have fur?

221 . How easy is it to imagine a raccoon that doesn't have fur?

222. How easy is it to imagine a rabbit that doesn't have fur?

223. How easy is it to imagine a squirrel that doesn't have fur'?

224. How easy is it to imagine a deer that doesn't have fur?

225. How easy is it to imagine a mammal that doesn't have fur?

226. How easy is it to imagine a stuffed toy that doesn't have fur?

227. How easy is it to imagine a gerbil that doesn't have fur?

228. How easy is it to imagine a hamster that doesn't have fur?

229. How easy is it to imagine a sky that isn't blue?

230. How easy is it to imagine an ocean that isn't blue?

231. How easy is it to imagine water that isn't blue?

232. How easy is it to imagine blood that isn't blue?

233. How easy is it to imagine a vein that isn't blue?

234. How easy is it to imagine ink that isn't blue?

235. How easy is it to imagine blueberries that aren't blue?

236. How easy is it to imagine jeans that aren't blue?

237. How easy is it to imagine lakes that aren't blue?

238. How easy is it to imagine a police car that isn't blue?

239. How easy is it to imagine baby boy's clothes that aren't blue?

240 . How easy is it to imagine police uniforms that aren't blue?

241. How easy is it to imagine school uniforms that aren't blue?

242. How easy is it to imagine a building that isn't large?

243. How easy is it to imagine a universe that isn't large?

244. How easy is it to imagine an elephant that isn't large?

245. How easy is it to imagine a bear that isn't large?

246. How easy is it to imagine a wooly mammoth that isn't large?

247. How easy is it to imagine a warehouse that isn't large?

248. How easy is it to imagine an ocean that isn't large?

249. How easy is it to imagine office buildings that aren't large?

250. How easy is it to imagine a sun that isn't large?

251. How easy is it to imagine a moon that isn't large?

252. How easy is it to imagine mountains that aren't large?

253. How easy is it to imagine rainbows that aren't large?

254. How easy is it to imagine seas that aren't large?

255. How easy is it to imagine a forest that isn't large? 
256. How easy is it to imagine continents that aren't large?

257. How easy is it to imagine cities that aren't large?

258. How easy is it to imagine a planet that isn't large?

259. How easy is it to imagine a galaxy that isn't large?

260. How easy is it to imagine a solar system that isn't large?

261. How easy is it to imagine a whale that isn't large?

262. How easy is it to imagine a giraffe that isn't large'?

263. How easy is it to imagine granola that isn't crunchy?

264. How easy is it to imagine candy that isn't crunchy?

265. How easy is it to imagine nuts that aren't crunchy?

266. How easy is it to imagine pretzels that aren't crunchy?

267. How easy is it to imagine crackers that aren't crunchy?

268. How easy is it to imagine chips that aren't crunchy?

269. How easy is it to imagine celery that isn't crunchy?

270 . How easy is it to imagine carrots that aren't crunchy?

271. How easy is it to imagine rice krispies that aren't crunchy?

272. How easy is it to imagine apples that aren't crunchy?

273. How easy is it to imagine a man that doesn't walk?

274. How easy is it to imagine a dog that doesn't walk?

275.How easy is it to imagine a cat that doesn't walk?

276. How easy is it to imagine an animal that doesn't walk?

277. How easy is it to imagine an elephant that doesn't walk?

278. How easy is it to imagine birds that don't walk?

279. How easy is it to imagine insects that don't walk?

280 . How easy is it to imagine a horse that doesn't walk?

281.How easy is it to imagine a cow that doesn't walk?

282.How easy is it to imagine a sheep that doesn't walk?

283. How easy is it to imagine a donkey that doesn't walk?

284. How easy is it to imagine a camel that doesn't walk?

285. How easy is it to imagine a robot that doesn't walk?

286. How easy is it to imagine a bird that can't fly?

287. How easy is it to imagine an airplane that can't fly?

288. How easy is it to imagine a rocket that can't fly?

289. How easy is it to imagine insects that can't fly?

290. How easy is it to imagine kites that can't fly?

291. How easy is it to imagine hang gliders that can't fly?

292. How easy is it to imagine a bee that can't fly? 
293. How easy is it to imagine a butterfly that can't fly?

294. How easy is it to imagine fly saucers that can't fly?

295. How easy is it to imagine a fly that can't fly?

296. How easy is it to imagine a space shuttle that can't fly?

297. How easy is it to imagine a helicopter that can't fly?

298. How easy is it to imagine an eagle that can't fly?

299. How easy is it to imagine a hawk that can't fly?

300 . How easy is it to imagine a sparrow that can't fly?

301 . How easy is it to imagine a robin that can't fly?

302. How easy is it to imagine a jet that can't fly?

303. How easy is it to imagine a Frisbee that can't fly?

304. How easy is it to imagine a cardinal that isn't red?

305. How easy is it to imagine lips that aren't red?

306. How easy is it to imagine strawberries that aren't red?

307. How easy is it to imagine raspberries that aren't red?

308. How easy is it to imagine berries that aren't red?

309. How easy is it to imagine a watermelon that isn't red?

310. How easy is it to imagine an apple that isn't red?

311. How easy is it to imagine a tomato that isn't red?

312. How easy is it to imagine blood that isn't red?

313. How easy is it to imagine roses that aren't red?

314. How easy is it to imagine stop signs that aren't red?

315. How easy is it to imagine cherries that aren't red?

316. How easy is it to imagine hearts that aren't red?

317. How easy is it to imagine fire engines that aren't red?

318. How easy is it to imagine peppers that aren't red?

319. How easy is it to imagine cardinals that aren't red?

320. How easy is it to imagine people that don't swim?

321. How easy is it to imagine a fish that doesn't swim?

322. How easy is it to imagine sharks that don't swim?

323. How easy is it to imagine a turtle that doesn't swim?

324. How easy is it to imagine eels that don't swim?

325. How easy is it to imagine ducks that don't swim?

326. How easy is it to imagine swans that don't swim?

327. How easy is it to imagine a dolphin that doesn't swim?

328. How easy is it to imagine a whale that doesn't swim?

329. How easy is it to imagine a penguin that doesn't swim? 
330. How easy is it to imagine an animal that doesn't have a tail?

331 . How easy is it to imagine a donkey that doesn't have a tail?

332. How easy is it to imagine a horse that doesn't have a tail?

333. How easy is it to imagine a bird that doesn't have a tail?

334. How easy is it to imagine a whale that doesn't have a tail?

335. How easy is it to imagine a cat that doesn't have a tail?

336. How easy is it to imagine an elephant that doesn't have a tail?

337. How easy is it to imagine a rabbit that doesn't have a tail?

338. How easy is it to imagine a deer that doesn't have a tail?

339. How easy is it to imagine a rat that doesn't have a tail?

340. How easy is it to imagine a mouse that doesn't have a tail?

341. How easy is it to imagine a dog that doesn't have a tail?

342. How easy is it to imagine a lizard that doesn't have a tail?

343. How easy is it to imagine a lion that doesn't have a tail?

344. How easy is it to imagine a pig that doesn't have a tail?

345. How easy is it to imagine a cow that doesn't have a tail?

346. How easy is it to imagine a kangaroo that doesn't have a tail?

347. How easy is it to imagine a monkey that doesn't have a tail?

348. How easy is it to imagine a fox that doesn't have a tail?

349. How easy is it to imagine a kite that doesn't have a tail?

350. How easy is it to imagine a human that isn't alive?

351. How easy is it to imagine an animal that isn't alive?

352 . How easy is it to imagine a plant that isn't alive?

353. How easy is it to imagine a frog that isn't alive?

354. How easy is it to imagine a bug that isn't alive?

355. How easy is it to imagine a rabbit that isn't alive?

356. How easy is it to imagine a worm that isn't alive?

357. How easy is it to imagine a bear that isn't alive?

358. How easy is it to imagine a dog that isn't alive?

359. How easy is it to imagine a cat that isn't alive?

360. How easy is it to imagine a fish that isn't alive?

361. How easy is it to imagine a horse that isn't alive?

362. How easy is it to imagine an ant that isn't alive?

363. How easy is it to imagine a fly that isn't alive?

364. How easy is it to imagine grass that isn't alive?

365. How easy is it to imagine a flower that isn't alive?

366. How easy is it to imagine an organism that isn't alive? 
367. How easy is it to imagine bacteria that aren't alive?

368. How easy is it to imagine a mammal that isn't alive?

369. How easy is it to imagine fungus that isn't alive?

370. How easy is it to imagine a bird that isn't alive?

371 . How easy is it to imagine a virus that isn't alive?

372. How easy is it to imagine a food that isn't edible?

373. How easy is it to imagine a candy that isn't edible?

374. How easy is it to imagine a vegetable that isn't edible?

375. How easy is it to imagine a fruit that isn't edible?

376. How easy is it to imagine meat that isn't edible?

377. How easy is it to imagine cereal that isn't edible?

378. How easy is it to imagine a cookie that isn't edible?

379. How easy is it to imagine a chicken that isn't edible?

380 . How easy is it to imagine a hamburger that isn't edible?

381. How easy is it to imagine a banana that isn't edible?

382. How easy is it to imagine an apple that isn't edible?

383. How easy is it to imagine an orange that isn't edible?

384. How easy is it to imagine a carrot that isn't edible?

385. How easy is it to imagine rice that isn't edible?

386. How easy is it to imagine a noodle that isn't edible?

387. How easy is it to imagine an ice cube that isn't edible?

388. How easy is it to imagine a fish that isn't edible?

389. How easy is it to imagine cheese that isn't edible?

390. How easy is it to imagine a pocketbook that isn't leather?

391. How easy is it to imagine a coat that isn't leather?

392. How easy is it to imagine a saddle that isn't leather'?

393. How easy is it to imagine a boot that isn't leather?

394. How easy is it to imagine a watchband that isn't leather?

395. How easy is it to imagine a belt that isn't leather?

\section{Set B}

396. How easy is it to imagine a couch that isn't leather?

397. How easy is it to imagine a car interior that isn't leather?

398. How easy is it to imagine a shoe that isn't leather?

399. How easy is it to imagine a wallet that isn't leather?

400. How easy is it to imagine a briefcase that isn't leather?

401. How easy is it to imagine a cup that doesn't have a handle? 
402. How easy is it to imagine a mug that doesn't have a handle?

403. How easy is it to imagine a pot that doesn't have a handle?

404. How easy is it to imagine a pocketbook that doesn't have a handle?

405. How easy is it to imagine a basket that doesn't have a handle?

406. How easy is it to imagine a car door that doesn't have a handle?

407. How easy is it to imagine a lunch box that doesn't have a handle?

408. How easy is it to imagine a toolbox that doesn't have a handle?

409. How easy is it to imagine a briefcase that doesn't have a handle?

410 . How easy is it to imagine an umbrella that doesn't have a handle?

411 . How easy is it to imagine a shopping bag that doesn't have a handle?

412. How easy is it to imagine a pan that doesn't have a handle?

413. How easy is it to imagine glue that isn't sticky?

414. How easy is it to imagine tape that isn't sticky?

415. How easy is it to imagine bubble gum that isn't sticky?

416. How easy is it to imagine tar that isn't sticky?

417. How easy is it to imagine honey that isn't sticky?

418. How easy is it to imagine syrup that isn't sticky?

419. How easy is it to imagine molasses that isn't sticky?

420. How easy is it to imagine candy that isn't sticky?

421. How easy is it to imagine a lollipop that isn't sticky?

422. How easy is it to imagine a scotch tape that isn't sticky?

423. How easy is it to imagine a packing tape that isn't sticky?

424. How easy is it to imagine adhesive that isn't sticky?

425. How easy is it to imagine a band-aid that isn't sticky?

426. How easy is it to imagine a rubber cement that isn't sticky?

427. How easy is it to imagine a sticker that isn't sticky?

428. How easy is it to imagine jelly that isn't sticky?

429. How easy is it to imagine jam that isn't sticky?

430. How easy is it to imagine peanut butter that isn't sticky?

431. How easy is it to imagine garbage that isn't smelly?

432. How easy is it to imagine manure that isn't smelly?

433. How easy is it to imagine a skunk that isn't smelly?

434. How easy is it to imagine a foot that isn't smelly?

435. How easy is it to imagine ammonia that isn't smelly?

436. How easy is it to imagine bleach that isn't smelly?

437. How easy is it to imagine fish that isn't smelly?

438. How easy is it to imagine a rotten egg that isn't smelly? 
439. How easy is it to imagine a gym sock that isn't smelly?

440. How easy is it to imagine a public bathroom that isn't smelly?

441. How easy is it to imagine spoiled milk that isn't smelly"?

442. How easy is it to imagine garlic that isn't smelly?

443. How easy is it to imagine an onion that isn't smelly?

444. How easy is it to imagine sulfur that isn't smelly?

445. How easy is it to imagine a body order that isn't smelly?

446. How easy is it to imagine a halitosis that isn't smelly?

447. How easy is it to imagine water that isn't liquid?

448. How easy is it to imagine juice that isn't liquid?

449. How easy is it to imagine soda that isn't liquid?

450. How easy is it to imagine beer that isn't liquid?

451. How easy is it to imagine wine that isn't liquid?

452. How easy is it to imagine alcohol that isn't liquid?

453. How easy is it to imagine blood that isn't liquid?

454. How easy is it to imagine rain that isn't liquid?

455. How easy is it to imagine milk that isn't liquid?

456. How easy is it to imagine oil that isn't liquid?

457. How easy is it to imagine a tear that isn't liquid?

458. How easy is it to imagine a soup that isn't liquid?

459. How easy is it to imagine a pool that isn't liquid?

460.How easy is it to imagine an ocean that isn't liquid?

461. How easy is it to imagine a sun that isn't hot?

462. How easy is it to imagine a fire that isn't hot?

463. How easy is it to imagine an oven that isn't hot?

464. How easy is it to imagine a stovetop that isn't hot?

465. How easy is it to imagine a candle that isn't hot?

466. How easy is it to imagine a fireplace that isn't hot?

467. How easy is it to imagine a heater that isn't hot?

468. How easy is it to imagine a summer that isn't hot?

469. How easy is it to imagine cayenne pepper that isn't hot?

470. How easy is it to imagine coffee that isn't hot?

471. How easy is it to imagine tea that isn't hot?

472. How easy is it to imagine cinnamon that isn't hot?

473. How easy is it to imagine a jalapeno that isn't hot?

474. How easy is it to imagine a chipolte pepper that isn't hot?

475. How easy is it to imagine salsa that isn't hot? 
476. How easy is it to imagine a toaster that isn't hot? 477. How easy is it to imagine boiling water that isn't hot? 478. How easy is it to imagine steam that isn't hot? 479. How easy is it to imagine a chili pepper that isn't hot? 480. How easy is it to imagine a candy that isn't sweet? 481. How easy is it to imagine a fruit that isn't sweet? 482. How easy is it to imagine a cake that isn't sweet? 483. How easy is it to imagine a cookie that isn't sweet? 484. How easy is it to imagine a pie that isn't sweet? 485. How easy is it to imagine ice cream that isn't sweet? 486. How easy is it to imagine a Popsicle that isn't sweet? 487. How easy is it to imagine juice that isn't sweet? 488. How easy is it to imagine a soda that isn't sweet? 489. How easy is it to imagine honey that isn't sweet? 490. How easy is it to imagine chocolate that isn't sweet? 491. How easy is it to imagine an apple that isn't sweet? 492. How easy is it to imagine caramel that isn't sweet? 493. How easy is it to imagine a cherry that isn't sweet? 494. How easy is it to imagine a pastry that isn't sweet? 495. How easy is it to imagine a cotton candy that isn't sweet? 496. How easy is it to imagine lemonade that isn't sweet? 497. How easy is it to imagine a lollipop that isn't sweet? 498. How easy is it to imagine a gumdrop that isn't sweet? 499. How easy is it to imagine a dessert that isn't sweet? 500 . How easy is it to imagine a knife that isn't sharp? 501. How easy is it to imagine a sword that isn't sharp? 502. How easy is it to imagine a thumbtack that isn't sharp? 503. How easy is it to imagine a razor that isn't sharp? 504. How easy is it to imagine scissors that aren't sharp? 505. How easy is it to imagine a blade that isn't sharp? 506. How easy is it to imagine a needle that isn't sharp? 507. How easy is it to imagine a worm that isn't slimy? 508. How easy is it to imagine mucus that isn't slimy? 509. How easy is it to imagine a snail that isn't slimy? 510. How easy is it to imagine a leech that isn't slimy? 511. How easy is it to imagine seaweed that isn't slimy? 512.How easy is it to imagine a jellyfish that isn't slimy? 
513. How easy is it to imagine an oyster that isn't slimy?

514. How easy is it to imagine a lotion that isn't slimy?

515. How easy is it to imagine oil that isn't slimy?

516. How easy is it to imagine a slug that isn't slimy?

517. How easy is it to imagine an airplane that isn't noisy?

518. How easy is it to imagine traffic that isn't noisy?

519. How easy is it to imagine a drum that isn't noisy?

520. How easy is it to imagine a siren that isn't noisy?

521 . How easy is it to imagine a horn that isn't noisy?

522. How easy is it to imagine a cymbal that isn't noisy?

523. How easy is it to imagine a party that isn't noisy?

524. How easy is it to imagine a concert that isn't noisy?

525. How easy is it to imagine a club that isn't noisy?

526. How easy is it to imagine a drill that isn't noisy?

527. How easy is it to imagine a jackhammer that isn't noisy?

528. How easy is it to imagine a crying baby that isn't noisy?

529. How easy is it to imagine construction that isn't noisy?

530 . How easy is it to imagine fireworks that aren't noisy?

531. How easy is it to imagine a lemon that isn't sour?

532. How easy is it to imagine a lime that isn't sour?

533. How easy is it to imagine vinegar that isn't sour?

534. How easy is it to imagine bad milk that isn't sour?

535. How easy is it to imagine a green apple that isn't sour?

536. How easy is it to imagine a rabbit that doesn't hop?

537. How easy is it to imagine a kangaroo that doesn't hop?

538. How easy is it to imagine a grasshopper that doesn't hop?

539. How easy is it to imagine a frog that doesn't hop?

540. How easy is it to imagine a toad that doesn't hop?

541. How easy is it to imagine a cricket that doesn't hop?

542. How easy is it to imagine a Tigger that doesn't hop?

543.How easy is it to imagine a flea that doesn't hop?

544. How easy is it to imagine a peanut that doesn't have a shell?

545. How easy is it to imagine a walnut that doesn't have a shell?

546. How easy is it to imagine a pecan that doesn't have a shell?

547. How easy is it to imagine a chestnut that doesn't have a shell?

548. How easy is it to imagine a mollusk that doesn't have a shell?

549. How easy is it to imagine a clam that doesn't have a shell? 
550. How easy is it to imagine a snail that doesn't have a shell?

551 . How easy is it to imagine a crab that doesn't have a shell?

552 . How easy is it to imagine a shrimp that doesn't have a shell?

553. How easy is it to imagine a scallop that doesn't have a shell?

554. How easy is it to imagine a lobster that doesn't have a shell?

555 . How easy is it to imagine a seed that doesn't have a shell?

556. How easy is it to imagine a cashew that doesn't have a shell?

557. How easy is it to imagine a pistachio that doesn't have a shell?

558. How easy is it to imagine a turtle that doesn't have a shell?

559. How easy is it to imagine an oyster that doesn't have a shell?

560 . How easy is it to imagine a hermit crab that doesn't have a shell?

561. How easy is it to imagine an M\&M that doesn't have a shell?

562 . How easy is it to imagine a sun that isn't yellow?

563. How easy is it to imagine a lemon that isn't yellow?

564. How easy is it to imagine a highlighter that isn't yellow?

565. How easy is it to imagine lemonade that isn't yellow?

566. How easy is it to imagine a banana that isn't yellow?

567. How easy is it to imagine a tennis ball that isn't yellow?

568. How easy is it to imagine corn that isn't yellow?

569. How easy is it to imagine a yield sign that isn't yellow?

570. How easy is it to imagine a school bus that isn't yellow?

571. How easy is it to imagine a bee that isn't yellow?

572.How easy is it to imagine cheese that isn't yellow?

573. How easy is it to imagine a taxi that isn't yellow?

574. How easy is it to imagine a big bird that isn't yellow?

575.How easy is it to imagine a legal pad that isn't yellow?

576. How easy is it to imagine a pillow that isn't soft?

577. How easy is it to imagine cotton that isn't soft?

578. How easy is it to imagine skin that isn't soft?

579. How easy is it to imagine fur that isn't soft?

580 . How easy is it to imagine a kitten that isn't soft?

581 . How easy is it to imagine a puppy that isn't soft?

582. How easy is it to imagine silk that isn't soft?

583. How easy is it to imagine cashmere that isn't soft?

584. How easy is it to imagine a rabbit that isn't soft?

585. How easy is it to imagine a baby that isn't soft?

586. How easy is it to imagine a rose petal that isn't soft? 
587. How easy is it to imagine satin that isn't soft?

588. How easy is it to imagine velvet that isn't soft?

589. How easy is it to imagine a feather that isn't soft?

590. How easy is it to imagine a fruit that doesn't have seeds?

591. How easy is it to imagine a vegetable that doesn't have seeds?

592. How easy is it to imagine a tree that doesn't have seeds?

593. How easy is it to imagine an apple that doesn't have seeds?

594 . How easy is it to imagine a grape that doesn't have seeds?

595.How easy is it to imagine a tomato that doesn't have seeds?

596. How easy is it to imagine a pumpkin that doesn't have seeds?

597. How easy is it to imagine a sunflower that doesn't have seeds?

598. How easy is it to imagine an orange that doesn't have seeds?

599. How easy is it to imagine a grapefruit that doesn't have seeds?

600 .How easy is it to imagine a watermelon that doesn't have seeds?

601 . How easy is it to imagine a cucumber that doesn't have seeds?

602 . How easy is it to imagine snow that isn't cold?

603. How easy is it to imagine a freezer that isn't cold?

604 . How easy is it to imagine a cellar that isn't cold?

605. How easy is it to imagine Antarctica that isn't cold?

606. How easy is it to imagine ice cream that isn't cold?

607. How easy is it to imagine an ice cube that isn't cold?

608. How easy is it to imagine a Popsicle that isn't cold?

609 . How easy is it to imagine a winter that isn't cold?

610 . How easy is it to imagine a blizzard that isn't cold?

611 . How easy is it to imagine a refrigerator that isn't cold?

612.How easy is it to imagine air-conditioning that isn't cold?

613. How easy is it to imagine a swimming-pool that isn't cold?

614. How easy is it to imagine a glacier that isn't cold?

615 . How easy is it to imagine a frozen-food that isn't cold?

616. How easy is it to imagine an icicle that isn't cold?

617. How easy is it to imagine an animal that doesn't have skin?

618. How easy is it to imagine a person that doesn't have skin?

619. How easy is it to imagine a grape that doesn't have skin?

620 .How easy is it to imagine chicken that doesn't have skin?

621 . How easy is it to imagine a cow that doesn't have skin?

622.How easy is it to imagine a dog that doesn't have skin?

623. How easy is it to imagine a rabbit that doesn't have skin? 
624. How easy is it to imagine a bird that doesn't have skin?

625 . How easy is it to imagine a monkey that doesn't have skin?

626. How easy is it to imagine an onion that doesn't have skin?

627 . How easy is it to imagine garlic that doesn't have skin?

628. How easy is it to imagine an apple that doesn't have skin?

629. How easy is it to imagine a tomato that doesn't have skin?

630. How easy is it to imagine a mammal that doesn't have skin?

631 . How easy is it to imagine a reptile that doesn't have skin?

632. How easy is it to imagine a snake that doesn't have skin?

633. How easy is it to imagine an alligator that doesn't have skin?

634. How easy is it to imagine a fruit that doesn't have skin?

635. How easy is it to imagine a vegetable that doesn't have skin?

636. How easy is it to imagine a mirror that isn't reflective?

637. How easy is it to imagine glass that isn't reflective?

638. How easy is it to imagine aluminum that isn't reflective?

639. How easy is it to imagine chrome that isn't reflective?

640.How easy is it to imagine steel that isn't reflective?

641 . How easy is it to imagine a potato chip that isn't salty?

642 .How easy is it to imagine a pretzel that isn't salty?

643. How easy is it to imagine a nacho chip that isn't salty?

644. How easy is it to imagine soy sauce that isn't salty?

645. How easy is it to imagine seawater that isn't salty?

646. How easy is it to imagine a margarita that isn't salty?

647 . How easy is it to imagine a tear that isn't salty?

648. How easy is it to imagine a food that isn't salty?

649. How easy is it to imagine sweat that isn't salty?

650 . How easy is it to imagine popcorn that isn't salty?

651 . How easy is it to imagine a peanut that isn't salty?

652. How easy is it to imagine a nut that isn't salty?

653. How easy is it to imagine a cracker that isn't salty?

654 . How easy is it to imagine a french fry that isn't salty?

655. How easy is it to imagine a saltine that isn't salty?

656. How easy is it to imagine a flower that doesn't have leaves?

657.How easy is it to imagine a bush that doesn't have leaves?

658. How easy is it to imagine a vine that doesn't have leaves?

659. How easy is it to imagine a plant that doesn't have leaves?

660 . How easy is it to imagine a forest that doesn't have leaves? 
661. How easy is it to imagine an oak that doesn't have leaves?

662. How easy is it to imagine an herb that doesn't have leaves?

663. How easy is it to imagine a weed that doesn't have leaves?

664. How easy is it to imagine lettuce that doesn't have leaves?

665.How easy is it to imagine spinach that doesn't have leaves?

666. How easy is it to imagine a bear that isn't ferocious?

667. How easy is it to imagine a lion that isn't ferocious?

668. How easy is it to imagine a tiger that isn't ferocious'?

669.How easy is it to imagine an alligator that isn't ferocious?

670.How easy is it to imagine a crocodile that isn't ferocious?

671. How easy is it to imagine a wild animal that isn't ferocious?

672. How easy is it to imagine glass that isn't transparent?

673. How easy is it to imagine Plexiglas that isn't transparent?

674. How easy is it to imagine plastic that isn't transparent?

675. How easy is it to imagine a soda bottle that isn't transparent?

676. How easy is it to imagine air that isn't transparent?

677. How easy is it to imagine water that isn't transparent?

678. How easy is it to imagine oil that isn't transparent?

679. How easy is it to imagine a tear that isn't transparent?

680. How easy is it to imagine ice that isn't transparent?

681 . How easy is it to imagine a yield sign that isn't triangular?

682. How easy is it to imagine a piece of pie that isn't triangular?

683. How easy is it to imagine a sandwich that isn't triangular?

684. How easy is it to imagine a slice of pizza that isn't triangular?

685 . How easy is it to imagine an airplane that isn't dangerous?

686. How easy is it to imagine a wet road that isn't dangerous?

687. How easy is it to imagine a fire that isn't dangerous?

688. How easy is it to imagine an earthquake that isn't dangerous?

689. How easy is it to imagine a hurricane that isn't dangerous?

690.How easy is it to imagine a tornado that isn't dangerous?

691.How easy is it to imagine a robber that isn't dangerous?

692.How easy is it to imagine a murderer that isn't dangerous?

693.How easy is it to imagine a snake that isn't dangerous?

694. How easy is it to imagine a cancer that isn't dangerous?

695. How easy is it to imagine a stroke that isn't dangerous?

696. How easy is it to imagine a wild animal that isn't dangerous?

697.How easy is it to imagine a war that isn't dangerous? 
698. How easy is it to imagine a lion that isn't dangerous? 699. How easy is it to imagine a gun that isn't dangerous? 700. How easy is it to imagine a knife that isn't dangerous? 701. How easy is it to imagine drag racing that isn't dangerous?

702. How easy is it to imagine scuba diving that isn't dangerous'?

703. How easy is it to imagine a wheel that doesn't roll?

704. How easy is it to imagine a ball that doesn't roll? 705. How easy is it to imagine a log that doesn't roll? 706. How easy is it to imagine a tire that doesn't roll? 707. How easy is it to imagine a snowball that doesn't roll? 708. How easy is it to imagine a penny that doesn't roll? 709. How easy is it to imagire a cat that isn't furry? 710. How easy is it to imagine a dog that isn't furry? 711. How easy is it to imagine a hamster that isn't furry? 712. How easy is it to imagine a gerbil that isn't furry? 713. How easy is it to imagine a squirrel that isn't furry? 714. How easy is it to imagine a rabbit that isn't furry? 715. How easy is it to imagine an animal that isn't furry? 716. How easy is it to imagine a tree that isn't tall?

717. How easy is it to imagine a building that isn't tall?

718. How easy is it to imagine a ladder that isn't tall?

719. How easy is it to imagine a flagpole that isn't tall?

720. How easy is it to imagine a tower that isn't tall?

721. How easy is it to imagine a streetlight that isn't tall?

722. How easy is it to imagine a basketball player that isn't tall?

723. How easy is it to imagine a telephone pole that isn't tall?

724. How easy is it to imagine a mountain that isn't tall?

725. How easy is it to imagine leaves that aren't green?

726. How easy is it to imagine grass that isn't green?

727. How easy is it to imagine a tree that isn't green?

728. How easy is it to imagine a vegetable that isn't green?

729. How easy is it to imagine broccoli that isn't green?

730. How easy is it to imagine a pea that isn't green?

731. How easy is it to imagine money that isn't green?

732. How easy is it to imagine a plant that isn't green?

733. How easy is it to imagine an apple that isn't green?

734. How easy is it to imagine a traffic-light that isn't green? 
735. How easy is it to imagine a frog that isn't green?

736. How easy is it to imagine a lizard that isn't green?

737. How easy is it to imagine moss that isn't green?

738. How easy is it to imagine a pear that isn't green?

739. How easy is it to imagine an herb that isn't green?

740. How easy is it to imagine artificial turf that isn't green?

741. How easy is it to imagine an emerald that isn't green?

742. How easy is it to imagine a shamrock that isn't green?

743. How easy is it to imagine Mexican food that isn't spicy?

744. How easy is it to imagine Indian food that isn't spicy?

745. How easy is it to imagine a buffalo wing that isn't spicy?

746. How easy is it to imagine Cajun food that isn't spicy?

747. How easy is it to imagine construction work that isn't loud?

748. How easy is it to imagine yelling that isn't loud?

749. How easy is it to imagine screaming that isn't loud?

750. How easy is it to imagine crying that isn't loud?

751. How easy is it to imagine a horn that isn't loud?

752. How easy is it to imagine traffic that isn't loud?

753. How easy is it to imagine an earthquake that isn't loud?

754. How easy is it to imagine an accident that isn't loud?

755. How easy $s$ it to imagine a motorcycle that isn't loud?

756. How easy is it to imagine a jackhammer that isn't loud?

757. How easy is it to imagine an airplane that isn't loud?

758. How easy is it to imagine a concert that isn't loud?

759. How easy is it to imagine an avalanche that isn't loud?

760. How easy is it to imagine an explosion that isn't loud?

761. How easy is it to imagine gun-fire that isn't loud?

762. How easy is it to imagine a siren that isn't loud?

763.How easy is it to imagine a firework that isn't loud?

764. How easy is it to imagine a baby crying that isn't loud?

765. How easy is it to imagine stomping that isn't loud?

766. How easy is it to imagine thunder that isn't loud?

767. How easy is it to imagine a rocket that isn't loud?

768. How easy is it to imagine a first class ticket that isn't extravagant?

769. How easy is it to imagine jewelry that isn't extravagant?

770.How easy is it to imagine a diamond that isn't extravagant?

771. How easy is it to imagine a wedding that isn't extravagant? 
772. How easy is it to imagine a Broadway play that isn't extravagant?

773. How easy is it to imagine a palace that isn't extravagant?

774. How easy is it to imagine a yacht that isn't extravagant?

775. How easy is it to imagine a ball gown that isn't extravagant?

776. How easy is it to imagine a wedding cake that isn't extravagant?

777. How easy is it to imagine a fancy wine that isn't extravagant?

778. How easy is it to imagine a Dalmatian that isn't spotted?

779. How easy is it to imagine a cow that isn't spotted?

780. How easy is it to imagine a cheetah that isn't spotted?

781. How easy is it to imagine a leopard that isn't spotted?

782. How easy is it to imagine a winter that isn't freezing?

783. How easy is it to imagine a freezer that isn't freezing?

784. How easy is it to imagine air conditioning that isn't freezing?

785. How easy is it to imagine ice that isn't freezing?

786. How easy is it to imagine snow that isn't freezing?

787. How easy is it to imagine ice cream that isn't freezing?

788. How easy is it to imagine a north pole that isn't freezing?

789. How easy is it to imagine a Popsicle that isn't freezing?

790. How easy is it to imagine sleet that isn't freezing? 


\section{APPENDIX B \\ COMPLETE SET OF SURPRISE QUESTIONS-EXPERIMENT I}

\section{Set A}

1. How surprised would you be to find a snake that isn't scary"?

2. How surprised would you be to find a monster that isn't scary'?

3. How surprised would you be to find a vampire that isn't seary?

4. How surprised would you be to lind a bat that isn't scary?

5. How surprised would you be to find a spider that isn't scary?

6. How surprised would you be to find a haunted house that isn't seary?

7. How surprised would you be to find a ghost that isn't scary?

8. How surprised would you be to find a witch that isn't scary?

9. How surprised would you be to find a nightmare that isn't seary?

10. How surprised would you be to find a car that isn't fast?

11. How surprised would you be to find a cliectah that isn't fast?

12. How suiprised would you be to find a plane that isn't fast?

13. How surprised would you be to find a millisceond that isn't fast?

14. How surprised would you be to find a leopard that isn't fast?

15. How surprised would you be to find a roadrunner that isn't fast?

16. How surprised would you be to find a sports car that isn't fast?

17. How surprised would you be to find a racear that isn't fast?

18. How surprised would you be to find track athletes that aren't fast?

19. How surprised would you be to find a horse race that isn't fast?

20. How surprised would you be to find a Concorde that isn't fast?

21. How surprised would you be to find a train that isn't fast?

22. How surprised would you be to find a speedboat that isn't fast?

23. How surprised would you be to find light that isn't fast?

24. Hlow surprised would you be to find cyanide that isn't poisonous?

25. How surprised would you be to find lead that isn't poisonous'?

26. How surprised would you be to find elemicals that aren't poisonous?

27. How surprised would you be to find venom that isn't poisonous?

28. How surprised would you be to find stryehnine that isn't poisonous?

29. How surprised would you be to find ammonia that isn't poisonous'?

30. How surprised would you be to find bleach that isn't poisonous?

31. How surprised would you be to find roach killer that isn't poisonous?

32. How surprised would you be to find a weed killer that isn't poisonous? 
33. How surprised would you be to find a spider that isn't poisonous'?

34. How surprised would you be to find a gas that isn't poisonous?

35. How surprised would you be to find a household cleaner that isn't poisonous'?

36. How surprised would you be to find a berry that isn't poisonous?

37. How surprised would you be to find hemlock that isn't poisonous?

38. How surprised would you be to find a clock face that isn't round?

39. How surprised would you be to find a traffic circle that isn't round?

40. How surprised would you be to find a ring that isn't round?

41. How surprised would you be to find a wheel that isn't round?

42. How surprised would you be to find glasses that aren't round'?

43. How surprised would you be to find a dome that isn't round?

44. How surprised would you be to find a planet that isn't round?

45. How surprised would you be to find a moon that isn't round?

46. How surprised would you be to find a CD that isn't round?

47. How surprised would you be to find a record that isn't round?

48. How surprised would you be to find eyes that aren't round?

49. How surprised would you be to find a ball that isn't round?

50. How surprised would you be to find a lollipop that isn't round?

51. How surprised would you be to find an orange that isn't round?

52. How surprised would you be to find an earth that isn't round?

53. How surprised would you be to find a sun that isn't round?

54. How surprised would you be to find a cookie that isn't round?

55. How surprised would you be to find a glass that isn't clear?

56. How surprised would you be to find water that isn't clear?

57. How surprised would you be to find tears that aren't clear?

58. How surprised would you be to find plastic that isn't clear?

59. How surprised would you be to find air that isn't clear?

60. How surprised would you be to find cellophane that isn't clear?

61. How surprised would you be to find Plexiglas that isn't clear?

62. How surprised would you be to find a window that isn't clear?

63. How surprised would you be to find eyeglasses that aren't clear?

64. How surprised would you be to find saran wrap that isn't clear?

65 . How surprised would you be to find broth that isn't clear?

66. How surprised would you be to find contacts that aren't clear?

67. How surprised would you be to find bread that isn't grainy?

68. How surprised would you be to find wood that isn't grainy?

69. How surprised would you be to find cereal that isn't grainy? 
70. How surprised would you be to find sand that isn't grainy?

71. How surprised would you be to find dirt that isn't grainy"?

72. How surprised would you be to find grout that isn't grainy?

73. How surprised would you be to find sandpaper that isn't grainy?

74. How surprised would you be to find sugar that isn't grainy?

75. How surprised would you be to find a desk that isn't wooden'?

76. How surprised would you be to find a chair that isn't wooden?

77. How surprised would you be to find a bed that isn't wooden?

78. How surprised would you be to find a house that isn't wooden?

79. How surprised would you be to find shutters that aren't wooden'?

80. How surprised would you be to find pirate legs that aren't wooden?

81. How surprised would you be to find a door that isn't wooden'?

82. How surprised would you be to find birdhouses that aren't wooden?

83. How surprised would you be to find fence posts that aren't wooden?

84. How surprised would you be to find dressers that aren't wooden?

85. How surprised would you be to find a bench that isn't wooden?

86. How surprised would you be to find a crate that isn't wooden?

87. How surprised would you be to find a tree that isn't wooden?

88. How surprised would you be to find a baseball bat that isn't wooden'?

89. How surprised would you be to find a puppet that isn't wooden?

90. How surprised would you be to find blocks that aren't wooden?

91. How surprised would you be to find floors that aren't wooden?

92. How surprised would you be to find cabinets that aren't wooden?

93. How surprised would you be to find an oar that isn't wooden?

94. How surprised would you be to find a log cabin that isn't wooden?

95. How surprised would you be to find pencils that aren't wooden?

96. How surprised would you be to find a raft that isn't wooden?

97. How surprised would you be to find a car that doesn't have wheels?

98. How surprised would you be to find a truck that doesn't have wheels?

99. How surprised would you be to find a bicycle that doesn't have wheels?

100. How surprised would you be to find a tricycle that doesn't have wheels?

101. How surprised would you be to find an airplane that doesn't have wheels?

102. How surprised would you be to find a van that doesn't have wheels?

103. How surprised would you be to find a skateboard that doesn't have wheels?

104. How surprised would you be to find a scooter that doesn't have wheels?

105. How surprised would you be to find a motorcycle that doesn't have wheels?

106. How surprised would you be to find a wheelchair that doesn't have wheels? 
107. How surprised would you be to find an office chair that doesn't have whecls?

108. How surprised would you be to find a wagon that doesn't have wheels?

109. How surprised would you be to find a wheelbarrow that doesn't have wheels'?

110.How surprised would you be to find a train that doesn't have wheels?

111. How surprised would you be to find a unicycle that doesn't have wheels?

112.How surprised would you be to find a baby carriage that doesn't have wheels?

113. How surprised would you be to find a roller coaster that doesn't have wheels?

114. How surprised would you be to find a go-cart that doesn't have wheels?

115. How surprised would you be to find a bus that doesn't have wheels?

116. How surprised would you be to find a matchbox car that doesn't have wheels?

117. How surprised would you be to find roller skates that don't have wheels?

118. How surprised would you be to find roller blades that don't have wheels?

119. How surprised would you be to find toys that don't have wheels?

120. How surprised would you be to find a tire that isn't rubber?

121. How surprised would you be to find a ball that isn't rubber?

122. How surprised would you be to find a doll that isn't rubber?

123. How surprised would you be to find a garden hose that isn't rubber?

124. How surprised would you be to find latex gloves that aren't rubber?

125.How surprised would you be to find rain boots that aren't rubber?

126. How surprised would you be to find an eraser that isn't rubber?

127. How surprised would you be to find dish gloves that aren't rubber?

128. How surprised would you be to find Tupperware that isn't plastic?

129. How surprised would you be to find a CD case that isn't plastic?

130. How surprised would you be to find a cup that isn't plastic?

131. How surprised would you be to find straws that aren't plastic?

132. How surprised would you be to find shampoo bottles that aren't plastic?

133. How surprised would you be to find soda bottles that aren't plastic?

134. How surprised would you be to find a pen that isn't plastic?

135. How surprised would you be to find shopping bags that aren't plastic?

136. How surprised would you be to find cassette tapes that aren't plastic?

137.How surprised would you be to find a milk jug that isn't plastic?

138. How surprised would you be to find a bottle that isn't plastic?

139. How surprised would you be to find an apricot that isn't orange?

140. How surprised would you be to find a carrot that isn't orange?

141. How surprised would you be to find a construction sign that isn't orange?

142. How surprised would you be to find an orange that isn't orange?

143. How surprised would you be to find Sunkist soda that isn't orange? 
144. How surprised would you be to find a road cone that isn't orange?

145. How surprised would you be to find a tiger that isn't orange?

146. How surprised would you be to find a sun that isn't orange?

147. How surprised would you be to find a pumpkin that isn't orange?

148. How surprised would you be to find a grape that isn't juicy?

149. How surprised would you be to find citrus fruit that isn't juicy?

150. How surprised would you be to find candy that isn't juicy'?

151. How surprised would you be to find a melon that isn't juicy?

152. How surprised would you be to find an orange that isn't juicy?

153. How surprised would you be to find a strawberry that isn't juicy?

154. How surprised would you be to find a plum that isn't juicy?

155. How surprised would you be to find a steak that isn't juicy?

156. How surprised would you be to find a pineapple that isn't juicy?

157. How surprised would you be to find an apple that isn't juicy?

158. How surprised would you be to find a peach that isn't juicy?

159. How surprised would you be to find a grapefruit that isn't juicy?

160. How surprised would you be to find a drinking glass that isn't glass?

161. How surprised would you be to find a TV screen that wasn't glass?

162. How surprised would you be to find a window that isn't glass?

163.How surprised would you be to find a mirror that isn't glass?

164.How surprised would you be to find a vase that isn't glass?

165. How surprised would you be to find a bowl that isn't glass?

166.How surprised would you be to find a wine glass that isn't glass?

167.How surprised would you be to find a green house that isn't glass?

168. How surprised would you be to find a bottle that isn't glass?

169. How surprised would you be to find a cup that isn't glass?

170.How surprised would you be to find a light bulb that isn't glass?

171. How surprised would you be to find a windshield that isn't glass?

172. How surprised would you be to find Tupperware container that doesn't store things?

173. How surprised would you be to find a box that doesn't store things?

174. How surprised would you be to find a bag that doesn't store things?

175. How surprised would you be to find a closet that doesn't store things?

176.How surprised would you be to find a crate that doesn't store things?

177.How surprised would you be to find a dresser that doesn't store things?

178. How surprised would you be to find a cabinet that doesn't store things?

179. How surprised would you be to find an attic that doesn't store things?

180.How surprised would you be to find a garage that doesn't store things? 
181. How surprised would you be to find a trunk that doesn't store things'? 182.How surprised would you be to find drawers that don't store things?

183. How surprised would you be to find a suitcase that doesn't store things? 184. How surprised would you be to find a pantry that doesn't store things'? 185. How surprised would you be to find a cellar that doesn't store things? 186. How surprised would you be to find a chest that doesn't store things? 187. How surprised would you be to find a locker that doesn't store things? 188. How surprised would you be to find a folder that doesn't store things? 189. How surprised would you be to find a computer file that doesn't store things? 190.How surprised would you be to find a desk that doesn't store things? 191. How surprised would you be to find a shelf that doesn't store things? 192.How surprised would you be to find a refrigerator that doesn't store things? 193. How surprised would you be to find a time capsule that doesn't store things? 194.How surprised would you be to find a safe that doesn't store things? 195.How surprised would you be to find a shed that doesn't store things? 196. How surprised would you be to find a bank that doesn't store things? 197.How surprised would you be to find a fruit that doesn't grow on trees? 198. How surprised would you be to find apples that don't grow on trees? 199. How surprised would you be to find oranges that don't grow on trees? 200.How surprised would you be to find bananas that don't grow on trees? 201.How surprised would you be to find leaves that aren't grow on trees? 202. How surprised would you be to find bark that isn't growing on trees? 203.How surprised would you be to find flowers that don't grow on trees? 204.How surprised would you be to find plums that don't grow on trees? 205.How surprised would you be to find pears that don't grow on trees? 206. How surprised would you be to find lemons that don't grow on trees? 207. How surprised would you be to find limes that don't grow on trees? 208. How surprised would you be to find grapefruits that don't grow on trees? 209. How surprised would you be to find fungus that doesn't grow on trees? 210 .How surprised would you be to find peaches that don't grow on trees? 211.How surprised would you be to find branches that don't grow on trees? 212.How surprised would you be to find cherries that don't grow on trees? 213.How surprised would you be to find pinecones that don't grow on trees? 214. How surprised would you be to find nuts that don't grow on trees? 215. How surprised would you be to find an animal that doesn't have fur? 216 . How surprised would you be to find a dog that doesn't have fur? 217. How surprised would you be to find a cat that doesn't have fur? 
218 . How surprised would you be to find a bear that doesn't have fur'? 219. How surprised would you be to find a tiger that doesn't have fur? 220. How surprised would you be to find a lion that doesn't have fur? 221 . How surprised would you be to find a raccoon that doesn't have fur? 222. How surprised would you be to find a rabbit that doesn't have fur? 223. How surprised would you be to find a squirrel that doesn't have fur? 224. How surprised would you be to find a deer that doesn't have fur? 225. How surprised would you be to find a mammal that doesn't have fur? 226. How surprised would you be to find a stuffed toy that doesn't have fur? 227. How surprised would you be to find a gerbil that doesn't have fur? 228 . How surprised would you be to find a hamster that doesn't have fur? 229. How surprised would you be to find a sky that isn't blue? 230. How surprised would you be to find an ocean that isn't blue? 231. How surprised would you be to find water that isn't blue? 232. How surprised would you be to find blood that isn't blue? 233. How surprised would you be to find a vein that isn't blue? 234. How surprised would you be to find ink that isn't blue? 235. How surprised would you be to find blueberries that aren't blue? 236. How surprised would you be to find jeans that aren't blue? 237. How surprised would you be to find lakes that aren't blue? 238. How surprised would you be to find a police car that isn't blue? 239. How surprised would you be to find baby boy's clothes that aren't blue? 240 .How surprised would you be to find police uniforms that aren't blue? 241.How surprised would you be to find school uniforms that aren't blue?

242.How surprised would you be to find a building that isn't large?

243. How surprised would you be to find a universe that isn't large? 244. How surprised would you be to find an elephant that isn't large? 245. How surprised would you be to find a bear that isn't large?

246. How surprised would you be to find a wooly mammoth that isn't large?

247. How surprised would you be to find a warehouse that isn't large? 248. How surprised would you be to find an ocean that isn't large? 249. How surprised would you be to find office buildings that aren't large? 250. How surprised would you be to find a sun that isn't large? 251. How surprised would you be to find a moon that isn't large? 252. How surprised would you be to find mountains that aren't large? 253. How surprised would you be to find rainbows that aren't large? 254. How surprised would you be to find seas that aren't large? 
255. How surprised would you be to find a forest that isn't large?

256. How surprised would you be to find continents that aren't large?

257. How surprised would you be to find cities that aren't large?

258. How surprised would you be to find a planet that isn't large?

259. How surprised would you be to find a galaxy that isn't large?

260 . How surprised would you be to find a solar system that isn't large?

261. How surprised would you be to find a whale that isn't large?

262. How surprised would you be to find a giraffe that isn't large?

263. How surprised would you be to find granola that isn't crunchy?

264. How surprised would you be to find candy that isn't crunchy?

265. How surprised would you be to find nuts that aren't crunchy?

266. How surprised would you be to find pretzels that aren't crunchy?

267. How surprised would you be to find crackers that aren't crunchy?

268. How surprised would you be to find chips that aren't crunchy?

269. How surprised would you be to find celery that isn't crunchy?

270. How surprised would you be to find carrots that aren't crunchy?

271. How surprised would you be to find rice krispies that aren't crunchy?

272.How surprised would you be to find apples that aren't crunchy?

273.How surprised would you be to find a man that doesn't walk?

274. How surprised would you be to find a dog that doesn't walk?

275.How surprised would you be to find a cat that doesn't walk?

276. How surprised would you be to find an animal that doesn't walk?

277. How surprised would you be to find an elephant that doesn't walk?

278. How surprised would you be to find birds that don't walk?

279.How surprised would you be to find insects that don't walk?

280.How surprised would you be to find a horse that doesn't walk?

281 .How surprised would you be to find a cow that doesn't walk?

282.How surprised would you be to find a sheep that doesn't walk?

283. How surprised would you be to find a donkey that doesn't walk?

284 . How surprised would you be to find a camel that doesn't walk?

285 . How surprised would you be to find a robot that doesn't walk?

286 . How surprised would you be to find a bird that can't fly?

287. How surprised would you be to find an airplane that can't fly?

288. How surprised would you be to find a rocket that can't fly?

289 . How surprised would you be to find insects that can't fly?

290 . How surprised would you be to find kites that can't fly?

291 . How surprised would you be to find hang gliders that can't fly? 
292. How surprised would you be to find a bee that can't fly?

293. How surprised would you be to find a butterfly that can't fly'?

294. How surprised would you be to find fly saucers that can't fly?

295 . How surprised would you be to find a fly that can't fly'?

296. How surprised would you be to find a space shuttle that can't fly"?

297. How surprised would you be to find a helicopter that can't fly

298. How surprised would you be to find an eagle that can't fly?

299. How surprised would you be to find a hawk that can't fly?

300 . How surprised would you be to find a sparrow that can't fly?

301. How surprised would you be to find a robin that can't fly?

302 . How surprised would you be to find a jet that can't fly?

303. How surprised would you be to find a Frisbee that can't fly?

304. How surprised would you be to find a cardinal that isn't red?

305. How surprised would you be to find lips that aren't red?

306. How surprised would you be to find strawberries that aren't red?

307. How surprised would you be to find raspberries that aren't red?

308. How surprised would you be to find berries that aren't red?

309. How surprised would you be to find a watermelon that isn't red?

310 . How surprised would you be to find an apple that isn't red?

311. How surprised would you be to find a tomato that isn't red?

312. How surprised would you be to find blood that isn't red?

313.How surprised would you be to find roses that aren't red?

314. How surprised would you be to find stop signs that aren't red?

315. How surprised would you be to find cherries that aren't red?

316. How surprised would you be to find hearts that aren't red?

317. How surprised would you be to find fire engines that aren't red?

318. How surprised would you be to find peppers that aren't red?

319. How surprised would you be to find cardinals that aren't red?

320. How surprised would you be to find people that don't swim?

321. How surprised would you be to find a fish that doesn't swim?

322. How surprised would you be to find sharks that don't swim?

323. How surprised would you be to find a turtle that doesn't swim?

324. How surprised would you be to find eels that don't swim?

325. How surprised would you be to find ducks that don't swim?

326. How surprised would you be to find swans that don't swim?

327 . How surprised would you be to find a dolphin that doesn't swim?

328. How surprised would you be to find a whale that doesn't swim? 
329. How surprised would you be to find a penguin that doesn't swim?

330. How surprised would you be to find an animal that doesn't have a tail?

331. How surprised would you be to find a donkey that doesn't have a tail?

332. How surprised would you be to find a horse that doesn't have a tail'?

333. How surprised would you be to find a bird that doesn't have a tail?

334. How surprised would you be to find a whale that doesn't have a tail?

335. How surprised would you be to find a cat that doesn't have a tail?

336. How surprised would you be to find an elephant that doesn't have a tail?

337. How surprised would you be to find a rabbit that doesn't have a tail?

338. How surprised would you be to find a deer that doesn't have a tail?

339. How surprised would you be to find a rat that doesn't have a tail?

340. How surprised would you be to find a mouse that doesn't have a tail?

341 . How surprised would you be to find a dog that doesn't have a tail?

342. How surprised would you be to find a lizard that doesn't have a tail?

343. How surprised would you be to find a lion that doesn't have a tail?

344. How surprised would you be to find a pig that doesn't have a tail?

345. How surprised would you be to find a cow that doesn't have a tail?

346. How surprised would you be to find a kangaroo that doesn't have a tail?

347. How surprised would you be to find a monkey that doesn't have a tail?

348. How surprised would you be to find a fox that doesn't have a tail?

349. How surprised would you be to find a kite that doesn't have a tail?

350 . How surprised would you be to find a human that isn't alive?

351.How surprised would you be to find an animal that isn't alive?

352. How surprised would you be to find a plant that isn't alive?

353. How surprised would you be to find a frog that isn't alive?

354. How surprised would you be to find a bug that isn't alive?

355. How surprised would you be to find a rabbit that isn't alive?

356. How surprised would you be to find a worm that isn't alive?

357. How surprised would you be to find a bear that isn't alive?

358 . How surprised would you be to find a dog that isn't alive?

359. How surprised would you be to find a cat that isn't alive?

360 . How surprised would you be to find a fish that isn't alive?

361 . How surprised would you be to find a horse that isn't alive?

362 . How surprised would you be to find an ant that isn't alive?

363. How surprised would you be to find a fly that isn't alive?

364 . How surprised would you be to find grass that isn't alive?

365. How surprised would you be to find a flower that isn't alive? 
366. How surprised would you be to find an organism that isn't alive?

367. How surprised would you be to find bacteria that aren't alive?

368. How surprised would you be to find a mammal that isn't alive?

369. How surprised would you be to find fungus that isn't alive?

370. How surprised would you be to find a bird that isn't alive?

371. How surprised would you be to find a virus that isn't alive?

372. How surprised would you be to find a food that isn't edible?

373. How surprised would you be to find a candy that isn't edible?

374. How surprised would you be to find a vegetable that isn't edible?

375. How surprised would you be to find a fruit that isn't edible?

376. How surprised would you be to find meat that isn't edible?

377. How surprised would you be to find cereal that isn't edible?

378. How surprised would you be to find a cookie that isn't edible?

379. How surprised would you be to find a chicken that isn't edible?

380 . How surprised would you be to find a hamburger that isn't edible?

381 . How surprised would you be to find a banana that isn't edible?

382. How surprised would you be to find an apple that isn't edible?

383. How surprised would you be to find an orange that isn't edible?

384. How surprised would you be to find a carrot that isn't edible?

385. How surprised would you be to find rice that isn't edible?

386. How surprised would you be to find a noodle that isn't edible?

387. How surprised would you be to find an ice cube that isn't edible?

388. How surprised would you be to find a fish that isn't edible?

389. How surprised would you be to find cheese that isn't edible?

390 . How surprised would you be to find a pocketbook that isn't leather?

391.How surprised would you be to find a coat that isn't leather?

392. How surprised would you be to find a saddle that isn't leather?

393. How surprised would you be to find a boot that isn't leather?

394. How surprised would you be to find a watchband that isn't leather?

395. How surprised would you be to find a belt that isn't leather?

\section{Set B}

396. How surprised would you be to find a couch that isn't leather?

397. How surprised would you be to find a car interior that isn't leather?

398. How surprised would you be to find a shoe that isn't leather?

399. How surprised would you be to find a wallet that isn't leather?

400 . How surprised would you be to find a briefcase that isn't leather? 
401. How surprised would you be to find a cup that doesn't have a handle?

402. How surprised would you be to find a mug that doesn't have a handle?

403. How surprised would you be to find a pot that doesn't have a handle?

404. How surprised would you be to find a pocketbook that doesn't have a handle?

405. How surprised would you be to find a basket that doesn't have a handle?

406. How surprised would you be to find a car door that doesn't have a handle?

407. How surprised would you be to find a lunch box that doesn't have a handle?

408. How surprised would you be to find a toolbox that doesn't have a handle?

409. How surprised would you be to find a briefcase that doesn't have a handle?

410 . How surprised would you be to find an umbrella that doesn't have a handle?

411. How surprised would you be to find a shopping bag that doesn't have a handle?

412. How surprised would you be to find a pan that doesn't have a handle?

413. How surprised would you be to find glue that isn't sticky?

414.How surprised would you be to find tape that isn't sticky?

415. How surprised would you be to find bubble gum that isn't sticky?

416. How surprised would you be to find tar that isn't sticky?

417. How surprised would you be to find honey that isn't sticky?

418 .How surprised would you be to find syrup that isn't sticky?

419. How surprised would you be to find molasses that isn't sticky?

420.How surprised would you be to find candy that isn't sticky?

421. How surprised would you be to find a lollipop that isn't sticky?

422. How surprised would you be to find a scotch tape that isn't sticky?

423. How surprised would you be to find a packing tape that isn't sticky?

424. How surprised would you be to find adhesive that isn't sticky?

425. How surprised would you be to find a band-aid that isn't sticky?

426. How surprised would you be to find a rubber cement that isn't sticky?

427.How surprised would you be to find a sticker that isn't sticky?

428. How surprised would you be to find jelly that isn't sticky?

429. How surprised would you be to find jam that isn't sticky?

430. How surprised would you be to find peanut butter that isn't sticky?

431. How surprised would you be to find garbage that isn't smelly?

432.How surprised would you be to find manure that isn't smelly?

433. How surprised would you be to find a skunk that isn't smelly?

434. How surprised would you be to find a foot that isn't smelly?

435. How surprised would you be to find ammonia that isn't smelly?

436. How surprised would you be to find bleach that isn't smelly?

437. How surprised would you be to find fish that isn't smelly? 
438. How surprised would you be to find a rotten egg that isn't smelly?

439. How surprised would you be to find a gym sock that isn't smelly?

440 . How surprised would you be to find a public bathroom that isn't smelly'?

441 . How surprised would you be to find spoiled milk that isn't smelly?

442. How surprised would you be to find garlic that isn't smelly?

443. How surprised would you be to find an onion that isn't smelly?

444. How surprised would you be to find sulfur that isn't smelly?

445. How surprised would you be to find a body order that isn't smelly?

446. How surprised would you be to find a halitosis that isn't smelly?

447. How surprised would you be to find water that isn't liquid?

448. How surprised would you be to find juice that isn't liquid?

449. How surprised would you be to find soda that isn't liquid?

450 . How surprised would you be to find beer that isn't liquid?

451. How surprised would you be to find wine that isn't liquid?

452. How surprised would you be to find alcohol that isn't liquid?

453. How surprised would you be to find blood that isn't liquid?

454. How surprised would you be to find rain that isn't liquid?

455.How surprised would you be to find milk that isn't liquid?

456. How surprised would you be to find oil that isn't liquid?

457.How surprised would you be to find a tear that isn't liquid?

458. How surprised would you be to find a soup that isn't liquid?

459. How surprised would you be to find a pool that isn't liquid?

460 . How surprised would you be to find an ocean that isn't liquid?

461. How surprised would you be to find a sun that isn't hot?

462. How surprised would you be to find a fire that isn't hot?

463. How surprised would you be to find an oven that isn't hot?

464. How surprised would you be to find a stovetop that isn't hot?

465. How surprised would you be to find a candle that isn't hot?

466. How surprised would you be to find a fireplace that isn't hot?

467. How surprised would you be to find a heater that isn't hot?

468 . How surprised would you be to find a summer that isn't hot?

469. How surprised would you be to find cayenne pepper that isn't hot?

470. How surprised would you be to find coffee that isn't hot?

471 .How surprised would you be to find tea that isn't hot?

472. How surprised would you be to find cinnamon that isn't hot?

473. How surprised would you be to find a jalapeno that isn't hot?

474. How surprised would you be to find a chipolte pepper that isn't hot? 
475. How surprised would you be to find salsa that isn't hot?

476. How surprised would you be to find a toaster that isn't hot?

477. How surprised would you be to find boiling water that isn't hot?

478. How surprised would you be to find steam that isn't hot?

479. How surprised would you be to find a chili pepper that isn't hot?

480. How surprised would you be to find a candy that isn't sweet?

481 . How surprised would you be to find a fruit that isn't sweet?

482. How surprised would you be to find a cake that isn't sweet?

483. How surprised would you be to find a cookie that isn't sweet?

484. How surprised would you be to find a pie that isn't sweet?

485. How surprised would you be to find ice cream that isn't sweet?

486. How surprised would you be to find a Popsicle that isn't sweet?

487. How surprised would you be to find juice that isn't sweet?

488. How surprised would you be to find a soda that isn't sweet?

489. How surprised would you be to find honey that isn't sweet?

490 . How surprised would you be to find chocolate that isn't sweet?

491. How surprised would you be to find an apple that isn't sweet?

492. How surprised would you be to find caramel that isn't sweet?

493. How surprised would you be to find a cherry that isn't sweet?

494. How surprised would you be to find a pastry that isn't sweet?

495. How surprised would you be to find a cotton candy that isn't sweet?

496. How surprised would you be to find lemonade that isn't sweet?

497. How surprised would you be to find a lollipop that isn't sweet?

498. How surprised would you be to find a gumdrop that isn't sweet?

499. How surprised would you be to find a dessert that isn't sweet?

500. How surprised would you be to find a knife that isn't sharp?

501 . How surprised would you be to find a sword that isn't sharp?

502. How surprised would you be to find a thumbtack that isn't sharp?

503. How surprised would you be to find a razor that isn't sharp?

504. How surprised would you be to find scissors that aren't sharp?

505 . How surprised would you be to find a blade that isn't sharp?

506. How surprised would you be to find a needle that isn't sharp?

507.How surprised would you be to find a worm that isn't slimy?

508. How surprised would you be to find mucus that isn't slimy?

509. How surprised would you be to find a snail that isn't slimy?

510 .How surprised would you be to find a leech that isn't slimy?

511 .How surprised would you be to find seaweed that isn't slimy? 
512. How surprised would you be to find a jellyfish that isn't slimy?

513. How surprised would you be to find an oyster that isn't slimy?

514. How surprised would you be to find a lotion that isn't slimy?

515. How surprised would you be to find oil that isn't slimy'?

516 . How surprised would you be to find a slug that isn't slimy?

517. How surprised would you be to find an airplane that isn't noisy?

518. How surprised would you be to find traffic that isn't noisy?

519. How surprised would you be to find a drum that isn't noisy'?

520. How surprised would you be to find a siren that isn't noisy?

521. How surprised would you be to find a horn that isn't noisy?

522. How surprised would you be to find a cymbal that isn't noisy?

523. How surprised would you be to find a party that isn't noisy?

524. How surprised would you be to find a concert that isn't noisy?

525. How surprised would you be to find a club that isn't noisy?

526. How surprised would you be to find a drill that isn't noisy?

527. How surprised would you be to find a jackhammer that isn't noisy?

528 . How surprised would you be to find a crying baby that isn't noisy?

529. How surprised would you be to find construction that isn't noisy?

530. How surprised would you be to find fireworks that aren't noisy?

531. How surprised would you be to find a lemon that isn't sour?

532. How surprised would you be to find a lime that isn't sour?

533. How surprised would you be to find vinegar that isn't sour?

534. How surprised would you be to find bad milk that isn't sour?

535. How surprised would you be to find a green apple that isn't sour?

536. How surprised would you be to find a rabbit that doesn't hop?

537. How surprised would you be to find a kangaroo that doesn't hop?

538. How surprised would you be to find a grasshopper that doesn't hop?

539. How surprised would you be to find a frog that doesn't hop?

540. How surprised would you be to find a toad that doesn't hop?

541 . How surprised would you be to find a cricket that doesn't hop?

542 .How surprised would you be to find a Tigger that doesn't hop?

543. How surprised would you be to find a flea that doesn't hop?

544 . How surprised would you be to find a peanut that doesn't have a shell?

545. How surprised would you be to find a walnut that doesn't have a shell?

546. How surprised would you be to find a pecan that doesn't have a shell?

547 . How surprised would you be to find a chestnut that doesn't have a shell?

548 . How surprised would you be to find a mollusk that doesn't have a shell? 
549. How surprised would you be to find a clam that doesn't have a shell?

550 . How surprised would you be to find a snail that doesn't have a shell? 551 . How surprised would you be to find a crab that doesn't have a shell? 552 . How surprised would you be to find a shrimp that doesn't have a shell? 553. How surprised would you be to find a scallop that doesn't have a shell'? 554. How surprised would you be to find a lobster that doesn't have a shell'? 555 . How surprised would you be to find a seed that doesn't have a shell'? 556 . How surprised would you be to find a cashew that doesn't have a shell? 557 . How surprised would you be to find a pistachio that doesn't have a shell? 558 . How surprised would you be to find a turtle that doesn't have a shell? 559 . How surprised would you be to find an oyster that doesn't have a shell? 560 . How surprised would you be to find a hermit crab that doesn't have a shell? 561 . How surprised would you be to find an M\&M that doesn't have a shell?

562. How surprised would you be to find a sun that isn't yellow?

563. How surprised would you be to find a lemon that isn't yellow?

564. How surprised would you be to find a highlighter that isn't yellow?

565 . How surprised would you be to find lemonade that isn't yellow?

566. How surprised would you be to find a banana that isn't yellow?

567. How surprised would you be to find a tennis ball that isn't yellow?

568 . How surprised would you be to find corn that isn't yellow?

569. How surprised would you be to find a yield sign that isn't yellow?

570. How surprised would you be to find a school bus that isn't yellow?

571. How surprised would you be to find a bee that isn't yellow?

572.How surprised would you be to find cheese that isn't yellow?

573. How surprised would you be to find a taxi that isn't yellow?

574. How surprised would you be to find a big bird that isn't yellow?

575. How surprised would you be to find a legal pad that isn't yellow?

576. How surprised would you be to find a pillow that isn't soft?

577. How surprised would you be to find cotton that isn't soft?

578. How surprised would you be to find skin that isn't soft?

579. How surprised would you be to find fur that isn't soft?

580. How surprised would you be to find a kitten that isn't soft?

581.How surprised would you be to find a puppy that isn't soft?

582. How surprised would you be to find silk that isn't soft?

583. How surprised would you be to find cashmere that isn't soft?

584. How surprised would you be to find a rabbit that isn't soft?

585. How surprised would you be to find a baby that isn't soft? 
586. How surprised would you be to find a rose petal that isn't soft?

587. How surprised would you be to find satin that isn't soft?

588. How surprised would you be to find velvet that isn't soft?

589. How surprised would you be to find a feather that isn't soft?

590.How surprised would you be to find a fruit that doesn't have seeds?

591 . How surprised would you be to find a vegetable that doesn't have seeds?

592. How surprised would you be to find a tree that doesn't have seeds?

593. How surprised would you be to find an apple that doesn't have seeds?

594.How surprised would you be to find a grape that doesn't have seeds?

595 . How surprised would you be to find a tomato that doesn't have seeds?

596. How surprised would you be to find a pumpkin that doesn't have seeds?

597. How surprised would you be to find a sunflower that doesn't have seeds?

598. How surprised would you be to find an orange that doesn't have seeds?

599. How surprised would you be to find a grapefruit that doesn't have seeds?

600 .How surprised would you be to find a watermelon that doesn't have seeds?

601 .How surprised would you be to find a cucumber that doesn't have seeds?

602 . How surprised would you be to find snow that isn't cold?

603. How surprised would you be to find a freezer that isn't cold?

604 . How surprised would you be to find a cellar that isn't cold?

605. How surprised would you be to find Antarctica that isn't cold?

606 . How surprised would you be to find ice cream that isn't cold?

607 . How surprised would you be to find an ice cube that isn't cold?

608. How surprised would you be to find a Popsicle that isn't cold?

609 . How surprised would you be to find a winter that isn't cold?

610 . How surprised would you be to find a blizzard that isn't cold?

611 .How surprised would you be to find a refrigerator that isn't cold?

612 . How surprised would you be to find air-conditioning that isn't cold?

613.How surprised would you be to find a swimming-pool that isn't cold?

614.How surprised would you be to find a glacier that isn't cold?

615. How surprised would you be to find a frozen-food that isn't cold?

616. How surprised would you be to find an icicle that isn't cold?

617 . How surprised would you be to find an animal that doesn't have skin?

618 . How surprised would you be to find a person that doesn't have skin?

619 .How surprised would you be to find a grape that doesn't have skin?

620 . How surprised would you be to find chicken that doesn't have skin?

621 .How surprised would you be to find a cow that doesn't have skin?

622.How surprised would you be to find a dog that doesn't have skin? 
623. How surprised would you be to find a rabbit that doesn't have skin?

624 . How surprised would you be to find a bird that doesn't have skin?

625. How surprised would you be to find a monkey that doesn't have skin?

626. How surprised would you be to find an onion that doesn't have skin'?

627. How surprised would you be to find garlic that doesn't have skin?

628 . How surprised would you be to find an apple that doesn't have skin'?

629.How surprised would you be to find a tomato that doesn't have skin?

630 . How surprised would you be to find a mammal that doesn't have skin?

631.How surprised would you be to find a reptile that doesn't have skin?

632. How surprised would you be to find a snake that doesn't have skin?

633. How surprised would you be to find an alligator that doesn't have skin?

634.How surprised would you be to find a fruit that doesn't have skin?

635 . How surprised would you be to find a vegetable that doesn't have skin?

636. How surprised would you be to find a mirror that isn't reflective?

637. How surprised would you be to find glass that isn't reflective?

638. How surprised would you be to find aluminum that isn't reflective?

639. How surprised would you be to find chrome that isn't reflective?

640 . How surprised would you be to find steel that isn't reflective?

641 . How surprised would you be to find a potato chip that isn't salty?

642 . How surprised would you be to find a pretzel that isn't salty?

643.How surprised would you be to find nacho chip that isn't salty?

644. How surprised would you be to find soy sauce that isn't salty?

645.How surprised would you be to find sea water that isn't salty?

646. How surprised would you be to find a margarita that isn't salty?

647. How surprised would you be to find a tear that isn't salty?

648 . How surprised would you be to find a food that isn't salty?

649 . How surprised would you be to find sweat that isn't salty?

650 . How surprised would you be to find popcorn that isn't salty?

651 . How surprised would you be to find a peanut that isn't salty?

652 . How surprised would you be to find a nut that isn't salty?

653. How surprised would you be to find a cracker that isn't salty?

654. How surprised would you be to find a french fry that isn't salty?

655 . How surprised would you be to find a saltine that isn't salty?

656. How surprised would you be to find a flower that doesn't have leaves?

657. How surprised would you be to find a bush that doesn't have leaves?

658. How surprised would you be to find a vine that doesn't have leaves?

659 . How surprised would you be to find a plant that doesn't have leaves? 
660.How surprised would you be to find a forest that doesn't have leaves?

661. How surprised would you be to find an oak that doesn't have leaves?

662. How surprised would you be to find an herb that doesn't have leaves'?

663. How surprised would you be to find a weed that doesn't have leaves?

664. How surprised would you be to find lettuce that doesn't have leaves?

665 .How surprised would you be to find spinach that doesn't have leaves?

666. How surprised would you be to find a bear that isn't ferocious?

667. How surprised would you be to find a lion that isn't ferocious?

668. How surprised would you be to find a tiger that isn't ferocious?

669 . How surprised would you be to find an alligator that isn't ferocious?

670 .How surprised would you be to find a crocodile that isn't ferocious?

671.How surprised would you be to find a wild animal that isn't ferocious?

672.How surprised would you be to find glass that isn't transparent?

673. How surprised would you be to find Plexiglas that isn't transparent?

674. How surprised would you be to find plastic that isn't transparent?

675. How surprised would you be to find a soda bottle that isn't transparent?

676. How surprised would you be to find air that isn't transparent?

677 . How surprised would you be to find water that isn't transparent?

678. How surprised would you be to find oil that isn't transparent?

679. How surprised would you be to find a tear that isn't transparent?

680. How surprised would you be to find ice that isn't transparent?

681 .How surprised would you be to find a yield sign that isn't triangular?

682. How surprised would you be to find a piece of pie that isn't triangular?

683 . How surprised would you be to find a sandwich that isn't triangular?

684 .How surprised would you be to find a slice of pizza that isn't triangular?

685.How surprised would you be to find an airplane that isn't dangerous?

686 . How surprised would you be to find a wet road that isn't dangerous?

687 .How surprised would you be to find a fire that isn't dangerous?

688. How surprised would you be to find an earthquake that isn't dangerous?

689. How surprised would you be to find a hurricane that isn't dangerous?

690. How surprised would you be to find a tornado that isn't dangerous?

691. How surprised would you be to find a robber that isn't dangerous?

692. How surprised would you be to find a murderer that isn't dangerous?

693.How surprised would you be to find a snake that isn't dangerous?

694. How surprised would you be to find a cancer that isn't dangerous?

695.How surprised would you be to find a stroke that isn't dangerous?

696. How surprised would you be to find a wild animal that isn't dangerous? 
697. How surprised would you be to find a war that isn't dangerous?

698. How surprised would you be to find a lion that isn't dangerous'?

699 . How surprised would you be to find a gun that isn't dangerous?

700. How surprised would you be to find a knife that isn't dangerous?

701.How surprised would you be to find drag racing isn't dangerous?

702. How surprised would you be to find scuba diving that isn't dangerous?

703. How surprised would you be to find a wheel that doesn't roll?

704.How surprised would you be to find a ball that doesn't roll?

705. How surprised would you be to find a log that doesn't roll?

706. How surprised would you be to find a tire that doesn't roll?

707. How surprised would you be to find a snowball that doesn't roll?

708. How surprised would you be to find a penny that doesn't roll?

709. How surprised would you be to find a cat that isn't furry?

710. How surprised would you be to find a dog that isn't furry?

711. How surprised would you be to find a hamster that isn't furry?

712. How surprised would you be to find a gerbil that isn't furry?

713. How surprised would you be to find a squirrel that isn't furry?

714. How surprised would you be to find a rabbit that isn't furry?

715. How surprised would you be to find an animal that isn't furry?

716. How surprised would you be to find a tree that isn't tall?

717. How surprised would you be to find a building that isn't tall?

718. How surprised would you be to find a ladder that isn't tall?

719. How surprised would you be to find a flagpole that isn't tall?

720 . How surprised would you be to find a tower that isn't tall?

721 . How surprised would you be to find a streetlight that isn't tall?

722. How surprised would you be to find a basketball player that isn't tall?

723. How surprised would you be to find a telephone pole that isn't tall?

724. How surprised would you be to find a mountain that isn't tall?

725. How surprised would you be to find leaves that aren't green?

726. How surprised would you be to find grass that isn't green?

727. How surprised would you be to find a tree that isn't green?

728. How surprised would you be to find a vegetable that isn't green?

729. How surprised would you be to find broccoli that isn't green?

730 . How surprised would you be to find a pea that isn't green?

731. How surprised would you be to find money that isn't green?

732. How surprised would you be to find a plant that isn't green?

733. How surprised would you be to find an apple that isn't green? 
734. How surprised would you be to find a traffic-light that isn't green?

735. How surprised would you be to find a frog that isn't green'?

736. How surprised would you be to find a lizard that isn't green?

737. How surprised would you be to find moss that isn't green?

738. How surprised would you be to find a pear that isn't green?

739. How surprised would you be to find an herb that isn't green?

740 . How surprised would you be to find artificial turf that isn't green?

741. How surprised would you be to find an emerald that isn't green?

742. How surprised would you be to find a shamrock that isn't green?

743. How surprised would you be to find Mexican food that isn't spicy?

744. How surprised would you be to find Indian food that isn't spicy?

745. How surprised would you be to find a buffalo wing that isn't spicy?

746. How surprised would you be to find Cajun food that isn't spicy?

747. How surprised would you be to find construction work that isn't loud?

748. How surprised would you be to find yelling that isn't loud?

749. How surprised would you be to find screaming that isn't loud?

750. How surprised would you be to find crying that isn't loud?

751 . How surprised would you be to find a horn that isn't loud?

752. How surprised would you be to find traffic that isn't loud?

753. How surprised would you be to find an earthquake that isn't loud?

754. How surprised would you be to find an accident that isn't loud?

755. How surprised would you be to find a motorcycle that isn't loud?

756. How surprised would you be to find a jackhammer that isn't loud?

757. How surprised would you be to find an airplane that isn't loud?

758. How surprised would you be to find a concert that isn't loud?

759. How surprised would you be to find an avalanche that isn't loud?

760 . How surprised would you be to find an explosion that isn't loud?

761. How surprised would you be to find gun-fire that isn't loud?

762. How surprised would you be to find a siren that isn't loud?

763. How surprised would you be to find a firework that isn't loud?

764. How surprised would you be to find a baby crying that isn't loud?

765. How surprised would you be to find stomping that isn't loud?

766. How surprised would you be to find thunder that isn't loud?

767. How surprised would you be to find a rocket that isn't loud?

768. How surprised would you be to find a first class ticket that isn't extravagant?

769. How surprised would you be to find jewelry that isn't extravagant?

770 . How surprised would you be to find a diamond that isn't extravagant? 
771. How surprised would you be to find a wedding that isn't extravagant'?

772. How surprised would you be to find a Broadway play that isn't extravagant?

773. How surprised would you be to find a palace that isn't extravagant?

774. How surprised would you be to find a yacht that isn't extravagant?

775. How surprised would you be to find a ball gown that isn't extravagant'?

776. How surprised would you be to find a wedding cake that isn't extravagant?

777. How surprised would you be to find a fancy wine that isn't extravagant?

778. How surprised would you be to find a Dalmatian that isn't spotted'?

779. How surprised would you be to find a cow that isn't spotted?

780. How surprised would you be to find a cheetah that isn't spotted'?

781. How surprised would you be to find a leopard that isn't spotted?

782. How surprised would you be to find a winter that isn't freezing?

783. How surprised would you be to find a freezer that isn't freezing?

784. How surprised would you be to find air conditioning that isn't freezing?

785. How surprised would you be to find ice that isn't freezing?

786. How surprised would you be to find snow that isn't freezing?

787. How surprised would you be to find ice cream that isn't freezing?

788. How surprised would you be to find that the North Pole isn't freezing?

789. How surprised would you be to find a Popsicle that isn't freezing?

790. How surprised would you be to find sleet that isn't freezing? 


\section{APPENDIX C \\ COMPLETE SET OF SALIENCE QUESTIONS-EXPERIMENT I}

\section{Set A}

1. How much does the property scary stand out in your thoughts about snakes?

2. How much does the property scary stand out in your thoughts about monsters?

3. How much does the property scary stand out in your thoughts about vampires?

4. How much does the property scary stand out in your thoughts about bats?

5. How much does the property scary stand out in your thoughts about spiders?

6. How much does the property scary stand out in your thoughts about haunted houses?

7. How much does the property scary stand out in your thoughts about ghosts?

8. How much does the property scary stand out in your thoughts about witches?

9. How much does the property scary stand out in your thoughts about nightmares?

10. How much does the property fast stand out in your thoughts about cars?

11. How much does the property fast stand out in your thoughts about cheetahs?

12. How much does the property fast stand out in your thoughts about planes?

13. How much does the property fast stand out in your thoughts about milliseconds?

14. How much does the property fast stand out in your thoughts about leopards?

15. How much does the property fast stand out in your thoughts about roadrunners?

16. How much does the property fast stand out in your thoughts about sports cars?

17. How much does the property fast stand out in your thoughts about racecars?

18. How much does the property fast stand out in your thoughts about track athletes?

19. How much does the property fast stand out in your thoughts about horse races?

20. How much does the property fast stand out in your thoughts about concords?

21. How much does the property fast stand out in your thoughts about trains?

22. How much does the property fast stand out in your thoughts about speedboats?

23. How much does the property fast stand out in your thoughts about light?

24. How much does the property poisonous stand out in your thoughts about cyanide?

25. How much does the property poisonous stand out in your thoughts about lead?

26. How much does the property poisonous stand out in your thoughts about chemicals?

27. How much does the property poisonous stand out in your thoughts about venom?

28. How much does the property poisonous stand out in your thoughts about strychnine?

29. How much does the property poisonous stand out in your thoughts about ammonia?

30. How much does the property poisonous stand out in your thoughts about bleach? 
31. How much does the property poisonous stand out in your thoughts about roach killers?

32. How much does the property poisonous stand out in your thoughts about weed killer?

33. How much does the property poisonous stand out in your thoughts about spiders?

34. How much does the property poisonous stand out in your thoughts about gas?

35. How much does the property poisonous stand out in your thoughts about household cleaners?

36. How much does the property poisonous stand out in your thoughts about berries?

37. How much does the property poisonous stand out in your thoughts about hemlock?

38. How much does the property round stand out in your thoughts about clock faces?

39. How much does the property round stand out in your thoughts about traffic circles?

40. How much does the property round stand out in your thoughts about rings?

41. How much does the property round stand out in your thoughts about wheels?

42. How much does the property round stand out in your thoughts about glasses?

43. How much does the property round stand out in your thoughts about domes?

44. How much does the property round stand out in your thoughts about planets?

45. How much does the property round stand out in your thoughts about moons?

46. How much does the property round stand out in your thoughts about CD's?

47. How much does the property round stand out in your thoughts about records?

48. How much does the property round stand out in your thoughts about eyes?

49. How much does the property round stand out in your thoughts about balls?

50. How much does the property round stand out in your thoughts about lollipops?

51. How much does the property round stand out in your thoughts about oranges?

52. How much does the property round stand out in your thoughts about earth?

53. How much does the property round stand out in your thoughts about suns?

54. How much does the property round stand out in your thoughts about cookies?

55. How much does the property clear stand out in your thoughts about glass?

56. How much does the property clear stand out in your thoughts about water?

57 . How much does the property clear stand out in your thoughts about tears?

58. How much does the property clear stand out in your thoughts about plastic?

59. How much does the property clear stand out in your thoughts about air?

60. How much does the property clear stand out in your thoughts about cellophane?

61. How much does the property clear stand out in your thoughts about Plexiglas?

62. How much does the property clear stand out in your thoughts about windows?

63. How much does the property clear stand out in your thoughts about eyeglasses?

64. How much does the property clear stand out in your thoughts about saran wrap? 
65. How much does the property clear stand out in your thoughts about broth?

66. How much docs the property clear stand out in your thoughts about contacts?

67. How much does the property grainy stand out in your thoughts about bread?

68. How much does the property grainy stand out in your thoughts about wood?

69. How much does the property grainy stand out in your thoughts about cereal'?

70. How much does the property grainy stand out in your thoughts about sand?

71. How much does the property grainy stand out in your thoughts about dirt?

72. How much does the property grainy stand out in your thoughts about grout?

73. How much docs the property grainy stand out in your thoughts about sandpaper?

74. How much does the property grainy stand out in your thoughts about sugar"?

75. How much does the property wooden stand out in your thoughts about desks"?

76. How much does the property wooden stand out in your thoughts about chairs?

77. How much does the property wooden stand out in your thoughts about beds"?

78. How much does the property wooden stand out in your thoughts about houses'?

79. How much does the property wooden stand out in your thoughts about shutters?

80. How much does the property wooden stand out in your thoughts about pirate legs?

81. How much does the property wooden stand out in your thoughts about doors?

82. How much does the property wooden stand out in your thoughts about birdhouses?

83. How much docs the property wooden stand out in your thoughts about fence posts?

84. How much does the property wooden stand out in your thoughts about dressers"?

85. How much does the property wooden stand out in your thoughts about benches"?

S6. How much does the property wooden stand out in your thoughts about crates"?

87. How much does the property wooden stand out in your thoughts about trees?

88. How much does the property wooden stand out in your thoughts about baseball bats??

89. How much does the property wooden stand out in your thoughts about puppets?

90. How much does the property wooden stand out in your thoughts about blocks?

91. How much does the property wooden stand out in your thoughts about floors?

92. How much does the property wooden stand out in your thoughts about cabinets?

93. How much docs the property wooden stand out in your thoughts about oars?

94. How much does the property wooden stand out in your thoughts about log cabins?

95. How much does the property wooden stand out in your thoughts about pencils?

96. How much does the property wooden stand out in your thoughts about rafts?

97. How much does the property has whecks stand out in your thoughts about cars"?

98. How much does the property has whecks stand out in your thoughts about trucks?

99. How much does the property has wheels stand out in your thoughts about bieycles?

100. How much does the property has whecls stand out in your thoughts about tricycles? 
101. How much does the property has wheels stand out in your thoughts about airplanes?

102. How much does the property has wheels stand out in your thoughts about vans?

103. How much does the property has wheels stand out in your thoughts about skateboards?

104. How much does the property has wheels stand out in your thoughts about scooters?

105.How much does the property has wheels stand out in your thoughts about motorcycles?

106.How much does the property has wheels stand out in your thoughts about wheelchairs'?

107.How much does the property has wheels stand out in your thoughts about office chairs?

108. How much does the property has wheels stand out in your thoughts about wagons?

109.How much does the property has wheels stand out in your thoughts about wheelbarrows?

110.How much does the property has wheels stand out in your thoughts about trains?

111. How much does the property has wheels stand out in your thoughts about unicycles?

112.How much does the property has wheels stand out in your thoughts about baby carriages?

113.How much does the property has wheels stand out in your thoughts about roller coasters?

114. How much does the property has wheels stand out in your thoughts about go-carts?

115. How much does the property has wheels stand out in your thoughts about buses?

116. How much does the property has wheels stand out in your thoughts about matchbox cars?

117. How much does the property has wheels stand out in your thoughts about roller-skates?

118. How much does the property has wheels stand out in your thoughts about roller blades?

119.How much does the property has wheels stand out in your thoughts about toys?

120.How much does the property rubber stand out in your thoughts about tires?

121. How much does the property rubber stand out in your thoughts about balls?

122.How much does the property rubber stand out in your thoughts about dolls?

123. How much does the property rubber stand out in your thoughts about garden hoses?

124. How much does the property rubber stand out in your thoughts about latex gloves?

125.How much does the property rubber stand out in your thoughts about rain boots?

126. How much does the property rubber stand out in your thoughts about erasers?

127.How much does the property rubber stand out in your thoughts about dish gloves? 
128. How much does the property plastic stand out in your thoughts about Tupperware?

129. How much does the property plastic stand out in your thoughts about CD cases?

130. How much does the property plastic stand out in your thoughts about cups?

131. How much does the property plastic stand out in your thoughts about straws"?

132. How much does the property plastic stand out in your thoughts about shampoo bottles?

133. How much does the property plastic stand out in your thoughts about soda bottles"?

134. How much does the property plastic stand out in your thoughts about pens?

135. How much does the property plastic stand out in your thoughts about shopping bags?

136. How much does the property plastic stand out in your thoughts about cassette tapes?

137. How much does the property plastic stand out in your thoughts about milk jugs?

138. How much does the property plastic stand out in your thoughts about bottles?

139. How much does the property orange stand out in your thoughts about apricots?

140. How much does the property orange stand out in your thoughts about carrots?

141. How much does the property orange stand out in your thoughts about construction signs?

142. How much does the property orange stand out in your thoughts about oranges?

143. How much does the property orange stand out in your thoughts about Sunkist sodas?

144. How much does the property orange stand out in your thoughts about road cones?

145.How much does the property orange stand out in your thoughts about tigers?

146. How much does the property orange stand out in your thoughts about suns?

147. How much does the property orange stand out in your thoughts about pumpkins?

148. How much does the property juicy stand out in your thoughts about grapes?

149. How much does the property juicy stand out in your thoughts about citrus fruit?

150. How much does the property juicy stand out in your thoughts about candy?

151. How much does the property juicy stand out in your thoughts about melons?

152.How much does the property juicy stand out in your thoughts about oranges?

153.How much does the property juicy stand out in your thoughts about strawberries?

154. How much does the property juicy stand out in your thoughts about plums?

155. How much does the property juicy stand out in your thoughts about steaks?

156. How much does the property juicy stand out in your thoughts about pineapples?

157. How much does the property juicy stand out in your thoughts about apples?

158. How much does the property juicy stand out in your thoughts about peaches?

159. How much does the property juicy stand out in your thoughts about grapefruits? 
160. How much does the property glass stand out in your thoughts about drinking glasses?

161. How much does the property glass stand out in your thoughts about TV screens?

162. How much does the property glass stand out in your thoughts about windows?

163. How much does the property glass stand out in your thoughts about mirrors?

164. How much does the property glass stand out in your thoughts about vases?

165. How much does the property glass stand out in your thoughts about bowls?

166. How much does the property glass stand out in your thoughts about wine glasses?

167. How much does the property glass stand out in your thoughts about greenhouses?

168. How much does the property glass stand out in your thoughts about bottles?

169. How much does the property glass stand out in your thoughts about cups?

170. How much does the property glass stand out in your thoughts about light bulbs?

171. How much does the property glass stand out in your thoughts about windshields?

172.How much does the property stores things stand out in your thoughts about Tupperware?

173. How much does the property stores things stand out in your thoughts about boxes?

174. How much does the property stores things stand out in your thoughts about bags?

175. How much does the property stores things stand out in your thoughts about closets?

176. How much does the property stores things stand out in your thoughts about crates?

177.How much does the property stores things stand out in your thoughts about dressers?

178. How much does the property stores things stand out in your thoughts about cabinets?

179. How much does the property stores things stand out in your thoughts about attics?

180.How much does the property stores things stand out in your thoughts about garages?

181. How much does the property stores things stand out in your thoughts about trunks?

182.How much does the property stores things stand out in your thoughts about drawers?

183.How much does the property stores things stand out in your thoughts about suitcases?

184.How much does the property stores things stand out in your thoughts about pantries?

185. How much does the property stores things stand out in your thoughts about cellars?

186. How much does the property stores things stand out in your thoughts about chests?

187.How much does the property stores things stand out in your thoughts about lockers?

188. How much does the property stores things stand out in your thoughts about folders? 
189. How much does the property stores things stand out in your thoughts about computer files?

190. How much does the property stores things stand out in your thoughts about desks?

191. How much does the property stores things stand out in your thoughts about shelves?

192. How much does the property stores things stand out in your thoughts about refrigerators?

193. How much does the property stores things stand out in your thoughts about time capsules?

194. How much does the property stores things stand out in your thoughts about safes?

195. How much does the property stores things stand out in your thoughts about sheds?

196. How much does the property stores things stand out in your thoughts about banks?

197. How much does the property grown on trees stand out in your thoughts about fruit?

198. How much does the property grown on trees stand out in your thoughts about apples?

199.How much does the property grown on trees stand out in your thoughts about oranges?

200.How much does the property grown on trees stand out in your thoughts about bananas?

201.How much does the property grown on trees stand out in your thoughts about leaves?

202.How much does the property grown on trees stand out in your thoughts about bark?

203.How much does the property grown on trees stand out in your thoughts about flowers?

204.How much does the property grown on trees stand out in your thoughts about plums?

205.How much does the property grown on trees stand out in your thoughts about pears?

206.How much does the property grown on trees stand out in your thoughts about lemons?

207. How much does the property grown on trees stand out in your thoughts about limes?

208.How much does the property grown on trees stand out in your thoughts about grapefruits?

209.How much does the property grown on trees stand out in your thoughts about fungus?

210.How much does the property grown on trees stand out in your thoughts about peaches?

211.How much does the property grown on trees stand out in your thoughts about branches? 
212.How much does the property grown on trees stand out in your thoughts about cherries?

213.How much does the property grown on trees stand out in your thoughts about pinecones?

214. How much does the property grown on trees stand out in your thoughts about nuts'?

215 . How much does the property has fur stand out in your thoughts about animals?

216 . How much does the property has fur stand out in your thoughts about dogs?

217 . How much does the property has fur stand out in your thoughts about cats?

218 . How much does the property has fur stand out in your thoughts about bears?

219.How much does the property has fur stand out in your thoughts about tigers?

220 .How much does the property has fur stand out in your thoughts about lions?

221 .How much does the property has fur stand out in your thoughts about raccoons?

222.How much does the property has fur stand out in your thoughts about rabbits?

223.How much does the property has fur stand out in your thoughts about squirrels?

224. How much does the property has fur stand out in your thoughts about deer?

225.How much does the property has fur stand out in your thoughts about mammals?

226. How much does the property has fur stand out in your thoughts about stuffed toys?

227.How much does the property has fur stand out in your thoughts about gerbils?

228. How much does the property has fur stand out in your thoughts about hamsters?

229. How much does the property blue stand out in your thoughts about skies?

230.How much does the property blue stand out in your thoughts about oceans?

231. How much does the property blue stand out in your thoughts about water?

232. How much does the property blue stand out in your thoughts about blood?

233.How much does the property blue stand out in your thoughts about veins?

234. How much does the property blue stand out in your thoughts about ink?

235. How much does the property blue stand out in your thoughts about blueberries?

236.How much does the property blue stand out in your thoughts about jeans?

237.How much does the property blue stand out in your thoughts about lakes?

238. How much does the property blue stand out in your thoughts about police cars?

239. How much does the property blue stand out in your thoughts about baby boy's clothes?

240.How much does the property blue stand out in your thoughts about police uniforms?

241.How much does the property blue stand out in your thoughts about school uniforms?

242.How much does the property large stand out in your thoughts about buildings?

243. How much does the property large stand out in your thoughts about a universe?

244.How much does the property large stand out in your thoughts about elephants? 
245. How much does the property large stand out in your thoughts about bears?

246. How much does the property large stand out in your thoughts about wooly mammoths?

247. How much does the property large stand out in your thoughts about warehouses?

248. How much does the property large stand out in your thoughts about oceans?

249. How much does the property large stand out in your thoughts about office buildings?

250 . How much does the property large stand out in your thoughts about suns?

251 . How much does the property large stand out in your thoughts about moons?

252 .How much does the property large stand out in your thoughts about mountains?

253. How much does the property large stand out in your thoughts about rainbows?

254 . How much does the property large stand out in your thoughts about seas?

255 . How much does the property large stand out in your thoughts about forests?

256 . How much does the property large stand out in your thoughts about continents?

257 . How much does the property large stand out in your thoughts about cities?

258. How much does the property large stand out in your thoughts about planets?

259 . How much does the property large stand out in your thoughts about galaxies?

260 . How much does the property large stand out in your thoughts about solar systems?

261. How much does the property large stand out in your thoughts about whales?

262.How much does the property large stand out in your thoughts about giraffes?

263. How much does the property crunchy stand out in your thoughts about granola?

264 . How much does the property crunchy stand out in your thoughts about candy?

265 . How much does the property crunchy stand out in your thoughts about nuts?

266. How much does the property crunchy stand out in your thoughts about pretzels?

267 . How much does the property crunchy stand out in your thoughts about crackers?

268. How much does the property crunchy stand out in your thoughts about chips?

269 . How much does the property crunchy stand out in your thoughts about celery?

270 .How much does the property crunchy stand out in your thoughts about carrots?

271 . How much does the property crunchy stand out in your thoughts about rice krispies?

272.How much does the property crunchy stand out in your thoughts about apples?

273. How much does the property can walk stand out in your thoughts about man?

274. How much does the property can walk stand out in your thoughts about dogs?

275 . How much does the property can walk stand out in your thoughts about cats?

276 . How much does the property can walk stand out in your thoughts about animals?

277 .How much does the property can walk stand out in your thoughts about elephants?

278. How much does the property can walk stand out in your thoughts about birds?

279. How much does the property can walk stand out in your thoughts about insects? 
280. How much does the property ean walk stand out in your thoughts about horses?

281. How much does the property can walk stand out in your thoughts about cows?

282. How much does the property can walk stand out in your thoughts about sheep"?

283. How much does the property can walk stand out in your thoughts about donkeys?

284. How much does the property can walk stand out in your thoughts about eamels?

285 . How much does the property can walk stand out in your thoughts about robots?

286. How much does the property can fly stand out in your thoughts about birds?

287. How much does the property can fly stand out in your thoughts about airplanes?

288 . How much does the property can fly stand out in your thoughts about rockets?

289. How much does the property can fly stand out in your thoughts about insects?

290 . How much does the property can fly stand out in your thoughts about kites?

291. How much does the property can fly stand out in your thoughts about hang gliders?

292. How much does the property can fly stand out in your thoughts about bees?

293. How much does the property can fly stand out in your thoughts about butterflies?

294. How much does the property can fly stand out in your thoughts about flying saucers?

295. How much does the property can fly stand out in your thoughts about flies?

296. How much does the property can fly stand out in your thoughts about space shuttles?

297. How much does the property can fly stand out in your thoughts about helicopters?

298. How much does the property can fly stand out in your thoughts about eagles'?

299. How much does the property can fly stand out in your thoughts about hawks?

300. How much does the property can fly stand out in your thoughts about sparrows?

301. How much does the property can fly stand out in your thoughts about robins?

302. How much does the property can fly stand out in your thoughts about jets?

303. How much does the property ean fly stand out in your thoughts about Frisbees?

304. How much does the property red stand out in your thoughts about cardinals?

305. How much does the property red stand out in your thoughts about lips?

306. How much does the property red stand out in your thoughts about strawberries?

307.How much does the property red stand out in your thoughts about raspberries?

308. How much does the property red stand out in your thoughts about berries?

309. How much does the property red stand out in your thoughts about watermelon?

310. How much does the property red stand out in your thoughts about apples?

311. How much does the property red stand out in your thoughts about tomatoes?

312. How much does the property red stand out in your thoughts about blood?

313. How much does the property red stand out in your thoughts about roses?

314.How much does the property red stand out in your thoughts about stop signs? 
315. How much does the property red stand out in your thoughts about cherries?

316. How much does the property red stand out in your thoughts about hearts?

317. How much does the property red stand out in your thoughts about fire engines?

318. How much does the property red stand out in your thoughts about peppers?

319. How much does the property red stand out in your thoughts about cardinals?

320 . How much does the property can swim stand out in your thoughts about people?

321 . How much does the property can swim stand out in your thoughts about fish?

322. How much does the property can swim stand out in your thoughts about sharks'?

323. How much does the property can swim stand out in your thoughts about turtles?

324 . How much does the property can swim stand out in your thoughts about eels?

325 . How much does the property can swim stand out in your thoughts about ducks?

326 . How much does the property can swim stand out in your thoughts about swans?

327. How much does the property can swim stand out in your thoughts about dolphins?

328 . How much does the property can swim stand out in your thoughts about whales?

329. How much does the property can swim stand out in your thoughts about penguins?

330 . How much does the property has a tail stand out in your thoughts about animals?

331. How much does the property has a tail stand out in your thoughts about donkeys?

332. How much does the property has a tail stand out in your thoughts about horses?

333. How much does the property has a tail stand out in your thoughts about birds?

334. How much does the property has a tail stand out in your thoughts about whales?

335. How much does the property has a tail stand out in your thoughts about cats?

336. How much does the property has a tail stand out in your thoughts about elephants?

337. How much does the property has a tail stand out in your thoughts about rabbits?

338. How much does the property has a tail stand out in your thoughts about deer?

339. How much does the property has a tail stand out in your thoughts about rats?

340 . How much does the property has a tail stand out in your thoughts about mice?

341. How much does the property has a tail stand out in your thoughts about dogs'?

342. How much does the property has a tail stand out in your thoughts about lizards?

343. How much does the property has a tail stand out in your thoughts about lions?

344. How much does the property has a tail stand out in your thoughts about pigs?

345. How much does the property has a tail stand out in your thoughts about cows?

346. How much does the property has a tail stand out in your thoughts about kangaroos?

347 . How much does the property has a tail stand out in your thoughts about monkeys?

348. How much does the property has a tail stand out in your thoughts about foxes?

349. How much does the property has a tail stand out in your thoughts about kites?

350.How much does the property is alive stand out in your thoughts about humans?

351. How much does the property is alive stand out in your thoughts about animals? 
352. How much does the property is alive stand out in your thoughts about plants? 353. How much does the property is alive stand out in your thoughts about frogs? 354. How much does the property is alive stand out in your thoughts about bugs? 355. How much does the property is alive stand out in your thoughts about rabbits? 356 . How much does the property is alive stand out in your thoughts about worms? 357. How much does the property is alive stand out in your thoughts about bears? 358. How much does the property is alive stand out in your thoughts about dogs? 359. How much does the property is alive stand out in your thoughts about cats? 360 . How much does the property is alive stand out in your thoughts about fish? 361. How much does the property is alive stand out in your thoughts about horses? 362 .How much does the property is alive stand out in your thoughts about ants? 363. How much does the property is alive stand out in your thoughts about flies? 364. How much does the property is alive stand out in your thoughts about grass? 365 . How much does the property is alive stand out in your thoughts about flowers? 366. How much does the property is alive stand out in your thoughts about organisms? 367. How much does the property is alive stand out in your thoughts about bacteria? 368. How much does the property is alive stand out in your thoughts about mammals? 369. How much does the property is alive stand out in your thoughts about fungi? 370.How much does the property is alive stand out in your thoughts about birds? 371 . How much does the property is alive stand out in your thoughts about viruses? 372. How much does the property edible stand out in your thoughts about food? 373. How much does the property edible stand out in your thoughts about candy? 374. How much does the property edible stand out in your thoughts about vegetables? 375. How much does the property edible stand out in your thoughts about fruit? 376. How much does the property edible stand out in your thoughts about meat? 377 .How much does the property edible stand out in your thoughts about cereals? 378. How much does the property edible stand out in your thoughts about cookies? 379. How much does the property edible stand out in your thoughts about chicken? 380 . How much does the property edible stand out in your thoughts about hamburgers? 381. How much does the property edible stand out in your thoughts about bananas? 382. How much does the property edible stand out in your thoughts about apples? 383. How much does the property edible stand out in your thoughts about oranges? 384. How much does the property edible stand out in your thoughts about carrots? 385. How much does the property edible stand out in your thoughts about rice? 386. How much does the property edible stand out in your thoughts about noodles? 387. How much does the property edible stand out in your thoughts about ice cubes? 388. How much does the property edible stand out in your thoughts about fish? 
389. How much does the property edible stand out in your thoughts about cheese?

390. How much does the property leather stand out in your thoughts about pocketbooks?

391. How much does the property leather stand out in your thoughts about coats?

392. How much does the property leather stand out in your thoughts about saddles'?

393. How much does the property leather stand out in your thoughts about boots?

394.How much does the property leather stand out in your thoughts about watchbands"?

395. How much does the property leather stand out in your thoughts about belts?

\section{Set B}

396. How much does the property leather stand out in your thoughts about couches?

397. How much does the property leather stand out in your thoughts about car interiors?

398. How much does the property leather stand out in your thoughts about shoes?

399. How much does the property leather stand out in your thoughts about wailets?

400. How much does the property leather stand out in your thoughts about briefcases?

401. How much does the property has a handle stand out in your thoughts about cups?

402.How much does the property has a handle stand out in your thoughts about mugs?

403.How much does the property has a handle stand out in your thoughts about pots?

404. How much does the property has a handle stand out in your thoughts about pocketbooks?

405. How much does the property has a handle stand out in your thoughts about baskets?

406. How much does the property has a handle stand out in your thoughts about car doors?

407.How much does the property has a handle stand out in your thoughts about lunch boxes?

408. How much does the property has a handle stand out in your thoughts about toolboxes?

409. How much does the property has a handle stand out in your thoughts about briefcases?

410. How much does the property has a handle stand out in your thoughts about umbrellas?

411. How much does the property has a handle stand out in your thoughts about shopping bags?

412. How much does the property has a handle stand out in your thoughts about pans?

413. How much does the property sticky stand out in your thoughts about glue?

414. How much does the property sticky stand out in your thoughts about tape?

415.How much does the property sticky stand out in your thoughts about bubble gum?

416. How much does the property sticky stand out in your thoughts about tar? 
417. How much does the property sticky stand out in your thoughts about honey?

418. How much does the property sticky stand out in your thoughts about syrup?

419. How much does the property sticky stand out in your thoughts about molasses"?

420 . How much does the property sticky stand out in your thoughts about candy?

421. How much does the property sticky stand out in your thoughts about lollipops?

422. How much does the property sticky stand out in your thoughts about scotch tape?

423. How much does the property sticky stand out in your thoughts about packing tape'?

424. How much does the property sticky stand out in your thoughts about adhesives'?

425. How much does the property sticky stand out in your thoughts about band-ids?

426. How much does the property sticky stand out in your thoughts about rubber cement?

427. How much does the property sticky stand out in your thoughts about stickers?

428. How much does the property sticky stand out in your thoughts about jelly?

429. How much does the property sticky stand out in your thoughts about jam?

430. How much does the property sticky stand out in your thoughts about peanut butter?

431. How much does the property smelly stand out in your thoughts about garbage?

432. How much does the property smelly stand out in your thoughts about manure?

433. How much does the property smelly stand out in your thoughts about skunk?

434. How much does the property smelly stand out in your thoughts about feet?

435. How much does the property smelly stand out in your thoughts about ammonia?

436. How much does the property smelly stand out in your thoughts about bleach?

437. How much does the property smelly stand out in your thoughts about fish?

438. How much does the property smelly stand out in your thoughts about rotten eggs?

439. How much does the property smelly stand out in your thoughts about gym socks?

440. How much does the property smelly stand out in your thoughts about public bathrooms?

441. How much does the property smelly stand out in your thoughts about spoiled milk?

442. How much does the property smelly stand out in your thoughts about garlic?

443. How much does the property smelly stand out in your thoughts about onions?

444. How much does the property smelly stand out in your thoughts about sulfur?

445. How much does the property smelly stand out in your thoughts about body order?

446. How much does the property smelly stand out in your thoughts about halitosis?

447. How much does the property liquid stand out in your thoughts about water?

448. How much does the property liquid stand out in your thoughts about juice?

449. How much does the property liquid stand out in your thoughts about soda?

450 . How much does the property liquid stand out in your thoughts about beer?

451 . How much does the property liquid stand out in your thoughts about wine?

452. How much does the property liquid stand out in your thoughts about alcohol? 
453. How much does the property liquid stand out in your thoughts about blood?

454. How much does the property liquid stand out in your thoughts about rain?

455. How much does the property liquid stand out in your thoughts about milk:?

456. How much does the property liquid stand out in your thoughts about oil?

457. How much does the property liquid stand out in your thoughts about tears"?

458 . How much does the property liquid stand out in your thoughts about soup?

459. How much does the property liquid stand out in your thoughts about pools?

460 . How much does the property liquid stand out in your thoughts about oceans?

461. How much does the property hot stand out in your thoughts about suns"?

462. How much does the property hot stand out in your thoughts about fire?

463. How much does the property hot stand out in your thoughts about ovens?

464. How much does the property hot stand out in your thoughts about stovetops"?

465. How much does the property hot stand out in your thoughts about candles?

466. How much does the property hot stand out in your thoughts about fireplaces?

467. How much does the property hot stand out in your thoughts about heaters?

468. How much does the property hot stand out in your thoughts about summers?

469. How much does the property hot stand out in your thoughts about caycnne peppers?

470. How much does the property hot stand out in your thoughts about coffee?

471 . How much does the property hot stand out in your thoughts about tea?

472. How much does the property hot stand out in your thoughts about cinnamon?

473. How much does the property hot stand out in your thoughts about jalapenos?

474. How much does the property hot stand out in your thoughts about chipolte peppers?

475. How much does the property hot stand out in your thoughts about salsa?

476. How much does the property hot stand out in your thoughts about toasters'?

477. How much does the property hot stand out in your thoughts about boiling water"?

478. How much does the property hot stand out in your thoughts about steam?

479. How much does the property hot stand out in your thoughts about chili peppers"?

480 . How much does the property sweet stand out in your thoughts about candy?

481. How much does the property sweet stand out in your thoughts about fruit?

482. How much docs the property sweet stand out in your thoughts about cake?

483. How much does the property swect stand out in your thoughts about cookies"?

484. How much does the property sweet stand out in your thoughts about pies?

485. How much does the property sweet stand out in your thoughts about icc cream?

486. How much does the property sweet stand out in your thoughts about Popsicles?

487. How much does the property sweet stand out in your thoughts about juices?

488. How much does the property swcet stand out in your thoughts about sodas?

489. How much does the property sweet stand out in your thoughts about honey? 
490. How much does the property sweet stand out in your thoughts about chocolate?

491. How much does the property sweet stand out in your thoughts about apples?

492. How much does the property sweet stand out in your thoughts about caramel?

493. How much does the property sweet stand out in your thoughts about cherries'?

494. How much does the property sweet stand out in your thoughts about pastries?

495. How much does the property sweet stand out in your thoughts about cotton candy?

496. How much does the property sweet stand out in your thoughts about lemonade?

497. How much does the property sweet stand out in your thoughts about lollipops?

498. How much does the property sweet stand out in your thoughts about gumdrops"?

499. How much does the property sweet stand out in your thoughts about dessert?

500 . How much does the property sharp stand out in your thoughts about knives?

501 . How much does the property sharp stand out in your thoughts about swords?

502 . How much does the property sharp stand out in your thoughts about thumbtacks?

503. How much does the property sharp stand out in your thoughts about razors?

504. How much does the property sharp stand out in your thoughts about scissors?

505 .How much does the property sharp stand out in your thoughts about blades?

506 . How much does the property sharp stand out in your thoughts about needles?

507.How much does the property slimy stand out in your thoughts about worms?

508. How much does the property slimy stand out in your thoughts about mucus?

509. How much does the property slimy stand out in your thoughts about snails?

510 . How much does the property slimy stand out in your thoughts about leeches?

511. How much does the property slimy stand out in your thoughts about seaweed?

512. How much does the property slimy stand out in your thoughts about jellyfish?

513. How much does the property slimy stand out in your thoughts about oysters?

514.How much does the property slimy stand out in your thoughts about lotions?

515. How much does the property slimy stand out in your thoughts about oils?

516 .How much does the property slimy stand out in your thoughts about slugs?

517 .How much does the property noisy stand out in your thoughts about airplanes?

518. How much does the property noisy stand out in your thoughts about traffic?

519. How much does the property noisy stand out in your thoughts about drums?

520.How much does the property noisy stand out in your thoughts about sirens?

521 . How much does the property noisy stand out in your thoughts about horns?

522. How much does the property noisy stand out in your thoughts about cymbals?

523. How much does the property noisy stand out in your thoughts about parties?

524.How much does the property noisy stand out in your thoughts about concerts?

525. How much does the property noisy stand out in your thoughts about clubs?

526. How much does the property noisy stand out in your thoughts about drills? 
527. How much does the property noisy stand out in your thoughts about jackhammers? 528 . How much does the property noisy stand out in your thoughts about crying babies"? 529 . How much does the property noisy stand out in your thoughts about construction? 530 . How much does the property noisy stand out in your thoughts about fireworks? 531. How much does the property sour stand out in your thoughts about lemons?

532. How much does the property sour stand out in your thoughts about limes?

533. How much does the property sour stand out in your thoughts about vinegar? 534. How much does the property sour stand out in your thoughts about bad milk? 535. How much does the property sour stand out in your thoughts about green apples? 536 . How much does the property can hop stand out in your thoughts about rabbits? 537. How much does the property can hop stand out in your thoughts about kangaroos? 538. How much does the property can hop stand out in your thoughts about grasshoppers?

539. How much does the property can hop stand out in your thoughts about frogs? 540 . How much does the property can hop stand out in your thoughts about toads? 541. How much does the property can hop stand out in your thoughts about crickets? 542. How much does the property can hop stand out in your thoughts about Tigger? 543. How much does the property can hop stand out in your thoughts about fleas? 544.How much does the property has shells stand out in your thoughts about peanuts? 545.How much does the property has shells stand out in your thoughts about walnuts? 546.How much does the property has shells stand out in your thoughts about pecans? 547. How much does the property has shells stand out in your thoughts about chestnuts? 548. How much does the property has shells stand out in your thoughts about mollusks? 549. How much does the property has shells stand out in your thoughts about clams? 550.How much does the property has shells stand out in your thoughts about snails? 551. How much does the property has shells stand out in your thoughts about crabs? 552 .How much does the property has shells stand out in your thoughts about shrimps? 553.How much does the property has shells stand out in your thoughts about scallops? 554. How much does the property has shells stand out in your thoughts about lobsters? 555.How much does the property has shells stand out in your thoughts about seeds? 556. How much does the property has shells stand out in your thoughts about cashews? 557. How much does the property has shells stand out in your thoughts about pistachios? 558. How much does the property has shells stand out in your thoughts about turtles? 559. How much does the property has shells stand out in your thoughts about oysters? 560 . How much does the property has shells stand out in your thoughts about hermit crabs?

561. How much does the property has shells stand out in your thoughts about M\&M's? 
562 . How much does the property yellow stand out in your thoughts about a sun?

563 . How much does the property yellow stand out in your thoughts about lemons'?

564 . How much does the property yellow stand out in your thoughts about highlighters?

565 . How much does the property yellow stand out in your thoughts about lemonade'?

566 . How much does the property yellow stand out in your thoughts about bananas?

567 . How much does the property yellow stand out in your thoughts about tennis balls?

568 . How much does the property yellow stand out in your thoughts about corn?

569 . How much does the property yellow stand out in your thoughts about yield signs?

570 . How much does the property yellow stand out in your thoughts about school buses?

571 . How much does the property yellow stand out in your thoughts about bees?

572 .How much does the property yellow stand out in your thoughts about cheese?

573. How much does the property yellow stand out in your thoughts about taxis?

574. How much does the property yellow stand out in your thoughts about Big Bird?

575.How much does the property yellow stand out in your thoughts about legal pads?

576. How much does the property soft stand out in your thoughts about pillows?

577.How much does the property soft stand out in your thoughts about cotton?

578. How much does the property soft stand out in your thoughts about skin?

579. How much does the property soft stand out in your thoughts about fur?

580 .How much does the property soft stand out in your thoughts about kittens?

581. How much does the property soft stand out in your thoughts about puppies?

582 .How much does the property soft stand out in your thoughts about silk?

583.How much does the property soft stand out in your thoughts about cashmere?

584.How much does the property soft stand out in your thoughts about rabbits?

585 .How much does the property soft stand out in your thoughts about babies?

586 . How much does the property soft stand out in your thoughts about rose petals?

587 .How much does the property soft stand out in your thoughts about satin?

588. How much does the property soft stand out in your thoughts about velvet?

589. How much does the property soft stand out in your thoughts about feathers?

590 . How much does the property has seeds stand out in your thoughts about fruits?

591.How much does the property has seeds stand out in your thoughts about vegetables?

592. How much does the property has seeds stand out in your thoughts about trees?

593. How much does the property has seeds stand out in your thoughts about apples?

594. How much does the property has seeds stand out in your thoughts about grapes?

595. How much does the property has seeds stand out in your thoughts about tomatoes?

596. How much does the property has seeds stand out in your thoughts about pumpkins?

597. How much does the property has seeds stand out in your thoughts about sunflowers?

598. How much does the property has seeds stand out in your thoughts about oranges? 
599. How much does the property has seeds stand out in your thoughts about grapefruits?

600 . How much does the property has seeds stand out in your thoughts about watermelon?

601. How much does the property has seeds stand out in your thoughts about cucumbers?

602. How much does the property cold stand out in your thoughts about snow?

603. How much does the property cold stand out in your thoughts about freezers'?

604 . How much does the property cold stand out in your thoughts about cellars'?

605. How much does the property cold stand out in your thoughts about Antarctica?

606 . How much does the property cold stand out in your thoughts about ice cream?

607 . How much does the property cold stand out in your thoughts about ice cubes?

608. How much does the property cold stand out in your thoughts about Popsicles?

609 . How much does the property cold stand out in your thoughts about winters?

610 . How much does the property cold stand out in your thoughts about blizzards?

611 . How much does the property cold stand out in your thoughts about refrigerators?

612.How much does the property cold stand out in your thoughts about air-conditioning?

613.How much does the property cold stand out in your thoughts about swimming-pools?

614. How much does the property cold stand out in your thoughts about glaciers?

615 . How much does the property cold stand out in your thoughts about frozen-foods?

616. How much does the property cold stand out in your thoughts about icicles?

617. How much does the property skin stand out in your thoughts about animals?

618 . How much does the property skin stand out in your thoughts about people?

619. How much does the property skin stand out in your thoughts about grapes?

620 . How much does the property skin stand out in your thoughts about chickens"?

621 . How much does the property skin stand out in your thoughts about cows?

622 . How much does the property skin stand out in your thoughts about dogs?

623. How much does the property skin stand out in your thoughts about rabbits?

624. How much does the property skin stand out in your thoughts about birds?

625 . How much does the property skin stand out in your thoughts about monkeys?

626 . How much does the property skin stand out in your thoughts about onions?

627. How much does the property skin stand out in your thoughts about garlic?

628 . How much does the property skin stand out in your thoughts about apples?

629. How much does the property skin stand out in your thoughts about tomatoes?

630.How much does the property skin stand out in your thoughts about mammals?

631 . How much does the property skin stand out in your thoughts about reptiles?

632.How much does the property skin stand out in your thoughts about snakes?

633. How much does the property skin stand out in your thoughts about alligators? 
634. How much does the property skin stand out in your thoughts about fruits?

635. How much does the property skin stand out in your thoughts about vegetables?

636. How much does the property reflective stand out in your thoughts about mirrors"?

637. How much does the property reflective stand out in your thoughts about glass?

638. How much does the property reflective stand out in your thoughts about aluminum?

639 . How much does the property reflective stand out in your thoughts about chrome?

640 . How much does the property reflective stand out in your thoughts about steel?

641 . How much does the property salty stand out in your thoughts about potato chips?

642 . How much does the property salty stand out in your thoughts about pretzels?

643 . How much does the property salty stand out in your thoughts about nacho chips?

644 . How much does the property salty stand out in your thoughts about soy sauce?

645 . How much does the property salty stand out in your thoughts about seawater?

646 .How much does the property salty stand out in your thoughts about margaritas?

647 .How much does the property salty stand out in your thoughts about tears?

648 . How much does the property salty stand out in your thoughts about food?

649. How much does the property salty stand out in your thoughts about sweat?

650 .How much does the property salty stand out in your thoughts about popcorn?

651 .How much does the property salty stand out in your thoughts about peanuts?

652 .How much does the property salty stand out in your thoughts about nuts?

653.How much does the property salty stand out in your thoughts about crackers?

654 .How much does the property salty stand out in your thoughts about french fries?

655.How much does the property salty stand out in your thoughts about saltines?

656.How much does the property has leaves stand out in your thoughts about flowers?

657 .How much does the property has leaves stand out in your thoughts about bushes?

658. How much does the property has leaves stand out in your thoughts about vines?

659.How much does the property has leaves stand out in your thoughts about plants?

660 .How much does the property has leaves stand out in your thoughts about forests?

661 . How much does the property has leaves stand out in your thoughts about oaks?

662. How much does the property has leaves stand out in your thoughts about herbs?

663. How much does the property has leaves stand out in your thoughts about weeds?

664 . How much does the property has leaves stand out in your thoughts about lettuce?

665 . How much does the property has leaves stand out in your thoughts about spinach?

666 .How much does the property ferocious stand out in your thoughts about bears?

667 .How much does the property ferocious stand out in your thoughts about lions?

668 . How much does the property ferocious stand out in your thoughts about tigers?

669 . How much does the property ferocious stand out in your thoughts about alligators?

670. How much does the property ferocious stand out in your thoughts about crocodiles? 
671. How much does the property ferocious stand out in your thoughts about wild animals?

672. How much does the property transparent stand out in your thoughts about glass?

673. How much does the property transparent stand out in your thoughts about Plexiglas?

674. How much does the property transparent stand out in your thoughts about plastic"?

675. How much does the property transparent stand out in your thoughts about soda bottles?

676. How much does the property transparent stand out in your thoughts about air?

677. How much does the property transparent stand out in your thoughts about water?

678. How much does the property transparent stand out in your thoughts about oil?

679. How much does the property transparent stand out in your thoughts about tears?

680 . How much does the property transparent stand out in your thoughts about ice?

681 . How much does the property triangular stand out in your thoughts about yield signs?

682. How much does the property triangular stand out in your thoughts about a piece of pie?

683. How much does the property triangular stand out in your thoughts about sandwiches?

684. How much does the property triangular stand out in your thoughts about a slice of pizza?

685. How much does the property dangerous stand out in your thoughts about airplanes'?

686 . How much does the property dangerous stand out in your thoughts about wet roads?

687. How much does the property dangerous stand out in your thoughts about fire?

688. How much does the property dangerous stand out in your thoughts about earthquakes?

689. How much does the property dangerous stand out in your thoughts about hurricanes?

690. How much does the property dangerous stand out in your thoughts about tornados?

691. How much does the property dangerous stand out in your thoughts about robbers?

692. How much does the property dangerous stand out in your thoughts about murderers?

693. How much does the property dangerous stand out in your thoughts about snakes?

694. How much does the property dangerous stand out in your thoughts about cancers?

695. How much does the property dangerous stand out in your thoughts about strokes?

696. How much does the property dangerous stand out in your thoughts about wild animals?

697. How much does the property dangerous stand out in your thoughts about war?

698. How much does the property dangerous stand out in your thoughts about lions? 
699. How much does the property dangerous stand out in your thoughts about guns?

700 . How much does the property dangerous stand out in your thoughts about knives?

701.How much does the property dangerous stand out in your thoughts about drag racing?

702.How much does the property dangerous stand out in your thoughts about scuba diving?

703.How much does the property can roll stand out in your thoughts about wheels?

704.How much does the property can roll stand out in your thoughts about balls?

705. How much does the property can roll stand out in your thoughts about logs'?

706. How much does the property can roll stand out in your thoughts about tires?

707.How much does the property can roll stand out in your thoughts about snowballs?

708. How much does the property can roll stand out in your thoughts about pennies?

709. How much does the property furry stand out in your thoughts about cats?

710.How much does the property furry stand out in your thoughts about dogs?

711. How much does the property furry stand out in your thoughts about hamsters?

712. How much does the property furry stand out in your thoughts about gerbils?

713. How much does the property furry stand out in your thoughts about squirrels?

714. How much does the property furry stand out in your thoughts about rabbits?

715. How much does the property furry stand out in your thoughts about animals?

716. How much does the property tall stand out in your thoughts about trees?

717. How much does the property tall stand out in your thoughts about buildings?

718. How much does the property tall stand out in your thoughts about ladders?

719.How much does the property tall stand out in your thoughts about flagpoles?

720.How much does the property tall stand out in your thoughts about towers?

721. How much does the property tall stand out in your thoughts about streetlights?

722.How much does the property tall stand out in your thoughts about basketball players?

723.How much does the property tall stand out in your thoughts about telephone poles?

724.How much does the property tall stand out in your thoughts about mountains?

725.How much does the property green stand out in your thoughts about leaves?

726. How much does the property green stand out in your thoughts about grass?

727. How much does the property green stand out in your thoughts about trees?

728. How much does the property green stand out in your thoughts about vegetables?

729. How much does the property green stand out in your thoughts about broccoli?

730. How much does the property green stand out in your thoughts about peas?

731. How much does the property green stand out in your thoughts about money?

732. How much does the property green stand out in your thoughts about plants? 
733. How much does the property green stand out in your thoughts about apples?

734. How much does the property green stand out in your thoughts about traffic-lights?

735. How much does the property green stand out in your thoughts about frogs?

736. How much does the property green stand out in your thoughts about lizards?

737. How much does the property green stand out in your thoughts about moss?

738. How much does the property green stand out in your thoughts about pears"?

739. How much does the property green stand out in your thoughts about herbs?

740. How much does the property green stand out in your thoughts about artificial turf?

741. How much does the property green stand out in your thoughts about emeralds?

742. How much does the property green stand out in your thoughts about shamrocks?

743. How much does the property spicy stand out in your thoughts about Mexican food?

744. How much does the property spicy stand out in your thoughts about Indian food?

745. How much does the property spicy stand out in your thoughts about buffalo wings?

746. How much does the property spicy stand out in your thoughts about Cajun food?

747. How much does the property loud stand out in your thoughts about construction work?

748. How much does the property loud stand out in your thoughts about yelling?

749. How much does the property loud stand out in your thoughts about screaming?

750 . How much does the property loud stand out in your thoughts about crying?

751.How much does the property loud stand out in your thoughts about horns?

752. How much does the property loud stand out in your thoughts about traffic?

753.How much does the property loud stand out in your thoughts about earthquakes?

754.How much does the property loud stand out in your thoughts about accidents?

755.How much does the property loud stand out in your thoughts about motorcycles?

756. How much does the property loud stand out in your thoughts about jackhammers?

757.How much does the property loud stand out in your thoughts about airplanes?

758. How much does the property loud stand out in your thoughts about concerts?

759.How much does the property loud stand out in your thoughts about avalanches?

760. How much does the property loud stand out in your thoughts about explosions?

761. How much does the property loud stand out in your thoughts about gun-fire?

762. How much does the property loud stand out in your thoughts about sirens?

763. How much does the property loud stand out in your thoughts about fireworks?

764. How much does the property loud stand out in your thoughts about babies crying?

765.How much does the property loud stand out in your thoughts about stomping?

766. How much does the property loud stand out in your thoughts about thunder?

767. How much does the property loud stand out in your thoughts about rockets? 
768. How much does the property extravagant stand out in your thoughts about first class tickets?

769. How much does the property extravagant stand out in your thoughts about jewelry?

770 . How much does the property extravagant stand out in your thoughts about diamonds?

771. How much does the property extravagant stand out in your thoughts about weddings?

772. How much does the property extravagant stand out in your thoughts about Broadway plays?

773. How much does the property extravagant stand out in your thoughts about palaces?

774. How much does the property extravagant stand out in your thoughts about yachts?

775. How much does the property extravagant stand out in your thoughts about ball gowns?

776. How much does the property extravagant stand out in your thoughts about wedding cakes?

777.How much does the property extravagant stand out in your thoughts about fancy wines?

778. How much does the property spotted stand out in your thoughts about Dalmatians?

779. How much does the property spotted stand out in your thoughts about cows?

780. How much does the property spotted stand out in your thoughts about cheetahs?

781. How much does the property spotted stand out in your thoughts about leopards?

782.How much does the property freezing stand out in your thoughts about winters?

783.How much does the property freezing stand out in your thoughts about freezers?

784. How much does the property freezing stand out in your thoughts about air conditioning?

785. How much does the property freezing stand out in your thoughts about ice?

786. How much does the property freezing stand out in your thoughts about snow?

787. How much does the property freezing stand out in your thoughts about ice cream?

788. How much does the property freezing stand out in your thoughts about the North Pole?

789. How much does the property freezing stand out in your thoughts about Popsicles'?

790. How much does the property freezing stand out in your thoughts about sleet? 


\section{APPENDIX D \\ COMPLETE SET OF SURPRISE QUESTIONS-EXPERIMENT I}

\section{Set A}

1. Of all the things that are scary how many of them are snakes?

2. Of all the things that are scary how many of them are monsters?

3. Of all the things that are scary how many of them are vampires?

4. Of all the things that are scary how many of them are bats?

5. Of all the things that are scary how many of them are spiders?

6. Of all the things that are scary how many of them are haunted houses?

7. Of all the things that are scary how many of them are ghosts?

8. Of all the things that are scary how many of them are witches?

9. Of all the things that are scary how many of them are nightmares?

10. Of all the things that are fast how many of them are cars?

11. Of all the things that are fast how many of them are cheetahs?

12. Of all the things that are fast how many of them are planes?

13. Of all the things that are fast how many of them are milliseconds?

14. Of all the things that are fast how many of them are leopards?

15. Of all the things that are fast how many of them are roadrunners?

16. Of all the things that are fast how many of them are sports cars?

17. Of all the things that are fast how many of them are racecars?

18. Of all the things that are fast how many of them are track athletes?

19. Of all the things that are fast how many of them are horse races?

20. Of all the things that are fast how many of them are concords?

21. Of all the things that are fast how many of them are trains?

22. Of all the things that are fast how many of them are speedboats?

23. Of all the things that are fast how many of them are light?

24. Of all the things that are poisonous how many of them are cyanide?

25. Of all the things that are poisonous how many of them are lead?

26. Of all the things that are poisonous how many of them are chemicals?

27. Of all the things that are poisonous how many of them are venom?

28. Of all the things that are poisonous how many of them are strychnine?

29. Of all the things that are poisonous how many of them are ammonia?

30. Of all the things that are poisonous how many of them are bleach?

31. Of all the things that are poisonous how many of them are roach killers?

32. Of all the things that are poisonous how many of them are weed killer? 
33. Of all the things that are poisonous how many of them are spiders?

34. Of all the things that are poisonous how many of them are gas?

35. Of all the things that are poisonous how many of them are household cleaners?

36. Of all the things that are poisonous how many of them are berries?

37. Of all the things that are poisonous how many of them are hemlock?

38. Of all the things that are round how many of them are clock faces?

39. Of all the things that are round how many of them are traffic circles?

40. Of all the things that are round how many of them are rings?

41. Of all the things that are round how many of them have whcels?

42. Of all the things that are round how many of them are glasses?

43. Of all the things that are round how many of them are domes?

44. Of all the things that are round how many of them are plancts?

45. Of all the things that are round how many of them are moons?

46. Of all the things that are round how many of them are CD's?

47. Of all the things that are round how many of them are records?

48. Of all the things that are round how many of them are eyes?

49. Of all the things that are round how many of them are balls?

50. Of all the things that are round how many of them are lollipops?

51. Of all the things that are round how many of them are oranges?

52. Of all the things that are round how many of them are earth?

53. Of all the things that are round how many of them are the sun?

54. Of all the things that are round how many of them are cookies?

55. Of all the things that are clear how many of them are glass?

56. Of all the things that are clear how many of them are water?

57. Of all the things that are clear how many of them are tears?

58. Of all the things that are clear how many of them are plastic?

59. Of all the things that are clear how many of them are air"?

60. Of all the things that are clear how many of them are cellophane?

61. Of all the things that are clear how many of them are Plexiglas?

62. Of all the things that are clear how many of them are windows?

63. Of all the things that are clear how many of them are eyeglasses?

64. Of all the things that are clear how many of them are saran wrap?

65. Of all the things that are clear how many of them are broth?

66. Of all the things that are clear how many of them are contacts?

67. Of all the things that are grainy how many of them are bread?

68. Of all the things that are grainy how many of them are wood?

69. Of all the things that are grainy how many of them arc cereal? 
70. Of all the things that are grainy how many of them are sand?

71. Of all the things that are grainy how many of them are dirt?

72. Of all the things that are grainy how many of them are grout?

73. Of all the things that are grainy how many of them are sandpaper?

74. Of all the things that are grainy how many of them are sugar?

75. Of all the things that are wooden how many of them are desks?

76. Of all the things that are wooden how many of them are chairs?

77. Of all the things that are wooden how many of them are beds?

78. Of all the things that are wooden how many of them are houses?

79. Of all the things that are wooden how many of them are shutters?

80. Of all the things that are wooden how many of them are pirate legs?

81. Of all the things that are wooden how many of them are doors?

82. Of all the things that are wooden how many of them are birdhouses?

83. Of all the things that are wooden how many of them are fence posts?

84. Of all the things that are wooden how many of them are dressers?

85. Of all the things that are wooden how many of them are benches?

86. Of all the things that are wooden how many of them are crates?

87. Of all the things that are wooden how many of them are trees?

88. Of all the things that are wooden how many of them are baseball bats?

89. Of all the things that are wooden how many of them are puppets?

90. Of all the things that are wooden how many of them are blocks?

91. Of all the things that are wooden how many of them are floors?

92. Of all the things that are wooden how many of them are cabinets?

93. Of all the things that are wooden how many of them are oars?

94. Of all the things that are wooden how many of them are a log cabin?

95. Of all the things that are wooden how many of them are pencils?

96. Of all the things that are wooden how many of them are rafts?

97. Of all the things that have wheels how many of them are cars?

98. Of all the things that have wheels how many of them are trucks?

99. Of all the things that have wheels how many of them are bicycles?

100. Of all the things that have wheels how many of them are tricycles

101. Of all the things that have wheels how many of them are airplanes

102. Of all the things that have wheels how many of them are vans

103.Of all the things that have wheels how many of them are skateboards?

104. Of all the things that have wheels how many of them are scooters

105.Of all the things that have wheels how many of them are motorcycles

106. Of all the things that have wheels how many of them are wheelchairs? 
107. Of all the things that have wheels how many of them are office chairs?

108. Of all the things that have wheels how many of them are wagons?

109. Of all the things that have wheels how many of them are wheelbarrows?

110.Of all the things that have wheels how many of them are trains?

111. Of all the things that have wheels how many of them are unicycles?

112. Of all the things that have wheels how many of them are baby carriages?

113. Of all the things that have wheels how many of them are roller coasters?

114. Of all the things that have wheels how many of them are go-carts?

115.Of all the things that have wheels how many of them are buses?

116. Of all the things that have wheels how many of them are matchbox cars?

117. Of all the things that have wheels how many of them are roller-skates?

118. Of all the things that have wheels how many of them are roller blades?

119. Of all the things that have wheels how many of them are toys?

120.Of all the things that are rubber how many of them are tires?

121. Of all the things that are rubber how many of them are balls?

122. Of all the things that are rubber how many of them are dolls?

123. Of all the things that are rubber how many of them are garden hoses?

124. Of all the things that are rubber how many of them are latex gloves?

125. Of all the things that are rubber how many of them are rain boots?

126. Of all the things that are rubber how many of them are erasers?

127. Of all the things that are rubber how many of them are dish gloves?

128. Of all the things that are plastic how many of them are Tupperware?

129.Of all the things that are plastic how many of them are CD cases?

130. Of all the things that are plastic how many of them are cups?

131.Of all the things that are plastic how many of them are straws?

132. Of all the things that are plastic how many of them are shampoo bottles?

133. Of all the things that are plastic how many of them are soda bottles?

134. Of all the things that are plastic how many of them are pens?

135.Of all the things that are plastic how many of them are shopping bags?

136.Of all the things that are plastic how many of them are cassette tapes?

137. Of all the things that are plastic how many of them are milk jugs?

138. Of all the things that are plastic how many of them are bottles?

139. Of all the things that are orange how many of them are apricots?

140.Of all the things that are orange how many of them are carrots?

141. Of all the things that are orange how many of them are construction signs?

142. Of all the things that are orange how many of them are oranges?

143. Of all the things that are orange how many of them are Sunkist sodas? 
144. Of all the things that are orange how many of them are road cones?

145. Of all the things that are orange how many of them are tigers?

146. Of all the things that are orange how many of them are the sun?

147. Of all the things that are orange how many of them are pumpkins?

148. Of all the things that are juicy how many of them are grapes?

149. Of all the things that are juicy how many of them are citrus fruits?

150. Of all the things that are juicy how many of them are candy?

151.Of all the things that are juicy how many of them are melons?

152. Of all the things that are juicy how many of them are oranges?

153. Of all the things that are juicy how many of them are strawberries?

154.Of all the things that are juicy how many of them are plums?

155. Of all the things that are juicy how many of them are steaks?

156. Of all the things that are juicy how many of them are pineapples?

157. Of all the things that are juicy how many of them are apples?

158.Of all the things that are juicy how many of them are peaches?

159. Of all the things that are juicy how many of them are grapefruits?

160. Of all the things that are glass how many of them are drinking glasses?

161.Of all the things that are glass how many of them are TV screens?

162.Of all the things that are glass how many of them are windows?

163.Of all the things that are glass how many of them are mirrors?

164.Of all the things that are glass how many of them are vases?

165.Of all the things that are glass how many of them are bowls?

166.Of all the things that are glass how many of them are wine glasses?

167. Of all the things that are glass how many of them are greenhouses?

168. Of all the things that are glass how many of them are bottles?

169.Of all the things that are glass how many of them are cups?

170.Of all the things that are glass how many of them are light bulbs?

171.Of all the things that are glass how many of them are windshields?

172. Of all the things that store things how many of them are Tupperware?

173. Of all the things that store things how many of them are boxes?

174. Of all the things that store things how many of them are bags?

175.Of all the things that store things how many of them are closets?

176.Of all the things that store things how many of them are crates?

177. Of all the things that store things how many of them are dressers?

178.Of all the things that store things how many of them are cabinets?

179. Of all the things that store things how many of them are attics?

180.Of all the things that store things how many of them are garages? 
181. Of all the things that store things how many of them are trunks?

182. Of all the things that store things how many of them are drawers? 183. Of all the things that store things how many of them are suitcases? 184. Of all the things that store things how many of them are pantries? 185. Of all the things that store things how many of them are cellars? 186. Of all the things that store things how many of them are chests? 187.Of all the things that store things how many of them are lockers? 188. Of all the things that store things how many of them are folders? 189. Of all the things that store things how many of them are computer files? 190. Of all the things that store things how many of them are desks? 191. Of all the things that store things how many of them are shelves? 192. Of all the things that store things how many of them are refrigerators? 193. Of all the things that store things how many of them are time capsules? 194. Of all the things that store things how many of them are safes? 195. Of all the things that store things how many of them are sheds? 196. Of all the things that store things how many of them are banks? 197. Of all the things that are grown on trees how many of them are fruit? 198. Of all the things that are grown on trees how many of them are apples? 199. Of all the things that are grown on trees how many of them are oranges? 200. Of all the things that are grown on trees how many of them are bananas? 201. Of all the things that are grown on trees how many of them are leaves? 202. Of all the things that are grown on trees how many of them are bark? 203. Of all the things that are grown on trees how many of them are flowers? 204.Of all the things that are grown on trees how many of them are plums? 205.Of all the things that are grown on trees how many of them are pears? 206. Of all the things that are grown on trees how many of them are lemons? 207.Of all the things that are grown on trees how many of them are limes? 208.Of all the things that are grown on trees how many of them are grapefruits? 209. Of all the things that are grown on trees how many of them are funguses? 210. Of all the things that are grown on trees how many of them are peaches? 211.Of all the things that are grown on trees how many of them are branches? 212.Of all the things that are grown on trees how many of them are cherries? 213. Of all the things that are grown on trees how many of them are pinecones? 214. Of all the things that are grown on trees how many of them are nuts? 215.Of all the things that have fur how many of them are animals? 216.Of all the things that have fur how many of them are dogs? 217.Of all the things that have fur how many of them are cats? 
218. Of all the things that have fur how many of them are bears?

219. Of all the things that have fur how many of them are tigers?

220. Of all the things that have fur how many of them are lions?

221. Of all the things that have fur how many of them are raccoons?

222. Of all the things that have fur how many of them are rabbits?

223. Of all the things that have fur how many of them are squirrels?

224.Of all the things that have fur how many of them are deer?

225. Of all the things that have fur how many of them are mammals?

226. Of all the things that have fur how many of them are stuffed toys?

227. Of all the things that have fur how many of them are gerbils?

228. Of all the things that have fur how many of them are hamsters?

229.Of all the things that are blue how many of them are skies?

230. Of all the things that are blue how many of them are oceans?

231.Of all the things that are blue how many of them are water?

232. Of all the things that are blue how many of them are blood?

233. Of all the things that are blue how many of them are veins?

234. Of all the things that are blue how many of them are ink?

235. Of all the things that are blue how many of them are blueberries?

236. Of all the things that are blue how many of them are jeans?

237.Of all the things that are blue how many of them are lakes?

238. Of all the things that are blue how many of them are police cars?

239. Of all the things that are blue how many of them are baby boy's clothes?

240.Of all the things that are blue how many of them are police uniforms?

241.Of all the things that are blue how many of them are school uniforms?

242. Of all the things that are large how many of them are buildings?

243.Of all the things that are large how many of them are universes?

244.Of all the things that are large how many of them are elephants?

245.Of all the things that are large how many of them are bears?

246.Of all the things that are large how many of them are wooly mammoths?

247. Of all the things that are large how many of them are warehouses?

248. Of all the things that are large how many of them are oceans?

249. Of all the things that are large how many of them are office buildings?

250.Of all the things that are large how many of them are suns?

251.Of all the things that are large how many of them are moons?

252. Of all the things that are large how many of them are mountains?

253. Of all the things that are large how many of them are rainbows?

254. Of all the things that are large how many of them are seas? 
255. Of all the things that are large how many of them are forests?

256.Of all the things that are large how many of them are continents?

257. Of all the things that are large how many of them are cities?

258. Of all the things that are large how many of them are planets?

259.Of all the things that are large how many of them are galaxies?

260. Of all the things that are large how many of them are solar systems?

261. Of all the things that are large how many of them are whales?

262. Of all the things that are large how many of them are giraffes?

263. Of all the things that are crunchy how many of them are granola?

\section{Set B}

264. Of all the things that are crunchy how many of them are candy?

265. Of all the things that are crunchy how many of them are nuts?

266. Of all the things that are crunchy how many of them are pretzels?

267. Of all the things that are crunchy how many of them are crackers?

268. Of all the things that are crunchy how many of them are chips?

269. Of all the things that are crunchy how many of them are celery?

270. Of all the things that are crunchy how many of them are carrots?

271.Of all the things that are crunchy how many of them are rice krispies?

272. Of all the things that are crunchy how many of them are apples?

273. Of all the things that can walk how many of them are men?

274.Of all the things that can walk how many of them are dogs?

275 .Of all the things that can walk how many of them are cats?

276.Of all the things that can walk how many of them are animals?

277.Of all the things that can walk how many of them are elephants?

278.Of all the things that can walk how many of them are birds?

279.Of all the things that can walk how many of them are insects?

280. Of all the things that can walk how many of them are horses?

281 . Of all the things that can walk how many of them are cows?

282.Of all the things that can walk how many of them are sheep?

283.Of all the things that can walk how many of them are donkeys?

284. Of all the things that can walk how many of them are camels?

285 . Of all the things that can walk how many of them are robots?

286.Of all the things that can fly how many of them are birds?

287. Of all the things that can fly how many of them are airplanes?

288 . Of all the things that can fly how many of them are rockets? 
289. Of all the things that can fly how many of them are insects"?

290 . Of all the things that can fly how many of them are kites?

291. Of all the things that can fly how many of them are hang gliders?

292. Of all the things that can fly how many of them are bees?

293. Of all the things that can fly how many of them are butterflies?

294. Of all the things that can fly how many of them are flying saucers"?

295. Of all the things that can fly how many of them are flics

296. Of all the things that can fly how many of them are space shuttles?

297. Of all the things that can fly how many of them are helicopters?

298. Of all the things that can fly how many of them are cagles?

299. Of all the things that can fly how many of them are hawks?

300. Of all the things that can fly how many of them are sparrows?

301. Of all the things that can fly how many of them are robins?

302. Of all the things that can fly how many of them are jets?

303. Of all the things that can fly how many of them are Frisbees?

304. Of all the things that are red how many of them are cardinals?

305. Of all the things that are red how many of them are lips?

306. Of all the things that are red how many of them are strawberries?

307. Of all the things that are red how many of them are raspberries?

308. Of all the things that are red how many of them are berries?

309. Of all the things that are red how many of them are watermelon?

310. Of all the things that are red how many of them are apples?

311. Of all the things that are red how many of them are tomatoes?

312. Of all the things that are red how many of them are blood?

313.Of all the things that are red how many of them are roses?

314. Of all the things that are red how many of them are stop signs?

315. Of all the things that are red how many of them are cherries?

316.Of all the things that are red how many of them are hearts?

317. Of all the things that are red how many of them are fire engines"?

318. Of all the things that are red how many of them are peppers?

319. Of all the things that are red how many of them are cardinals?

320. Of all the things that can swim how many of them are people?

321. Of all the things that can swim how many of them are fish?

322. Of all the things that can swim how many of them are sharks?

323. Of all the things that can swin how many of them are turtles?

324. Of all the things that can swim how many of them are cels?

325. Of all the things that can swim how many of them are ducks? 
326. Of all the things that can swim how many of them are swans?

327. Of all the things that can swim how many of them are dolphins?

328. Of all the things that can swim how many of them are whales?

329. Of all the things that can swim how many of them are penguins?

330. Of all the things that have tails how many of them are animals?

331. Of all the things that have tails how many of them are donkeys?

332. Of all the things that have tails how many of them are horses'?

333. Of all the things that have tails how many of them are birds?

334. Of all the things that have tails how many of them are whales?

335. Of all the things that have tails how many of them are cats?

336. Of all the things that have tails how many of them are elephants?

337. Of all the things that have tails how many of them are rabbits?

338. Of all the things that have tails how many of them are deer?

339. Of all the things that have tails how many of them are rats?

340 . Of all the things that have tails how many of them are mice?

341 . Of all the things that have tails how many of them are dogs?

342 . Of all the things that have tails how many of them are lizards?

343. Of all the things that have tails how many of them are lions?

344 . Of all the things that have tails how many of them are pigs?

345. Of all the things that have tails how many of them are cows?

346. Of all the things that have tails how many of them are kangaroo?

347. Of all the things that have tails how many of them are monkeys?

348. Of all the things that have tails how many of them are foxes?

349. Of all the things that have tails how many of them are kites?

350 . Of all the things that are alive how many of them are humans?

351 . Of all the things that are alive how many of them are animals?

352. Of all the things that are alive how many of them are plants?

353. Of all the things that are alive how many of them are frogs?

354. Of all the things that are alive how many of them are bugs?

355.Of all the things that are alive how many of them are rabbits?

356.Of all the things that are alive how many of them are worms?

357. Of all the things that are alive how many of them are bears?

358. Of all the things that are alive how many of them are dogs?

359. Of all the things that are alive how many of them are cats?

360 . Of all the things that are alive how many of them are fish?

361 . Of all the things that are alive how many of them are horses?

362 . Of all the things that are alive how many of them are ants? 
363. Of all the things that are alive how many of them are flies?

364. Of all the things that are alive how many of them are grass?

365 . Of all the things that are alive how many of them are flowers?

366. Of all the things that are alive how many of them are organisms?

367. Of all the things that are alive how many of them are bacteria?

368. Of all the things that are alive how many of them are mammals?

369. Of all the things that are alive how many of them are fungi?

370 . Of all the things that are alive how many of them are birds?

371. Of all the things that are alive how many of them are viruses?

372. Of all the things that are edible how many of them are food?

373. Of all the things that are edible how many of them are candy?

374. Of all the things that are edible how many of them are vegetables?

375. Of all the things that are edible how many of them are fruit?

376. Of all the things that are edible how many of them are meat?

377. Of all the things that are edible how many of them are cereals?

378. Of all the things that are edible how many of them are cookies?

379. Of all the things that are edible how many of them are chicken?

380 . Of all the things that are edible how many of them are hamburgers?

381. Of all the things that are edible how many of them are bananas?

382. Of all the things that are edible how many of them are apples?

383. Of all the things that are edible how many of them are oranges?

384. Of all the things that are edible how many of them are carrots?

385. Of all the things that are edible how many of them are rice?

386. Of all the things that are edible how many of them are noodles?

387. Of all the things that are edible how many of them are ice cubes?

388. Of all the things that are edible how many of them are fish?

389. Of all the things that are edible how many of them are cheese?

390.Of all the things that are leather how many of them are pocketbooks?

391. Of all the things that are leather how many of them are coats?

392.Of all the things that are leather how many of them are saddles?

393. Of all the things that are leather how many of them are boots?

394. Of all the things that are leather how many of them are watchbands?

395. Of all the things that are leather how many of them are belts?

396.Of all the things that are leather how many of them are couches?

397. Of all the things that are leather how many of them are car interiors?

398. Of all the things that are leather how many of them are shoes?

399. Of all the things that are leather how many of them are wallets? 
400. Of all the things that are leather how many of them are briefcases? 401.Of all the things that have a handle how many of them are cups? 402. Of all the things that have a handle how many of them are mugs? 403. Of all the things that have a handle how many of them are pots? 404.Of all the things that have a handle how many of them are pocketbooks? 405. Of all the things that have a handle how many of them are baskets? 406. Of all the things that have a handle how many of them are car doors? 407. Of all the things that have a handle how many of them are lunch boxes? 408. Of all the things that have a handle how many of them are toolboxes? 409. Of all the things that have a handle how many of them are briefcases? 410 . Of all the things that have a handle how many of them are umbrellas? 411. Of all the things that have a handle how many of them are shopping bags? 412 . Of all the things that have a handle how many of them are pans? 413. Of all the things that are sticky how many of them are glue? 414. Of all the things that are sticky how many of them are tape? 415. Of all the things that are sticky how many of them are bubble gum? 416. Of all the things that are sticky how many of them are tar? 417. Of all the things that are sticky how many of them are honey? 418. Of all the things that are sticky how many of them are syrup? 419.Of all the things that are sticky how many of them are molasses? 420. Of all the things that are sticky how many of them are candy? 421.Of all the things that are sticky how many of them are lollipops? 422. Of all the things that are sticky how many of them are scotch-tape? 423.Of all the things that are sticky how many of them are packing tape? 424. Of all the things that are sticky how many of them are adhesives? 425.Of all the things that are sticky how many of them are band-aids? 426. Of all the things that are sticky how many of them are rubber cement? 427. Of all the things that are sticky how many of them are stickers? 428. Of all the things that are sticky how many of them are jelly? 429. Of all the things that are sticky how many of them are jam? 430. Of all the things that are sticky how many of them are peanut butter? 431.Of all the things that are smelly how many of them are garbage? 432. Of all the things that are smelly how many of them are manure? 433. Of all the things that are smelly how many of them are skunk? 434. Of all the things that are smelly how many of them are feet? 435. Of all the things that are smelly how many of them are ammonia? 436. Of all the things that are smelly how many of them are bleach? 
437. Of all the things that are smelly how many of them are fish?

438. Of all the things that are smelly how many of them are rotten eggs?

439. Of all the things that are smelly how many of them are gym socks?

440.Of all the things that are smelly how many of them are public bathroons?

441.Of all the things that are smelly how many of them are spoiled milk?

442. Of all the things that are smelly how many of them are garlic?

443. Of all the things that are smelly how many of them are onions?

444. Of all the things that are smelly how many of them are sulfur?

445. Of all the things that are smelly how many of them are body order?

446. Of all the thıngs that are smelly how many of them are halitosis?

447. Of all the things that are liquid how many of them are water?

448. Of all the things that are liquid how many of them are juice?

449. Of all the things that are liquid how many of them are soda?

450. Of all the things that are liquid how many of them are beer?

451.Of all the things that are liquid how many of them are wine?

452. Of all the things that are liquid how many of them are alcohol?

453. Of all the things that are liquid how many of them are blood?

454. Of all the things that are liquid how many of them are rain?

455. Of all the things that are liquid how many of them are milk?

456.Of all the things that are liquid how many of them are oil?

457. Of all the things that are liquid how many of them are tears?

458. Of all the things that are liquid how many of them are soup?

459. Of all the things that are liquid how many of them are pools?

460. Of all the things that are liquid how many of them are oceans?

461.Of all the things that are hot how many of them are suns?

462. Of all the things that are hot how many of them are fire?

463.Of all the things that are hot how many of them are ovens?

464. Of all the things that are hot how many of them are stovetops?

465.Of all the things that are hot how many of them are candles?

466. Of all the things that are hot how many of them are fireplaces?

467. Of all the things that are hot how many of them are heaters?

468. Of all the things that are hot how many of them are summers?

469. Of all the things that are hot how many of them are cayenne peppers?

470. Of all the things that are hot how many of them are coffee?

471. Of all the things that are hot how many of them are tea?

472. Of all the things that are hot how many of them are cinnamon?

473. Of all the things that are hot how many of them are jalapenos? 
474. Of all the things that are hot how many of them are chipolte peppers'?

475. Of all the things that are hot how many of them are salsa?

476. Of all the things that are hot how many of them are toaster ovens?

477. Of all the things that are hot how many of them are boiling water?

478. Of all the things that are hot how many of them are steam?

479. Of all the things that are hot how many of them are chili peppers?

480. Of all the things that are sweet how many of them are candy?

481. Of all the things that are sweet how many of them are fruit?

482. Of all the things that are sweet how many of them are cake?

483. Of all the things that are sweet how many of them are cookies?

484. Of all the things that are sweet how many of them are pies?

485. Of all the things that are sweet how many of them are ice cream?

486. Of all the things that are sweet how many of them are Popsicles?

487. Of all the things that are sweet how many of them are juices?

488. Of all the things that are sweet how many of them are sodas?

489. Of all the things that are sweet how many of them are honey?

490. Of all the things that are sweet how many of them are chocolate?

491. Of all the things that are sweet how many of them are apples?

492. Of all the things that are sweet how many of them are caramel?

493. Of all the things that are sweet how many of them are cherries?

494. Of all the things that are sweet how many of them are pastries?

495. Of all the things that are sweet how many of them are cotton candy?

496. Of all the things that are sweet how many of them are lemonade?

497. Of all the things that are sweet how many of them are lollipops?

498. Of all the things that are sweet how many of them are gumdrops?

499. Of all the things that are sweet how many of them are dessert?

500 . Of all the things that are sharp how many of them are knives?

501.Of all the things that are sharp how many of them are swords?

502. Of all the things that are sharp how many of them are thumbtacks?

503.Of all the things that are sharp how many of them are razors?

504.Of all the things that are sharp how many of them are scissors?

505.Of all the things that are sharp how many of them are blades?

506.Of all the things that are sharp how many of them are needles?

507. Of all the things that are slimy how many of them are worms?

508. Of all the things that are slimy how many of them are mucus?

509. Of all the things that are slimy how many of them are snails?

510.0 all the things that are slimy how many of them are leeches? 
511. Of all the things that are slimy how many of them are seaweed?

512. Of all the things that are slimy how many of them are jelly fish?

513. Of all the things that are slimy how many of them are oysters?

514. Of all the things that are slimy how many of them are lotions?

515. Of all the things that are slimy how many of them are oils?

516.Of all the things that are slimy how many of them are slugs?

517. Of all the things that are noisy how many of them are airplanes?

518. Of all the things that are noisy how many of them are traffic?

519 . Of all the things that are noisy how many of them are drums?

520 .Of all the things that are noisy how many of them are sirens?

521. Of all the things that are noisy how many of them are horns?

522 . Of all the things that are noisy how many of them are cymbals?

523. Of all the things that are noisy how many of them are parties?

524. Of all the things that are noisy how many of them are concerts?

525. Of all the things that are noisy how many of them are clubs?

526. Of all the things that are noisy how many of them are drills?

\section{Set C}

527. Of all the things that are noisy how many of them are jackhammers?

528 . Of all the things that are noisy how many of them are crying babies?

529. Of all the things that are noisy how many of them are construction?

530.Of all the things that are noisy how many of them are fireworks?

531.Of all the things that are sour how many of them are lemons?

532.Of all the things that are sour how many of them are limes?

533. Of all the things that are sour how many of them are vinegar?

534.Of all the things that are sour how many of them are bad milk?

535. Of all the things that are sour how many of them are green apples?

536.Of all the things that can hop how many of them are rabbits?

537. Of all the things that can hop how many of them are kangaroos?

538. Of all the things that can hop how many of them are grasshoppers?

539.Of all the things that can hop how many of them are frogs?

540.Of all the things that can hop how many of them are toads?

541.Of all the things that can hop how many of them are crickets?

542. Of all the things that can hop how many of them are Tigger?

543. Of all the things that can hop how many of them are fleas?

544.Of all the things that have shells how many of them are peanuts? 
545. Of all the things that have shells how many of them are walnuts? 546. Of all the things that have shells how many of them are pecans? 547. Of all the things that have shells how many of them are chestnuts? 548. Of all the things that have shells how many of them are mollusks? 549. Of all the things that have shells how many of them are clams? 550. Of all the things that have shells how many of them are snails? 551.Of all the things that have shells how many of them are crabs? 552. Of all the things that have shells how many of them are shrimps? 553.Of all the things that have shells how many of them are scallops? 554. Of all the things that have shells how many of them are lobsters? 555.Of all the things that have shells how many of them are seeds? 556. Of all the things that have shells how many of them are cashews? 557. Of all the things that have shells how many of them are pistachios? 558. Of all the things that have shells how many of them are turtles? 559 . Of all the things that have shells how many of them are oysters? 560. Of all the things that have shells how many of them are hermit crabs? 561. Of all the things that have shells how many of them are M\&M's? 562 . Of all the things that are yellow how many of them are suns? 563. Of all the things that are yellow how many of them are lemons? 564. Of all the things that are yellow how many of them are highlighters? 565.Of all the things that are yellow how many of them are lemonade? 566. Of all the things that are yellow how many of them are bananas? 567. Of all the things that are yellow how many of them are tennis balls? 568. Of all the things that are yellow how many of them are corn? 569.Of all the things that are yellow how many of them are yield signs? 570. Of all the things that are yellow how many of them are school buses?

571. Of all the things that are yellow how many of them are bees?

572. Of all the things that are yellow how many of them are cheese?

573. Of all the things that are yellow how many of them are taxis?

574. Of all the things that are yellow how many of them are Big Bird?

575.Of all the things that are yellow how many of them are legal pads?

576. Of all the things that are soft how many of them are pillows?

577. Of all the things that are soft how many of them are cotton?

578. Of all the things that are soft how many of them are skin?

579. Of all the things that are soft how many of them are fur?

580. Of all the things that are soft how many of them are kittens?

581. Of all the things that are soft how many of them are puppies? 
582. Of all the things that are soft how many of them are silk?

583. Of all the things that are soft how many of them are cashmere?

584. Of all the things that are soft how many of them are rabbits?

585. Of all the things that are soft how many of them are babies?

586. Of all the things that are soft how many of them are rose petals?

587. Of all the things that are soft how many of them are satin?

588. Of all the things that are soft how many of them are velvet?

589. Of all the things that are soft how many of them are feathers?

590. Of all the things that have seeds how many of them are fruits?

591. Of all the things that have seeds how many of them are vegetables?

592. Of all the things that have seeds how many of then are trees?

593. Of all the things that have seeds how many of them are apples?

594. Of all the things that have seeds how many of them are grapes?

595. Of all the things that have seeds how many of them are tomatoes?

596. Of all the things that have seeds how many of them are pumpkins?

597. Of all the things that have seeds how many of them are sunflowers?

598 . Of all the things that have seeds how many of them are oranges?

599. Of all the things that have seeds how many of them are grapefruits?

600 . Of all the things that have seeds how many of them are watermelon?

601 . Of all the things that have seeds how many of them are cucumbers?

602. Of all the things that are cold how many of them are snow?

603. Of all the things that are cold how many of them are freezers?

604. Of all the things that are cold how many of them are cellars?

605. Of all the things that are cold how many of them are Antarctica?

606. Of all the things that are cold how many of them are ice cream?

607 . Of all the things that are cold how many of them are ice cubes?

608 . Of all the things that are cold how many of then are Popsicles?

609 . Of all the things that are cold how many of them are winters?

610 . Of all the things that are cold how many of them are blizzards?

611 . Of all the things that are cold how many of them are refrigerators?

612.Of all the things that are cold how many of them are air-conditioning?

613.Of all the things that are cold how many of them are swimming-pools?

614 . Of all the things that are cold how many of them are glaciers?

615.Of all the things that are cold how many of them are frozen-foods?

616.Of all the things that are cold how many of them are icicles?

617. Of all the things that have skin how many of them are animals?

618.Of all the things that have skin how many of them are people? 
619. Of all the things that have skin how many of them are grapes? 620. Of all the things that have skin how many of them are chickens? 621 . Of all the things that have skin how many of them are cows? 622 . Of all the things that have skin how many of them are dogs? 623. Of all the things that have skin how many of them are rabbits? 624. Of all the things that have skin how many of them are birds? 625 . Of all the things that have skin how many of them are monkeys? 626. Of all the things that have skin how many of them are onions? 627 . Of all the things that have skin how many of them are garlic? 628 . Of all the things that have skin how many of them are apples? 629. Of all the things that have skin how many of them are tomatoes? 630 . Of all the things that have skin how many of them are mammals? 631. Of all the things that have skin how many of them are reptiles? 632. Of all the things that have skin how many of them are snakes? 633. Of all the things that have skin how many of them are alligators? 634. Of all the things that have skin how many of them are fruits? 635. Of all the things that have skin how many of them are vegetables? 636. Of all the things that are reflective how many of them are mirrors? 637. Of all the things that are reflective how many of them are glass? 638. Of all the things that are reflective how many of them are aluminum? 639. Of all the things that are reflective how many of them are chrome? 640 . Of all the things that are reflective how many of them are steel? 641 . Of all the things that are salty how many of them are potato chips? 642. Of all the things that are salty how many of them are pretzels? 643.Of all the things that are salty how many of them are nacho chips? 644. Of all the things that are salty how many of them are soy sauce? 645.Of all the things that are salty how many of them are seawater? 646.Of all the things that are salty how many of them are margaritas? 647. Of all the things that are salty how many of them are tears? 648. Of all the things that are salty how many of them are food? 649. Of all the things that are salty how many of them are sweat? 650 . Of all the things that are salty how many of them are popcorn? 651 . Of all the things that are salty how many of them are peanuts? 652. Of all the things that are salty how many of them are nuts? 653.Of all the things that are salty how many of them are crackers? 654. Of all the things that are salty how many of them are French fries? 655.Of all the things that are salty how many of them are saltines? 
656. Of all the things that have leaves how many of them are flowers? 657 . Of all the things that have leaves how many of them are bushes? 658 . Of all the things that have leaves how many of them are vines'? 659. Of all the things that have leaves how many of them are plants? 660 . Of all the things that have leaves how many of them are forests? 661 . Of all the things that have leaves how many of them are oaks? 662. Of all the things that have leaves how many of them are herbs? 663. Of all the things that have leaves how many of them are weeds? 664. Of all the things that have leaves how many of them are lettuces? 665. Of all the things that have leaves how many of them are spinach? 666. Of all the things that are ferocious how many of them are bears? 667. Of all the things that are ferocious how many of them are lions? 668. Of all the things that are ferocious how many of them are tigers? 669. Of all the things that are ferocious how many of them are alligators? 670. Of all the things that are ferocious how many of them are crocodiles? 671 . Of all the things that are ferocious how many of them are wild animals? 672. Of all the things that are transparent how many of them are glass? 673. Of all the things that are transparent how many of them are Plexiglas? 674.Of all the things that are transparent how many of them are plastic? 675.Of all the things that are transparent how many of them are soda bottles? 676. Of all the things that are transparent how many of them are air? 677. Of all the things that are transparent how many of them are water? 678. Of all the things that are transparent how many of them are oils? 679. Of all the things that are transparent how many of them are tears? 680. Of all the things that are transparent how many of them are ice? 681 .Of all the things that are triangular how many of them are yield signs? 682. Of all the things that are triangular how many of them are pieces of pie? 683. Of all the things that are triangular how many of them are sandwiches? 684. Of all the things that are triangular how many of them are slices of pizza? 685. Of all the things that are dangerous how many of them are airplanes? 686. Of all the things that are dangerous how many of them are wet roads? 687. Of all the things that are dangerous how many of them are fire? 688. Of all the things that are dangerous how many of them are earthquakes? 689. Of all the things that are dangerous how many of them are hurricanes? 690. Of all the things that are dangerous how many of them are tornados? 691. Of all the things that are dangerous how many of them are robbers? 692. Of all the things that are dangerous how many of them are murderers? 
693. Of all the things that are dangerous how many of them are snakes? 694. Of all the things that are dangerous how many of them are cancers? 695. Of all the things that are dangerous how many of them are strokes? 696. Of all the things that are dangerous how many of them are wild-animals? 697. Of all the things that are dangerous how many of them are war? 698. Of all the things that are dangerous how many of them are lions? 699. Of all the things that are dangerous how many of them are guns'? 700. Of all the things that are dangerous how many of them are knives? 701. Of all the things that are dangerous how many of them are drag racing? 702. Of all the things that are dangerous how many of them are seuba diving? 703. Of all the things that can roll how many of them are wheels? 704.Of all the things that can roll how many of them are balls? 705. Of all the things that can roll how many of them are logs? 706.Of all the things that can roll how many of them are tires? 707. Of all the things that can roll how many of them are snowballs? 708. Of all the things that can roll how many of them are pennies? 709. Of all the things that are furry how many of them are cats? 710.Of all the things that are furry how many of them are dogs? 711. Of all the things that are furry how many of them are hamsters? 712.Of all the things that are furry how many of them are gerbils? 713.Of all the things that are furry how many of them are squirrels? 714.Of all the things that are furry how many of them are rabbits? 715. Of all the things that are furry how many of them are animats? 716.Of all the things that are tall how many of them are trees?

717. Of all the things that are tall how many of them are buildings? 718. Of all the things that are tall how many of them are ladders? 719. Of all the things that are tall how many of them are flagpoles? 720. Of all the things that are tall how many of them are towers? 721. Of all the things that are tall how many of them are streetlights? 722. Of all the things that are tall how many of them are basketball players? 723. Of all the things that are tall how many of them are telephone poles? 724. Of all the things that are tall how many of them are mountains? 725. Of all the things that are green how many of them have leaves? 726. Of all the things that are green how many of them are grass? 727. Of all the things that are green how many of them are trees? 728. Of all the things that are green how many of them are vegetables? 729. Of all the things that are green how many of them are broceoli? 
730. Of all the things that are green how many of them are peas?

731. Of all the things that are green how many of them are money?

732. Of all the things that are green how many of them are plants?

733. Of all the things that are green how many of them are apples?

734. Of all the things that are green how many of them are traffic-lights?

735. Of all the things that are green how many of them are frogs?

736. Of all the things that are green how many of them are lizards?

737. Of all the things that are green how many of them are moss?

738. Of all the things that are green how many of them are pears?

739. Of all the things that are green how many of them are herbs?

740. Of all the things that are green how many of them are artificial turf?

741. Of all the things that are green how many of them are emeralds?

742. Of all the things that are green how many of them are shamrocks?

743. Of all the things that are spicy how many of them are Mexican foods?

744. Of all the things that are spicy how many of them are Indian foods?

745. Of all the things that are spicy how many of them are buffalo wings?

746. Of all the things that are spicy how many of them are Cajun food?

747. Of all the things that are loud how many of them are construction work?

748. Of all the things that are loud how many of them are yelling?

749. Of all the things that are loud how many of them are screaming?

750. Of all the things that are loud how many of them are crying?

751.Of all the things that are loud how many of them are horns?

752. Of all the things that are loud how many of them are traffic?

753.Of all the things that are loud how many of them are earthquakes?

754. Of all the things that are loud how many of them are accidents?

755.Of all the things that are loud how many of them are motorcycles?

756.Of all the things that are loud how many of them are jackhammers?

757. Of all the things that are loud how many of them are airplanes?

758. Of all the things that are loud how many of them are concerts?

759. Of all the things that are loud how many of them are avalanches?

760. Of all the things that are loud how many of them are explosions?

761. Of all the things that are loud how many of them are gun-fire?

762. Of all the things that are loud how many of them are sirens?

763. Of all the things that are loud how many of them are fireworks?

764. Of all the things that are loud how many of them are babies crying?

765.Of all the things that are loud how many of them are stomping?

766. Of all the things that are loud how many of them are thunder? 
767. Of all the things that are loud how many of them are rockets?

768. Of all the things that are extravagant how many of them are first class tickets?

769. Of all the things that are extravagant how many of them are jewelry?

770. Of all the things that are extravagant how many of them are diamonds?

771. Of all the things that are extravagant how many of them are weddings?

772. Of all the things that are extravagant how many of them are Broadway plays?

773. Of all the things that are extravagant how many of them are palaces?

774. Of all the things that are extravagant how many of them are yachts?

775. Of all the things that are extravagant how many of them are ball gowns?

776. Of all the things that are extravagant how many of them are wedding cakes?

777. Of all the things that are extravagant how many of them are fancy wines?

778. Of all the things that are spotted how many of them are Dalmatians?

779. Of all the things that are spotted how many of them are cows?

780. Of all the things that are spotted how many of them are cheetahs?

781.Of all the things that are spotted how many of them are leopards?

782. Of all the things that are freezing how many of them are winters?

783.Of all the things that are freezing how many of them are freezers?

784.Of all the things that are freezing how many of them are air conditioning?

785. Of all the things that are freezing how many of them are ice?

786. Of all the things that are freezing how many of them are snow?

787. Of all the things that are freezing how many of them are ice cream?

788. Of all the things that are freezing how many of them are the North Pole?

789. Of all the things that are freezing how many of them are Popsicles?

790. Of all the things that are freezing how many of them are sleet? 
APPENDIX E

EXPERIMENT 2 MEANS

\begin{tabular}{|c|c|c|c|c|}
\hline & Centrality 1 & Centrality 2 & Salience & Diagnosticity \\
\hline \multicolumn{5}{|l|}{ SCARY } \\
\hline$*$ SNAKE & 4.9 & 4.9 & 7.0 & 29.7 \\
\hline MONSTER & 6.6 & 6.1 & 6.8 & 27.6 \\
\hline VAMPIRE & 7.4 & 6.9 & 6.5 & 21.4 \\
\hline$\because \mathrm{BAT}$ & 5.8 & 4.0 & 6.1 & 23.4 \\
\hline$\because$ SPIDER & 5.8 & 4.7 & 6.2 & 31.5 \\
\hline HAUNTED HOUSE & 6.7 & 5.6 & 7.0 & 22.9 \\
\hline$\because$ GHOST & 5.8 & 4.6 & 7.2 & 20.1 \\
\hline WITCH & 5.4 & 3.7 & 5.8 & 16.1 \\
\hline NIGHTMARE & 8.4 & 7.7 & 9.0 & 46.5 \\
\hline \multicolumn{5}{|l|}{ FAST } \\
\hline$\because \mathrm{CAR}$ & 2.9 & 4.3 & 7.6 & 35.9 \\
\hline CHEETAH & 8.1 & 7.9 & 8.7 & 35.8 \\
\hline PLANE & 7.4 & 7.8 & 8.0 & 40.8 \\
\hline MILLISECOND & 9.3 & 8.1 & 8.9 & 48.1 \\
\hline LEOPARD & 7.3 & 7.6 & 7.7 & 24.7 \\
\hline ROA.DRUNNER & 8.0 & 8.1 & 7.6 & 26.7 \\
\hline$\because$ SPORTS CAR & 8.6 & 7.0 & 9.2 & 44.5 \\
\hline RACE CAR & 8.4 & 7.6 & 9.4 & 45.1 \\
\hline TRACK ATHLETES & 7.3 & 6.6 & 8.2 & 28.4 \\
\hline HORSE RACE & 7.2 & 7.1 & 7.3 & 27.7 \\
\hline CONCORDE & 8.2 & 7.7 & 7.8 & 44.7 \\
\hline TRAIN & 6.3 & 5.4 & 6.5 & 36.4 \\
\hline SPEED BOAT & 7.5 & 6.8 & 7.5 & 41.1 \\
\hline - $\quad$ LIGHT & 8.3 & 8.8 & 6.3 & 53.2 \\
\hline \multicolumn{5}{|l|}{ POISONOUS } \\
\hline CYANIDE & 8.7 & 9.0 & 8.4 & 48.9 \\
\hline LEAD & 7.5 & 8.1 & 7.1 & 36.1 \\
\hline$\because$ CHEMICALS & 5.9 & 5.3 & 7.8 & 61.2 \\
\hline$\because$ VENOM & 8.1 & 7.3 & 9.3 & 59.3 \\
\hline - $\quad$ STRYCHNINE & 8.5 & 8.5 & 5.9 & 51.2 \\
\hline - AMMONIA & 7.8 & 8.6 & 6.4 & 48.4 \\
\hline BLEACH & 7.3 & 8.8 & 6.8 & 49.6 \\
\hline ROACH KILLER & 8.2 & 7.7 & 7.4 & 51.2 \\
\hline WEED KILLER & 7.7 & 7.9 & 6.8 & 48.0 \\
\hline SPIDER & 3.6 & 3.7 & 5.8 & 37.1 \\
\hline GAS & 4.5 & 5.0 & 6.1 & 50.3 \\
\hline HOUSEHOLD CLEANER & 6.3 & 5.1 & 6.2 & 56.1 \\
\hline$\because$ BERRY & 2.3 & 2.5 & 4.8 & 21.9 \\
\hline HEMLOCK & 5.1 & 5.4 & 5.0 & 24.2 \\
\hline
\end{tabular}




\begin{tabular}{|c|c|c|c|c|}
\hline & Centrality 1 & Centrality 2 & Salience & Diagnosticity \\
\hline ROUND & & & & \\
\hline$\because$ CLOCKFACE & 5.1 & 3.9 & 8.2 & 31.1 \\
\hline TRAFFIC CIRCLE & 7.6 & 7.1 & 7.0 & 28.2 \\
\hline RING & 7.7 & 7.4 & 8.8 & 41.5 \\
\hline WHEEL & 8.7 & 9.2 & 9.1 & 38.0 \\
\hline$\because$ GLASSES & 5.6 & 4.2 & 6.8 & 36.5 \\
\hline DOME & 8.6 & 7.1 & 7.0 & 51.8 \\
\hline PLANET & 8.3 & 8.0 & 8.3 & 28.7 \\
\hline MOON & 7.9 & 7.5 & 7.7 & 27.5 \\
\hline $\mathrm{CD}$ & 8.6 & 8.5 & 8.1 & 51.6 \\
\hline RECORD & 9.0 & 8.7 & 7.9 & 45.9 \\
\hline EYES & 7.3 & 7.7 & 6.6 & 41.9 \\
\hline BALL & 7.8 & 7.4 & 9.1 & 61.9 \\
\hline$\therefore$ LOLLIPOP & 5.6 & 3.0 & 7.1 & 39.5 \\
\hline ORANGE & 8.9 & 7.0 & 8.3 & 45.2 \\
\hline - $\quad$ EARTH & 9.6 & 8.9 & 8.7 & 29.9 \\
\hline - SUN & 9.4 & 8.1 & 8.1 & 25.6 \\
\hline COOKIE & 5.8 & 2.8 & 7.3 & 33.5 \\
\hline
\end{tabular}

\begin{tabular}{ccccc}
\hline CLEAR & & & & \\
\hline GLASS & 4.2 & 3.4 & 8.6 & 48.6 \\
\hline WATER & 5.5 & 5.0 & 8.5 & 81.0 \\
\hline TEARS & 7.9 & 7.2 & 6.9 & 40.2 \\
\hline$*$ PLASTIC & 3.7 & 3.1 & 6.2 & 40.5 \\
\hline AIR & 7.2 & 5.4 & 7.7 & 59.7 \\
\hline$*$ CELLOPHANE & 6.4 & 5.1 & 7.9 & 36.6 \\
\hline PLEXIGLAS & 6.4 & 6.1 & 7.7 & 39.8 \\
\hline$\%$ WINDOW & 6.4 & 5.5 & 8.5 & 60.4 \\
\hline EYEGLASSES & 7.2 & 5.9 & 7.9 & 53.2 \\
\hline$\%$ SARAN WRAP & 6.7 & 5.1 & 8.2 & 46.3 \\
\hline BROTH & 4.5 & 3.2 & 4.8 & 25.4 \\
\hline CONTACTS & 6.1 & 6.1 & 7.8 & 42.8 \\
\hline \multicolumn{1}{c}{ GRAINY } & & & & \\
\hline BREAD & & & & \\
\hline WOOD & 6.1 & 4.9 & 4.9 & 32.7 \\
\hline CEREAL & 7.1 & 6.5 & 6.0 & 26.4 \\
\hline SAND & 7.3 & 5.1 & 5.6 & 33.1 \\
\hline DIRT & 9.4 & 8.2 & 9.1 & 60.4 \\
\hline GROUT & 7.7 & 7.2 & 7.4 & 45.2 \\
\hline SANDPAPER & 7.5 & 6.3 & 6.0 & 34.9 \\
\hline SUGAR & 9.2 & 8.7 & 8.1 & 38.0 \\
\hline & 8.6 & 7.5 & 7.2 & 38.3 \\
\hline WOODEN & & & & \\
\hline$\%$ DESK & 5.6 & 3.0 & 8.1 & 36.3 \\
\hline
\end{tabular}




\begin{tabular}{|c|c|c|c|c|}
\hline WOODEN cont' & Centrality 1 & Centrality 2 & Salience & Diagnosticity \\
\hline$\because$ CHAIR & 3.3 & 2.1 & 7.4 & 39.6 \\
\hline$\because$ BED & 3.2 & 2.9 & 6.3 & 35.3 \\
\hline$\therefore$ HOUSE & 4.6 & 3.5 & 7.5 & 46.1 \\
\hline$\because$ SHUTTERS & 5.1 & 3.8 & 7.7 & 30.6 \\
\hline$\because$ PIRATE LEGS & 7.1 & 5.1 & 8.2 & 24.1 \\
\hline$\div$ DOOR & 4.8 & 4.0 & 8.2 & 50.3 \\
\hline$\because$ BIRDHOUSES & 6.3 & 4.0 & 8.3 & 35.2 \\
\hline$\because$ FENCE POSTS & 6.8 & 4.3 & 8.3 & 37.7 \\
\hline$\because$ DRESSERS & 6.6 & 4.0 & 8.0 & 41.7 \\
\hline$\because \mathrm{BENCH}$ & 5.4 & 3.0 & 8.0 & 40.2 \\
\hline$\because$ CRATE & 3.4 & 3.1 & 6.3 & 34.8 \\
\hline TREE & 9.9 & 8.9 & 8.6 & 71.6 \\
\hline$\therefore$ BASEBALL BAT & 3.6 & 2.1 & 8.4 & 39.7 \\
\hline$\because$ PUPPET & 2.6 & 1.5 & 4.6 & 12.6 \\
\hline$\because \mathrm{BLOCKS}$ & 3.3 & 2.7 & 7.1 & 35.4 \\
\hline FLOORS & 3.6 & 2.2 & 7.1 & 47.5 \\
\hline$\because$ CABINETS & 6.2 & 4.1 & 7.6 & 52.0 \\
\hline OAR & 5.7 & 5.0 & 8.1 & 40.8 \\
\hline LOG CABIN & 9.2 & 8.8 & 9.4 & 45.8 \\
\hline$\because$ PENCILS & 4.7 & 3.6 & 7.6 & 38.1 \\
\hline RAFT & 3.7 & 3.6 & 5.5 & 16.2 \\
\hline \multicolumn{5}{|l|}{ HAVE (HAS) WHEELS } \\
\hline CAR & 8.3 & 8.5 & 7.9 & 64.7 \\
\hline TRUCK & 8.4 & 8.5 & 8.0 & 60.4 \\
\hline BICYCLE & 8.1 & 8.7 & 8.6 & 53.7 \\
\hline TRICYCLE & 8.4 & 8.7 & 8.2 & 43.2 \\
\hline - AIRPLANE & 5.8 & 8.0 & 5.1 & 41.3 \\
\hline - VAN & 8.5 & 8.7 & 7.1 & 49.7 \\
\hline SKATEBOARD & 7.8 & 8.6 & 7.3 & 39.8 \\
\hline SCOOTER & 7.9 & 8.4 & 7.1 & 45.2 \\
\hline MOTORCYCLE & 8.5 & 8.8 & 8.3 & 51.0 \\
\hline WHEELCHAIR & 8.9 & 9.0 & 8.7 & 47.7 \\
\hline$\because$ OFFICE CHAIR & 5.0 & 4.7 & 6.8 & 35.3 \\
\hline WAGON & 7.7 & 8.6 & 7.3 & 44.1 \\
\hline WHEELBARROW & 7.5 & 8.1 & 7.7 & 44.8 \\
\hline - TRAIN & 7.3 & 8.3 & 5.2 & 47.3 \\
\hline UNICYCLE & 8.0 & 7.9 & 8.5 & 30.1 \\
\hline - BABY CARRIAGE & 8.1 & 8.7 & 6.8 & 46.4 \\
\hline - ROLLERCOASTER & 7.2 & 8.6 & 5.1 & 38.7 \\
\hline - GO-CART & 7.6 & 8.8 & 6.6 & 33.1 \\
\hline - BUS & 8.4 & 8.9 & 7.6 & 48.1 \\
\hline MATCHBOX CAR & 7.2 & 7.4 & 7.0 & 40.8 \\
\hline ROLLER SKATES & 8.0 & 8.9 & 8.5 & 43.0 \\
\hline ROLLER BLADES & 8.1 & 8.6 & 8.4 & 46.7 \\
\hline$\because$ TOYS & 2.7 & 1.9 & 4.5 & 33.9 \\
\hline
\end{tabular}




\begin{tabular}{|c|c|c|c|c|}
\hline RUBBER & Centrality 1 & Centrality 2 & Salience & Diagnosticity \\
\hline TIRE & 7.2 & 7.1 & 9.1 & 51.6 \\
\hline$\because$ BALL & 4.4 & 3.9 & 7.2 & 41.2 \\
\hline$\div$ DOLL & 2.9 & 2.1 & 4.2 & 25.0 \\
\hline GARDEN HOSE & 8.6 & 7.0 & 6.8 & 33.4 \\
\hline LATEX GLOVES & 8.4 & 7.7 & 7.5 & 42.8 \\
\hline RAIN BOOTS & 6.9 & 6.2 & 7.6 & 39.8 \\
\hline ERASER & 8.0 & 6.1 & 6.9 & 45.6 \\
\hline DISH GLOVES & 8.6 & 6.9 & 7.2 & 39.0 \\
\hline \multicolumn{5}{|l|}{ PLASTIC } \\
\hline TUPPERWARE & 9.1 & 7.7 & 9.2 & 52.4 \\
\hline CD CASE & 7.4 & 6.7 & 7.0 & 35.7 \\
\hline$\div$ CUP & 3.1 & 3.5 & 7.8 & 40.3 \\
\hline STRAWS & 8.8 & 6.8 & 8.2 & 42.1 \\
\hline SHAMPOO BOTTLE & 8.4 & 6.3 & 8.0 & 41.4 \\
\hline$*$ SODA BOTTLE & 5.7 & 4.8 & 8.4 & 42.6 \\
\hline PEN & 6.2 & 5.2 & 6.4 & 40.8 \\
\hline$\therefore$ SHOPPING BAGS & 3.9 & 3.5 & 7.9 & 36.4 \\
\hline CASSETTE TAPES & 8.5 & 8.2 & 7.0 & 42.9 \\
\hline MILK JUG & 6.6 & 4.5 & 7.4 & 46.3 \\
\hline$\because$ BOTTLE & 4.5 & 2.2 & 6.8 & 47.8 \\
\hline \multicolumn{5}{|l|}{ ORANGE } \\
\hline APRICOT & 8.2 & 6.4 & 6.4 & 28.4 \\
\hline CARROT & 8.7 & 7.6 & 9.0 & 45.3 \\
\hline CONSTRUCTION SIGN & 7.1 & 5.7 & 7.8 & 46.3 \\
\hline ORANGE & 8.3 & 8.0 & 9.8 & 66.4 \\
\hline SUNKIST SODA & 7.5 & 7.6 & 8.8 & 47.3 \\
\hline ROAD CONE & 8.0 & 6.7 & 8.6 & 42.1 \\
\hline TIGER & 6.0 & 5.5 & 7.2 & 37.9 \\
\hline SUN & 4.9 & 5.8 & 6.6 & 26.1 \\
\hline$*$ PUMPKIN & 7.3 & 7.1 & 9.3 & 47.8 \\
\hline \multicolumn{5}{|l|}{ JUICY } \\
\hline GRAPE & 7.0 & 5.9 & 6.4 & 37.3 \\
\hline CITRUS FRUIT & 6.9 & 6.6 & 7.6 & 52.0 \\
\hline$\because$ CANDY & 2.3 & 2.9 & 4.5 & 17.9 \\
\hline MELON & 7.4 & 5.9 & 7.6 & 38.2 \\
\hline$\because$ ORANGE & 7.5 & 6.0 & 8.4 & 46.7 \\
\hline STRAWBERRY & 6.7 & 5.4 & 7.3 & 41.3 \\
\hline PLUM & 7.8 & 5.8 & 7.3 & 35.6 \\
\hline$\because$ STEAK & 4.8 & 3.9 & 7.0 & 35.5 \\
\hline PINEAPPLE & 7.3 & 6.0 & 7.2 & 45.6 \\
\hline$\because$ APPLE & 6.0 & 4.5 & 6.8 & 34.4 \\
\hline PEACH & 7.1 & 5.9 & 7.6 & 39.8 \\
\hline GRAPEFRUIT & 7.4 & 6.8 & 7.2 & 36.6 \\
\hline
\end{tabular}


GLASS

Centrality 1 Centrality 2 Salience Diagnosticity

\begin{tabular}{|c|c|c|c|c|}
\hline * DRINKING GLASS & 5.5 & 5.7 & 8.0 & 46.1 \\
\hline TV SCREEN & 9.2 & 7.1 & 6.8 & 54.1 \\
\hline$\because$ WINDOW & 8.2 & 4.8 & 8.9 & 67.1 \\
\hline MIRROR & 9.1 & 7.1 & 9.0 & 53.1 \\
\hline$\because$ VASE & 5.6 & 3.8 & 8.1 & 33.3 \\
\hline$\because$ BOWL & 3.5 & 2.4 & 6.3 & 27.3 \\
\hline WINE GLASS & 8.2 & 6.5 & 9.1 & 45.8 \\
\hline GREENHOUSE & 8.7 & 6.1 & 8.2 & 41.8 \\
\hline$\because$ BOTTLE & 3.6 & 2.4 & 7.5 & 43.6 \\
\hline$\therefore$ CUP & 2.9 & 1.8 & 6.3 & 28.8 \\
\hline - LIGHT BULB & 8.9 & 8.4 & 7.2 & 48.5 \\
\hline WINDSHIELD & 8.3 & 7.4 & 9.2 & 47.8 \\
\hline \multicolumn{5}{|l|}{ STORE(S) THINGS } \\
\hline TUPPERWARE & 7.3 & 8.0 & 8.6 & 39.4 \\
\hline $\mathrm{BOX}$ & 7.1 & 7.5 & 8.7 & 52.1 \\
\hline BAG & 6.2 & 7.0 & 6.8 & 36.7 \\
\hline CLOSET & 8.8 & 8.8 & 8.9 & 51.3 \\
\hline CRATE & 8.2 & 7.2 & 8.0 & 39.0 \\
\hline DRESSER & 8.9 & 8.3 & 8.6 & 38.4 \\
\hline CABINET & 8.7 & 8.9 & 8.8 & 41.9 \\
\hline ATTIC & 8.7 & 7.6 & 8.7 & 49.0 \\
\hline GARAGE & 8.8 & 7.9 & 8.3 & 44.2 \\
\hline TRUNK & 8.5 & 7.6 & 8.3 & 33.0 \\
\hline DRAWERS & 8.7 & 8.1 & 8.1 & 38.9 \\
\hline - SUITCASE & 7.7 & 8.3 & 6.9 & 33.9 \\
\hline PANTRY & 8.8 & 8.4 & 8.1 & 41.1 \\
\hline CELLAR & 8.3 & 7.5 & 8.5 & 43.3 \\
\hline CHEST & 8.4 & 7.8 & 8.6 & 37.6 \\
\hline LOCKER & 8.2 & 7.9 & 8.4 & 39.1 \\
\hline FOLDER & 7.6 & 7.8 & 8.0 & 38.5 \\
\hline COMPUTER FILE & 8.1 & 8.3 & 8.3 & 43.7 \\
\hline DESK & 7.4 & 6.7 & 7.6 & 46.5 \\
\hline SHELF & 7.7 & 7.2 & 7.9 & 48.5 \\
\hline$\because$ REFRIGERATOR & 8.7 & 9.1 & 8.0 & 46.6 \\
\hline TIME CAPSULE & 8.7 & 8.8 & 7.9 & 26.0 \\
\hline SAFE & 8.8 & 8.5 & 8.9 & 38.8 \\
\hline SHED & 8.3 & 8.3 & 8.5 & 33.2 \\
\hline - BANK & 8.5 & 8.1 & 5.8 & 43.3 \\
\hline
\end{tabular}

\section{GROWS ON TREES}

\begin{tabular}{ccccc}
\hline$\div \quad$ FRUIT & 6.6 & 4.3 & 7.4 & 59.0 \\
\hline APPLE & 8.8 & 8.7 & 8.2 & 39.8 \\
\hline ORANGE & 8.8 & 7.8 & 7.7 & 39.1 \\
\hline$\bullet \quad$ BANANA & 8.3 & 8.5 & 6.8 & 37.2 \\
\hline
\end{tabular}


GROWS ON TREES cont'

\section{Centrality 1 Centrality 2 Salience Diagnosticity}

\begin{tabular}{ccccc}
\hline$*$ LEAVES & 7.7 & 5.4 & 9.4 & 68.4 \\
\hline BARK & 9.1 & 7.3 & 8.9 & 60.8 \\
\hline$\bullet$ FLOWERS & 3.2 & 2.2 & 4.6 & 33.7 \\
\hline$\bullet$ PLUMS & 8.2 & 8.0 & 5.8 & 30.5 \\
\hline$\bullet$ PEARS & 8.5 & 8.4 & 6.9 & 32.0 \\
\hline$\bullet$ LEMONS & 8.4 & 8.0 & 6.0 & 32.4 \\
\hline$\bullet$ LIMES & 8.4 & 7.9 & 5.7 & 34.8 \\
\hline GRAPEFRUITS & 8.2 & 7.1 & 6.2 & 31.9 \\
\hline FUNGUS & 4.5 & 3.6 & 4.2 & 25.6 \\
\hline$\bullet \quad$ PEACHES & 8.8 & 8.4 & 7.1 & 29.9 \\
\hline BRANCHES & 9.5 & 6.4 & 8.9 & 63.4 \\
\hline$\bullet \quad$ CHERRIES & 8.5 & 7.9 & 6.4 & 27.3 \\
\hline PINECONES & 8.6 & 8.3 & 8.1 & 27.5 \\
\hline NUTS & 6.2 & 5.4 & 5.3 & 25.1 \\
\hline
\end{tabular}

\section{HAVE (HAS) FUR}

\begin{tabular}{|c|c|c|c|c|}
\hline$\because$ ANIMAL & 5.3 & 5.1 & 8.8 & 77.6 \\
\hline$\because \quad$ DOG & 7.2 & 7.0 & 8.8 & 40.6 \\
\hline$\because$ CAT & 7.0 & 6.5 & 9.0 & 37.8 \\
\hline BEAR & 8.8 & 8.5 & 8.6 & 33.5 \\
\hline TIGER & 8.5 & 7.7 & 8.0 & 28.3 \\
\hline LION & 8.6 & 8.5 & 8.2 & 31.3 \\
\hline - RACCOON & 8.6 & 8.4 & 7.4 & 29.5 \\
\hline RABBIT & 8.5 & 8.4 & 8.4 & 30.1 \\
\hline - $\quad$ SQUIRREL & 8.4 & 8.7 & 7.7 & 29.4 \\
\hline - DEER & 8.0 & 7.8 & 6.9 & 28.2 \\
\hline$\because$ MAMMAL & 4.7 & 4.1 & 7.0 & 60.0 \\
\hline$\because$ STUFFED TOY & 5.9 & 4.3 & 7.5 & 37.1 \\
\hline GERBIL & 7.5 & 7.6 & 7.5 & 30.8 \\
\hline HAMSTER & 7.2 & 8.1 & 7.5 & 29.4 \\
\hline
\end{tabular}

\begin{tabular}{|c|c|c|c|c|}
\hline (IS) BLUE & & & & \\
\hline$\because$ SKY & 5.6 & 4.6 & 9.2 & 39.6 \\
\hline$\because$ OCEAN & 6.3 & 4.1 & 9.0 & 36.9 \\
\hline$\because$ WATER & 3.7 & 3.2 & 8.2 & 37.1 \\
\hline BLOOD & 2.0 & 3.3 & 3.3 & 9.70 \\
\hline VEIN & 6.0 & 6.4 & 6.3 & 36.1 \\
\hline$\therefore$ INK & 2.7 & 2.1 & 7.8 & 34.1 \\
\hline$\because$ BLUEBERRIES & 6.9 & 6.5 & 9.4 & 37.6 \\
\hline$*$ JEANS & 4.4 & 2.4 & 9.0 & 41.4 \\
\hline$\because$ LAKES & 5.5 & 3.6 & 7.4 & 35.6 \\
\hline$\because \quad$ POLICE CAR & 3.4 & 2.2 & 7.2 & 24.1 \\
\hline $\begin{array}{l}\text { BABY BOY'S } \\
\text { CLOTHES }\end{array}$ & 4.4 & 2.2 & 8.3 & 29.4 \\
\hline
\end{tabular}


Centrality 1 Centrality 2 Salience Diagnosticity

IS BLUE Cont'

\begin{tabular}{ccccc}
\hline $\begin{array}{l}\text { POLICE } \\
\text { UNIFORMS }\end{array}$ & 5.9 & 3.6 & 8.4 & 38.0 \\
\hline $\begin{array}{l}\text { SCHOOL } \\
\text { UNIFORMS }\end{array}$ & 3.9 & 1.6 & 5.2 & 20.5 \\
\hline $\begin{array}{l}\text { (IS) LARGE } \\
\text { BUILDING }\end{array}$ & 4.6 & 2.6 & 7.7 & 39.6 \\
\hline UNIVERSE & 8.7 & 8.3 & 9.7 & 31.5 \\
\hline$\quad$ ELEPHANT & 7.3 & 6.3 & 8.8 & 32.7 \\
\hline BEAR & 6.0 & 5.8 & 7.5 & 25.1 \\
\hline WOOLY MAMMOUTH & 8.3 & 7.3 & 8.1 & 18.1 \\
\hline WAREHOUSE & 7.4 & 6.4 & 7.6 & 32.2 \\
\hline OCEAN & 9.3 & 8.2 & 9.4 & 29.5 \\
\hline OFFICE BUILDINGS & 5.9 & 8.7 & 7.5 & 38.8 \\
\hline SUN & 8.2 & 8.2 & 8.2 & 22.5 \\
\hline MOON & 7.7 & 7.4 & 7.3 & 22.7 \\
\hline$\quad$ MOUNTAINS & 7.7 & 6.6 & 8.7 & 33.4 \\
\hline RAINBOWS & 7.5 & 4.5 & 5.8 & 19.2 \\
\hline SEAS & 8.3 & 6.4 & 8.7 & 29.4 \\
\hline$\quad$ FOREST & 7.1 & 4.7 & 8.1 & 31.0 \\
\hline$\quad$ CONTINENT & 8.6 & 6.9 & 9.1 & 24.1 \\
\hline$\quad$ CITIES & 7.2 & 4.6 & 8.5 & 42.2 \\
\hline PLANET & 8.5 & 7.0 & 9.0 & 53.3 \\
\hline GALAXY & 9.4 & 8.4 & 9.5 & 30.8 \\
\hline SOLAR SYSTEM & 9.4 & 8.5 & 9.7 & 34.7 \\
\hline$\%$ WHALE & 7.6 & 6.8 & 9.1 & 31.8 \\
\hline GIRAFFE & 7.2 & 6.7 & 7.4 & 22.7 \\
\hline & & & & \\
\hline
\end{tabular}

(IS) CRUNCHY

\begin{tabular}{lllll}
\hline \multicolumn{1}{c}{$*$ GRANOLA } & 6.9 & 5.2 & 7.9 & 25.3 \\
\hline \multicolumn{1}{c}{ CANDY } & 5.0 & 2.0 & 5.9 & 30.7 \\
\hline NUTS & 7.8 & 6.9 & 7.4 & 39.8 \\
\hline PRETZELS & 7.2 & 6.6 & 7.9 & 38.1 \\
\hline CRACKERS & 7.5 & 7.2 & 7.5 & 44.6 \\
\hline CHIPS & 8.2 & 7.5 & 8.2 & 47.4 \\
\hline CELERY & 8.0 & 6.7 & 8.8 & 37.8 \\
\hline CARROTS & 7.8 & 7.3 & 8.4 & 37.3 \\
\hline RICE KRISPIES & 7.0 & 7.1 & 8.1 & 37.7 \\
\hline APPLES & 6.4 & 5.9 & 6.2 & 37.7 \\
\hline
\end{tabular}

\begin{tabular}{lllll}
\hline \multicolumn{1}{c}{ WALKS } & & & & \\
\hline \multicolumn{1}{c}{ MAN } & 3.9 & 3.3 & 9.1 & 59.2 \\
\hline DOG & 6.4 & 6.6 & 8.0 & 45.8 \\
\hline CAT & 6.6 & 6.7 & 7.9 & 45.0 \\
\hline ANIMAL & 6.1 & 5.7 & 7.5 & 67.6 \\
\hline
\end{tabular}




\begin{tabular}{|c|c|c|c|c|}
\hline WALKS cont' & Centrality 1 & Centrality 2 & Salience & Diagnosticity \\
\hline ELEPHANT & 7.4 & 7.2 & 7.6 & 36.1 \\
\hline BIRDS & 5.5 & 5.0 & 4.4 & 33.1 \\
\hline INSECTS & 4.6 & 4.4 & 4.4 & 37.0 \\
\hline HORSE & 7.6 & 7.5 & 7.9 & 41.1 \\
\hline COW & 7.3 & 7.2 & 7.2 & 41.8 \\
\hline SHEEP & 7.5 & 7.3 & 7.0 & 40.0 \\
\hline DONKEY & 7.7 & 7.1 & 7.4 & 38.1 \\
\hline CAMEL & 7.6 & 7.3 & 7.4 & 36.8 \\
\hline$\because \mathrm{ROBOT}$ & 4.4 & 2.9 & 5.6 & 22.2 \\
\hline \multicolumn{5}{|l|}{ CAN FLY } \\
\hline$*$ BIRD & 6.1 & 5.6 & 9.6 & 67.8 \\
\hline$\because$ AIRPLANE & 8.2 & 7.3 & 9.3 & 53.6 \\
\hline ROCKET & 7.5 & 7.1 & 8.3 & 41.0 \\
\hline$*$ INSECTS & 3.6 & 3.8 & 7.5 & 52.6 \\
\hline KITES & 6.1 & 6.2 & 7.7 & 41.0 \\
\hline HANG GLIDERS & 6.3 & 6.9 & 7.8 & 39.5 \\
\hline$\because$ BEE & 6.7 & 6.8 & 8.4 & 45.7 \\
\hline BUTTERFLY & 7.1 & 7.1 & 8.7 & 45.4 \\
\hline FLYING SAUCER & 6.9 & 7.1 & 7.6 & 25.1 \\
\hline FLY & 6.8 & 7.3 & 8.6 & 55.8 \\
\hline SPACE SHUTTLE & 7.4 & 8.2 & 8.4 & 39.8 \\
\hline HELICOPTER & 7.7 & 7.5 & 8.9 & 43.9 \\
\hline EAGLE & 7.8 & 7.9 & 8.9 & 42.1 \\
\hline HAWK & 7.7 & 7.7 & 8.8 & 43.1 \\
\hline$\because$ SPARROW & 7.0 & 7.4 & 8.8 & 46.5 \\
\hline ROBIN & 7.1 & 7.8 & 8.8 & 44.5 \\
\hline JET & 7.8 & 7.5 & 8.9 & 40.9 \\
\hline FRISBEE & 6.6 & 7.1 & 6.8 & 26.0 \\
\hline CARDINAL & 8.2 & 5.8 & 8.9 & 40.7 \\
\hline \multicolumn{5}{|l|}{ (IS) RED } \\
\hline$\%$ LIPS & 6.4 & 4.7 & 8.6 & 38.8 \\
\hline$*$ STRAWBERRIES & 7.7 & 6.3 & 9.1 & 53.3 \\
\hline RASPBERRIES & 6.4 & 4.3 & 7.5 & 40.8 \\
\hline BERRIES & 3.6 & 2.4 & 6.5 & 32.0 \\
\hline$\because$ WATERMELON & 5.6 & 5.5 & 7.4 & 42.0 \\
\hline APPLE & 3.2 & 2.6 & 8.4 & 45.3 \\
\hline$\because$ TOMATO & 4.9 & 5.0 & 9.4 & 95.3 \\
\hline BLOOD & 7.9 & 6.6 & 9.8 & 64.2 \\
\hline ROSES & 3.9 & 3.1 & 9.1 & 42.1 \\
\hline$\because$ STOP SIGNS & 7.9 & 7.9 & 9.8 & 58.6 \\
\hline$\because$ CHERRIES & 7.2 & 6.4 & 9.4 & 54.2 \\
\hline HEARTS & 7.4 & 6.1 & 9.3 & 62.1 \\
\hline FIRE ENGINES & 7.2 & 5.8 & 9.6 & 54.3 \\
\hline$\therefore$ PEPPERS & 4.1 & 2.5 & 7.2 & 30.0 \\
\hline CARDINALS & 7.1 & 5.9 & 8.8 & 41.4 \\
\hline
\end{tabular}




\section{Centrality 1 Centrality 2 Salience Diagnosticity}

\begin{tabular}{|c|c|c|c|c|}
\hline$\because$ PEOPLE & 3.9 & 3.7 & 6.8 & 44.4 \\
\hline FISH & 9.3 & 9.4 & 9.8 & 74.0 \\
\hline SHARKS & 9.2 & 9.7 & 9.5 & 61.1 \\
\hline$*$ TURTLE & 6.9 & 6.5 & 8.5 & 44.2 \\
\hline - EELS & 9.0 & 9.3 & 7.9 & 54.9 \\
\hline DUCKS & 7.3 & 8.5 & 8.2 & 56.4 \\
\hline SWANS & 7.6 & 8.6 & 8.1 & 49.4 \\
\hline DOLPHIN & 9.1 & 9.6 & 9.6 & 60.3 \\
\hline WHALE & 8.9 & 9.6 & 9.3 & 57.4 \\
\hline PENGUIN & 6.7 & 7.6 & 6.7 & 53.8 \\
\hline
\end{tabular}

\section{HAVE (HAS) A TAIL}

\begin{tabular}{lllll}
\hline ANIMAL & 4.7 & 4.0 & 7.4 & 71.1 \\
\hline DONKEY & 6.9 & 7.4 & 6.8 & 48.6 \\
\hline HORSE & 7.0 & 7.6 & 7.5 & 51.9 \\
\hline BIRD & 6.7 & 6.3 & 4.9 & 31.1 \\
\hline$\bullet \quad$ WHALE & 7.9 & 8.4 & 5.9 & 46.0 \\
\hline$\cdot$ CAT & 6.6 & 7.1 & 8.8 & 57.8 \\
\hline$\bullet \quad$ ELEPHANT & 7.8 & 8.3 & 5.8 & 51.9 \\
\hline RABBIT & 7.1 & 7.9 & 6.2 & 50.5 \\
\hline DEER & 5.9 & 6.9 & 5.6 & 33.4 \\
\hline RAT & 7.9 & 7.2 & 7.8 & 49.5 \\
\hline MOUSE & 7.6 & 7.7 & 8.0 & 50.1 \\
\hline \multirow{*}{*}{ DOG } & 5.8 & 5.3 & 8.8 & 49.2 \\
\hline LIZARD & 7.4 & 6.8 & 7.6 & 45.5 \\
\hline LION & 7.4 & 8.3 & 7.2 & 47.0 \\
\hline PIG & 7.1 & 7.5 & 7.1 & 46.0 \\
\hline$\bullet \quad$ COW & 7.5 & 7.6 & 6.2 & 43.5 \\
\hline$\bullet \quad$ KANGAROO & 7.0 & 8.1 & 5.5 & 38.0 \\
\hline MONKEY & 6.5 & 7.0 & 6.8 & 46.7 \\
\hline FOX & 7.8 & 8.2 & 7.0 & 43.8 \\
\hline KITE & 4.6 & 4.0 & 5.5 & 34.1 \\
\hline
\end{tabular}

\begin{tabular}{lllll} 
(IS) ALIVE & & & & \\
\hline HUMAN & 4.8 & 6.9 & 9.2 & 64.2 \\
\hline ANIMAL & 3.6 & 5.9 & 9.0 & 72.2 \\
\hline PLANT & 3.3 & 5.6 & 7.8 & 62.0 \\
\hline FROG & 2.8 & 4.7 & 8.3 & 41.0 \\
\hline BUG & 2.5 & 3.2 & 7.8 & 44.5 \\
\hline RABBIT & 3.8 & 6.0 & 8.4 & 45.7 \\
\hline WORM & 3.2 & 3.0 & 7.5 & 41.0 \\
\hline BEAR & 4.8 & 6.6 & 8.7 & 41.4 \\
\hline CAT & 4.0 & 6.8 & 8.7 & 49.0 \\
\hline & 3.9 & 6.4 & 8.7 & 47.7 \\
\hline
\end{tabular}


Centrality 1 Centrality 2 Salience Diagnosticity

(IS) ALIVE cont'

\begin{tabular}{|c|c|c|c|c|}
\hline$\because$ FISH & 2.8 & 4.2 & 8.4 & 44.0 \\
\hline$\because$ HORSE & 4.7 & 6.7 & 8.7 & 43.3 \\
\hline$\because$ ANT & 2.4 & 3.2 & 7.9 & 44.0 \\
\hline$\therefore$ FLY & 2.4 & 3.6 & 7.8 & 42.4 \\
\hline$\because$ GRASS & 3.4 & 3.1 & 6.7 & 42.2 \\
\hline$\because$ FLOWER & 3.5 & 3.2 & 7.9 & 42.5 \\
\hline$\because$ ORGANISM & 5.1 & 5.3 & 7.5 & 79.2 \\
\hline BACTERIA & 6.3 & 5.5 & 6.4 & 51.7 \\
\hline$\because$ MAMMAL & 3.7 & 5.8 & 8.9 & 68.2 \\
\hline FUNGUS & 6.3 & 5.0 & 6.0 & 37.9 \\
\hline$\div$ BIRD & 3.5 & 5.3 & 8.7 & 41.7 \\
\hline VIRUS & 6.9 & 6.0 & 6.5 & 36.3 \\
\hline
\end{tabular}

\section{(IS) EDIBLE}

\begin{tabular}{|c|c|c|c|c|}
\hline$\because$ FOOD & 4.2 & 6.0 & 9.6 & 91.6 \\
\hline$\because$ CANDY & 5.0 & 6.1 & 8.3 & 55.1 \\
\hline$\because$ VEGETABLE & 5.1 & 4.8 & 8.8 & 54.1 \\
\hline$\because$ FRUIT & 4.6 & 4.9 & 8.9 & 58.5 \\
\hline$\because$ MEAT & 5.1 & 4.4 & 8.1 & 51.3 \\
\hline CEREAL & 6.1 & 13 & 8.8 & 49.3 \\
\hline$\because$ COOKIE & 5.6 & 6.5 & 8.8 & 47.9 \\
\hline$\because$ CHICKEN & 5.2 & 5.0 & 8.2 & 48.0 \\
\hline$\because$ HAMBURGER & 5.1 & 5.1 & 8.3 & 44.8 \\
\hline$\because$ BANANA & 5.6 & 5.8 & 8.3 & 43.7 \\
\hline$\because$ APPLE & 5.1 & 6.2 & 8.7 & 45.6 \\
\hline$\because$ ORANGE & 5.8 & 6.0 & 8.7 & 43.5 \\
\hline$\because$ CARROT & 6.0 & 6.3 & 8.4 & 41.9 \\
\hline$\because$ RICE & 5.9 & 6.8 & 8.2 & 44.8 \\
\hline$\because \quad$ NOODLES & 5.7 & 6.9 & 8.6 & 45.2 \\
\hline - ICE CUBE & 6.8 & 7.0 & 5.4 & 34.6 \\
\hline$\because \quad$ FISH & 3.9 & 4.2 & 7.3 & 35.8 \\
\hline$\because$ CHEESE & 5.3 & 5.8 & 8.2 & 42.0 \\
\hline \multicolumn{5}{|l|}{ (IS) LEATHER } \\
\hline$\therefore$ POCKETBOOK & 3.3 & 1.8 & 6.6 & 32.2 \\
\hline$\because$ COAT & 1.6 & 1.5 & 6.4 & 37.3 \\
\hline SADDLE & 6.8 & 6.5 & 7.6 & 43.7 \\
\hline$\div \mathrm{BOOT}$ & 4.2 & 3.5 & 7.1 & 38.5 \\
\hline$\therefore$ WATCHBAND & 2.1 & 2.2 & 6.2 & 34.7 \\
\hline$\because$ BELT & 4.7 & 3.2 & 8.2 & 50.4 \\
\hline$\because \mathrm{COUCH}$ & 2.0 & 1.8 & 6.3 & 28.8 \\
\hline$\because$ CAR INTERIOR & 2.0 & 1.4 & 6.3 & 31.6 \\
\hline$\therefore$ SHOE & 2.2 & 1.7 & 6.5 & 45.1 \\
\hline$\because$ WALLET & 3.1 & 2.2 & 8.2 & 46.3 \\
\hline$\because \quad$ BRIEFCASE & 4.4 & 3.4 & 6.5 & 48.5 \\
\hline
\end{tabular}




\section{Centrality 1 Centrality 2 Salience Diagnosticity}

\begin{tabular}{lllll}
\hline CUP & 3.3 & 3.1 & 4.9 & 36.2 \\
\hline MUG & 5.9 & 6.5 & 7.6 & 56.3 \\
\hline POT & 6.9 & 6.7 & 7.4 & 53.1 \\
\hline POCKETBOOK & 4.1 & 4.5 & 5.7 & 54.5 \\
\hline BASKET & 5.3 & 5.5 & 5.5 & 52.9 \\
\hline \multicolumn{1}{c}{ CAR DOOR } & 9.1 & 8.9 & 6.3 & 65.1 \\
\hline LUNCH BOX & 6.8 & 7.6 & 5.8 & 57.8 \\
\hline TOOLBOX & 6.7 & 7.6 & 5.6 & 57.2 \\
\hline BRIEFCASE & 6.9 & 7.5 & 6.0 & 58.4 \\
\hline \multicolumn{1}{c}{ UMBRELLA } & 8.4 & 8.7 & 5.2 & 59.8 \\
\hline SHOPPING BAG & 5.8 & 5.0 & 5.2 & 60.2 \\
\hline PAN & 7.3 & 7.0 & 6.3 & 43.8 \\
\hline
\end{tabular}

\begin{tabular}{|c|c|c|c|c|}
\hline (IS) STICKY & & & & \\
\hline GLUE & 8.2 & 7.9 & 8.4 & 56.8 \\
\hline TAPE & 8.2 & 7.6 & 7.5 & 55.5 \\
\hline BUBBLE GUM & 7.5 & 8.2 & 7.8 & 51.3 \\
\hline - TAR & 8.7 & 8.1 & 7.1 & 51.5 \\
\hline - HONEY & 9.3 & 9.0 & 6.9 & 51.2 \\
\hline - SYRUP & 8.8 & 8.9 & 7.2 & 52.3 \\
\hline - MOLASSES & 8.7 & 8.4 & 6.9 & 50.9 \\
\hline CANDY & 5.5 & 6.6 & 5.1 & 42.4 \\
\hline - LOLLIPOP & 7.1 & 7.8 & 5.4 & 49.9 \\
\hline SCOTCH TAPE & 7.4 & 7.5 & 6.9 & 44.1 \\
\hline PACKING TAPE & 8.0 & 8.0 & 7.0 & 43.4 \\
\hline ADHESIVE & 8.0 & 7.7 & 7.1 & 45.0 \\
\hline BAND-AID & 6.7 & 6.4 & 5.8 & 38.6 \\
\hline RUBBER CEMENT & 7.5 & 7.5 & 6.3 & 37.4 \\
\hline STICKER & 7.1 & 6.7 & 6.4 & 50.2 \\
\hline - JELLY & 6.9 & 7.2 & 4.3 & 38.2 \\
\hline - JAM & 7.0 & 7.1 & 4.3 & 38.6 \\
\hline PEANUT BUTTER & 7.1 & 7.0 & 4.5 & 36.8 \\
\hline \multicolumn{5}{|l|}{ (IS) SMELLY } \\
\hline$\because$ GARBAGE & 7.0 & 6.4 & 8.6 & 59.3 \\
\hline$\because$ MANURE & 8.8 & 8.1 & 9.5 & 52.2 \\
\hline$\because \quad$ SKUNKS & 8.2 & 7.8 & 9.4 & 51.9 \\
\hline$\because$ FOOT & 4.9 & 4.1 & 6.4 & 40.4 \\
\hline - $\quad$ AMMONIA & 8.7 & 8.2 & 6.8 & 37.2 \\
\hline - BLEACH & 8.6 & 7.8 & 6.5 & 37.2 \\
\hline FISH & 6.8 & 7.0 & 7.7 & 45.3 \\
\hline ROTTEN EGG & 9.0 & 8.9 & 9.5 & 56.0 \\
\hline$\therefore$ GYM SOCK & 7.6 & 6.8 & 8.0 & 44.0 \\
\hline PUBLIC BATHROOM & 6.9 & 6.0 & 7.6 & 49.5 \\
\hline
\end{tabular}


(IS) SMELLY Cont'

Centrality 1 Centrality 2 Salience Diagnosticity

\begin{tabular}{ccccc}
\hline SPOILED MILK & 9.1 & 8.5 & 7.9 & 47.5 \\
\hline$\bullet \quad$ GARLIC & 8.1 & 7.5 & 6.6 & 37.4 \\
\hline ONION & 7.5 & 7.1 & 6.5 & 33.7 \\
\hline SULFUR & 7.7 & 8.2 & 7.1 & 45.2 \\
\hline BODY ODOR & 7.4 & 6.6 & 7.9 & 50.1 \\
\hline$\bullet$ HALITOSIS & 8.8 & 7.4 & 4.8 & 34.9 \\
\hline
\end{tabular}

\begin{tabular}{|c|c|c|c|c|}
\hline \multicolumn{5}{|l|}{ (IS) LIQUID } \\
\hline$*$ WATER & 6.8 & 7.0 & 9.4 & 74.5 \\
\hline JUICE & 7.3 & 7.9 & 7.5 & 52.7 \\
\hline - SODA & 8.8 & 8.4 & 7.0 & 50.4 \\
\hline - $\quad$ BEER & 9.3 & 8.7 & 7.2 & 49.8 \\
\hline - WINE & 9.3 & 8.9 & 7.1 & 46.3 \\
\hline - ALCOHOL & 9.1 & 8.6 & 7.2 & 54.3 \\
\hline BLOOD & 7.1 & 8.2 & 5.4 & 52.0 \\
\hline RAIN & 6.9 & 8.2 & 8.0 & 57.1 \\
\hline MILK & 6.8 & 7.9 & 6.4 & 42.1 \\
\hline$\cdot$ OIL & 8.1 & 8.6 & 5.4 & 42.1 \\
\hline - $\quad$ TEAR & 8.6 & 8.9 & 5.6 & 53.0 \\
\hline - SOUP & 7.7 & 7.9 & 5.7 & 50.3 \\
\hline - POOL & 8.2 & 8.3 & 7.8 & 59.9 \\
\hline - OCEAN & 9.0 & 9.5 & 8.0 & 75.9 \\
\hline \multicolumn{5}{|l|}{ (IS) HOT } \\
\hline SUN & 8.0 & 9.1 & 9.1 & 66.5 \\
\hline FIRE & 8.6 & 9.4 & 9.4 & 70.4 \\
\hline$\because$ OVEN & 3.5 & 6.1 & 7.9 & 41.4 \\
\hline$\because$ STOVE & 2.9 & 5.6 & 7.5 & 42.0 \\
\hline CANDLE & 3.4 & 5.9 & 5.9 & 35.5 \\
\hline FIREPLACE & 3.9 & 6.1 & 7.2 & 42.0 \\
\hline$\because$ HEATER & 4.6 & 5.3 & 7.6 & 46.2 \\
\hline$\because$ SUMMER & 4.1 & 4.4 & 7.8 & 41.9 \\
\hline CAYENNE PEPPER & 7.1 & 7.4 & 7.7 & 41.7 \\
\hline$*$ COFFEE & 2.8 & 3.0 & 6.9 & 29.2 \\
\hline$\because$ TEA & 3.3 & 3.0 & 6.7 & 25.4 \\
\hline CINNAMON & 2.3 & 3.1 & 3.1 & 13.0 \\
\hline JALAPENO & 6.2 & 7.6 & 8.7 & 45.4 \\
\hline CHIPOLTE & 7.0 & 7.5 & 7.0 & 35.9 \\
\hline SALSA & 3.8 & 3.4 & 6.2 & 26.7 \\
\hline TOASTER & 3.8 & 3.9 & 5.6 & 40.0 \\
\hline BOILING WATER & 9.1 & 9.2 & 9.3 & 58.3 \\
\hline STEAM & 7.7 & 7.6 & 7.5 & 40.9 \\
\hline CHILI PEPPER & 6.9 & 7.6 & 8.1 & 45.3 \\
\hline
\end{tabular}




\section{Centrality 1 Centrality 2 Salience Diagnosticity}

(IS) SWEET

\begin{tabular}{lllll}
\multicolumn{1}{c}{ (IS) SWEET } & & & & \\
\hline CANDY & 6.3 & 4.1 & 8.8 & 52.6 \\
\hline FRUIT & 4.3 & 3.5 & 5.6 & 41.6 \\
\hline CAKE & 6.2 & 4.9 & 7.9 & 44.8 \\
\hline COOKIE & 6.5 & 4.9 & 7.6 & 44.5 \\
\hline PIE & 6.9 & 4.6 & 7.5 & 36.1 \\
\hline ICE CREAM & 6.9 & 5.6 & 7.4 & 47.9 \\
\hline POPSICLE & 7.0 & 5.0 & 6.4 & 38.6 \\
\hline JUICE & 5.3 & 4.1 & 6.0 & 38.5 \\
\hline SODA & 7.0 & 4.9 & 6.4 & 40.9 \\
\hline HONEY & 7.9 & 8.6 & 7.9 & 46.7 \\
\hline CHOCOLATE & 6.0 & 6.3 & 7.9 & 52.7 \\
\hline APPLE & 5.3 & 3.8 & 4.4 & 21.9 \\
\hline CARAMEL & 7.1 & 6.7 & 6.8 & 39.2 \\
\hline CHERRY & 6.3 & 4.1 & 5.2 & 28.2 \\
\hline PASTRY & 6.9 & 5.4 & 7.1 & 46.3 \\
\hline COTTON CANDY & 8.1 & 7.4 & 8.4 & 49.1 \\
\hline LEMONADE & 5.4 & 4.9 & 4.4 & 41.0 \\
\hline LOLLIPOP & 6.8 & 5.3 & 7.5 & 44.4 \\
\hline GUMDROP & 7.1 & 5.4 & 7.1 & 39.9 \\
\hline DESSERT & 6.4 & 4.7 & 7.8 & 59.1 \\
\hline
\end{tabular}

\begin{tabular}{|c|c|c|c|c|}
\hline \multicolumn{5}{|l|}{ (IS) SHARP } \\
\hline$*$ KNIFE & 5.9 & 5.0 & 9.5 & 60.1 \\
\hline$\because$ SWORD & 6.4 & 5.7 & 9.4 & 46.0 \\
\hline THUMBTACK & 6.2 & 6.3 & 7.2 & 48.1 \\
\hline$\because$ RAZOR & 7.1 & 5.3 & 9.2 & 58.9 \\
\hline$\because$ SCISSORS & 5.8 & 5.0 & 7.3 & 51.9 \\
\hline$\because$ BLADES & 6.6 & 6.0 & 9.0 & 62.5 \\
\hline NEEDLE & 6.9 & 6.7 & 7.9 & 61.9 \\
\hline \multicolumn{5}{|l|}{ (IS) SLIMY } \\
\hline WORM & 7.4 & 5.6 & 6.4 & 42.8 \\
\hline - MUCUS & 8.9 & 8.1 & 7.5 & 54.4 \\
\hline - SNAIL & 7.6 & 7.4 & 6.6 & 39.7 \\
\hline - $\quad$ LEECH & 7.9 & 7.7 & 6.3 & 45.9 \\
\hline SEAWEED & 7.0 & 7.7 & 7.1 & 43.2 \\
\hline - JELLYFISH & 8.1 & 8.1 & 6.5 & 45.9 \\
\hline - OYSTER & 7.7 & 7.4 & 5.6 & 39.2 \\
\hline - LOTION & 7.4 & 6.3 & 4.5 & 36.2 \\
\hline - OIL & 7.8 & 7.8 & 5.2 & 42.2 \\
\hline SLUG & 8.1 & 7.3 & 7.0 & 39.0 \\
\hline
\end{tabular}


Centrality 1 Centrality 2 Salience Diagnosticity

\begin{tabular}{lllll}
\hline AIRPLANE & 6.7 & 7.2 & 5.9 & 45.4 \\
\hline TRAFFIC & 4.9 & 6.3 & 6.7 & 47.3 \\
\hline DRUM & 6.5 & 7.3 & 6.5 & 35.9 \\
\hline SIREN & 7.0 & 7.8 & 8.0 & 47.3 \\
\hline HORN & 5.8 & 7.5 & 6.8 & 34.3 \\
\hline CYMBAL & 5.2 & 7.3 & 5.7 & 27.3 \\
\hline PARTY & 5.7 & 5.2 & 6.1 & 48.7 \\
\hline CONCERT & 7.2 & 7.2 & 7.1 & 48.2 \\
\hline CLUB & 7.5 & 7.5 & 7.1 & 42.0 \\
\hline DRILL & 7.6 & 7.1 & 7.6 & 32.6 \\
\hline JACKHAMMER & 7.9 & 7.8 & 8.4 & 36.9 \\
\hline CRYING BABY & 8.1 & 7.3 & 5.9 & 34.6 \\
\hline CONSTRUCTION & 7.8 & 7.2 & 7.9 & 41.6 \\
\hline FIREWORKS & 7.9 & 7.8 & 7.9 & 29.9 \\
\hline
\end{tabular}

\begin{tabular}{|c|c|c|c|c|}
\hline \multicolumn{5}{|l|}{ (IS) SOUR } \\
\hline LEMON & 8.5 & 7.9 & 8.6 & 43.7 \\
\hline LIME & 8.1 & 8.2 & 8.1 & 37.5 \\
\hline VINEGAR & 8.2 & 8.3 & 7.4 & 37.1 \\
\hline BAD MILK & 8.1 & 8.4 & 7.0 & 34.9 \\
\hline GREEN APPLE & 5.8 & 6.3 & 5.3 & 31.8 \\
\hline \multicolumn{5}{|l|}{ (DOES) HOP } \\
\hline$\because$ RABBIT & 6.8 & 7.4 & 8.4 & 49.3 \\
\hline$\because$ KANGAROO & 7.5 & 8.0 & 9.3 & 42.7 \\
\hline * GRASSHOPPER & 7.7 & 7.9 & 9.0 & 43.0 \\
\hline$\because$ FROG & 7.0 & 7.9 & 8.7 & 42.2 \\
\hline TOAD & 6.8 & 7.6 & 7.4 & 34.6 \\
\hline CRICKET & 7.2 & 7.6 & 6.6 & 33.2 \\
\hline TIGGER & 6.2 & 6.0 & 7.0 & 28.7 \\
\hline - FLEA & 7.2 & 5.5 & 4.7 & 26.0 \\
\hline \multicolumn{5}{|l|}{ HAVE (HAS) A SHELL } \\
\hline PEANUT & 2.8 & 3.9 & 6.3 & 32.4 \\
\hline WALNUT & 5.2 & 4.7 & 6.6 & 35.7 \\
\hline PECAN & 4.1 & 4.7 & 5.4 & 3600 \\
\hline CHESTNUT & 5.3 & 4.7 & 6.1 & 32.6 \\
\hline MOLLUSK & 6.4 & 5.5 & 6.2 & 35.6 \\
\hline CLAM & 6.3 & 6.5 & 7.4 & 38.8 \\
\hline SNAIL & 6.1 & 7.0 & 8.0 & 35.8 \\
\hline CRAB & 7.3 & 7.2 & 7.3 & 37.8 \\
\hline SHRIMP & 4.3 & 5.8 & 5.2 & 34.4 \\
\hline SCALLOP & 3.8 & 5.9 & 3.9 & 31.6 \\
\hline LOBSTER & 6.7 & 7.6 & 6.9 & 40.9 \\
\hline
\end{tabular}




\begin{tabular}{|c|c|c|c|c|}
\hline & Centrality 1 & Centrality 2 & Salience & Diagnosticity \\
\hline \multicolumn{5}{|c|}{$\begin{array}{l}\text { HAVE (HAS) A SHELL } \\
\text { cont' }\end{array}$} \\
\hline SEED & 3.8 & 4.1 & 4.2 & 25.0 \\
\hline CASHEW & 3.4 & 4.1 & 4.2 & 21.8 \\
\hline$\because$ PISTACHIO & 4.8 & 5.0 & 6.8 & 33.8 \\
\hline TURTLE & 8.6 & 8.9 & 8.8 & 46.0 \\
\hline OYSTER & 6.7 & 6.6 & 7.2 & 35.5 \\
\hline HERMIT CRAB & 7.0 & 6.8 & 7.6 & 35.6 \\
\hline - M\& M & 7.3 & 7.0 & 4.2 & 39.0 \\
\hline \multicolumn{5}{|l|}{ (IS) YELLOW } \\
\hline$\because$ SUN & 6.4 & 5.3 & 8.2 & 33.9 \\
\hline$\because$ LEMON & 7.3 & 6.3 & 9.4 & 48.1 \\
\hline$\because$ HIGHLIGHTER & 3.4 & 2.2 & 7.4 & 24.9 \\
\hline LEMONADE & 3.3 & 3.7 & 8.5 & 37.7 \\
\hline$*$ BANANA & 4.9 & 4.2 & 8.7 & 45.4 \\
\hline TENNIS BALL & 4.1 & 3.6 & 5.5 & 31.4 \\
\hline$\div$ CORN & 4.8 & 4.9 & 7.0 & 37.6 \\
\hline YIELD SIGN & 6.3 & 5.4 & 4.9 & 41.0 \\
\hline$*$ SCHOOL BUS & 6.3 & 5.1 & 8.6 & 46.1 \\
\hline BEE & 6.1 & 5.0 & 6.8 & 37.3 \\
\hline$\because$ CHEESE & 2.9 & 3.5 & 5.5 & 30.9 \\
\hline$\because$ TAXI & 5.0 & 4.0 & 7.7 & 37.8 \\
\hline$\because$ BIG BIRD & 6.3 & 4.6 & 7.9 & 28.0 \\
\hline LEGAL PAD & 5.4 & 4.3 & 6.1 & 34.6 \\
\hline
\end{tabular}

\section{(IS) SOFT}

\begin{tabular}{lllll}
\hline \multicolumn{1}{c}{$*$ PILLOW } & 5.2 & 4.7 & 7.6 & 41.5 \\
\hline COTTON & 6.7 & 6.0 & 6.6 & 40.2 \\
\hline SKIN & 4.6 & 3.8 & 5.2 & 30.5 \\
\hline FUR & 6.7 & 5.8 & 7.1 & 46.5 \\
\hline KITTEN & 8.1 & 7.1 & 7.8 & 42.0 \\
\hline PUPPY & 7.2 & 7.0 & 7.5 & 42.6 \\
\hline SILK & 9.1 & 7.8 & 7.6 & 32.0 \\
\hline CASHMERE & 8.3 & 7.5 & 8.3 & 32.0 \\
\hline RABBIT & 8.2 & 7.2 & 7.1 & 39.5 \\
\hline BABY & 7.6 & 7.8 & 8.2 & 43.5 \\
\hline ROSE PETAL & 7.9 & 7.1 & 6.2 & 32.9 \\
\hline SATIN & 8.3 & 7.8 & 7.5 & 31.3 \\
\hline VELVET & 8.6 & 7.6 & 7.4 & 32.8 \\
\hline FEATHER & 7.7 & 6.2 & 5.6 & 34.7 \\
\hline
\end{tabular}

\begin{tabular}{lllll}
\hline \multicolumn{1}{c}{ HAS SEEDS } & & & & \\
\hline FRUIT & 5.2 & 4.3 & 6.1 & 53.9 \\
\hline VEGETABLE & 5.0 & 3.4 & 4.6 & 41.1 \\
\hline TREE & 5.2 & 5.0 & 4.6 & 51.1 \\
\hline
\end{tabular}




\section{HAS SEEDS cont'}

\begin{tabular}{lc}
\hline APPLE & 7.5 \\
\hline GRAPE & 4.5 \\
\hline TOMATO & 7.8 \\
\hline PUMPKIN & 8.3 \\
\hline SUNFLOWER & 7.8 \\
\hline ORANGE & 6. \\
\hline GRAPEFRUIT & 6.2 \\
\hline$\quad$ WATERMELON & 5.2 \\
\hline$\quad$ CUCUMBER & 6. \\
\hline
\end{tabular}

\begin{tabular}{ll}
\hline 7.5 & 6.0 \\
\hline 4.5 & 4.3 \\
\hline 7.8 & 6.5 \\
\hline 8.3 & 7.6 \\
\hline 7.8 & 7.9 \\
\hline 6.1 & 5.2 \\
\hline 6.2 & 6.0 \\
\hline 5.2 & 5.4 \\
\hline 6.3 & 7.0 \\
\hline
\end{tabular}

6.0

6.5

7.6

7.9

5.2

6.0

7.0

Salience Diagnosticity

(IS) COLD

\begin{tabular}{ccccc}
\hline SNOW & 8.2 & 8.2 & 9.1 & 59.6 \\
\hline FREEZER & 7.5 & 7.7 & 9.0 & 53.7 \\
\hline CELLAR & 4.4 & 4.6 & 5.7 & 33.9 \\
\hline ANTARCTICA & 8.5 & 8.7 & 9.2 & 52.0 \\
\hline ICE CREAM & 8.3 & 7.6 & 8.6 & 46.8 \\
\hline ICE CUBE & 8.9 & 8.3 & 9.0 & 51.5 \\
\hline POPSICLE & 7.7 & 7.8 & 7.4 & 47.4 \\
\hline WINTER & 4.6 & 5.4 & 9.2 & 58.0 \\
\hline BLIZZARD & 7.9 & 9.0 & 9.6 & 57.1 \\
\hline$*$ REFRIGERATOR & 5.4 & 5.8 & 7.3 & 49.9 \\
\hline AIR-CONDITIONING & 5.8 & 5.6 & 6.5 & 47.0 \\
\hline SWIMMING POOL & 3.7 & 3.9 & 4.9 & 34.4 \\
\hline GLACIER & 8.9 & 9.2 & 8.0 & 55.7 \\
\hline FROZEN FOOD & 7.9 & 7.0 & 7.8 & 47.0 \\
\hline ICICLE & 9.0 & 8.4 & 8.4 & 47.5 \\
\hline
\end{tabular}

\section{HAVE (HAS) SKIN}

\begin{tabular}{clllll}
\hline$\bullet$ & ANIMAL & 7.7 & 9.2 & 4.5 & 72.8 \\
\hline$\bullet$ & PERSON & 9.2 & 9.7 & 6.9 & 68.8 \\
\hline$\bullet$ & GRAPE & 6.5 & 7.2 & 3.6 & 46.8 \\
\hline$\bullet$ CHICKEN & 6.1 & 7.2 & 4.1 & 39.6 \\
\hline$\bullet$ & COW & 7.2 & 8.3 & 3.6 & 43.7 \\
\hline$\bullet$ & DOG & 8.3 & 9.0 & 3.3 & 46.0 \\
\hline$\bullet$ & RABBIT & 8.1 & 8.7 & 3.6 & 40.3 \\
\hline$\bullet$ & BIRD & 8.3 & 8.5 & 3.4 & 38.9 \\
\hline$\bullet$ & MONKEY & 9.1 & 9.0 & 3.8 & 43.6 \\
\hline$\bullet$ & ONION & 4.7 & 5.7 & 3.2 & 33.1 \\
\hline$\bullet$ & GARLIC & 4.2 & 5.2 & 2.8 & 32.8 \\
\hline APPLE & 3.9 & 5.4 & 4.1 & 48.3 \\
\hline$\bullet$ & TOMATO & 6.7 & 6.5 & 3.2 & 46.3 \\
\hline$\bullet$ & MAMMAL & 8.5 & 9.2 & 4.9 & 64.5 \\
\hline$\bullet$ & REPTILE & 7.3 & 8.3 & 5.4 & 52.0 \\
\hline$\bullet$ & SNAKE & 8.5 & 8.1 & 5.9 & 49.5 \\
\hline
\end{tabular}


HAVE (HAS) SKIN cont'

\section{Centrality 1 Centrality 2 Salience Diagnosticity}

\begin{tabular}{|c|c|c|c|c|}
\hline ALLIGATOR & 9.0 & 8.8 & 5.5 & 50.4 \\
\hline FRUIT & 5.6 & 5.7 & 3.6 & 48.3 \\
\hline VEGETABLE & 5.2 & 5.4 & 3.4 & 42.1 \\
\hline
\end{tabular}

\section{(IS) REFLECTIVE}

\begin{tabular}{lllll}
\multicolumn{1}{c}{ MIRROR } & 8.9 & 7.8 & 9.7 & 74.3 \\
\hline GLASS & 4.9 & 4.9 & 6.0 & 49.3 \\
\hline ALUMINUM & 5.6 & 5.4 & 4.5 & 41.3 \\
\hline CHROME & 5.8 & 5.1 & 4.9 & 35.7 \\
\hline STEEL & 4.5 & 4.7 & 4.5 & 30.5 \\
\hline
\end{tabular}

\begin{tabular}{|c|c|c|c|c|}
\hline (IS) SALTY & & & & \\
\hline POTATO CHIP & 6.1 & 4.1 & 7.1 & 46.8 \\
\hline$*$ PRETZEL & 4.5 & 4.1 & 7.5 & 42.0 \\
\hline NACHO CHIP & 5.6 & 4.5 & 5.5 & 39.5 \\
\hline SOY SAUCE & 5.8 & 5.8 & 6.4 & 41.3 \\
\hline SEAWATER & 7.9 & 7.8 & 8.5 & 64.9 \\
\hline MARGARITA & 4.9 & 4.8 & 5.7 & 36.2 \\
\hline TEAR & 6.8 & 6.5 & 5.5 & 49.7 \\
\hline$*$ FOOD & 2.2 & 1.8 & 4.0 & 46.8 \\
\hline SWEAT & 6.8 & 6.0 & 4.5 & 44.0 \\
\hline POPCORN & 4.1 & 3.5 & 5.2 & 40.3 \\
\hline$\because$ PEANUT & 4.7 & 3.0 & 5.3 & 38.3 \\
\hline$\nLeftarrow$ NUT & 4.3 & 2.9 & 5.4 & 40.6 \\
\hline CRACKER & 4.1 & 2.8 & 5.1 & 37.5 \\
\hline FRENCH FRY & 4.5 & 3.6 & 6.3 & 45.7 \\
\hline SALTINE & 6.5 & 5.4 & 7.3 & 41.6 \\
\hline \multicolumn{5}{|c|}{ HAVE (HAS) LEAVES } \\
\hline FLOWER & 4.1 & 4.5 & 5.5 & 48.3 \\
\hline BUSH & 6.3 & 5.3 & 6.8 & 40.9 \\
\hline VINE & 6.3 & 5.1 & 6.4 & 44.8 \\
\hline$\because$ PLANT & 6.7 & 5.6 & 8.1 & 63.7 \\
\hline FOREST & 8.3 & 7.9 & 7.2 & 57.0 \\
\hline $\mathrm{OAK}$ & 5.9 & 6.2 & 6.4 & 45.9 \\
\hline HERB & 6.7 & 5.5 & 5.7 & 37.8 \\
\hline WEED & 5.5 & 5.5 & 5.5 & 39.1 \\
\hline - LETTUCE & 9.2 & 8.0 & 6.4 & 50.1 \\
\hline SPINACH & 8.7 & 7.6 & 6.8 & 41.6 \\
\hline \multicolumn{5}{|l|}{ (IS) FEROCIOUS } \\
\hline BEAR & 5.9 & 6.8 & 7.6 & 45.8 \\
\hline$\div$ LION & 6.3 & 6.8 & 8.3 & 47.3 \\
\hline$\because$ TIGER & 5.9 & 6.7 & 8.1 & 49.7 \\
\hline ALLIGATOR & 6.4 & 7.4 & 8.4 & 47.3 \\
\hline
\end{tabular}


(IS) FEROCIOUS cont'

Centrality 1 Centrality 2 Salience Diagnosticity

CROCODILE

WILD ANIMAL

\begin{tabular}{llll}
\hline 6.7 & 7.6 & 8.4 & 47.6 \\
\hline 5.6 & 5.8 & 6.2 & 67.0 \\
\hline
\end{tabular}

(IS) TRANSPARENT

\begin{tabular}{lllll}
\hline \multicolumn{1}{c}{ GLASS } & 6.6 & 4.8 & 8.9 & 53.1 \\
\hline PLEXIGLAS & 7.2 & 4.9 & 6.5 & 53.7 \\
\hline \multicolumn{1}{c}{ PLASTIC } & 3.9 & 3.7 & 5.4 & 29.9 \\
\hline SODA BOTTLE & 5.6 & 3.7 & 5.7 & 29.1 \\
\hline AIR & 7.7 & 7.6 & 7.4 & 74.2 \\
\hline WATER & 5.1 & 6.1 & 6.7 & 54.5 \\
\hline OIL & 4.2 & 6.9 & 3.8 & 22.0 \\
\hline \multicolumn{6}{c}{ TEAR } & 8.8 & 7.0 & 5.5 & 42.8 \\
\hline ICE & 5.9 & 5.6 & 5.1 & 35.1 \\
\hline
\end{tabular}

(IS) TRIANGULAR

\begin{tabular}{lllll}
\hline YIELD SIGN & 8.0 & 6.7 & 5.8 & 41.7 \\
\hline PIECE OF PIE & 6.1 & 4.1 & 6.6 & 38.6 \\
\hline SANDWICH & 2.2 & 2.4 & 3.3 & 22.9 \\
\hline \multirow{*}{*}{ SLICE OF PIZZA } & 4.3 & 2.7 & 6.9 & 46.1 \\
\hline
\end{tabular}

(IS) DANGEROUS

\begin{tabular}{lllll}
\hline AIRPLANE & 5.3 & 5.0 & 5.3 & 28.2 \\
\hline WET ROAD & 5.8 & 6.0 & 6.5 & 60.5 \\
\hline FIRE & 6.1 & 7.3 & 7.5 & 53.9 \\
\hline EARTHQUAKE & 7.6 & 7.4 & 8.0 & 44.1 \\
\hline TORNADO & 8.3 & 8.8 & 7.7 & 48.5 \\
\hline ROBBER & 8.0 & 6.8 & 7.6 & 49.3 \\
\hline$\%$ MURDERER & 9.1 & 8.3 & 9.7 & 57.8 \\
\hline SNAKE & 6.1 & 5.3 & 5.9 & 34.8 \\
\hline CANCER & 8.6 & 8.0 & 7.7 & 58.1 \\
\hline STROKE & 9.0 & 8.0 & 7.1 & 50.6 \\
\hline WILD ANIMAL & 6.3 & 6.6 & 6.3 & 39.1 \\
\hline WAR & 9.6 & 9.1 & 9.6 & 63.9 \\
\hline LION & 6.7 & 6.9 & 7.7 & 39.4 \\
\hline$\%$ GUN & 7.6 & 8.2 & 9.1 & 67.9 \\
\hline$\%$ KNIFE & 6.0 & 6.4 & 7.9 & 50.7 \\
\hline DRAG RACING & 7.4 & 7.0 & 7.0 & 37.8 \\
\hline SCUBA DIVING & 4.2 & 5.4 & 4.4 & 27.8 \\
\hline HURRICANE & 7.7 & 7.8 & 7.1 & 45.0 \\
\hline & & & & \\
\hline (DOES) ROLL & & & & \\
\hline$\%$ WHEEL & 6.0 & 7.2 & 8.7 & 71.0 \\
\hline BALL & 7.4 & 7.3 & 8.6 & 65.6 \\
\hline LOG & 5.0 & 6.1 & 6.7 & 39.4 \\
\hline TIRE & 6.9 & 6.5 & 8.2 & 60.0 \\
\hline
\end{tabular}


(DOES) ROLL cont'

\section{Centrality 1 Centrality 2 Salience Diagnosticity}

\begin{tabular}{|c|c|c|c|c|}
\hline SNOWBALL & 5.6 & 6.7 & 5.1 & 32.7 \\
\hline PENNY & 6.1 & 6.0 & 4.6 & 36.0 \\
\hline \multicolumn{5}{|l|}{ (IS) FURRY } \\
\hline CAT & 5.6 & 5.4 & 7.8 & 49.9 \\
\hline DOG & 5.3 & 5.1 & 6.9 & 48.9 \\
\hline HAMSTER & 7.3 & 7.2 & 6.8 & 42.5 \\
\hline GERBIL & 7.5 & 7.4 & 6.5 & 41.8 \\
\hline SQUIRREL & 7.6 & 7.4 & 6.1 & 45.8 \\
\hline RABBIT & 7.4 & 7.3 & 7.8 & 46.4 \\
\hline ANIMAL & 3.6 & 4.0 & 7.2 & 77.5 \\
\hline \multicolumn{5}{|l|}{ (IS) TALL } \\
\hline$\because$ TREE & 3.4 & 3.0 & 6.4 & 47.7 \\
\hline$\because$ BUILDING & 3.9 & 3.2 & 7.1 & 50.6 \\
\hline$\because \quad$ LADDER & 3.2 & 3.0 & 6.0 & 29.5 \\
\hline$\because$ FLAGPOLE & 5.9 & 4.7 & 6.9 & 40.0 \\
\hline$\because$ TOWER & 6.5 & 6.9 & 9.0 & 51.8 \\
\hline STREETLIGHT & 5.6 & 5.1 & 4.7 & 38.9 \\
\hline $\begin{aligned} & \because \text { BASKETBALL } \\
& \text { PLAYER } \\
&\end{aligned}$ & 4.9 & 4.0 & 7.6 & 36.7 \\
\hline TELEPHONE POLE & 7.6 & 6.2 & 6.3 & 40.9 \\
\hline MOUNTAIN & 6.7 & 6.7 & 7.6 & 57.7 \\
\hline \multicolumn{5}{|l|}{ (IS) GREEN } \\
\hline$\therefore$ LEAVES & 2.8 & 2.6 & 7.9 & 54.7 \\
\hline$\because$ GRASS & 4.2 & 3.9 & 9.1 & 55.7 \\
\hline$\because$ TREE & 3.5 & 3.0 & 7.3 & 50.4 \\
\hline$\because$ VEGETABLE & 3.4 & 2.0 & 6.6 & 45.5 \\
\hline BROCCOLI & 7.4 & 6.3 & 9.1 & 50.7 \\
\hline$\because$ PEA & 6.9 & 5.8 & 8.0 & 50.8 \\
\hline$\because$ MONEY & 5.0 & 3.7 & 8.1 & 48.4 \\
\hline$\because$ PLANT & 4.9 & 3.0 & 8.3 & 61.3 \\
\hline$\because$ APPLE & 2.2 & 2.1 & 5.0 & 29.4 \\
\hline$\because$ TRAFFIC LIGHT & 2.9 & 3.3 & 6.1 & 36.3 \\
\hline$\because$ FROG & 3.7 & 3.8 & 7.2 & 34.4 \\
\hline LIZARD & 4.6 & 3.7 & 5.7 & 27.0 \\
\hline MOSS & 5.8 & 4.8 & 6.7 & 35.7 \\
\hline PEAR & 5.0 & 4.8 & 4.7 & 30.0 \\
\hline HERB & 5.0 & 4.5 & 5.7 & 32.3 \\
\hline ARTIFICIAL TURF & 6.8 & 7.4 & 7.6 & 40.9 \\
\hline EMERALD & 8.0 & 8.2 & 7.8 & 40.7 \\
\hline SHAMROCK & 8.8 & 8.1 & 8.9 & 39.7 \\
\hline
\end{tabular}




\section{Centrality 1 Centrality 2 Salience Diagnosticity}

(IS) Spicy

\begin{tabular}{ccccc}
\hline MEXICAN FOOD & 4.5 & 4.7 & 7.9 & 42.8 \\
\hline INDIAN FOOD & 5.4 & 4.8 & 6.0 & 31.9 \\
\hline$\quad$ BUFFALO WINGS & 5.4 & 4.7 & 7.6 & 37.7 \\
\hline CAJUN FOOD & 6.2 & 5.9 & 8.0 & 44.5 \\
\hline
\end{tabular}

\begin{tabular}{lllll}
\hline \multicolumn{1}{c}{ (IS) LOUD } & & & & \\
\hline CONSTRUCTION WORK & 6.9 & 6.9 & 6.6 & 42.6 \\
\hline YELLING & 7.4 & 7.9 & 7.5 & 37.3 \\
\hline SCREAMING & 7.5 & 7.8 & 7.3 & 35.2 \\
\hline CRYING & 5.9 & 4.3 & 5.1 & 22.3 \\
\hline HORN & 6.2 & 5.9 & 6.3 & 35.2 \\
\hline TRAFFIC & 5.1 & 5.9 & 5.4 & 29.0 \\
\hline$\quad$ EARTHQUAKE & 6.5 & 7.0 & 4.5 & 26.0 \\
\hline ACCIDENT & 5.8 & 4.7 & 4.7 & 31.6 \\
\hline MOTORCYCLE & 7.2 & 6.1 & 6.4 & 38.8 \\
\hline JACKHAMMMER & 8.0 & 6.7 & 7.2 & 43.5 \\
\hline AIRPLANE & 6.4 & 7.6 & 6.0 & 40.5 \\
\hline CONCERT & 7.5 & 7.4 & 7.1 & 43.6 \\
\hline$\bullet \quad$ AVALANCHE & 6.5 & 7.8 & 5.1 & 32.0 \\
\hline EXPLOSION & 8.3 & 8.4 & 8.6 & 45.9 \\
\hline GUN-FIRE & 7.2 & 6.7 & 7.6 & 45.0 \\
\hline SIREN & 7.6 & 6.7 & 8.2 & 45.1 \\
\hline FIREWORK & 7.9 & 6.8 & 8.4 & 34.9 \\
\hline$\bullet \quad$ CRYING BABY & 7.0 & 5.0 & 5.2 & 31.6 \\
\hline STOMPING & 6.1 & 4.4 & 4.8 & 22.2 \\
\hline THUNDER & 6.9 & 6.3 & 7.4 & 35.0 \\
\hline ROCKET & 6.6 & 7.6 & 7.6 & 35.2 \\
\hline
\end{tabular}

\section{(IS) EXTRAVAGANT}

\begin{tabular}{ccccc}
\hline FIRST CLASS TICKET & 5.8 & 5.7 & 6.5 & 31.2 \\
\hline$\%$ JEWELRY & 4.2 & 3.6 & 6.2 & 47.7 \\
\hline DIAMOND & 5.7 & 4.9 & 6.8 & 51.2 \\
\hline$*$ WEDDING & 3.9 & 3.3 & 6.2 & 42.5 \\
\hline BROADWAY PLAY & 5.8 & 4.3 & 4.4 & 31.4 \\
\hline PALACE & 6.4 & 6.9 & 8.1 & 50.5 \\
\hline YACHT & 6.1 & 5.6 & 7.0 & 40.0 \\
\hline$*$ BALL GOWN & 6.1 & 4.9 & 7.9 & 36.8 \\
\hline WEDDING CAKE & 5.3 & 3.4 & 5.7 & 31.2 \\
\hline FANCY WINE & 6.5 & 5.6 & 5.8 & 33.6 \\
\hline
\end{tabular}




\section{Centrality 1 Centrality 2 Salience Diagnosticity}

\begin{tabular}{lllll}
\multicolumn{1}{c}{ (IS) SPOTTED } & & & & \\
\hline DALMATIAN & 8.4 & 7.2 & 8.9 & 44.0 \\
\hline COW & 5.3 & 4.1 & 5.4 & 42.0 \\
\hline CHEETAH & 7.8 & 7.1 & 7.7 & 43.6 \\
\hline LEOPARD & 8.1 & 7.0 & 7.9 & 43.0 \\
\hline & & & & \\
\hline (IS) FREEZING & & & & \\
\hline WINTER & 3.5 & 4.0 & 8.5 & 45.3 \\
\hline FREEZER & 5.9 & 6.3 & 8.2 & 50.8 \\
\hline AIR CONDITIONING & 4.5 & 4.6 & 5.4 & 30.9 \\
\hline ICE & 7.8 & 8.0 & 9.2 & 57.6 \\
\hline \multicolumn{6}{r}{ SNOW } & 7.3 & 6.5 & 8.4 & 49.3 \\
\hline ICE CREAM & 6.6 & 6.3 & 7.4 & 38.5 \\
\hline NORTH POLE & 8.7 & 8.7 & 9.0 & 41.6 \\
\hline POPSICLE & 7.0 & 6.7 & 6.7 & 31.3 \\
\hline SLEET & 6.8 & 7.4 & 7.5 & 32.6 \\
\hline
\end{tabular}




\section{APPENDIX F}

\section{LIST 1-HIGH SALIENCE/LOW CENTRALITY ITEMS}

\begin{tabular}{|c|c|c|}
\hline $\begin{array}{l}\text { HAS FUR } \\
\text { Cats }\end{array}$ & $\begin{array}{l}\text { Animal } \\
\text { Mammals } \\
\end{array}$ & $\begin{array}{l}\text { Dogs } \\
\text { Stuffed toy }\end{array}$ \\
\hline HASA TAIL & Animal & Cat \\
\hline \multicolumn{3}{|l|}{ Dog } \\
\hline$I S A L I V E$ & Animal & Plant \\
\hline Frog & Bug & Rabbit \\
\hline Worm & Bear & Dog \\
\hline Cat & Fish & Horse \\
\hline Ant & Fly & Grass \\
\hline Flower & Organism & Mammal \\
\hline Bird & Human & \\
\hline HOPS & Rabbit & Frog \\
\hline Kangaroo & Grasshopper & \\
\hline FLIES & Bird & Airplane \\
\hline Insect & Bee & Sparrow \\
\hline \multicolumn{3}{|l|}{ Cardinal } \\
\hline SWIMS & People & Turtles \\
\hline GROWS ON TREES & Flowers & Fruit \\
\hline \multicolumn{3}{|l|}{ Leaves } \\
\hline WALKS & Man & Robot \\
\hline FEROCIOUS & Lion & Tiger \\
\hline SCARY & Ghosts & Bats \\
\hline Snakes & Spiders & \\
\hline LARGE & Whales & Elephant \\
\hline Mountain & Forest & Continent \\
\hline \multicolumn{3}{|l|}{ Cities } \\
\hline TALL & Tower & Basketball Player \\
\hline Tree & Building & Ladder \\
\hline \multicolumn{3}{|l|}{ Flagpole } \\
\hline GREEN & Leaves & Grass \\
\hline Trees & Vegetables & Peas \\
\hline Money & Plants & Apple \\
\hline Traffic Light & Frog & \\
\hline
\end{tabular}




\begin{tabular}{|c|c|c|}
\hline JUICY & Apple & Steak \\
\hline Candy & Orange & \\
\hline CRUNCHY & Granola & Candy \\
\hline HAS SEEDS & Watermelon & \\
\hline EDIBLE & Food & Candy \\
\hline Vegetable & Fruit & Meat \\
\hline Cookie & Chicken & Hamburger \\
\hline Banana & Apple & Orange \\
\hline Carrot & Rice & Noodles \\
\hline Fish & Cheese & \\
\hline HAS LEAVES & Plant & \\
\hline LIQUID & Water & \\
\hline SWEET & Candy & Fruit \\
\hline Cakes & Cookies & Pies \\
\hline HAS WHEELS & Office chair & Toys \\
\hline SPICY & Mexican Food & Buffalo Wings \\
\hline Cajun Food & Jalapenos & Salsa \\
\hline HOT & Oven & Stove \\
\hline Fireplace & Heater & Summer \\
\hline Coffee & Tea & \\
\hline HAS A SHELL & Pistachio & \\
\hline SALTY & Nuts & Potato Chip \\
\hline Pretzel & Peanuts & Crackers \\
\hline French Fries & Food & \\
\hline ORANGE & Pumpkin & \\
\hline ROUND & Glasses & Lollipop \\
\hline \multicolumn{3}{|l|}{ Clock Face } \\
\hline RED & Lips & Strawberries \\
\hline Raspberries & Berries & Watermelon \\
\hline Apple & Tomato & Blood \\
\hline Rose & Stop Sign & Cherries \\
\hline Hearts & Fire Engine & Peppers \\
\hline \multicolumn{3}{|l|}{ Cardinal } \\
\hline$B L U E$ & Sky & School uniforms \\
\hline Ocean & Water & Ink \\
\hline Blueberries & Jeans & Lakes \\
\hline Police car & Baby boy's clothes & Police uniforms \\
\hline
\end{tabular}




\begin{tabular}{|c|c|c|}
\hline$\frac{Y E L L O W}{\text { Lemon }}$ & Sun & Big Bird \\
\hline Lemon & Highlighter & Lemonade \\
\hline Banana & Corn & School Bus \\
\hline Cheese & Taxi & \\
\hline DANGEROUS & Murderer & Gun \\
\hline \multicolumn{3}{|l|}{ Knife } \\
\hline POISONOUS & Chemicals & Berries \\
\hline Venom & Spider & \\
\hline SHARP & Knife & Sword \\
\hline Razor & Scissors & Blades \\
\hline LEATHER & Pocketbook & Coat \\
\hline Boot & Watchband & Belt \\
\hline Couch & Car interior & Shoe \\
\hline Wallet & Briefcase & \\
\hline WOOD & Pencil & Oar \\
\hline Desk & Chair & Bed \\
\hline House & Shutter & Pirate leg \\
\hline Door & $\begin{array}{l}\text { Birdhouse } \\
\end{array}$ & Fence post \\
\hline Dresser & Bench & Crate \\
\hline Baseball bat & Puppet & Blocks \\
\hline Floors & Cabinets & \\
\hline ROLLS & Wheels & \\
\hline RUBBER & Tire & Ball \\
\hline \multicolumn{3}{|l|}{ Doll } \\
\hline PLASTIC & Cup & Bottle \\
\hline Soda bottle & Shopping bag & \\
\hline CLEAR & Glass & Water \\
\hline Plastic & Cellophane & Window \\
\hline \multicolumn{3}{|l|}{ Saran wrap } \\
\hline TRANSPARENT & Glass & Tear \\
\hline \multicolumn{3}{|l|}{ Plastic } \\
\hline COLD & Snow & Freezer \\
\hline Winter & Refrigerator & Antarctica \\
\hline GLASS & Drinking glass & Cup \\
\hline Window & Vase & Bowl \\
\hline \multicolumn{3}{|l|}{ Bottle } \\
\hline REFLECTIVE & Mirror & \\
\hline FREEZING & Winter & Snow \\
\hline Freezer & & \\
\hline
\end{tabular}




\begin{tabular}{|c|c|c|}
\hline SMELLS & Garbage & Manure \\
\hline Skunks & Foot & Gym Sock \\
\hline SOFT & Pillows & \\
\hline EXTRAVAGANT & Wedding & Ball gown \\
\hline \multicolumn{3}{|l|}{ Jewelry } \\
\hline TRIANGULAR & Slice of Pizza & \\
\hline FAST & Sports car & Race car \\
\hline \multicolumn{3}{|l|}{ Car } \\
\hline STORES THINGS & Refrigerator & \\
\hline
\end{tabular}




\section{APPENDIX G}

\section{LIST 2-HIGH CENTRALITY/LOW SALIENCE ITEMS}

\begin{tabular}{|c|c|c|}
\hline WHEELS & Airplane & Van \\
\hline Train & Baby carriage & Roller coaster \\
\hline Go-cart & Bus & \\
\hline HAS A TAIL & Whale & Elephant \\
\hline Cow & Kangaroo & \\
\hline GROWS ON TREES & Bananas & Plums \\
\hline Pears & Lemons & Limes \\
\hline Peaches & Cherries & \\
\hline SLIMYY & Leech & Jellyfish \\
\hline Oysters & Lotion & Oil \\
\hline Mucus & Snails & \\
\hline LIQUID & Soda & Beer \\
\hline Wine & Alcohol & Tear \\
\hline Oil & Soup & Ocean \\
\hline \multicolumn{3}{|l|}{ Pool } \\
\hline SMELLS & Halitosis & Garlic \\
\hline Ammonia & Bleach & \\
\hline STICKY & Jam & Peanut butter \\
\hline Tar & Honey & Syrup \\
\hline Molasses & Lollipop & Jelly \\
\hline HAS SKIN & Animals & Person \\
\hline Grapes & Chicken & Cow \\
\hline Dog & Rabbit & Bird \\
\hline Monkeys & Onion & Garlic \\
\hline Tomato & Mammals & Reptiles \\
\hline Snakes & Alligators & Fruit \\
\hline \multicolumn{3}{|l|}{ Vegetables } \\
\hline HAS FUR & Squirrel & Deer \\
\hline \multicolumn{3}{|l|}{ Raccoon } \\
\hline POISONOUS & Strychnine & Ammonia \\
\hline ROUND & Earth & Sun \\
\hline FAST & Light & \\
\hline GLASS & Light bulb & \\
\hline STORES THINGS & Suitcase & Bank \\
\hline HAS SEEDS & Cucumber & \\
\hline
\end{tabular}




\begin{tabular}{|c|c|c|}
\hline SWIMS & Eels & \\
\hline HAS A HANDLE & Car Door & Umbrella \\
\hline$E D I B L E$ & Ice cube & \\
\hline HOPS & Fleas & \\
\hline HAS A SHELL & M\&M's & \\
\hline IS DANGEROUS & Stroke & \\
\hline HAS LEAVES & Lettuce & \\
\hline LOUD & Crying Baby & Earthquake \\
\hline
\end{tabular}


APPENDIX H

\section{SENTENCE AND QUESTION LISTS FOR EXPERIMENT 4}

\section{List 1A-Experiment 4}

\begin{tabular}{|c|c|c|c|}
\hline SENTENCE & PROPERTY & $\begin{array}{l}\text { SENTENCE } \\
\text { TYPE }\end{array}$ & $\begin{array}{l}\text { PROPERTY } \\
\text { TYPE }\end{array}$ \\
\hline The boy arrived at class carrying his tap shoes. & noisy & nonbiased & central \\
\hline Sue went to the store to buy a candy bar. & rectangle & nonbiased & salient \\
\hline When we were little, we used to play in the attic. & above & nonbiased & central \\
\hline Sam and Judy decided to go skydiving. & is dangerous & nonbiased & salient \\
\hline Jack couldn't decide where to plant the flowers. & alive & nonbiased & central \\
\hline They put away all of the appetizers. & taste good & nonbiased & salient \\
\hline It is very crowded at the beach. & sandy & nonbiased & central \\
\hline Larry blocked while Tim took the basketball. & orange & nonbiased & salient \\
\hline At the park, $\mathrm{Al}$ found a tennis ball. & bounces & nonbiased & central \\
\hline On the side of the road was a traffic sign. & square & nonbiased & salient \\
\hline Frank went to the new movie about a spaceship. & can fly & nonbiased & central \\
\hline There is a new store downtown that rents videotapes. & rectangle & nonbiased & salient \\
\hline Honey is made by bumblebees. & can sting & nonbiased & central \\
\hline Under a huge rock hid many lobsters. & are red & nonbiased & salient \\
\hline Mom bought new curtains for my window. & clear & nonbiased & central \\
\hline $\begin{array}{l}\text { While refinishing the kitchen, Albert bought a new } \\
\text { refrigerator. }\end{array}$ & white & nonbiased & salient \\
\hline It was not a bad day for traffic. & crowded & nonbiased & central \\
\hline Mark couldn't fit into his old pair of jeans. & blue & nonbiased & salient \\
\hline Timmy wanted to get food for the frogs. & eat flies & central biased & central \\
\hline The power went out because of the lightning. & zig-zag & central biased & salient \\
\hline $\begin{array}{l}\text { To protect them from fire, we put the documents in } \\
\text { the safe. }\end{array}$ & has lock & central biased & central \\
\hline We could see our reflection on the television set. & is heavy & central biased & salient \\
\hline We dug in the sand to find the oysters. & have shells & central biased & central \\
\hline Digging in the dirt was a large pig. & dirty & central biased & salient \\
\hline John cut his hand on the ice skates. & have blades & central biased & central \\
\hline We hung the ornaments all around the Christmas tree. & has point & central biased & salient \\
\hline Don ate the top off of the slice of pizza. & has cheese & central biased & central \\
\hline Kevin only drank his tea with sugar. & is white & central biased & salient \\
\hline Jacob stood at the plate and lifted his baseball bat. & has handle & central biased & central \\
\hline $\begin{array}{l}\text { Approaching the top, we held on to the bar of the } \\
\text { roller coaster. }\end{array}$ & has thrills & central biased & salient \\
\hline $\begin{array}{l}\text { Sally listened eagerly to the first strains from tonight's } \\
\text { concert. }\end{array}$ & has music & central biased & central \\
\hline Walking by the river was the Dalmatian. & has spots & central biased & salient \\
\hline $\begin{array}{l}\text { Before using them in the pie, we needed to prepare the } \\
\text { cherries. }\end{array}$ & have pits & central biased & central \\
\hline On our trip, we saw baby and mother kangaroos. & can hop & central biased & salient \\
\hline
\end{tabular}




\section{SENTENCE}

\section{PROPERTY}

SENTENCE

TYPE

PROPI:RTY

We needed to strain the juice from the grapefruit.

Shedding was a normal event for snakes.

central biased central

\begin{tabular}{ll} 
Shedding was a normal event for snakes. & can hiss \\
\hline A fresh coat of paint was needed for the school bus. & has seat
\end{tabular}

central biased salient

has seats

salient biased central

To make sure they weren't spoiled, we examined the

bag of grapes.

Pulling them out of the ground, we admired the crop

of potatoes.

We needed to arrange the desks in rows in the classroom.

As it rolled under the stove, Laura wished she had been more careful with the coins.

Kelly wasn't worried because she had only dropped

the soda bottle.

For practice, the racer always used an Olympic-sized

pool.

Even at night in New York, we could easily spot a

taxi.

are green

salient biased salient

have skin

salient biased central

Is square

salient biased salient

have value

salient biased central

The stewardess brought the meal to the passenger on

the airplane.

is plastic

salient biased salient

Because of his beliefs, the activist refused to visit the

zoo.

has water

salient biased central

is yellow

salient biased salient

In trying to reach the roof, we tried many different

ladders.

has wings

salient biased central

has cages

salient biased salient

have rungs

salient biased central

Because it felt cold against his skin, Timmy didn't like

sitting in the shopping cart.

Is metal

salient biased salient

Richard was embarrassed when he sneezed during the

sermon at church.

holy

salient biased central

For decoration, Carmen hung a strand of jalapenos. red

From the bow of the ship, Billie admired the ocean. is water

salient biased salient

To surprise his wife, Teddy made reservations for

their anniversary.

celebrated

salient biased central

It took them a long time to travel to China.

While visiting the museum, we saw the skeletons of dinosaurs.

large

salient biased salient

Climbing on the leaf was a fuzzy caterpillar.

are huge

salient biased central

Ron sat down and wrote his name on the cover of the

test booklet.

lays eggs

salient biased salient

Paul loved to play the drum.

blue

control

central

Standing on the ground, Gerry stared up at the roof.

Terry gave Ilene pita.

loud

control

salient

loud

control

central

As the car rolled past, we couldn't help but notice the

hubcaps.

triangular

control

salient

made of dough

control

central

Reaching into the bag, Jill grabbed a chip.

We couldn't wait to take a trip to Chicago.

For a snack, Jason always ate crackers.

\begin{tabular}{lll} 
silver & control & salient \\
\hline potato & control & central \\
\hline far & control & salient \\
\hline salty & control & central \\
\hline
\end{tabular}

In the morning Julie got ready and put on her necklace.

metal

control

salient 


\begin{tabular}{llll}
\hline \multicolumn{1}{c}{ SENTENCE } & PROPERTY & $\begin{array}{l}\text { SENTENCE } \\
\text { TYPE }\end{array}$ & $\begin{array}{l}\text { PROPIERTY } \\
\text { TYPE: }\end{array}$ \\
\hline $\begin{array}{l}\text { For their wedding, Joe and Susan received a lot of } \\
\text { crystal. }\end{array}$ & sparkles & control & ccntral \\
\hline Randy picked up the book and put on his glasses. & clear & control & salicnt \\
\hline Percy decided to chew a piece of gum. & sticky & control & central \\
\hline Pat reached over to the table and picked up her ring. & round & control & salient \\
\hline In the morning, Arnie always enjoyed a muffin. & sweet & control & central \\
\hline Before writing the report, Jan needed to pick up paper. is white & control & salient \\
\hline Rob was in charge of laying the floor. & under & control & central \\
\hline Tom always had problems writing the number zero. & oval & control & salient \\
\hline
\end{tabular}


Did the boy have tap shoes?

Did they play in the den?

Was it Jack who was deciding where to plant the flowers?

Is it empty at the beach?

Did Al find a tennis ball?

Was it Tom who went to the movies?

Is honey made by bumblebees?

Did mom buy new windows?

Was it a good day for traffic?

Did Timmy want to feed his frog?

Were the documents in the drawer?

Did we dig in the sand for oysters?

Did John cut his hands with ice skates?

Did Don eat the top of the cherry pie?

Was it Jacob standing at the plate?

Did Sally listen eagerly to hear tonight's TV show?

Did the cherries need to be prepared?

Was it orange juice that needed to be strained?

Did the school bus need a fresh coat of paint?

Were carrots pulled from out of the ground?

Did Laura wish she had been more careful with the coins?

Did the racer use the ocean to practice in?

Did the stewardess bring a meal to the passenger?

Did they try to reach the roof with a truck?

Did Richard sneeze during the sermon?

Was it Jacob who enjoyed the ocean from the bow of the ship?

Did it take a long time to travel to China?

Was it a spider climbing on the leaf?

Did Paul love to play the drum?

Did Terry give Ilene a pretzel?

Did Jill grab a chip?

Did Jason always eat apples?

Did Joe and Susan receive crystal for their wedding?

Was Percy chewing tobacco?

Did Arnie enjoy a muffin in the morning?

Was Rob in charge of putting up wallpaper? 
List 1B-Experiment 4

\begin{tabular}{|c|c|c|c|}
\hline SENTENCE & PROPERTY & $\begin{array}{l}\text { SENTENCE } \\
\text { TYPE }\end{array}$ & $\begin{array}{l}\text { PROPERTY } \\
\text { TYPE }\end{array}$ \\
\hline The boy arrived at class carrying his tap shoes. & shiny & nonbiased & salient \\
\hline Sue went to the store to buy a candy bar. & is sweet & nonbiased & central \\
\hline When we were little, we used to play in the attic. & dusty & nonbiased & salient \\
\hline Sam and Judy decided to go skydiving. & adventurous & nonbiased & central \\
\hline Jack couldn't decide where to plant the flowers. & pretty & nonbiased & salient \\
\hline They put away all of the appetizers. & are food & nonbiased & central \\
\hline It is very crowded at the beach. & is hot & nonbiased & salient \\
\hline Larry blocked while Tim took the basketball. & bounce & nonbiased & central \\
\hline At the park, $\mathrm{Al}$ found a tennis ball. & yellow & nonbiased & salient \\
\hline On the side of the road was a traffic sign. & bright & nonbiased & central \\
\hline Frank went to the new movie about a spaceship. & silver & nonbiased & salient \\
\hline There is a new store downtown that rents videotapes. & can record & nonbiased & central \\
\hline Honey is made by bumblebees. & has stripes & nonbiased & salient \\
\hline Under a huge rock hid many lobsters. & claws & nonbiased & central \\
\hline Mom bought new curtains for my window. & square & nonbiased & salient \\
\hline $\begin{array}{l}\text { While refinishing the kitchen, Albert bought a new } \\
\text { refrigerator. }\end{array}$ & cold & nonbiased & central \\
\hline It was not a bad day for traffic. & annoying & nonbiased & salient \\
\hline Mark couldn't fit into his old pair of jeans. & denim & nonbiased & central \\
\hline Timmy wanted to get food for the frogs. & are green & central biased & salient \\
\hline The power went out because of the lightning. & electric & central biased & central \\
\hline $\begin{array}{l}\text { To protect them from fire, we put the documents in the } \\
\text { safe. }\end{array}$ & is metal & central biased & salient \\
\hline We could see our reflection on the television set. & has screen & central biased & central \\
\hline We dug in the sand to find the oysters. & is slimy & central biased & salient \\
\hline Digging in the dirt was a large pig. & snout & central biased & central \\
\hline John cut his hand on the ice skates. & are leather & central biased & salient \\
\hline We hung the ornaments all around the Christmas tree. & has branches & central biased & central \\
\hline Don ate the top off of the slice of pizza. & triangular & central biased & salient \\
\hline Kevin only drank his tea with sugar. & has grains & central biased & central \\
\hline Jacob stood at the plate and lifted his baseball bat. & is wooden & central biased & salient \\
\hline $\begin{array}{l}\text { Approaching the top, we held on to the bar of the roller } \\
\text { coaster. }\end{array}$ & has hills & central biased & central \\
\hline $\begin{array}{l}\text { Sally listened eagerly to the first strains from tonight's } \\
\text { concert. }\end{array}$ & are noisy & central biased & salient \\
\hline Walking by the river was the Dalmatian. & has paws & central biased & central \\
\hline $\begin{array}{l}\text { Before using them in the pie, we needed to prepare the } \\
\text { cherries. }\end{array}$ & are red & central biased & salient \\
\hline On our trip, we saw baby and mother kangaroos. & has pouch & central biased & central \\
\hline We needed to strain the juice from the grapefruit. & is sour & central biased & salient \\
\hline Shedding was a normal event for snakes. & has scales & central biased & central \\
\hline A fresh coat of paint was needed for the school bus. & is yellow & salient biased & salient \\
\hline
\end{tabular}




\section{SENTENCE}

To make sure they weren't spoiled, we examined the bag

of grapes.

Pulling them out of the ground, we admired the crop of potatoes.

PROPERTY SENTENCE TYPE

PROPERIY

TYPE

has seeds salient biascd central

is brown salient biased salient

We needed to arrange the desks in rows in the classroom. has students salient biased central

As it rolled away, Laura wished she were more careful

with the coins.

Kelly wasn't worried because she had only dropped the soda bottle.

are round salient biased salient

For practice, the racer always used an Olympic-sized pool.

has volume salient biased central

Even at night in New York, we could easily spot a taxi.

The stewardess brought the meal to the passenger on the airplane.

are square salient biased salient

has wheels salient biased central

has seats salient biased salient

Because of his beliefs, the activist refused to visit the zoo. have animals salient biased central

In trying to reach the roof, we tried many different

ladders.

Because it felt cold ,Timmy didn't like sitting in the

shopping cart.

are tall salient biased salient

Richard was embarrassed when he sneezed during the

sermon at church.

For decoration, Carmen hung a strand of jalapenos.

From the bow of the ship, Billie admired the ocean.

To surprise his wife, Teddy made reservations for their

anniversary.

carries salient biased central

It took them a long time to travel to China.

quiet salient biased salient

While visiting the museum, we marveled at the skeletons of dinosaurs.

hot salient biased central

is blue salient biased salient

At the intersection was a flashing light.

Percy was afraid of the sight of blood.

In the morning Tracy got ready and put on her ring.

At the pueblo, we watched the women make tortillas.

Phil needed to replace his watchband.

Cathy always wore that beautiful necklace.

For lunch, Rebecca's mother packed potato chips.

Roberta climbed up the old wall.

Chris liked to eat pretzels.

is yearly salient biased central

is far

salient biased salient

For the multiple choice exam Jen brought five pencils.

For school, Walter needed to buy a new computer.

Tom really liked to chew gum.

lay eggs salient biased central

is yellow control salient

liquid control central

round control salient

made of corn control central

have a hole control salient

We looked forward to going to Florida and seeing

flamingoes.

Arnie really enjoyed a morning muffin.

To plant the flowers, Rich dug a hole.

In the afternoon, Rachel enjoyed a latte.

meth

meta

\begin{tabular}{lll} 
metal & control & central \\
greasy & control & salient \\
\hline rock & control & central \\
\hline twisted & control & salient \\
\hline sharp & control & central \\
\hline expensive & control & salient \\
sticky & control & central \\
\hline
\end{tabular}

pink control salient

sweet control central

round control salient

to drink control central




\begin{tabular}{llll}
\hline SENTENCE & PROPERTY & SENTENCE & PROPERTY \\
& & TYPE & TYPE \\
\hline The coats were stored in the closet. & dark & control & salicnt \\
\hline For breakfast, Harry ate an omelet. & yolk & control & central \\
\hline
\end{tabular}


Did the boy have tap shoes?

Did they play in the den?

Was it Jack who was deciding where to plant the flowers?

Is it empty at the beach?

Did Al find a tennis ball?

Was it Tom who went to the movies?

Is honey made by bumblebees?

Did mom buy new windows?

Was it a good day for traffic?

Did Timmy want to feed his frog?

Were the documents in the drawer?

Did we dig in the sand for oysters?

Did John cut his hands with ice skates?

Did Don eat the top of the cherry pie?

Was it Jacob standing at the plate?

Did Sally listen eagerly to hear tonight's TV show?

Did the cherries need to be prepared?

Was it orange juice that needed to be strained?

Did the school bus need a fresh coat of paint?

Were the carrots pulled from out of the ground?

Did Laura wish she had been more careful with the coins?

Did the racer use the ocean to practice in?

Did the stewardess bring a meal to the passenger?

Did they try to reach the roof with a truck?

Did Richard sneeze during the sermon?

Was it Jacob who enjoyed the ocean from the bow of the ship?

Did it take a long time to travel to China?

Was the flashing light on the corner?

Did Tracy put on her ring?

Did Paul need to replace his whole watch?

Did Rebecca's mom pack her potato chips?

Did Chris like to eat popcorn?

Was it Walter who needed to buy a new computer?

Were we going to see penguins?

Did Rich dig a hole?

Were the coats stored on a coat rack? 
List 2A-Experiment 4

\begin{tabular}{|c|c|c|c|}
\hline SENTENCE & PROPERTY & $\begin{array}{l}\text { SENTENCE } \\
\text { TYPE }\end{array}$ & $\begin{array}{l}\text { PROPFRTY } \\
\text { IYPI: }\end{array}$ \\
\hline Mary danced across the stage in her new tap shoes. & noisy & central biased & eentral \\
\hline Tom really enjoyed the taste of the candy bar. & reetangle & central biased & salient \\
\hline We could hear noise coming from the attic. & above & eentral biased & central \\
\hline After rock climbing, they plan on going skydiving. & is dangerous & central biased & salient \\
\hline In the vase filled with water were some flowers. & alive & central biased & eentral \\
\hline We were full beeause of the appetizers. & taste good & central biased & salient \\
\hline Jim loves to remove his shoes and walk on the beach. & sandy & eentral biased & eentral \\
\hline $\begin{array}{l}\text { Coming down the court, Larry had good control of the } \\
\text { basketball }\end{array}$ & orange & eentral biased & salient \\
\hline Using a wall, we practiced hitting a tennis ball. & bounces & central biased & central \\
\hline Even at night, we could clearly see the traffic sign. & square & central biased & salient \\
\hline We couldn't wait to take a ride in the spaceship. & can fly & eentral biased & eentral \\
\hline $\begin{array}{l}\text { For the birth of their first child, Paul and Wendy bought } \\
\text { videotapes. }\end{array}$ & rectangle & central biased & salient \\
\hline $\begin{array}{l}\text { If you are going to the meadow, watch out for all of the } \\
\text { bumblebees. }\end{array}$ & can sting & central biased & central \\
\hline You should be careful not to step on lobsters. & is red & eentral biased & salient \\
\hline Grandfather looked at the rain through the window. & clear & central biased & eentral \\
\hline $\begin{array}{l}\text { To keep them fresh, we put the chicken and meat into } \\
\text { the refrigerator. }\end{array}$ & white & central biased & salient \\
\hline The cars couldn't move quickly because of the traffic. & crowded & central biased & eentral \\
\hline Terry brought fabric to make a new pair of jeans. & blue & central biased & salient \\
\hline The lily pad provided camouflage for the frogs. & eat flies & salient biased & eentral \\
\hline We looked in the sky and saw the lightning. & zig-zag & salient biased & salient \\
\hline $\begin{array}{l}\text { To protect them from fire, we the documents in the } \\
\text { safe. }\end{array}$ & has a lock & salient biased & central \\
\hline Jerry and Bob moved the television set. & is heavy & salient biased & salient \\
\hline I don't like the feel of oysters. & has shell & salient biased & eentral \\
\hline Rolling around in the pen was the pig. & dirty & salient biased & salient \\
\hline $\begin{array}{l}\text { Before the winter, we always clean the boots of our ice } \\
\text { skates. }\end{array}$ & has blades & salient biased & central \\
\hline We put the star on the top of the Christmas tree. & has a point & salient biased & salient \\
\hline He designed a plate for a single slice of pizza. & has cheese & salient biased & central \\
\hline At home, we only use processed sugar. & is white & salient biased & salient \\
\hline Don was upset that he had broken the baseball bat. & has handle & salient biased & central \\
\hline $\begin{array}{l}\text { Whipping around the curve, we yelled as we rode on } \\
\text { the roller coaster. }\end{array}$ & has thrills & salient biased & salient \\
\hline $\begin{array}{l}\text { We were concerned that we were sitting too close to the } \\
\text { stage at the concert. }\end{array}$ & has music & salient biased & central \\
\hline Mark wanted to take a picture of a Dalmatian. & has spots & salient biased & salient \\
\hline We were amazed at the ripeness of the cherries. & has pits & salient biased & eentral \\
\hline $\begin{array}{l}\text { Moving quickly across the field were two large } \\
\text { kangaroos. }\end{array}$ & can hop & salient biased & salient \\
\hline
\end{tabular}




\section{SENTENCE}

PROPERTY

SENTENCE

TYPE

PROPERTY

The young boy made a face when he first tasted the grapefruit.

We heard a noise before we noticed the two snakes.

We bought our tickets and walked into the movie

theater.

Kara picked flowers and cut the stems.

Flying through the air was a beautiful robin.

After finishing her computer project, Mari stored the

diskette.

At the art museurn, Lilly saw many wonderful

paintings.

While unpacking groceries, Dave put away the

shampoo bottle.

Gary examined the car engine.

In the field were hundreds of daisies.

In the Antarctic, Mari saw a real penguin.

For their vacation, Ron and Sue took their dog to the

kennel.

has pulp

salient biased central

can hiss

salient biased salient

has seats

control

central

are green control salient

has skin

control

central

is square control

salient

has value

control

central

To reach the dishes, Roz needed a step stool.

is plastic

control

salient

has water

control

central

is yellow control salient

In the morning, Julie got ready and put on her necklace.

For Pat's birthday, her parents took her to Jerusalem.

Before going out, Tia put on lipstick.

has wings

control

central

Will warned Dot to watch out for the puddle.

Dave got a big promotion.

Coming towards them was an angry bear.

have cages

control

salient

have rungs

control

central

Vicki went to New York to see all of the buildings.

Tom bought a cage for the canary.

holy

control

salient

The car needed more antifreeze.

While at the music store, Jim bought cymbals.

The restaurant ran out of tortilla chips.

For breakfast, Andy had a bagel.

The 17th century museum housed fine examples of armor.

red

control

central

control

salient

is water

control

central

celebrated

control

salient

large

control

central

are huge control salient

lays eggs nonbiased central

blue nonbiased salient

loud nonbiased central

triangular nonbiased salient

made of dough nonbiased central

While at the supermarket, John picked up two bags of

french fries.

nonbiased salient

Neil Armstrong was the first man to walk on the moon. far

The vendor on the corner sells the best pretzels.

Al went to the department store to buy a butcher's

knife.

While shopping, we looked at the green gem.

Rick lost the roll of scotch tape.

It only costs twenty-five cents for bubble gum.

The doctor gave Dave a yellow lollipop.

Melting in John's hand were the M\&M's.

silver

nonbiased central

potato

nonbiased

salient

salty

nonbiased

central

metal

nonbiased salient

sparkles

nonbiased central

clear

nonbiased salient

sticky

nonbiased central

round

nonbiased

salient

sweet

nonbiased

central 


\begin{tabular}{|c|c|c|c|}
\hline SENTENCE & PROPERTY & $\begin{array}{l}\text { SENTENCE } \\
\text { TYPE }\end{array}$ & $\begin{array}{l}\text { PROPERTY } \\
\text { TYPE }\end{array}$ \\
\hline At Andrew's farm, they bottle milk. & is white & nonbiased & salient \\
\hline $\begin{array}{l}\text { Rich has over three hundred bottles of wine in his } \\
\text { cellar. }\end{array}$ & under & nonbiased & central \\
\hline For breakfast everyday, Casey has two eggs. & oval & nonbiased & salient \\
\hline
\end{tabular}


Did Mary dance across the stage?

Was there noise coming from the kitchen?

Was there water in the vase?

Does Jim wear shoes on the beach?

Did we practice hitting a tennis ball?

Were we taking a ride on a trolley?

Are bumblebees in the meadow?

Did grandfather look through the door?

Was there traffic?

Were toads camouflaged by the lily pad?

Were the documents protected from fire?

Do I like the feel of oysters?

Do we clean the boots of our ice skates?

Could the plate fit three slices of pizza?

Was Don upset?

Were we sitting too far from the stage?

Were the cherries ripe?

Did the boy make a sound of disgust?

Did we buy tickets?

Was a bluebird flying through the air?

Did Lily go to the museum?

Was Gary examining the car paint?

Was Mari in the Antarctic?

Was Roz trying to reach the glasses?

Did Pat go to Jerusalem?

Did Will warn Dot about the dog?

Was the bear angry?

Was the cage for the parrot?

Was Jim at the music store?

Did Andy eat a muffin?

Was John at the supermarket?

Are the pretzels the worst?

Were we shopping?

Does a candy bar cost twenty-five cents?

Did John have M\&M's?

Does Rich have over three hundred wine bottles? 


\section{List 2B-Experiment 4}

\begin{tabular}{|c|c|c|c|}
\hline SENTENCE & PROPERTY & $\begin{array}{l}\text { SENTENCE } \\
\text { TYPE }\end{array}$ & $\begin{array}{l}\text { PROPERTY } \\
\text { TYPE }\end{array}$ \\
\hline Mary danced across the stage in her new tap shoes. & shiny & central biascd & salicnt \\
\hline Tom really enjoyed the taste of the candy bar. & is swect & central biased & central \\
\hline We could hear noise coming from the attic. & dusty & central biased & salient \\
\hline After rock climbing, they plan on going skydiving. & adventurous & central biased & central \\
\hline In the vase filled with water were some flowers. & pretty & central biased & salicnt \\
\hline We were full because of the appetizers. & are food & central biased & central \\
\hline Jim loves to remove his shoes and walk on the beach. & is hot & central biased & salicnt \\
\hline $\begin{array}{l}\text { Coming down the court, Larry had good control of the } \\
\text { basketball }\end{array}$ & bounce & central biased & central \\
\hline Using a wall, we practiced hitting a tennis ball. & yellow & central biased & salient \\
\hline Even at night, we could clearly see the traffic sign. & bright & central biased & central \\
\hline We couldn't wait to take a ride in the spaceship. & silver & central biased & salient \\
\hline $\begin{array}{l}\text { For the birth of their first child, Paul and Wendy bought } \\
\text { videotapes. }\end{array}$ & can record & central biased & central \\
\hline $\begin{array}{l}\text { If you are going to the meadow, watch out for all of the } \\
\text { bumblebees. }\end{array}$ & has stripes & central biased & salient \\
\hline You should be careful not to step on lobsters. & claws & central biased & central \\
\hline Grandfather looked at the rain through the window. & square & central biased & salient \\
\hline $\begin{array}{l}\text { To keep them fresh, we put the chicken and meat into the } \\
\text { refrigerator. }\end{array}$ & cold & central biased & central \\
\hline The cars couldn't move quickly because of the traffic. & annoying & central biased & salient \\
\hline Terry brought fabric to make a new pair of jeans. & denim & central biased & central \\
\hline The lily pad provided camouflage for the frogs. & are green & salient biased & salient \\
\hline We looked in the sky and saw the lightning. & electric & salient biased & central \\
\hline $\begin{array}{l}\text { To protect them from fire, we put the documents in the } \\
\text { safe. }\end{array}$ & is metal & salient biased & salient \\
\hline Jerry and Bob moved the television set. & has screen & salient biased & central \\
\hline I don't like the feel of oysters. & is slimy & salient biased & salient \\
\hline Rolling around in the pen was the pig. & snout & salient biased & central \\
\hline $\begin{array}{l}\text { Before the winter, we always clean the boots of our ice } \\
\text { skates. }\end{array}$ & are leather & salient biased & salient \\
\hline We put the star on the top of the Christmas tree. & has branches & salient biased & central \\
\hline He designed a plate for a single slice of pizza. & triangular & salient biased & salient \\
\hline At home, we only use processed sugar. & has grains & salient biased & central \\
\hline Don was upset that he had broken the baseball bat. & is wooden & salient biased & salient \\
\hline $\begin{array}{l}\text { Whipping around the curve, we yelled as we rode on the } \\
\text { roller coaster. }\end{array}$ & has hills & salient biased & central \\
\hline $\begin{array}{l}\text { We were concerned that we were sitting too close to the } \\
\text { stage at the concert. }\end{array}$ & are noisy & salient biased & salient \\
\hline Mark wanted to take a picture of a Dalmatian. & has paws & salient biased & central \\
\hline We were amazed at the ripeness of the cherries. & are red & salient biased & salient \\
\hline $\begin{array}{l}\text { Moving quickly across the field were two large } \\
\text { kangaroos. }\end{array}$ & has pouch & salient biased & central \\
\hline $\begin{array}{l}\text { The young boy made a face when he first tasted the } \\
\text { grapefruit. }\end{array}$ & is sour & salient biased & salient \\
\hline
\end{tabular}




\begin{tabular}{|c|c|c|c|}
\hline SENTENCE & PROPERTY & $\begin{array}{l}\text { SENTENCE } \\
\text { TYPE }\end{array}$ & $\begin{array}{l}\text { PROPERTY } \\
\text { TYPE }\end{array}$ \\
\hline We heard a noise before we noticed the two snakes & has scales & salient biased & central \\
\hline In the field were hundreds of daisies. & is yellow & control & salient \\
\hline In the backyard, Lisa planted tomatoes. & has seeds & control & central \\
\hline Coming towards them was an angry bear. & is brown & control & salient \\
\hline To prepare to be a chef, Gary enrolled in culinary school. & has students & control & central \\
\hline Pat reached over to the table and picked up her ring. & are round & control & salient \\
\hline $\begin{array}{l}\text { While unpacking groceries, Dave put away the shampoo } \\
\text { bottle. }\end{array}$ & has volume & control & central \\
\hline $\begin{array}{l}\text { After finishing her computer project, Mari stored the } \\
\text { diskettes. }\end{array}$ & are square & control & salient \\
\hline For his birthday, Brett wanted a new scooter. & has wheels & control & central \\
\hline We bought our tickets and walked into the movie theater. & has seats & control & salient \\
\hline Sylvia went to see the circus. & have animals & control & central \\
\hline In front of the school stood a silver flagpole. & are tall & control & salient \\
\hline Theresa's mother bought her a new backpack. & carries & control & central \\
\hline To study, Sandy went to the library. & quiet & control & salient \\
\hline For a vacation, Randy went to the beach. & hot & control & central \\
\hline $\begin{array}{l}\text { Ron sat down and wrote his name on the cover of the test } \\
\text { booklet. }\end{array}$ & is blue & control & salient \\
\hline Ken started college in the fall. & is yearly & control & central \\
\hline We couldn't wait to take a trip to Chicago. & is far & control & salient \\
\hline Climbing on the leaf was a fuzzy caterpillar. & lay eggs & control & central \\
\hline Tom bought a cage for the canary. & is yellow & nonbiased & salient \\
\hline The car needed more antifreeze. & liquid & nonbiased & central \\
\hline While at the music store, Jim bought cymbals. & round & nonbiased & salient \\
\hline The restaurant ran out of tortilla chips. & made of corn & nonbiased & central \\
\hline For breakfast, Andy had a bagel. & have a hole & nonbiased & salient \\
\hline The 17th century museum housed fine examples of armor. & metal & nonbiased & central \\
\hline $\begin{array}{l}\text { While at the supermarket, John picked up two bags of } \\
\text { french fries. }\end{array}$ & greasy & nonbiased & salient \\
\hline Neil Armstrong was the first man to walk on the moon. & rock & nonbiased & central \\
\hline The vendor on the corner sells the best pretzels. & twisted & nonbiased & salient \\
\hline Al went to the department store to buy a butcher's knife. & sharp & nonbiased & central \\
\hline While shopping, we looked at the green gem. & expensive & nonbiased & salient \\
\hline Rick lost the roll of scotch tape. & sticky & nonbiased & central \\
\hline It only costs twenty-five cents for bubble gum. & pink & nonbiased & salient \\
\hline The doctor gave Dave a yellow lollipop. & sweet & nonbiased & central \\
\hline Melting in John's hand were the M\&M's. & round & nonbiased & salient \\
\hline At Andrew's farm, they bottle milk. & to drink & nonbiased & central \\
\hline Rich has over three hundred bottles of wine in his cellar. & dark & nonbiased & salient \\
\hline For breakfast everyday, Casey has two eggs. & yolk & nonbiased & central \\
\hline
\end{tabular}


Did Mary dance across the stage?

Was there noise coming from the kitchen?

Was there water in the vase?

Does Jim wear shoes on the beach?

Did we practice hitting a tennis ball?

Were we taking a ride on a trolley?

Are bumblebees in the meadow?

Did grandfather look through the door?

Was there traffic?

Were toads camouflaged by the lily pad?

Were the documents protected from fire?

Do I like the feel of oysters?

Do we clean the boots of our ice skates?

Could the plate fit three slices of pizza?

Was Don upset?

Were we sitting too far from the stage?

Were the cherries ripe?

Did the boy make a sound of disgust?

Were there daisies in the field?

Was the bear calm?

Was Pat reaching for her ring?

Was Mari working on a chemistry project?

Were we buying tickets?

Was the flagpole black?

Did Sandy study in the library?

Did Ron write his name on the notebook?

Were we going to Chicago?

Was the cage for the parrot?

Was Jim at the music store?

Did Andy eat a muffin?

Was John at the supermarket?

Are the pretzels the worst?

Were we shopping?

Does a candy bar cost twenty-five cents?

Did John have M\&M's?

Does Rich have over three hundred wine bottles? 
List 3A-Experiment 4

\begin{tabular}{|c|c|c|c|}
\hline SENTENCE & PROPERTY & $\begin{array}{l}\text { SENTENCE } \\
\text { TYPE }\end{array}$ & $\begin{array}{l}\text { PROPERTY } \\
\text { TYPI: }\end{array}$ \\
\hline Paul loved to play the drum. & noisy & control & central \\
\hline Rachel went to the store to buy a book. & rectangle & control & salient \\
\hline Paula kept her dolls in the bedroom. & above & control & central \\
\hline In the winter, Trina loved to go skiing. & is dangerous & control & salient \\
\hline At the zoo, Eva saw a walrus. & alive & control & central \\
\hline Arnie really enjoyed a morning muffin. & taste good & control & salient \\
\hline In the evening. Jake took a walk on the boardwalk. & sandy & control & central \\
\hline In the street were warning cones. & orange & control & salient \\
\hline For his birthday, Mark got a beach ball. & bounces & control & central \\
\hline $\begin{array}{l}\text { After finishing her computer project, Mari stored the } \\
\text { diskette. }\end{array}$ & square & control & salient \\
\hline On the pond were seventeen ducks. & can fly & control & central \\
\hline His school was building a new football field. & rectangle & control & salient \\
\hline At the beach, Joe saw some jellyfish. & can sting & control & central \\
\hline At the intersection was a flashing light. & is red & control & salient \\
\hline The teller sat behind the Plexiglas. & clear & control & central \\
\hline Before writing the report, Jan needed to pick up paper. & white & control & salient \\
\hline Paul really hated taking the subway. & crowded & control & central \\
\hline $\begin{array}{l}\text { Ron sat down and wrote his name on the cover of the test } \\
\text { booklet. }\end{array}$ & blue & control & salient \\
\hline Little Johnny went to the pond to catch frogs. & eats flies & nonbiased & central \\
\hline Children are often scared of lightning. & zig-zag & nonbiased & salient \\
\hline In Zachary's house, there is a safe. & has lock & nonbiased & central \\
\hline Tom sold his television set. & is heavy & nonbiased & salient \\
\hline The chef made a dish with oysters. & has shell & nonbiased & central \\
\hline Father won first prize at the county fair for his pig. & dirty & nonbiased & salient \\
\hline His older brother gave him the ice skates. & has blades & nonbiased & central \\
\hline The family went and bought a Christmas tree. & has a point & nonbiased & salient \\
\hline For lunch, Alex had a slice of pizza. & has cheese & nonbiased & central \\
\hline Rob went to the store to buy sugar. & is white & nonbiased & salient \\
\hline In the window was a brand new baseball bat. & has handle & nonbiased & central \\
\hline There was a long line for the roller coaster. & has thrills & nonbiased & salient \\
\hline Jim lost his ticket to the concert. & has music & nonbiased & central \\
\hline The fireman rode with a Dalmatian. & has spots & nonbiased & salient \\
\hline Greg made the pie with chemies. & has pits & nonbiased & central \\
\hline In Australia, there are many kangaroos. & can hop & nonbiased & salient \\
\hline For breakfast, Marsha likes to have a grapefruit. & has pulp & nonbiased & central \\
\hline Moving across the floor were two snakes. & can hiss & nonbiased & salient \\
\hline The children talked to their friends on the school bus. & has seats & central biased & central \\
\hline \multicolumn{2}{|c|}{ Discarding the unwanted innards, we ate the bag of grapes. are green } & \multicolumn{2}{|c|}{ central biased salient } \\
\hline Always wash the outsides before preparing baked potatoe & has skin & central biased & central \\
\hline
\end{tabular}




\section{SENTENCE}

PROPERTY SENTENCE PROPERTY

TYPE

TYPE

The teacher was not surprised to have such a full

classroom.

For lunch, David gave the cashier a handful of coins.

You need to be more careful when pouring from a full

soda bottle.

Walter always likes to watch his parents fill the pool.

While on a hill, the driver put the parking break on the taxi.

As the plane landed, the pilot adjusted the flaps on the airplane.

The toddler was excited about his first trip to the zoo.

Before using them, you should always check the sturdiness

of old ladders.

is square central biased salient

has value central biased central

is plastic central biased salient

has water central biased central

is yellow central biased salient

Because the Martin's had a long list, they decided to grab a

shopping cart.

has wings central biased central

have cages central biased salient

have rungs central biased central

The worshipers bowed their heads as they entered the church.

is metal central biased salient

It always brought tears to her eyes when she bit into jalapenos.

holy

central biased central

Lucy grabbed a towel after coming out from the ocean.

red

central biased salient

Once again, it was time to buy a gift for my parent's

anniversary.

is water central biased central

It took them a long time to travel across China.

celebrated central biased salient

In biology, we were taught about the reproduction of

dinosaurs.

large central biased central

Looking in the pet store window, Ken admired the

plumage of the canary.

are huge central biased salient

Scanning the shelf, we could see there was plenty of

antifreeze.

lays eggs salient biased central

The children used old plates covered with tin foil to make cymbals.

blue

salient biased salient

To pick up the salsa, Juan would grasp a corner on his tortilla chips.

At the bakery, Zack and Belinda helped them shape the

bagels.

loud

salient biased central

George was told by his boss at the museum to check the

polish of the armor.

triangular

salient biased salient

made of

dough

salient biased central

Tracy couldn't believe the residue left by the french fries.

Neil Armstrong checked the fuel supply for his trip to the moon.

silver salient biased salient

In her cooking class, Jill prepared the dough to make some homemade pretzels.

potato

salient biased central

far

salient biased salient

Pam could see her reflection in her new butcher's knife.

salty

salient biased central

Although he thought it was beautiful, the janitor couldn't rationalize buying such a gem.

To achieve a clean look, we only used scotch tape.

metal

salient biased salient

It was clear that what she put in her mouth was a piece of bubble gum.

sparkles salient biased central

clear salient biased salient

sticky

salient biased central 


\begin{tabular}{llll}
\hline \multicolumn{1}{c}{ SENTENCE } & PROPERTY & $\begin{array}{l}\text { SENTENCE } \\
\text { TYPE }\end{array}$ & $\begin{array}{l}\text { PROPERTY } \\
\text { TYPE }\end{array}$ \\
$\begin{array}{l}\text { Reaching into the bag, Sue could feel right away that there } \\
\text { was a lollipop. }\end{array}$ & round & salient biased & salient \\
\hline $\begin{array}{l}\text { Carol preferred plain, not peanut M\&M's. } \\
\text { Stan wiped away the moustache as he finished his milk. }\end{array}$ & is wheet & salient biased & central \\
\hline $\begin{array}{l}\text { Kathy was scared to go into the cellar. } \\
\text { Picking them up out of the nest, Stan admired the hen's }\end{array}$ & under & salient biased & central \\
eggs. & oval & salient biased & salient \\
\hline
\end{tabular}


Questions 3A-Experiment 4

Did Paul love to play the drum?

Did Paula keep her dolls in the living room?

Did Eva see a walrus at the zoo?

Did Jake take a walk on the beach?

For his birthday did Mark get a beach ball?

Were there two ducks on the pond?

Did Joe see some jellyfish?

Were the tellers behind metal bars?

Did Paul really hate the subway?

Did Johnny catch fish?

Does Zachary's house have a safe?

Was it my mom who made an oyster dish?

Are his skates from his brother?

Did Alex have a salad for lunch?

Was the baseball bat brand new?

Was the lost ticket for a baseball game?

Did Greg make the pie?

Did Marsha eat grapefruit for lunch?

Did the children talk on the bus?

Should you wash potatoes after cooking them?

Did David give the cashier coins?

Does Walter like to watch the bathtub being filled?

Did the pilot adjust the flaps on the airplane?

Should you use the old ladder and not check it?

Were the heads of the worshippers bowed?

Did Susan want to be introduced to Tom's son?

Was it my parent's anniversary?

Did Kevin admire the dogs?

Did the children make cymbals?

Were Zach and Belinda at the drugstore?

Was the residue left by the french fries?

Did Jill make bagels?

Did the janitor think the gem was beautiful?

Did she put the gum in her pocket?

Did Carol prefer plain M\&M's?

Was Kathy excited? 


\begin{tabular}{|c|c|c|c|}
\hline SENTENCE & PROPERTY & $\begin{array}{l}\text { SENTENCE } \\
\text { TYPE }\end{array}$ & $\begin{array}{l}\text { PROPLRTY } \\
\text { TYPE: }\end{array}$ \\
\hline Lance leaned over and picked up the penny. & shiny & control & salient \\
\hline In the morning Arnie always enjoyed a muffin. & is swcet & control & central \\
\hline Percy needed to get the trunk from the attic. & dusty & control & salient \\
\hline Holly wanted to go climbing. & adventurous & control & central \\
\hline For Theresa's birthday, Mark sent a bouquet. & pretty & control & salient \\
\hline On the airplane, John was only given a pack of crackers. & are food & control & central \\
\hline For a vacation, Randy went to the beach. & is hot & control & salient \\
\hline For his birthday, Mark got a beach ball. & bounce & control & central \\
\hline At the intersection was a flashing light. & yellow & control & salient \\
\hline For the party, Laura purchased the decorations. & bright & control & central \\
\hline $\begin{array}{l}\text { As the car rolled past, we couldn't help but notice the } \\
\text { hubcaps. }\end{array}$ & silver & control & salient \\
\hline Patty needed to buy some CD's. & can record & control & central \\
\hline Climbing on the leaf was a fuzzy caterpillar. & has stripes & control & salient \\
\hline Sitting on the perch was a beautiful parrot. & claws & control & central \\
\hline $\begin{array}{l}\text { After finishing her computer project, Mari stored the } \\
\text { diskette. }\end{array}$ & square & control & salient \\
\hline Jasper went on a trip to Canada. & cold & control & central \\
\hline Pulling hair is a typical behavior for toddlers. & annoying & control & salient \\
\hline Kate took her old jeans and made a pair of shorts. & denim & control & central \\
\hline Little Johnny went to the pond to catch frogs. & are green & nonbiased & salient \\
\hline Children are often scared of lightning. & electric & nonbiased & central \\
\hline In Zachary's house, there is a safe. & is metal & nonbiased & salient \\
\hline Tom sold his television set. & has screen & nonbiased & central \\
\hline The chef made a dish with oysters. & is slimy & nonbiased & salient \\
\hline Father's won first prize at the county fair for his pig. & snout & nonbiased & central \\
\hline His older brother gave him the ice skates. & are leather & nonbiased & salient \\
\hline The family went and bought a Christmas tree. & has branches & nonbiased & central \\
\hline For lunch, Alex had a slice of pizza. & triangular & nonbiased & salient \\
\hline Rob went to the store to buy sugar. & has grains & nonbiased & central \\
\hline In the window was a brand new baseball bat. & is wooden & nonbiased & salient \\
\hline There was a long line for the roller coaster. & has hills & nonbiased & central \\
\hline Jim lost his ticket to the concert. & are noisy & nonbiased & salient \\
\hline The fireman rode with a Dalmatian. & has paws & nonbiased & central \\
\hline Greg made the pie with cherries. & are red & nonbiased & salient \\
\hline In Australia, there are many kangaroos. & has pouch & nonbiased & central \\
\hline For breakfast, Marsha likes to have a grapefiuit. & is sour & nonbiased & salient \\
\hline Moving across the floor were two snakes. & has scales & nonbiased & central \\
\hline $\begin{array}{l}\text { After they boarded, the children talked to their friends on } \\
\text { the school bus. }\end{array}$ & is yellow & central biased & salient \\
\hline Discarding the unwanted innards, we ate the bag of grapes. & has seeds & central biased & central \\
\hline
\end{tabular}




\section{SENTENCE}

Always wash the outsides before preparing the baked potatoes.

The teacher was not surprised to have such a full classroom.

For lunch, David gave the cashier a handful of coins. You need to be more careful when pouring from a full soda bottle.

Walter always likes to watch his parents fill the pool. While on a hill, the driver put the parking break on the taxi.

As the plane landed, the pilot adjusted the flaps on the airplane.

The toddler was excited about his first trip to the zoo.

Before using them, you should always check the sturdines of old ladders.

Because the Martin's had a long list, they decided to grab a shopping cart.

The worshipers bowed their heads as they entered the church.

It always brought tears to her eyes when she bit into jalapenos.

Lucy grabbed a towel after coming out from the ocean.

Once again, it was time to buy a gift for my parent's anniversary.

It took them a long time to travel across China.

In biology, we were taught about the reproduction of dinosaurs.

Looking in the pet store window, Ken admired the plumage of the canary.

Scanning the shelf, we could see there was plenty of antifreeze.

The children used old plates covered with tin foil to make cymbals.

To pick up the salsa, Juan would grasp a corner on his tortilla chips.

At the bakery, Zack and Belinda helped them shape the bagels.

George was told by his boss at the museum to check the polish of the armor.

Tracy couldn't believe the residue left by the french fries. Neil Armstrong checked the fuel supply for his trip to the moon.

In her cooking class, Jill prepared the dough to make some homemade pretzels.

Pam could see her reflection in her new butcher's knife.

Although he thought it was beautiful, the janitor couldn't rationalize buying such a gem.

To achieve a clcan look, we only used scotch tape.

PROPERTY SENTENCE PROPERTY TYPI: TYPE

is brown central biased salient

has students central biased central are round central biased salient

has volume central biased central are square central biascd salient has wheels central biased central

has seats central biased salient have animals ccntral biased central are tall central biased salient carries central biased central quiet central biased salient hot central biased central is blue central biased salient is yearly central biased central is far central biased salient lay eggs central biased central is yellow salient biased salient liquid salient biased central round salient biased salient made of com salient biased central have a hole salient biased salient

metal salient biased central greasy salient biased salient rock salient biased central twisted salient biased salient sharp salient biased central expensive salient biased salient sticky salient biased central 


\begin{tabular}{llll}
\hline \multicolumn{1}{c}{ SENTENCE } & PROPERTY & $\begin{array}{l}\text { SENTINCE } \\
\text { TYPE }\end{array}$ & $\begin{array}{l}\text { PROPFRTY } \\
\text { TYPI: }\end{array}$ \\
$\begin{array}{l}\text { It was clear that what she put in her mouth was a piece of } \\
\text { bubble gum. }\end{array}$ & pink & salient biased & salient \\
\hline $\begin{array}{l}\text { Reaching into the bag, Sue could feel right away that there } \\
\text { was a lollipop. }\end{array}$ & sweet & salient biased & central \\
\hline $\begin{array}{l}\text { Carol preferred plain, not peanut M\&M's. } \\
\text { Stan wiped away the moustache as he finished his milk. }\end{array}$ & to drink & salient biased & central \\
\hline $\begin{array}{l}\text { Kathy was scared to go into the cellar. } \\
\text { Picking them up out of the nest, Stan admired the hen's }\end{array}$ & dark & salient biased & salient \\
eggs. & yolk & salient biased & central \\
\hline
\end{tabular}


Did Johnny catch fish?

Does Zachary's house have a safe?

Was it my mom who made an oyster dish?

Are his skates from his brother?

Did Alex have a salad for lunch?

Was the baseball bat brand new?

Was the lost ticket for a baseball game?

Did Greg make the pie?

Did Marsha eat grapefruit for lunch?

Did the children talk on the bus?

Should you wash potatoes after cooking them?

Did David give the cashier coins?

Does Walter like to watch the bathtub being filled?

Did the pilot adjust the flaps on the airplane?

Should you use the old ladder and not check it?

Were the heads of the worshippers bowed?

Did Susan want to be introduced to Tom's son?

Was it my parent's anniversary?

Did Kevin admire the dogs?

Did the children make cymbals?

Were Zach and Belinda at the drugstore?

Was the residue left by the french fries?

Did Jill make bagels?

Did the janitor think the gem was beautiful?

Did she put the gum in her pocket?

Did Carol prefer plain M\&M's?

Was Kathy excited? 


\begin{tabular}{|c|c|c|c|}
\hline SENTENCE & PROPERTY & $\begin{array}{c}\text { SENTENCE } \\
\text { TYPE }\end{array}$ & $\begin{array}{c}\text { PROPERTY } \\
\text { TYPE }\end{array}$ \\
\hline For the recital, Joe polished the tap shoes. & noisy & salient biased & central \\
\hline In Jim's hand was a piece of a candy bar. & rectangle & salient biased & salient \\
\hline For years, Mary hadn't gone into the attic. & above & salient biased & central \\
\hline Jill's mother did not want her to go skydiving. & is dangerous & salient biased & salient \\
\hline In the spring, we admired the blooming flowers. & alive & salient biased & central \\
\hline At the party, Cindy really enjoyed the appetizers. & taste good & salient biased & salient \\
\hline We love to sit out on the beach. & sandy & salient biased & central \\
\hline Against the blacktop, we could clearly see the basketball. & orange & salient biased & salient \\
\hline Because of the glare, we couldn't see the tennis ball. & bounces & salient biased & central \\
\hline They cut the metal to make a traffic sign. & square & salient biased & salient \\
\hline He painted the model of a spaceship. & can fly & salient biased & central \\
\hline A VCR is only designed to fit videotapes. & rectangle & salient biased & salient \\
\hline $\begin{array}{l}\text { Before going to the meadow, we told them how to spot } \\
\text { the bumblebees. }\end{array}$ & can sting & salient biased & central \\
\hline Out of the boiling water dad pulled five lobsters. & is red & salient biased & salient \\
\hline It was a standard size window. & clear & salient biased & central \\
\hline $\begin{array}{l}\text { We wanted to match the cabinet knobs with the } \\
\text { refrigerator. }\end{array}$ & white & salient biased & salient \\
\hline Hank was extremely late for work because of traffic. & crowded & salient biased & central \\
\hline I wanted to get a shirt to match my jeans. & blue & salient biased & salient \\
\hline Climbing on the tree branch was an iguana. & eats flies & control & central \\
\hline Coming down the slopes was the skier. & zig-zag & control & salient \\
\hline Every night Tina wrote in her diary. & has lock & control & central \\
\hline Coming home from the store, Jim carried the grocery bag. & is heavy & control & salient \\
\hline On the rock was a small snail. & has shell & control & central \\
\hline Paul went to the store to shop for a toilet. & dirty & control & salient \\
\hline Tom wanted to try his new lawn mower. & has blades & control & central \\
\hline Wendy had difficulty threading the needle. & has a point & control & salient \\
\hline For dinner, Meg prepared tortellini. & has cheese & control & central \\
\hline For the school project, Greta bought glue. & is white & control & salient \\
\hline While preparing dinner, Kira filled the pot. & has handle & control & central \\
\hline On vacation, Randy rented a speedboat. & has thrills & control & salient \\
\hline Paula really wanted that jewelry box. & has music & control & central \\
\hline On the safari, Lana saw a cheetah. & has spots & control & salient \\
\hline Phil eats his cereal with prunes. & has pits & control & central \\
\hline Marta's dog had fleas. & can hop & control & salient \\
\hline At the grocery store, Lance bought limes. & has pulp & control & central \\
\hline Climbing on the furniture was the gray cat. & can hiss & control & salient \\
\hline Broken down on the side of the road was the school bus. & has seats & nonbiased & central \\
\hline Good wine can be made from Napa Valley grapes. & are green & nonbiased & salient \\
\hline The meat loaf is served with potatoes. & has skin & nonbiased & central \\
\hline
\end{tabular}




\begin{tabular}{|c|c|c|c|}
\hline SENTENCE & PROPERTY & $\begin{array}{c}\text { SENTENCE } \\
\text { TYPE } \\
\end{array}$ & $\begin{array}{l}\text { PROPERTY } \\
\text { TYPE } \\
\end{array}$ \\
\hline The maintenance men painted the classroom. & is square & nonbiased & salient \\
\hline The soda machine only took coins. & has value & nonbiased & central \\
\hline Left in the car was an old soda bottle. & is plastic & nonbiased & salient \\
\hline Arthur and his wife sat around the pool. & has water & nonbiased & central \\
\hline To get home from the bar, Greg took a taxi. & is yellow & nonbiased & salient \\
\hline Because the team was late, they missed the airplane. & has wings & nonbiased & central \\
\hline The city is planning to build a new zoo. & have cages & nonbiased & salient \\
\hline The hardware store sold six different types of ladders. & have rungs & nonbiased & central \\
\hline It was Bart's job to collect all of the shopping carts. & is metal & nonbiased & salient \\
\hline On the corner is the city's oldest church. & holy & nonbiased & central \\
\hline Bill dropped the jar of jalapenos. & red & nonbiased & salient \\
\hline California is bordered by the ocean. & is water & nonbiased & central \\
\hline Pat was reminded of the anniversary. & celebrated & nonbiased & salient \\
\hline The United States recently normalized trade with China. & large & nonbiased & central \\
\hline $\begin{array}{l}\text { The experts argued about the cause of the extinction of } \\
\text { dinosaurs. }\end{array}$ & are huge & nonbiased & salient \\
\hline $\begin{array}{l}\text { In the spring, building a nest was a necessity for the } \\
\text { canary. }\end{array}$ & lays eggs & central biased & central \\
\hline Caren used a funnel when replacing her car's antifreeze. & blue & central biased & salient \\
\hline $\begin{array}{l}\text { Arnie couldn't stand it when his neighbor practiced the } \\
\text { cymbals. }\end{array}$ & loud & central biased & central \\
\hline $\begin{array}{l}\text { While in Mexico, the Damon's enjoyed the freshly made } \\
\text { tortilla chips. }\end{array}$ & triangular & central biased & salient \\
\hline $\begin{array}{l}\text { At the bakery, Zack and Belinda watched them prepare } \\
\text { the bagels. }\end{array}$ & made of dough & central biased & central \\
\hline As it fell, we could hear the clatter of the armor. & silver & central biased & salient \\
\hline $\begin{array}{l}\text { Starting from scratch, Wanda prepared a batch of french } \\
\text { fries. }\end{array}$ & potato & central biased & central \\
\hline $\begin{array}{l}\text { Neil Armstrong collected samples to bring back from the } \\
\text { moon. }\end{array}$ & far & central biased & salient \\
\hline $\begin{array}{l}\text { I had to order a drink after I finished eating all of the } \\
\text { pretzels. }\end{array}$ & salty & central biased & central \\
\hline $\begin{array}{l}\text { Because the meat was tough, Dan had to use a butcher's } \\
\text { knife. }\end{array}$ & metal & central biased & salient \\
\hline $\begin{array}{l}\text { Looking at it in the sunlight, Phil admired the beauty of } \\
\text { the gem. }\end{array}$ & sparkles & central biased & central \\
\hline To if it could hold papers, Kate touched the scotch tape. & clear & central biased & salient \\
\hline $\begin{array}{l}\text { Wiping his face, Oscar didn't know how to clean off the } \\
\text { bubble gum. }\end{array}$ & sticky & central biased & central \\
\hline For a snack, Mary wanted to have a lollipop. & round & central biased & salient \\
\hline To satisfy her craving, Hannah ate some M\&M's. & sweet & central biased & central \\
\hline With cookies, June only wanted to have some milk. & is white & central biased & salient \\
\hline Larry took the steps from the kitchen to get to the cellar. & under & central biased & central \\
\hline For breakfast, John only eats soft-boiled eggs. & oval & central biased & salient \\
\hline
\end{tabular}




\section{Questions 4A-Experiment 4}

Did Joe polish the tap shoes?

For years, has Mary not gone in the basement?

Did we admire the blooming flowers?

Do we hate the beach?

Could we not see the ball because there was a glare?

Was he painting a house?

Were they going out into the meadow?

Was the window small?

Was Hank late for work?

Was a fly climbing on the tree branch?

Did Tina write in her diary every night?

Was a slug on the rock?

Did Tom want to try his new lawn mower?

Did Meg prepare ravioli?

Did Kira fill the pot?

Did Paula really want a doll?

Does Phil eat his cereal with prunes?

Did Lance buy lemons?

Was the school bus broken down?

Does the meat loaf come with rice?

Does the machine take coins?

Was Arthur alone by the pool?

Did the team miss the airplane?

Were there six different types of ladders?

Is there a grocery store on the corner?

Is California next to the ocean?

Did the US normalize trade with Iraq?

Did the canary need to build a nest in the spring?

Did Arnie like when his neighbors practiced the cymbals?

Did Zach and Belinda watch them prepare bagels?

Was Wanda preparing a cake?

Was I eating pretzels?

Did Phil admire the gem?

Did Oscar have brownies on his face?

Did Hannah eat some M\&M's?

Was Larry going to the living room? 


\begin{tabular}{|c|c|c|c|}
\hline SENTENCE & PROPERTY & $\begin{array}{l}\text { SENTENCE } \\
\text { TYPE } \\
\end{array}$ & $\begin{array}{l}\text { PROPERTY } \\
\text { TYPE } \\
\end{array}$ \\
\hline For the recital, Joe polished the tap shoes. & shiny & salient biased & salient \\
\hline In Jim's hand was a piece of a candy bar. & is sweet & salient biased & central \\
\hline For years, Mary hadn't gone into the attic. & dusty & salient biased & salient \\
\hline Jill's mother did not want her to go skydiving. & adventurous & salient biased & central \\
\hline In the spring, we admired the blooming flowers. & pretty & salient biased & salient \\
\hline At the party, Cindy really enjoyed the appetizers. & are food & salient biased & central \\
\hline We love to sit out on the beach. & is hot & salient biased & salient \\
\hline $\begin{array}{l}\text { Against the blacktop, we could clearly see the } \\
\text { basketball. }\end{array}$ & bounce & salient biased & central \\
\hline Because of the glare, we couldn't see the tennis ball. & yellow & salient biased & salient \\
\hline They cut the metal to make a traffic sign. & bright & salient biased & central \\
\hline He painted the model of a spaceship. & silver & salient biased & salient \\
\hline A VCR is only designed to fit videotapes. & can record & salient biased & central \\
\hline $\begin{array}{l}\text { Before going to the meadow, we told them how to spot } \\
\text { the bumblebees. }\end{array}$ & has stripes & salient biased & salient \\
\hline Out of the boiling water dad pulled five lobsters. & claws & salient biased & central \\
\hline It was a standard size window. & square & salient biased & salient \\
\hline $\begin{array}{l}\text { We wanted to match the cabinet knobs with the } \\
\text { refrigerator. }\end{array}$ & cold & salient biased & central \\
\hline Hank was extremely late for work because of traffic. & annoying & salient biased & salient \\
\hline I wanted to get a shirt to match my jeans. & denim & salient biased & central \\
\hline Kara picked flowers and cut the stems. & are green & control & salient \\
\hline Sally went to the store to buy a stove. & electric & control & central \\
\hline In the morning, Julie got ready and put on her necklace. & is metal & control & salient \\
\hline Tom came in to the office and turned on the computer. & has screen & control & central \\
\hline At the Japanese restaurant, we ate some seaweed. & is slimy & control & salient \\
\hline At the zoo, we saw a warthog. & snout & control & central \\
\hline In the morning, Ken put on his sneakers. & are leather & control & salient \\
\hline Wendy was hiding in the bushes. & has branches & control & central \\
\hline Standing on the ground, Gerry stared up at the roof. & triangular & control & salient \\
\hline Perry prepared a plate of pancakes. & has grains & control & central \\
\hline May went out to prepare the boat. & is wooden & control & salient \\
\hline Will went on a trip to the farm. & has hills & control & central \\
\hline Paul loved to play the drum. & are noisy & control & salient \\
\hline For Bill's birthday, he got a cat. & has paws & control & central \\
\hline At the intersection was a flashing light. & are red & control & salient \\
\hline Theresa's mother bought her a new backpack. & has pouch & control & central \\
\hline Pam tasted the lime. & is sour & control & salient \\
\hline On a trip to Florida, Francis saw an alligator. & has scales & control & central \\
\hline Broken down on the side of the road was the school bus. & is yellow & nonbiased & salient \\
\hline Good wine can be made from Napa Valley grapes. & has seeds & nonbiased & central \\
\hline The meat loaf is served with potatoes. & is brown & nonbiased & salient \\
\hline
\end{tabular}




\begin{tabular}{|c|c|c|c|}
\hline SENTENCE & PROPERTY & $\begin{array}{c}\text { SENTENCI: } \\
\text { TYPE } \\
\end{array}$ & $\begin{array}{l}\text { PROPIERTY } \\
\text { TYPE }\end{array}$ \\
\hline The maintenance men painted the classroom. & has students & nonbiased & central \\
\hline The soda machine only took coins. & are round & nonbiased & salient \\
\hline Left in the car was an old soda bottle. & has volume & nonbiased & central \\
\hline Arthur and his wife sat around the pool. & are square & nonbiased & salient \\
\hline To get home from the bar, Greg took a taxi. & has wheels & nonbiased & central \\
\hline Because the team was late, they missed the airplane. & has seats & nonbiased & salient \\
\hline The city is planning to build a new zoo. & have animals & nonbiased & central \\
\hline The hardware store sold six different types of ladders. & are tall & nonbiased & salient \\
\hline It was Bart's job to collect all of the shopping carts. & carries & nonbiased & central \\
\hline On the corner is the city's oldest church. & quiet & nonbiased & salient \\
\hline Bill dropped the jar of jalapenos. & hot & nonbiased & central \\
\hline California is bordered by the ocean. & is blue & nonbiased & salient \\
\hline Pat was reminded of the anniversary. & is yearly & nonbiased & central \\
\hline The United States recently normalized trade with China. & is far & nonbiased & salient \\
\hline $\begin{array}{l}\text { The experts argued about the cause of the extinction of } \\
\text { dinosaurs. }\end{array}$ & lay eggs & nonbiased & central \\
\hline $\begin{array}{l}\text { In the spring, building a nest was a necessity for the } \\
\text { canary. }\end{array}$ & is yellow & central biased & salient \\
\hline Caren used a funnel when replacing her car's antifreeze. & liquid & central biased & central \\
\hline $\begin{array}{l}\text { Arnie couldn't stand it when his neighbor practiced the } \\
\text { cymbals. }\end{array}$ & round & central biased & salient \\
\hline $\begin{array}{l}\text { While in Mexico, the Damon's enjoyed the freshly made } \\
\text { tortilla chips. }\end{array}$ & made of corn & central biased & central \\
\hline $\begin{array}{l}\text { At the bakery, Zack and Belinda watched them prepare } \\
\text { the bagels. }\end{array}$ & have a hole & central biased & salient \\
\hline As it fell, we could hear the clatter of the armor. & metal & central biased & central \\
\hline $\begin{array}{l}\text { Starting from scratch, Wanda prepared a batch of french } \\
\text { fries. }\end{array}$ & greasy & central biased & salient \\
\hline $\begin{array}{l}\text { Neil Armstrong collected samples to bring back from the } \\
\text { moon. }\end{array}$ & rock & central biased & central \\
\hline $\begin{array}{l}\text { I had to order a drink after I finished eating all of the } \\
\text { pretzels. }\end{array}$ & twisted & central biased & salient \\
\hline $\begin{array}{l}\text { Because the meat was tough, Dan had to use a butcher's } \\
\text { knife. }\end{array}$ & sharp & central biased & central \\
\hline $\begin{array}{l}\text { Looking at it in the sunlight, Phil admired the beauty of } \\
\text { the gem. }\end{array}$ & expensive & central biased & salient \\
\hline To if it could hold papers, Kate touched the scotch tape. & sticky & central biased & central \\
\hline $\begin{array}{l}\text { Wiping his face, Oscar didn't know how to clean off the } \\
\text { bubble gum. }\end{array}$ & pink & central biased & salient \\
\hline For a snack, Mary wanted to have a lollipop. & sweet & central biased & central \\
\hline To satisfy her craving, Hannah ate some M\&M's. & round & central biased & salient \\
\hline With cookies, June only wanted to have some milk. & to drink & central biased & central \\
\hline Larry took the steps from the kitchen to get to the cellar. & dark & central biased & salient \\
\hline For breakfast, John only eats soft-boiled eggs. & yolk & central biased & central \\
\hline
\end{tabular}




\section{Questions 4B-Experiment 4}

Did Joe polish the tap shoes?

For years, has Mary not gone in the basement?

Did we admire the blooming flowers?

Do we hate the beach?

Could we not see the ball because there was a glare?

Was he painting a house?

Were they going out into the meadow?

Was the window small?

Was Hank late for work?

Did Kara cut the weeds?

Did Julie put on her necklace?

Did we eat tofu at the Japanese restaurant?

Did Ken put on his sneakers?

Did Gerry stare up at the clouds?

Was May preparing the boat?

Did Paul love to play the piano?

Was the light flashing?

Did Pam taste a lemon?

Was the school bus broken down?

Does the meat loaf come with rice?

Does the machine take coins?

Was Arthur alone by the pool?

Did the team miss the airplane?

Were there six different types of ladders?

Is there a grocery store on the corner?

Is California next to the ocean?

Did the US normalize trade with Iraq?

Did the canary need to build a nest in the spring?

Did Arnie like when his neighbors practiced the cymbals?

Did Zach and Belinda watch them prepare bagels?

Was Wanda preparing a cake?

Was I eating pretzels?

Did Phil admire the gem?

Did Oscar have brownies on his face?

Did Hannah eat some M\&M's?

Was Larry going to the living room? 
FALSE SENTENCES-Experiment 4

\begin{tabular}{|c|c|c|c|}
\hline SENTENCE & PROPERTY & $\begin{array}{l}\text { SENTENCE } \\
\text { TYPE }\end{array}$ & $\begin{array}{l}\text { PROPERTY } \\
\text { TYPI: }\end{array}$ \\
\hline $\begin{array}{l}\text { Karen couldn't believe that Jack thought he saw a } \\
\text { witch. }\end{array}$ & Is square & false & false \\
\hline Climbing up the wall was a large spider. & Is transparent. & false & false \\
\hline Harry was running away from the cheetah. & Has stripes. & false & false \\
\hline Paul was in the market to buy a new sports car & Has wings & false & false \\
\hline Coming down the track was a speeding train. & Is poisonous & false & false \\
\hline Gary and June went to the forest to pick some berries. & Has wheels & false & false \\
\hline Randy marveled at the beauty of the moon. & Is wooden & false & false \\
\hline Theresa had to stop at the store to buy some oranges. & Are plastic & false & false \\
\hline $\begin{array}{l}\text { Kim new if she was good, her mother would give her a } \\
\text { cookie. }\end{array}$ & Has fur & false & false \\
\hline $\begin{array}{l}\text { As we were packing for the picnic, we realized we } \\
\text { needed some saran wrap. }\end{array}$ & Is grainy & false & false \\
\hline Before Jim left for work, he put in his contact lenses. & Have legs & false & false \\
\hline $\begin{array}{l}\text { Even in the evening, Frank always enjoyed a bowl of } \\
\text { cereal. }\end{array}$ & Can fly & false & false \\
\hline My grandfather always built beautiful birdhouses. & Is Edible & false & false \\
\hline Before leaving in the canoe, make sure you have oars. & Is juicy & false & false \\
\hline Leah needed to buy school supplies, especially pencils. & Are alive & false & false \\
\hline $\begin{array}{l}\text { For Tom's sixth birthday, his parents bought him a } \\
\text { bicycle. }\end{array}$ & Can swim & false & false \\
\hline $\begin{array}{l}\text { We saw the new parents coming down the street with a } \\
\text { baby carriage. }\end{array}$ & Has a tail & false & false \\
\hline $\begin{array}{l}\text { Coming towards us at high speed was a girl on roller } \\
\text { skates. }\end{array}$ & Are crunchy & false & false \\
\hline $\begin{array}{l}\text { Maria was very happy that her parents bought her a } \\
\text { new doll. }\end{array}$ & Grows on trees & false & false \\
\hline $\begin{array}{l}\text { In preparation for going out in the rain, Courtney } \\
\text { pulled on her rain boots. }\end{array}$ & Are glass & false & false \\
\hline $\begin{array}{l}\text { A fter buying a soda, Melissa went to the counter to } \\
\text { grab a straw. }\end{array}$ & Walks & false & false \\
\hline Kelly looked in the closet to find a shopping bag. & Is cotton & false & false \\
\hline Yolanda went to the store to buy some carrots. & Are purple & false & false \\
\hline $\begin{array}{l}\text { Grant was excited to be going to the circus to see the } \\
\text { tiger. }\end{array}$ & Is rectangular & false & false \\
\hline $\begin{array}{l}\text { Even though she disliked most fruits, Emily loved to } \\
\text { eat plums. }\end{array}$ & Stores things & false & false \\
\hline $\begin{array}{l}\text { Because it was dinnertime, Robyn decided not to eat } \\
\text { the strawberries. }\end{array}$ & Is leather. & false & false \\
\hline $\begin{array}{l}\text { We didn't know what they wanted, so we bought them } \\
\text { a vase. }\end{array}$ & Can breathe & false & false \\
\hline As an addition to the house, they built a greenhouse. & Can hop & false & false \\
\hline $\begin{array}{l}\text { Because of the accident, Dara needed to replace the } \\
\text { windshield. }\end{array}$ & Is yellow & false & false \\
\hline Laurie pulled her car into the garage. & Has a shell & false & false \\
\hline On the first day of school, Kara was assigned a locker. & Is woolen. & false & false \\
\hline
\end{tabular}




\begin{tabular}{llll} 
& PROPERTY & TYPE & TYPE \\
\hline To be safe, Cory always stored his work in a folder. Is noisy & false & false \\
\hline In the fall, Debbic always goes to New England to look & &
\end{tabular}
at the leaves.

When Tim goes to Florida, he always brings baek lemons.

Are dangerous falsc false

Are ferocious false

false

For arts and crafts, the teacher collected a bunch of pinecones.

Because he was lonely, the old man bought a cat.

Sneaking through the bushes towards the trash was a

large raccoon.

Georgia was happy that she hadn't hit the deer.

Are circular false

false

Has feathers false false

Because Roberta wanted a pet, her mother bought her a hamster.

Kim sat on the grass and stared up at the sky.

Is rubber

false

false

Is gicen

false

false

Fiona rode around town in the new police car.

Is red

false

false

Once in a while Terry liked to go to the zoo to see the

elephants.

Is slimy

false

false

Before moving, the Stevens family stored many things

in a warehouse.

Is sweet

false

false

Shining above us was the sun.

Are sour

false

false

After the rain, DeeDee was sure she would be able to

see a rainbow.

Has skin

false

false

Is black

false

false

To go camping, the scout leader brought them to the state forest.

Is icy

false

false

Off of the side of the ship, Joey spotted a whale.

For a low-calorie snack. Vera liked to eat eelery.

For a class project, David built a robot.

Is sticky

false

false

Flying in the field was the most beautiful butterfly.

Warren was allergic to tomatoes.

Has wings

false

false

Perry went to the restaurant and ordered some buffalo wings.

Can walk

false

false

Phil's first pet was a hermit crab.

Is salty

false

false

Has seeds

false

false

Strewn across the bed were hundreds of rose petals.

After dinner, Chuck ate a snow cone.

Are loud

false

false

On a dare, Bill tried to climb to the top of the flagpolc. Has legs.

Are purple

false

false

Is silver

false

false

Are sharp

false

false

Kin went to the department store to look for a new

watch.

Is spicy

false

false

At the construction site, there were plenty of hammers. Has hair.

false

false

In the sunmer, Rachel loved to go out on the lake in a speedboat.

Is tall

false

false

On the Fourth of July, Andrea's family always goes to sce fireworks.

Has hinges

false

false

When eating at an expensive restaurant you should always use your napkin.

Is cardboard. false

false

While in the mountains, the climbers always looked out for avalanches.

Are soft

false

To cool down the soup. Larry put in an ice cubc.

Is spotted

false

false

false 


\begin{tabular}{|c|c|c|c|}
\hline SENTENCE & PROPERTY & $\begin{array}{c}\text { SENTENCI: } \\
\text { TYPE }\end{array}$ & $\begin{array}{c}\text { PROPERTY } \\
\text { TYPL }\end{array}$ \\
\hline $\begin{array}{l}\text { Whenever Tracy ate Japanese food, she always ordered } \\
\text { a large bowl of rice. }\end{array}$ & Is freezing & false & false \\
\hline $\begin{array}{l}\text { For Friday night dinner, mother usually prepared } \\
\text { hamburgers. }\end{array}$ & Are liquid & false & false \\
\hline $\begin{array}{l}\text { The preschool teacher always washed her hands so she } \\
\text { wouldn't spread germs. }\end{array}$ & Has pulp & false & false \\
\hline $\begin{array}{l}\text { While digging in the fresh soil, Marta came across a } \\
\text { large worm. }\end{array}$ & Is reflective & false & false \\
\hline With his birthday money, Zake wanted to buy a lizard. & Is metallic & false & false \\
\hline On a cruise in Alaska, we only saw one penguin. & Are paper & false & false \\
\hline Rich went to the pond to feed the ducks. & Are triangular & false & false \\
\hline $\begin{array}{l}\text { Beth was scared to go in the ocean because she was } \\
\text { a fraid of sharks. }\end{array}$ & Are extravagant & false & false \\
\hline $\begin{array}{l}\text { For Susan's birthday, her boyfriend bought a dozen } \\
\text { roses. }\end{array}$ & Are noisy & false & false \\
\hline
\end{tabular}


Did Jack think that he saw a witch?

Was Harry running from a mugger?

Was the train coming down the track?

Was Randy looking at the ceiling?

Would Kim get a cookie for being good?

Does Jim put on his glasses in the morning?

Did my grandfather build birdhouses?

Did Leah need to buy candy?

Did the new parents have a carriage?

Did Maria's parents buy her a new game?

Did Melissa buy a soda?

Did Yolanda go to buy steaks?

Does Emily dislike most fruits?

Did we buy them a plate?

Did Dara need to replace the windshield?

Was it Dawn who was assigned a locker?

Does Debbie go to look at the fall leaves?

Did a homeless man collect pinecones?

Was the raccoon sneaking towards the trash?

Did Roberta's mom buy her a snake?

Did Fiona ride in a police car?

Was it the Jones family that moved?

Was DeeDee sure that she would see a rainbow?

Did Joey see a dolphin?

Was it David who built a robot?

Was Warren allergic to peanuts?

Was Phil's first pet a hermit crab?

Did Chuck eat an ice popsicle?

Was it Kim who went to the department store?

Did Rachel love to go out on the rowboat?

Should you use your napkin at an expensive restaurant?

Did Larry put salt in his soup?

Did mother usually prepare hamburgers on Friday?

Did Marta find a little worm?

Did we see one penguin?

Was Beth scared to go in the ocean because of the jellyfish? 


\section{BIBLIOGRAPHY}

Ahn, W. (1998). Why are different features central for natural kinds and artifacts?: the role of causal status in determining feature centrality. Cognition, 69, 135-178.

Alba, J.W., Chromiak, W., Hashcr, L., \& Attig, M.S. (1980). Automatic encoding of eategory size information. Journal of Experimental Psychology: Human Leaming and Memory, $\underline{6}, 370-378$.

Anderson, J.R., \& Reder, L. (1979). An elaborative processing explanation of depth of proeessing. In L.S. Cermak \& F.1. M. Craik (Eds.), Levels of processing in human memory. Hillsdalc, NJ: Erlbaum.

Barsalou, L.W. (1982). Context-independent and Context-dependent information in coneepts. Memory \& Cognition, 10, 82-93.

Barsalou, L.W. (1983). Ad hoe categories. Memory \& Cognition, 11,211-227.

Barsalou, L.W. (2000). Being there enceptually: Simulating categories in preparation for situated action. In N.L. Stein, P.J. Bauer, \& M. Rabinowitz. (Eds.), Representation, memory, and development: Essays in honor of Jean Mandler. Mahwah, NJ: Erlbaum.

Barsalou, L.W., \& Ross, D.H. (1986). The role of automatic and strategic processing in sensitivity to superordinate and property frequency. Journal of Experimental Psychology: Learning, Memory, \& Cognition, 12, 116-134.

Billman, D., \& Heit, E. (1988). Observational lcarning from internal feedback: a simulation of an adaptive learning method. Cognitive Science, 12, 587-625.

Belleza, F.S. (1996). Mnemonic method to enhance storage and retrieval. In E. Bjork \& R. Bjork (Eds.), Handbook of perception and cognition (Vol. 10)San Diego, Ca: Academic Press.

Bower, G. H., \& Winzenz, D. (1970). Comparison of associative learning strategies. Psychonomic Seienec, 20, 199-120.

Brown, N. R. (1995). Estimation strategies and the judgment of event frequency. Journal of Experimental Psyehology: Learning, Memory, \& Cognition. 21, 1539-1553.

Brown, N.R. (1997). Context memory and the selection of frequeney estimation strategies. Journal of Experimental Psychology: Learning, Memory, \& Cognition, 23, 898-914. 
Bruner, J.S., Goodnow, J.J., \& Austin, G.A. (1956). A study of thinking. NY: John Wiley and Sons.

Chaigneau, S.E., \& Barsalou, L.W. (2001). The role of function in eategories. Invited article to appear in Theoriaet Historia Scientarium. http://userwww.service.emory.edu/ -barsalou/Publications/online.html

Corter, J. E., \& Gluek, M. A. (1992). Explaining basic eategories: feature predictability and information. Psychological Bulletin, 111, 291-303.

Craik, F.I.M., \& Lockhart, R.S. (1972). Levels of processing: a framework for memory research. Journal of Verbal Learning and Verbal Behavior, 11, 671-684.

Craik, F.I.M., \& Tulving, E. (1975). Depth of processing and the retention of words in episodic memory. Journal of Experimental Psychology: General, 104, 268-294.

Estes, Z., \& Glucksberg, S. (2000). Interactive property attribution in concept combination. Memory \& Cognition, 28, 24-28.

Greene, R.L. (1984). Incidental learning of event frequeney. Memory \& Cognition. 12, $90-95$.

Hasher, L., \& Zacks, R.T. (1979). Automatic and effortful processes in memory. Journal of Experimental Psychology: General, 108, 356-388.

Hintzman, D.L. (1988). Judgments of frequeney and recognition memory in a multiple-trace memory model. Psychological Review, 95, 528-551.

Johnson, K. E, \& Mervis, C. B. (1998). Impact of intuitive theories on feature recruitment throughout the continuum of expertise. Memory \& Cognition, 26, $382-401$.

Jonides, J., \& Jones, C. M. (1992). Direct coding for frequency of oceurrence. Journal of Experimental Psychology: Learning, Memory, \& Cognition, 18, 368-378.

Jonides, J., \& Naveh-Benjamin, M. (1987). Estimating frequency of occurrence. Journal of Experimental Psychology: Learning, Memory, \& Cognition, 13, 230240.

Komatsu, L. K. (1992). Recent views of conceptual structure. Psychological Bulletin, $\underline{112}, 500-526$.

Kersten, A.W., \& Billman, D. (1997). Event category learning. Journal of Experimental Psychology: Learning, Memory, \& Cognition, 23, 638-658. 
Kersten, A. W., Goldstone, R. L., \& Schaffert, A. (1998). Two competing attentional mechanisms in category learning. Journal of Experimental Psychology: Learning, Memory, \& Cognition, 24, 1437-1458.

Lamberts, K. (1995). Categorization under time pressure. Journal of Experimental Psychology: General, 124, 161-180.

Lamberts, K. (1998). The time course of categorization. Journal of Experimental Psychology: Learning, Memory, \& Cognition, 24, 695-711.

Love, B.C. (1996). Mutability, conceptual transformation, and context. In Proceedings of the Eighteenth Annual Conference of the Cognitive Science Society. (pp. 459-463). Mahwah, NJ: Erlbaum.

Malt, B.C., Ross, B.H., \& Murphy, G.L. (1995). Predicting features for members of natural categories when categorization is uncertain. Journal of Experimental Psychology: Learning, Memory, \& Cognition, 21, 646-661.

Margolis, E. \& Laurence, S. (Eds.), (1999). Concepts: core readings. Cambridge, Ma: The Mit Press.

Markman, A. B., \& Wisniewski, E. J. (1997). Similar and different: the differentiation of basic-level categories. Journal of Experimental Psychology: Learning. Memory, \& Cognition, 23, 54-70

McDaniel, M.A., \& Pressley, M. (Eds.) (1987). Imagery and related mnemonic processes. New York: Springer-Verlag.

Medin, D. L., Lynch, E.B., \& Solomon, K.O. (2000). Are there kinds of concepts? Annual Review of Psychology, 51, 121-147.

Mervis, C.B., and Greco, (1984). Parts and early conceptual development: comment on Tversky and Hemenway. Journal of Experimental Psychology: General, 113, 194-197.

Naveh-Benjamin, M., \& Jonides, J. (1986). On the automaticity of frequency coding: effects of competing task load, encoding strategy, and intention. Journal of Experimental Psychology: Learning, Memory, \& Cognition, 12, 378-386.

Pavio, A. (1995). Imagery and memory. In M.S. Gazzaniga (Ed.), The cognitive neurosciences. (pp.977-986). Cambridge, MA: MIT Press.

Ratcliff R. (1993). Methods for dealing with reaction time outliers. Psychological Bulletin, 114, 510-532. 
Rosch, E. H. (1978). Principles of categorization. In E.H. Rosch \& B.B. Lloyd (Eds.), Cognition and categorization. (pp. 28-48). Hillsdale, NJ: Erlbaum.

Sanders, R.E., Gonzales, E.G., Murphy, M.D., Liddle, C.L., \& Vitina, J.R. (1987). Frequency of occurrence and the criteria for automatic processing. Journal of Experimental Psychology: Learning, Memory, \& Cognition, 13, 241-250.

Sloman, S.A., \& Ahn, W. (1999). Feature centrality: naming versus imagining. Memory \& Cognition, 27, 526-537.

Sloman, S.A., Love, B.C., \& Ahn, W. (1998). Feature centrality and conceptual coherence. Cognitive Science, 22, 189-228.

Solomon, K. \& Barsalou, L.W. (2001). Grounding concepts in perceptual simulation: II. Evidence from property verification.

http://userwww.service.emory.edu/ barsalou/Publications/online.html

Spalding, T. L., \& Murphy, G. L (1999). What is learned in knowledge-related categories? Evidence from typicality and feature frequency judgments. Memory \& Cognition, 27, 856-867.

Tversky, B., \& Hemenway, K. (1984). Objects, parts, and categories. Journal of Experimental Psychology: General, 113, 169-193.

Wattenmaker, W.D. (1993). Incidental concept learning, feature frequency, and correlated properties. Journal of Experimental Psychology: Learning, Memory, \& Cognition, $\underline{19}, 203-222$.

Williams, K.W., \& Durso, F.T. (1986). Judging category frequency: automaticity or availability? Journal of Experimental Psychology: Learning, Memory, \& Cognition, 12, 387-396.

Winston, M.E., Chaffin, R., \& Herrmann, D. (1987). A taxonomy of part-whole relations. Cognitive Science, $11,417-444$.

Wisniewski, E.J., \& Love, B.C. (1998). Relational versus properties in conceptual combination. Journal of Memory \& Language, $\underline{38}$, 177-202.

Wu, L-1, \& Barsalou, L.W. (2001). Grounding concepts in perceptual simulation: I. Evidence from property generation.

http://userwww.service.emory.edu/ barsalou/Publications/online.html under review

Yeh, W., \& Barsalou, L.W. (2000). The situated nature of concepts. http://userwww.service.emory.edu/ barsalou/Publications/online.html under review. 


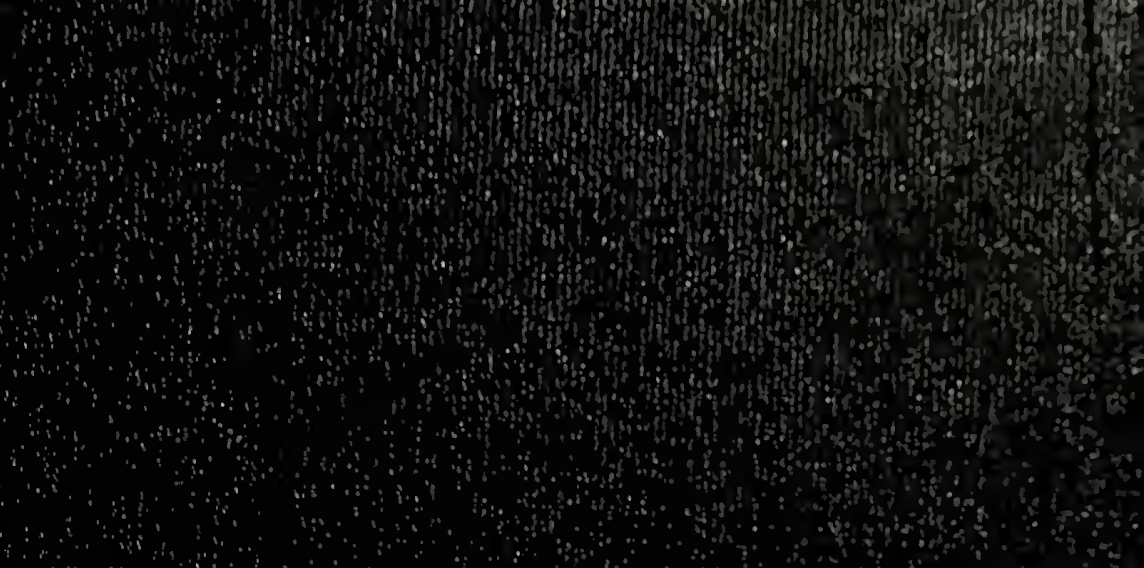

